\title{
WAKING UP TOGETHER: \\ CONTEMPLATION AND TRANSFORMATION \\ IN A HIGHER EDUCATION SETTING
}

\author{
A Dissertation \\ Presented to \\ The Faculty of the Curry School of Education, University of Virginia
}

In Partial Fulfillment

Of the Requirements for the Degree, Doctor of Philosophy

by

Mary M. Stewart-Silver, BA

May, 2016 
Copyright (C) 2016

Mary M. Stewart-Silver

All Rights Reserved

May, 2016 


\begin{abstract}
This qualitative case study explored the effects, in a Research 1 public university, of incorporating contemplative approaches into learning, organizational and institutional praxes. The centerpoint of the case was a new donor-funded Center in the setting, established to investigate contemplative practices. The two research questions were: How may contemplative praxis (practice and analysis of contemplation) inform and even transform higher education at this HEI? How may higher education praxis inform and even transform contemplative praxis? The study was a broad investigation of change processes on intra-personal, organizational, and institutional levels, all of which were investigated as complex systems. It explored the possibility that contemplative approaches support stakeholders in producing transformation within complex systems; it also explored how reducing complexity exerts power. In addition to participant observation over $31 / 2$ years, the study included 94 in-depth interviews. Participants included key stakeholders in the Center, leadership across the University, and interested parties from outside the setting. Findings include that external and internalized constraints in the HE setting challenge contemplative approaches, particularly in organizational and institutional change efforts; for contemplative approaches to be transformational - engendering emergence of deeply inclusive and innovative structural changes - in the context of an HEI, cultivation of first-person (self-awareness), secondperson (empathy, compassion), and third-person (as systems thinking) capacities are all necessary. Limitations include the fact that such a broad study, designed to investigate themes across several arenas of praxis in a large setting, does not allow for full exploration in any particular arena.
\end{abstract}




\title{
Dedication
}

\author{
To my mother, \\ Marjorie \\ January 20, 1922 - November 8, 2015
}

Thank you for helping me learn kindness, and that we are all in it together. 


\section{Acknowledgments}

I wish to extend my warm thanks to the Curry faculty who have encouraged and enlightened me over the years. Eric Bredo and Diane Hoffman welcomed me so well into Social Foundations many moons ago. Since, Derrick Alridge has been extremely supportive of my completing the dissertation and the program. Bob McNergney nurtured my progress with his kind intelligence. Carol Anne Spreen has been a deep inspiration, and I have appreciated her keen insight more than she knows. Rachel Wahl and Stan Trent gave me invaluable support and feedback. Rebecca Kneedler hung in there beyond all reason, and I am ever grateful to her for it.

I am inspired by the participants in my study. I have been informed and encouraged by the commitment of so many to student wellbeing and to positive change within and beyond the academy. I will respect the anonymity of my participants locally, but I extend great thanks to Rhonda Magee and Daniel Barbezat, two leaders in the national movement for a contemplative approach to transformation in and beyond higher education that is profoundly inclusive and equitable.

I am endlessly grateful to and for my children and their families: Isaac, Alia, Ezra, Maya, Luke, Jen, and grandchildren Mathias, Astrid, and Solveig. They are my teachers, and they keep my heart warm. My former husband Josh spent decades cheering me on. My awesome siblings Malcolm, Peggy, and Mamie have been like rocks for me, but way more fun. Friends Julie, Ruth, Mecca, and important others in my Visioning Group, my Dance Tribe, and the Presence Theatre Troupe are all part of who I am and hope to become. John, thank you for your good wishes for my success. Robert, you are a treasure. 


\section{CONTENTS}

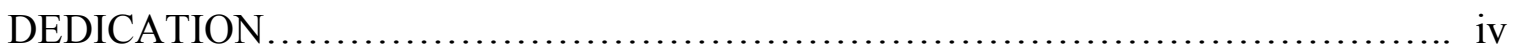

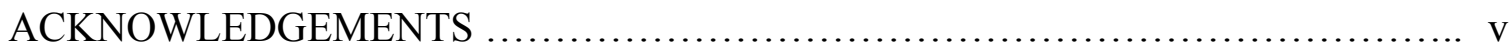

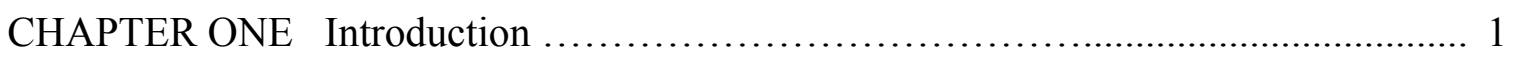

Research Questions ............................................. 5

Three Expansions and an Adjustment in Research Agenda ................... 6

An Overview of the Inquiry into Contemplative, Learning, Higher

Education, and Organizational Praxes ................................ 7

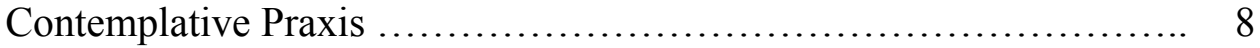

Contemplative praxis and learning praxis ....................... 9

Contemplative praxis and higher education praxis ................. 9

Contemplative praxis and organizational change praxis ............ 13

Overview of the Study Design ...................................... 15

Conceptual Framework: Complex Systems Theory ...................... 16

Interpretivism ......................................... 16

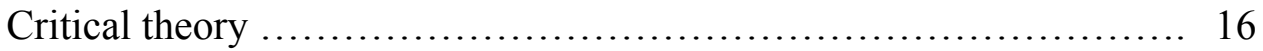

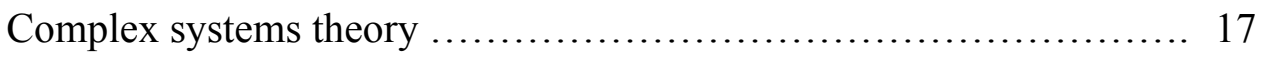

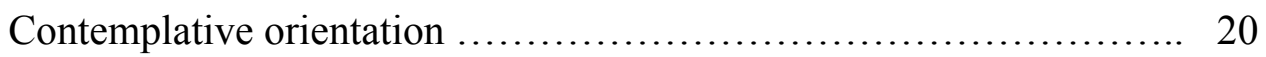

Purpose of the Study ............................................... 21

Forecasting the Study's Significance ............................... 22

Methods ........................................................ 23

Complexity Lens Informs My Research Methods ........................ 24

The Aims of Interpretivist Research Methodology ...................... 25

Case Study Method Scaffolds the Research Project ...................... 26

Evaluation and Participatory Action Research Methods .................... 28

Research Design ............................................... 32

Research Questions ........................................ 33 


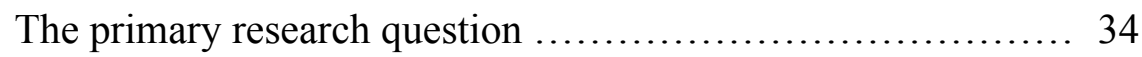

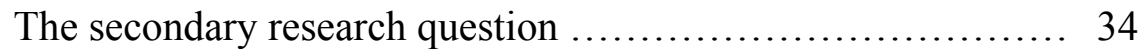

Unit of Analysis .......................................... 35

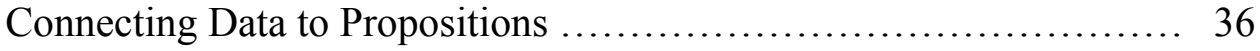

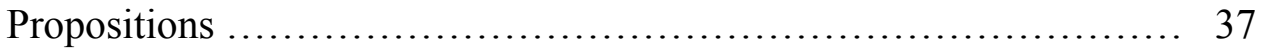

Primary propositions in the study $\ldots \ldots \ldots \ldots \ldots \ldots \ldots \ldots \ldots . \ldots \ldots$

Propositions evolved over the course of the research ......... 39

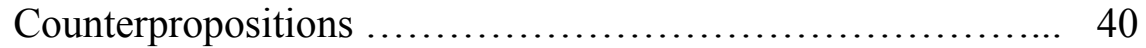

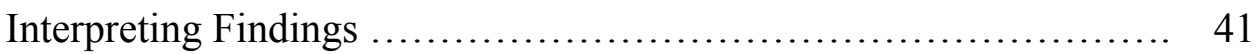

Data Collection and Analysis ...................................... 42

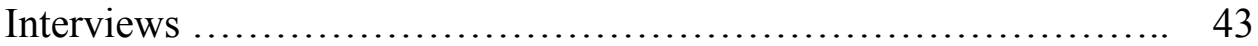

Anonymity and confidentiality ....................... 43

Interview participants $\ldots \ldots \ldots \ldots \ldots \ldots \ldots \ldots \ldots \ldots \ldots \ldots \ldots, 43$

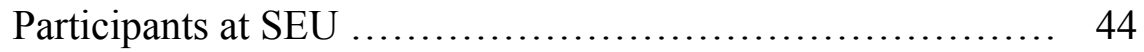

Participants at other HEIs ............................... 46

Founders and national leaders of the movement ............ 47

Participants outside of higher education .................. 47

Interview methods .................................... 47

Participant-observation .................................... 49

Document Review...................................... 50

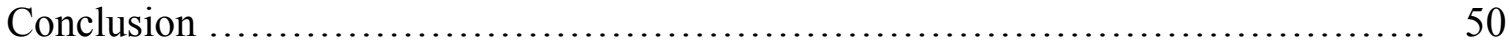

CHAPTER TWO Review of Related Literature ............................. 51

Framework for the Study $\ldots \ldots \ldots \ldots \ldots \ldots \ldots \ldots \ldots \ldots \ldots \ldots \ldots \ldots \ldots \ldots, \quad 51$

Contemplative Practices and Orientations ........................... 52

Toward defining contemplative practices and orientations, and their

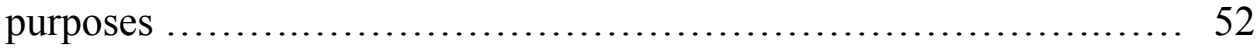

Buddhism-derived contemplative practices ................ 53

Centering prayer from the Christian tradition ................ 56 
Focus beyond the individual ............................ 58

Contemplative practices, context, and worldview ................... 59

How might contemplative practice and orientations reframe learning? 62

Cultivating "second person," (relational) capacities ............ 65

Contemplative Practice in Higher Ed Teaching, Learning, and Research ...... 66

The context for contemplative pedagogy in higher education ............ 66

Implementations of contemplative pedagogy in higher education ..... 69

Concerns that the incorporation of contemplative practices in higher education could entrench societal power dynamics .................... 72

Integrating contemplative practices with systems awareness in higher

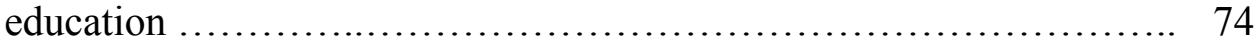

Higher education's roles in researching effects of contemplative practices in general ........................................... 80

Higher education's roles in researching effects of contemplation ....... 81

What is Higher Education For? Some Current Tensions in HE Praxis .......... 82

Higher education funding and philanthropic support ................. 83

Higher education and organizational change ....................... 85

Some Approaches to Transformative Organizational Praxis .................. 86

Complexity and organizational change ........................... 92

Conclusion .............................................................. 94

CHAPTER THREE The Case …............................................ 95

Legacy of Racism at SEU ......................................... 97

The CIC's Conception and Emergence ................................. 101

The "Yoga Dinner" and negotiation with the donor ................ 105

"Initial Conditions" ........................................... 108

Contemplative initiatives at SEU pre-dating the CIC ......... 108

Charles' role .......................................... 110

The initial role of funding ............................... 112

Coming Out Contemplative: The CIC's "Soft Roll-Out" .................... 116 


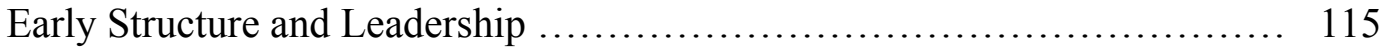

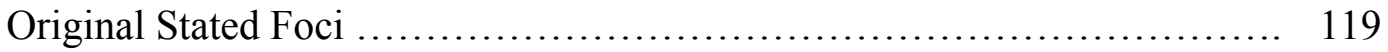

"The Contemplative Campus" ............................... 119

"The Contemplative Academy" ............................... 119

"The Contemplative Symposium" ............................. 121

"Core Commitments" ........................................ 122

National Context for the CIC ..................................... 122

Early Efforts by the CIC to Gather Input ............................ 123

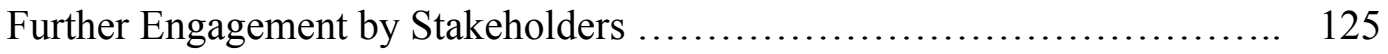

Donor Documents .......................................... 126

Events to Build Relationships with Colleagues Beyond SEU .............. 129

Events to Foster Relationships with Donors ......................... 133

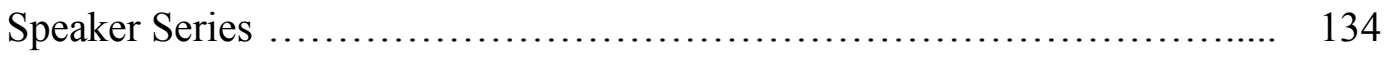

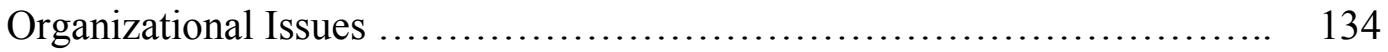

Structural changes among CIC stakeholders ...................... 134

Planning Circle retreat and after............................ 136

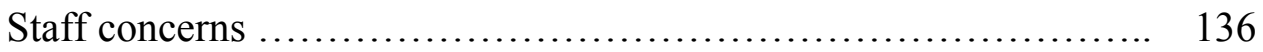

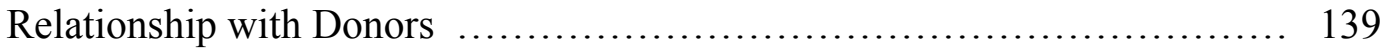

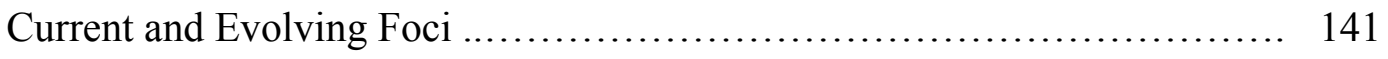

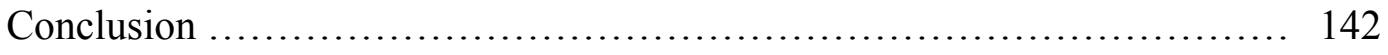

CHAPTER FOUR Analysis of Findings ................................... 149

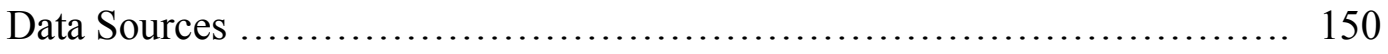

Analysis Through the Lens of Propositions .......................... 152

First, second, and third person praxis through lens of propositions ... 155

Interview Findings ................................................ 158

The Value and Nature of Contemplation $\ldots \ldots \ldots \ldots \ldots \ldots \ldots \ldots \ldots \ldots \ldots . . \ldots \ldots$

Contemplation can take many forms $\ldots \ldots \ldots \ldots \ldots \ldots \ldots \ldots \ldots \ldots \ldots 1$

Contemplative practices can bring awareness to habits ........... 162 
Contemplative practices can reinforce or antidote overemphasis on individualism

Effects of contemplative practices are difficult to parse.

Contemplative practice may engender "spiritual bypassing," or support greater relational awareness by increasing resilience.

Contemplative practices may cultivate self-awareness, resiliency, and change agency.

"Contemplative practices are necessary but not sufficient;" invoking a systems view

First, second, and third person experience in contemplative praxis ... 176

Contemplative Learning Praxis with Classroom Examples ................ 178

"Suspending the critical faculty" and "reading the self" ............ 180

Getting to know our "poor, crazy minds" ...................... 183

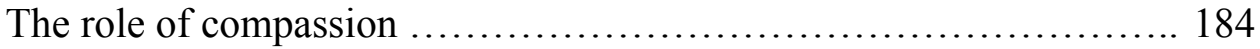

Contemplating "wisdom" and "presence" in the business schools ... 186

First, second and third person orientations in contemplative pedagogy 188

Challenges and Opportunities for Contemplative Praxis at SEU and

CIC's Role

Tensions in the HE context may open the door for contemplative approaches

Participants report incorporating contemplative approaches

Successfully

Participants report challenges to incorporating contemplative approaches

Commodification, in the service of institutional prestige concerns, can challenge contemplative approaches.

Prestige concerns may support a competitive approach among contemplative initiatives

Philanthropy, academic capitalism, and contemplative praxis 201

Incentive structures can challenge contemplative approaches 206

HE praxis can support collaboration ......................... 208

CIC's roles in promoting interdisciplinary collaboration 209 
Internalization of HE constraints by individuals

Student culture has internalized problematic HE culture; some contemplative responses

Systemic Inequity, Student Culture, and the CIC

Assets of HE Praxis Can Support Contemplative Praxis

Cultivating contemplative leadership and agency

Integrating differences across disciplines, for transformation and empowerment

Summary: Contemplative Approaches to Transforming HE Praxis 230

Organizational Praxis and the CIC 232

Research incubators 236

Contemplative Organizational Change Practices 239

Contemplative organizational praxis: pausing and silence 240

Contemplative Organizational Praxis as the Basis for the CIC's Institutional Change Work 249

Valuing contradiction: transformative discourse as collective inquiry 252

Power Dynamics in the Donor-CIC Relationship 254

Contemplating subordinance and dominance 256

Contemplating the source of survival 260

Contemplating Inequity 262

Conclusions 265

CHAPTER FIVE Conclusions 270

Limitations of the Study 270

My complex researcher role 271

My complex researcher role in action 271

Revisiting my research questions 275

Revisiting Contemplative Organizational Praxis 278

REFERENCES 281

APPENDIX Interview Protocol 


\section{Chapter One}

\section{Introduction}

Across the U.S. and beyond, a burgeoning movement is bringing contemplative practices and orientations into an increasing number of businesses, sports, health, medical, and educational settings. Such practices and approaches are being rapidly introduced into college and university settings, where proponents are incorporating them into classroom and co-curricular learning, research agendas, and clinical practices. This is a distinct and important part of a larger social movement promoting the value of "a third way of knowing that complements the rational and the sensory" (Hart, 2005, p. 29). Proponents at Higher Education Institutions (HEIs) maintain that these practices are appropriate to secular settings, broadly applicable, and increasingly validated by leading-edge research as potent antidotes for mounting stressors that challenge students and inhibit learning. Some advocates assert a more radical claim as well: that contemplative practices can renew the deeper purposes of higher education. In his Introduction to Contemplative Practices in Higher Education: Powerful Methods to Transform Teaching and Learning (Barbezat \& Bush, 2014, p. ix), Parker Palmer stated,

Students whose minds and hearts have been formed by contemplation of self as well as world are much more likely to become the kinds of ethical actors we need at a time when basic human values - values the academy arose, in part, to protect - are so widely threatened.

Reflective of this growing national movement has been the creation of numerous centers within colleges and universities to address and promote contemplative practices. Especially over the past decade, centers have been established at prestigious top ten privates (such as Harvard, Stanford, and Yale) and top ten publics (such as University of 
California at Los Angeles, University of Virginia, University of Michigan, and University of California at San Diego).

My study focused on such a center in a university setting, which I introduce below. I have used pseudonyms for the Center, the University, and participants, to protect anonymity and confidentiality to the degree reasonable and possible.

The current emergence of the Center for Investigating Contemplation (CIC) at Southeastern University (SEU) is at the forward edge of the movement to bring contemplation into higher education. Established less than five years ago and funded by a significant donation from an alum, this Center's inception was grounded in pre-existing programs across its university's campus that incorporated contemplative practices. Its presence was sufficiently welcomed by central administrators and decision-makers, and it was led from the beginning by a highly regarded professor hailed by many as a visionary who had previously spearheaded and developed diverse, innovative, successful and impactful projects. The Center's stated mission is a radical intervention in higher education, as it challenges paradigms about means and ends of learning, through bringing contemplation to pedagogy, research, and engagement. Moreover, its stated core principles indicate that the Center also purports a mission to challenge structural paradigms within the institutional setting of the University, by facilitating crossdisciplinary partnerships as well as "tight relationships between tradition, research, innovation, application, and engagement," and by "address[ing] issues of inclusivity and social justice." 
This case study of the emergence of this Center within a particular university is contextualized in the growing movement to bring contemplation into the changing landscape of U.S. higher education, a trend which is itself informed by a broad movement to incorporate contemplative practices in a wide range of societal contexts. To explore this range of mutually informative contexts or dimensions, this study employs lenses from four fields, for each of which the term praxis is used here to mean an integration of analysis and practice: contemplative praxis, learning praxis (which includes pedagogy, research, and engagement), organizational praxis, and higher education praxis. (In the case of this university, there is a significant arena of clinical praxis as well, via a major teaching hospital. My research touches on this realm, and indeed medical practice and research are important to the Center's mission, but a deep investigation of the clinical arena is beyond the scope of my research.) Although of course learning and research are prominent purposes of higher education, I parse higher education praxis from learning and research praxis to invoke, by the term higher education praxis, the full range of administrative, marketing, recruitment, human resource work, development, leadership, decision-making, incentivizing, and related business of the university, which facilitate and include, but which are not identical with, its overt pedagogical and research missions.

Key to my study is the question of how contemplative praxis may inform, and be informed by, each other praxis. Thus, throughout the dissertation - in the literature review, in presenting the case, in the analysis, and in drawing implications-I examine contemplative learning praxis, contemplative organizational praxis, and contemplative higher education institutional praxis. Of these three, the last is the most aspirational, or 
even theoretical, but it has become a vital concern for me in this study, with profound implications in the context of higher education generally.

In service of the my research agenda - to explore how contemplative praxis and higher education praxis may mutually inform, and even transform, each other-I engage dialectically with all four praxes, by examining how they inform each other, to undergird a holistic understanding of the case and its implications, and to show how this understanding may support, extend, or challenge current praxis in these four fields and at their interstices. I am very interested in how these praxes, alone and together, may generate adaptive learning, on intrapersonal, interpersonal, organizational, and institutional levels.

Thus, I examine tensions across these four lenses for their synergies and contradictions. How can contemplative praxis challenge the ways organizational change commonly occurs in higher education? How can contemplative praxis press for new developments in learning praxis? How can learning praxis inform organizational praxis, and in turn inform higher education (institutional) praxis? Is contemplative praxis a relevant response to, or antithetical to, current tensions in higher education praxis? In sum: how can contemplative praxis be invoked on any and all of these levels, and what difference(s) does it make to do so? Conversely, how do higher education praxis, organizational praxis, and learning praxis inform contemplative praxis?

The research design, described in a later section of this chapter, structures the investigation of how these four praxes are being enacted here on the ground, with what impact, in a particular Center at a prestigious university. In the research design, and in the 
literature review, I explore these praxes, and the conceptual lens of "complexity thinking." These provide a basis for my normative assertions about the transformational potential at the forward edge of learning, organizational, and institutional praxis, particularly when leveraged by contemplative praxis.

\section{Research Questions}

The primary research question is: How may contemplative praxis (practice and analysis of contemplation) inform and even transform higher education at this university? How, and with what impact, do (or do not) the Center's stakeholders, and others, invoke contemplative praxis as they theorize (implicitly and explicitly) and act, regarding vital purposes, processes and potentials of pedagogy (across disciplines; curricular and cocurricular), research, professional practice, organizational practice, institutional practice, and engagement on and beyond the campus?

My research proposal identified only the research question above, with subquestions, one of which was, "How do contemplative practice, higher education practice, the Contemplative Sciences Center, and the change processes each involve, inform each other?" I found as I delved into the study that I needed to expand and refine that subquestion, to acknowledge the "two-way system of determinant interrelationships" (Davies 2004, p. 21) that marks the interdependence of complex systems, as "complex nested systems." Davies wrote, "[R]egulation at one level produces characteristics at another level."

Therefore, I added a second research question: How may higher education praxis inform and even transform contemplative praxis? My question itself evolved over the 
course of my study. I first framed it thus: How may the proponents of contemplative praxis bring assets intrinsic to higher education praxis - inquiry, learning praxis, research, analysis, articulation of findings and new questions, generative discourse within, across, and beyond disciplines and institutions - to bear, in evolving fuller, more nuanced understanding of contemplative practices and orientations, and their potential effects in education and in society? Over time, I became more sensitive to the constraints and pressures within higher education praxis - as contrasted with the "assets" listed above - that may "inform and even transform contemplative praxis." I added the following to this second question: How may the institutional context of an HEI, and especially the context of this particular university at this moment in time, inform and even potentially transform how stakeholders characterize, value, and enact contemplative praxis?

\section{Three Expansions and an Adjustment in the Research Agenda}

When I designed this study, I conceived of the Center as the sole or primary purveyor of contemplative praxis in the setting. However, over the course of my research I have come to a more nuanced perception. My reference to contemplative praxis has expanded to include instantiations of contemplative methods and orientations in the setting, whether or not they are initiated or sanctioned by the Center. This brings elements of deeper inquiry and texture to the study, not least of which is the challenge of articulating definitions and purposes of contemplation given by participants not just inside but outside the Center's purview. It also brings into greater view the potential for dissonances among stakeholders about not only the purposes, means, and ends of contemplation, but about the purposes, means, and ends of the Center. 
I have also expanded my study to specifically assert that contemplative praxis can take many forms. My interest is in practices that are designed, or found, to enhance capacities for awareness that necessarily include, but are not limited to, self awareness. I will take this up further in later chapters. For now, I mean to clarify that I am not limiting my definition of contemplative praxis or practices to common notions of meditation or mindfulness. I am very much not limiting “contemplation” to a solitary practice. A major theme in my research has been the importance of exploring collective contemplative practices. A third expansion in my research agenda over time has been to incorporate perspectives of participants who may not be working at this particular university, but who I consider to be stakeholders in the endeavor to bring contemplative praxis to bear in higher education settings.

Lastly, an important adjustment in my research agenda over time has arisen from the realization that the Center is in very early stages of its development. Thus, I decided that the bulk of my efforts were better spent in eliciting and analyzing stakeholders' perspectives, concerns, and aspirations related to the Center, and to contemplative praxis in the higher education setting more generally, and in working to understand organizational and institutional structures and practices important to the case, rather than in purporting to decisively analyze programs that are for the most part still in gestation, let alone attempt to evaluate outcomes that have not yet occurred. These adjustments have broadened and enriched my research, which should bear greater fruit in my findings and conclusions.

\section{An Overview of the Inquiry into Contemplative, Learning, Higher Education, and}

\section{Organizational Praxes}


Building on my brief discussion of praxes, I introduce here the topic areas which I have explored in the literature review. I do so in most part by asking a range of questions. This study's purpose is not to answer all of questions below. These questions are meant to indicate the range of concerns involved in bringing contemplative practices into higher education. Moreover, they provide an entry point and framework for the research agenda, which is to examine stakeholders' (implicitly and explicitly expressed) aspirations and concerns about contemplative praxis, how they enact these perspectives, and with what consequences.

Below, I take in turn contemplative praxis, learning praxis, institutional/higher ed praxis (using these last terms interchangeably), and organizational praxis. I begin with contemplative praxis so as to bring it to bear on each other praxis, one at a time and then cumulatively. I explore the potential effects that contemplative approaches bring to learning praxis, learning (pedagogy, research, and engagement) being the overt priority in the setting. I then investigate contemplative learning praxis, vis-a-vis the complex dynamics of an institution of higher education, outlining some structures and motivating factors that change agents must contend with or leverage in their efforts to meaningfully incorporate contemplative praxis into the institution. This brings me to exploring organizational praxis, looking at how the Center functions, internally and externally, in its stated role of introducing and institutionalizing a focus on contemplative praxis.

\section{Contemplative praxis.}

What are contemplative practices and orientations? What informs and motivates proponents in practicing or promoting them? How important to their effect is the context 
(worldview, aesthetics, belief systems, culture) from which they derive and the context in which they are imparted? How do proponents purport that they add value to human growth, wellbeing, and learning, on individual and collective scales? How can their effects be studied and refined? What intended or unintended consequences of these practices should be explicitly explored?

\section{Contemplative praxis and learning praxis.}

How do contemplative practices emulate, augment, or diverge from other descriptions and prescriptions relevant to human development and learning, such as methods that promote social-emotional learning, values education, and liberatory or critical pedagogy? What new challenges does contemplative praxis pose regarding assessment of learning and teaching? The Center asserts engagement, inclusion, and social justice to be among its prioritized educational goals; how do and may contemplative practice and social justice interrelate in the context of learning? How do contemplative practices and orientations interface with, subvert, extend, and/or transform current learning praxis, including learning praxes that proponents already describe as "transformative learning"?

\section{Contemplative praxis and higher education praxis.}

How and why are proponents pressing to incorporate contemplative practices into higher education contexts? How do pressures in higher education praxis affect this incorporation? How does inclusion of contemplative practice square with, and challenge, traditional and contemporary learning praxes specific to higher education, in terms of pedagogy, student life, research priorities, engagement, and their interfaces? Are 
developmental and other learning needs of college and university students identified and addressed through such practice, and if so, how? Are contemplative practices useful for faculty members and others working in the setting, in their own personal and professional development, including as teachers, researchers, and role models for their students? Are there risks and concerns that need to be identified and tracked as contemplative methods are deployed? Equally importantly, what values are explicitly and implicitly motivating such pedagogical innovations?

The CIC asserts contemplative approaches to learning, engagement and social justice to be among its prioritized educational goals. Other initiatives on campus leverage contemplative approaches in promoting well-being, in pedagogy, in community building, and in efforts to develop agents of social change. I investigated stakeholders' understanding of the value added of contemplative approaches in all these arenas.

A college, and particularly a research university, is uniquely well positioned to conduct research about the effects of contemplative practices, and the Center's stated mission includes support of research agendas related to contemplative practice. Therefore, while some stakeholders express and enact a range of perspectives on pedagogical use of such practices, those who research possible effects of contemplative practices, in clinical and general populations as well as student populations, are challenged to develop research methods suited to their particular interests. Examples are developing measures of attention, resilience or compassion and their felt, cognitive or behavioral effects, as well as looking for correlative neurobiological markers. Clinical research can explore physical and psychological health effects of contemplative practices. 
Moreover, the Center asserts a priority on interdisciplinary research, particularly those integrating sciences and humanities. As a range of disciplinary and transdisciplinary approaches are brought to bear in researching contemplative practices, research agendas may include investigation, across a range of practices, participants, and settings: effects of practice; motivations for (teaching and learning) practice; and the impacts of context—physical, cultural, aesthetic, theoretical - on practice, and on the effects of practice. What new methodological strategies, and challenges to conceptual frameworks and collaborative capacities, may such interdisciplinarity entail? Equally importantly, what values are explicitly and implicitly motivating such research?

Some proponents say that a university's mission of supporting students' full development is resonant with facilitating direct experience of contemplative practices. However, such facilitation raises important concerns about the values and purposes of higher education, particularly a public institution. How are these concerns being addressed in the field of higher education, and what issues remain unresolved? These concerns link to profoundly important questions about the nature of reality (ontology), the means of knowing about reality (epistemology), and ethical enaction of values, all of which vitally underpin higher education's mission. Contemplative practices and orientations may challenge some implicit Western mainstream assumptions about reality, knowing reality, and, pivotally, the nature and purpose of the self. Contemplative praxis may foreground issues of what learning is for - on individual and collective levels - and bring forward implicit or explicit claims about the potential of contemplative methods to radically change views of self and of reality. 
These challenges to implicit assumptions about reality and the self may be interpreted as spiritual or religious in nature, and/or ethical or political. I began this study with the assumption that questions about introducing contemplative approaches would provoke quandaries about the place of spiritual or religious inquiry in a public education setting. I have not found this to be as widespread a concern among my participants as I had expected. However, my study has sensitized me, in a way I had not fully anticipated, to ethical and political concerns at the interface between contemplative praxis and neoliberal tendencies in current higher education praxis. A neoliberal view may see education as a private rather than a public good, and may also turn a blind eye to collective responsibility for social ills based in structural inequities.

Some proponents of contemplative praxis in higher education foreground issues of what learning is for, on individual and collective levels, and bring forward explicit claims about the potential of such praxis to radically change views of self and of reality. Some of these proponents express concern about the contrasting potential for contemplative praxis to accept and perhaps entrench a Westernized focus on the decontextualized individual. What might be the impact on, and the role of, higher education in exploring this range of possible uses for contemplative practice? What explorations of meaning and embodied ethics do proponents of contemplative praxis, inside and outside the CIC, identify as appropriate or inappropriate to the mission of higher education, particularly at a public university? Where do issues of the relationship of that educational mission to faith, belief, and religion become articulated, and how? How do higher education's mission, contemplative praxis, and informed action toward social justice and ecological responsibility interrelate? To a great degree, choices about 
what kinds of learning are valued in higher education are prototypical of what our culture values as learning. And yet there is societal critique of the failure of higher education to take on questions of values and responsibility to the greater good by leveraging expertise with sufficient dynamism to respond to urgent issues. There is concomitant, and at times contrasting, societal pressure for higher education to set aside concerns with what may seem to critics to be esoteric, socially or politically liberal, or otherwise misguided values, and to instead focus on producing graduates with technical and other job skills, who can thus contribute to a productive economy. Overarching these concerns is tension about whether higher education is a public or a private good, who benefits and therefore who should pay for it. What can dialogue about contemplative praxis in higher education contribute to a societal learning process about what learning is for, and about how higher education praxis facilitates such learning, or fails to do so?

Are the conditions that the Center-and contemplative initiatives at SEU unaffiliated with the Center-need for their development fosterable in the institutional setting of a public university? Do or can such initiatives exert impact that will make a real difference to higher education praxis at this university? How might the purportedly radical potential of contemplative praxis challenge elements of higher education praxisi.e. its underlying business principles, assumptions, and strategies - that have been firmly, if tacitly, entrenched in power dynamics privileging and incentivizing particular practices, stakeholders, and outcomes? As new pressures such as globalization, new technologies, cultural shifts and economic uncertainties demand that HEIs adapt, will contemplative praxis be marginalized further, or co-opted, by instrumentalist values? Can stakeholders frame contemplative praxis as helping HEIs to respond productively to 
aforementioned pressures, without undercutting or diluting the more provocative potentials of contemplative praxis?

\section{Contemplative praxis and organizational change praxis}

How does the Center define and fulfill its mission, and design and begin to carry out its strategic plan, as a new, donor-funded organization within multiple levels of institutional context? How will focus be balanced with inclusivity and collaboration, and what processes and structures will each entail? Who are all the stakeholders in relation to the Center and how is their participation elicited? What objections and aspirations are brought to bear by stakeholders about the contemplative approaches deployed, considered, or omitted by the Center, or about its organizational practices? Will inclusivity extend to incorporating these objections and aspirations? What will be learned, implicitly and explicitly, about communication and decision-making?

The Center exists in relation to institutional structures and expectations, at a wellestablished university, and in U.S. higher education in general, that include traditional disciplinary silos and other habits and policies that normalize hierarchical decisionmaking and competitive resource allocation. Also, centers exist in relation to priorities and influence of donors both current and future. However, the CIC purports to value innovation not only in the teaching (both content and methods) it will disseminate through courses and the learning it will foster through support of relevant research, but also in the way it develops and operates on an organizational level, and how it impacts and affects its institutional context. It asserts its aspiration to be a collaborative, cross- 
disciplinary, inclusive entity, with foci and strategies that are emergent, rather than predetermined or enforced in a top-down manner.

Therefore, the Center's stated mission suggests that part of the learning project it takes on must be organizational learning, possibly creating alternative structures and missions within a traditional institution, which involves bringing to light and changing habits, including those habits based in power dynamics that reproduce social inequalities, and privilege some identities (ways of knowing and being) while marginalizing others. The literature review below explored current praxis in the field of organizational theory, including praxis that explicitly relies on contemplative methods in the service of deep change within organizations and institutions. I have placed organizational praxis last in my inquiry, because I have come to perceive the need for contemplative organizational praxis as vital to leveraging a contemplative approach to both learning and institutional praxes.

\section{Overview of the Study Design}

The project was framed as a case study of organizational change using qualitative methods. The methods focused primarily on participant-observation and semi-structured interviews with stakeholders within the Center as well as in the broader context of a university, and in contemplative practices in higher education more generally. The study was informed by a complex systems lens, and incorporates elements of formative and developmental evaluation, and of participatory action research, to investigate: participants' explicit and implicit theories of how change happens on individual, organization, and institutional levels, and particularly how contemplative praxis leverages 
learning, institutional and organizational praxis; how these theories of change inform their aspirations and concerns regarding contemplative praxis in higher education and at a particular university; and how these theories of change affect how they act upon their aspirations and concerns.

\section{Conceptual Framework: Complex Systems Theory}

To guide my underlying questions about what constitutes, facilitates, and fails to facilitate, learning — on individual, institutional, and organizational levels - I draw on the following theoretical perspectives, and the synergy among them. The nexus point of these perspectives is the assertion that it is through bringing underlying intrapersonal and relational dynamics into awareness, including dynamics of difference and conflict, that transformative change may occur.

\section{Interpretivism}

An interpretivist view holds that people's varied perspectives are internally and relationally constructed through our unique experiences and orientations. This view invites us to explore how these perspectives are subjectively experienced and expressed in action - including communication and interaction—and how these perspectives and actions change over time.

\section{Critical theory}

Postmodern critical theory contributes vital analysis and critique of systems in which some groups and their members, and some worldviews, are privileged or empowered in various ways, while others are relatively disempowered. Critical theory 
helps expose and challenge dominant assumptions and practices that marginalize some human needs, capacities and lived experience.

I invoke critical theory in an open-ended way, because it is intrinsically a model that perceives the world as conflictual, and as such, it can be used to liberate new insights and actions or to foreclose them. Using critical theory only to concretize conflict and polarize factions may be short sighted. Freire (2002), in his description of conscientization, conveyed that the essence of critical theory is the liberation of the human imagination, the freedom to interpret one's life anew. If we are to invent the radically different world that critical theory values, then a skilled openness - to one's own subjective process as well as to alliances with many "others"-will be necessary.

\section{Complex systems theory}

Scientists across many disciplines have recently discovered and articulated the premise that phenomena previously understood and studied only as discrete and separate entities or processes, are in fact parts of "wholes" (Palmer \& Zajonc, 2010, pp. 78-79), systems which are far greater, in complexity, information, and dynamism (potential for variation and change) than the sum of parts. The primacy of relationality, and the dynamic processes relationality entails, must be investigated if we are to understand phenomena. This interest in the interdependence of parts and wholes informs my research on the learning taking place on individual, organizational, institutional, and societal levels.

Complexity theory is used increasingly in social science research, including educational research (e.g. Osberg \& Biesta, 2010), as well as in organizational change 
work, particularly in the practice of developmental evaluation Patton (2010). Complexity theory provides a useful way to understand "transformation," and has provided a plumb line through the praxes I have investigated. Because a complexity lens focuses on relational processes, it is compatible with a qualitative research approach and to a case study. Furthermore, complexity theory is resonant with teachings in many contemplative traditions. I was interested in investigating the potential of contemplative practices and orientations (which I call $C P \& O S$ ) to leverage adaptive learning and transformation in complex systems.

Variously called "living systems," dynamical systems, and complexity dynamics, complexity is observed in nature and social systems. In Developmental Evaluation, Patton (2010, p. 119) described the appeal of a complex systems lens for studying organizational behavior and other social phenomena. "The sources of nonlinearity, emergence, and unpredictability are deeply enmeshed in the complex web of relationships that we all experience .... Human actions include relational and emotional dynamics, as well as the context of organizational and societal norms, constraints, expectations." He stated that "the allure of systems thinking" is that it approaches and provides insight into important "human experience, interaction, and efforts at development .... Astute social innovators and developmental evaluators are attuned to these issues." Complex systems give rise to emergent structures, which are qualitatively different from their component parts, in ways that cannot be predicted from analyzing those parts.

I have followed Page (2009, disc 1) in describing complex systems as systems wherein diverse, connected, interdependent agents learn adaptively together, 
... co-evolving emergent (unpredictable, nonlinear, self-organizing) systems that are neither rigid nor chaotic, that are robust and yet sensitive to changing conditions, that are not controllable yet can be guided by astute adjustments in the parameters of diversity, connections, interdependencies, and adaptive learning.

To nurture conditions for emergence entails encouraging the balance of diversity, connections, interdependence and learning in the system. One way to do this is by attending to feedback loops of information flow: some feedback perpetuates patterns within the system, while other feedback disturbs those patterns. When patterns are disturbed, the system may head toward chaos. Guiding a human system from disturbance, through chaos and into emergence of new patterns in a desired direction, Page (2009) said, "begins with perceiving the system as an expression of relational processes which are nuanced, interdependent, powerful, and in constant flux.” Guiding a living system "takes the form not of control but of astute perception, and tweaking, of elements in the system so as to support the possibility of . . promoting" a dynamic balance of "enoughbut-not-too-much diversity, connections, interdependence and learning of and among agents that comprise the system." At the point of chaos, complex systems may break through to emergence or break down to retrench in previous patterns.

In human systems, guiding emergence requires attending to human reactivity in the face of confusion and chaos. Between disturbance and potential emergence, individuals and groups might reinforce patterns that withdraw awareness from some relational fields (reduce complexity), rather than guiding collective emergence. In Education and conflict: Complexity and chaos (p. 15), Lynn Davies defined "complexity shut down theory [as non-productive] conflict [that] arises when there is a lack of 
connectivity, of feedback, of use of information and of willingness to benefit from diversity."

Further, Davies (2004) approached the interface between a complexity lens and critical theory. She wrote (p. 26-27),

It needs to be acknowledged here that morality is not automatically part of education as a complex system, or as part of emergence. When a CAS [complex adaptive system] changes, it does so for survival and new order. This has nothing to do with whether such change leads toward social justice. ... It may be revolutionary, but there is nothing inherently progressive about it in terms of the greater sum of human happiness.

Davies' assertion amplifies the importance of learning to guide complexity skillfully toward desired outcomes, but moreover underscores the value of bringing critical theory to bear on a complexity view, to help perceive, and working to shift power dynamics. She wrote (2004, p. 33)

"I was concerned initially that complexity theory did not contain a theory of power." However, she continued, the "exquisite sensitivity" of a complex system means that there are "crucial transformation points" where small perturbations lead to major changes. "It is in these initiations [of disturbance] that power in social systems lies. It may be the theory of power par excellence."

\section{Contemplative orientation}

My theoretical framework—in which complex systems theory, interpretivism, and postmodern critical theory mutually inform each other-positions me to look for transformative learning and/or its absence, on and among the levels of the individual, institution, and organization. These theories all assume underlying interdependencies, 
capacities for growth, and the importance of bringing awareness to both the bigger picture and one's own assumptions and actions within it.

Further, there is much in what I call, for simplicity, a contemplative orientation, that can further synergize the components of my framework. Many contemplative orientations extend interpretivism's priority on understanding subjective experience, by asserting the value of deeply introspective inquiry, the possibility for radically increased awareness of one's own motivations and one's interrelatedness with reality beyond oneself, and direct experience of the primacy of our subjective orientations in how we construe, engage in, and create the conditions of our personal and shared lives. Postmodern critical theory exposes the existence and impacts of oppressive power dynamics, as manifest through habits and policies of resource allocation, institutional hierarchies, pressures from influential stakeholders, implicit and explicit assumptions about priorities and best practices in pedagogy and research, etc. Some contemplative orientations validate and respond to these assertions, by pressing for the use of rigorous practices to refine one's subjective capacities, and to deepen and transform one's experience of oneself and/or one's relationship to the whole. Such practices and orientations can illuminate and jar loose identifications with both greed and internalized oppression, and thereby facilitate the creation of a more compassionate and just world. And, true to complex systems theory, the relationality under investigation on all levels of my study is emergent rather than static, as are the flows of information and motivation involved, highlighting the importance of focusing on processes of interaction. Contemplative orientations purport to unencumber us of habits of perception and emotional reactivity that entrench us in static positions, and to train our capacities to pay 
attention, to regulate our emotions to reduce reactivity to change, to feel compassion, and to sense our interdependence.

\section{Purpose of the Study}

This study was grounded in an underlying normative interest: to discover and articulate potential transformative effects - and barriers to these effects - that contemplative praxis may bring to higher education praxis, including the learning (pedagogical, research, and engagement) praxis. The literature review has provided some grounding for the use here of the term "transformational" or "transformative" in the arenas of contemplative, learning, and organizational praxes, and in terms of the conceptual framework that complexity theory has provided in my study. Arthur Zajonc, Amherst College professor emeritus of physics, and former Director of the Center for Contemplative Mind in Society, stated:

The view on which contemporary higher education is constructed is too limited. Its impoverished and largely reductive understanding of the world inevitably leads to partial solutions to the [social and ecological] problems we face (.... The reflective, contemplative and experiential methods developed within the contemplative traditions offer a complimentary set of research methods for exploring the mind and the world. When taken together with conventional methods, an enriched research methodology and pedagogy are available for opening up new pathways for deepening and enlarging perspectives which can lead to real and lasting solutions to the problems we confront. . . . We seek to recast the traditional foundations for education into a truly integrative, transformative, and communal enterprise that cultivates the whole person in the fullest possible way. (A. Zajonc, website of the Association for Contemplative Mind in Higher Education (http://www.contemplativemind.org/programs/acmhe). Retrieved 6/01/14).

Zajonc made explicit here a vision of contemplative praxis' potential to transform higher education, through "an enriched research methodology and pedagogy" that develops agents of positive change. His phrase "integrative, transformative, and 
communal enterprise" may imply correlative transformations of organizational and institutional praxes in higher education. This study has explored these possibilities, and also extends to a reciprocal inquiry: How may learning, organizational, and higher education praxes challenge, refine, or expand understanding of the roles and value of contemplative praxis in developing agents of positive change?

\section{Forecasting the Study's Significance}

As higher education professionals nationwide increasingly design and implement a wide range of contemplative programs, case studies should be conducted in as many settings as possible, invoking a range of research questions and using a variety of theoretical frameworks, to analyze and track the change processes involved in each setting. Multiple case studies across varied settings, but within a general movement, can accelerate stakeholders' learning about nuances, challenges, and opportunities in this developing field. The lessons learned by rigorous study, including triangulation across many studies, can inform those interested in issues of design, implementation, and impact assessment of specific instantiations, and of the movement as a whole. This study of a contemplative center within a top ten public university, especially in the context of other contemplative initiatives in the setting, is a particularly intriguing model of what may be possible. The Center boasts relatively well-supported and otherwise auspicious beginnings at a university whose traditions and culture provocatively include both innovation and conservatism.

Also, this study extends to a meta-level inquiry, challenging traditional and current claims about what knowledge and learning are valuable, in higher education and 
by extrapolation in society at large. In fact, the inquiry about contemplative practice, values, and orientations broaches not just these epistemological questions, but ontological ones as well, about the nature of reality, and of consciousness. These epistemological and ontological concerns are focused by the study's normative concerns, and amplified by inquiry into how contemplative, learning, organizational, and institutional praxes might converge in the transformation of awareness of self and reality, and moreover in ethical action based in that transformed awareness.

\section{Methods}

My research methods were informed by a complexity lens and interpretivism. I used a case study approach that included elements of formative program evaluation and participatory action research. I gathered data through in-depth interviews, participantobservation, and document review.

\section{Complexity Lens Informs My Research Methods}

Osberg and Biesta (2010) stated, education "always involves choices." Choices about educational methods and purposes will always "open up" some "opportunities and pathways ... and 'ways of doing and being'; while 'narrow[ing] down' others." The authors asserted that

... those who engage in the justification of educational choices often do so using a language of values, whereas those who engage in research on the ways in which education actually opens up and closes down often do so using a language of power.

Further, they asserted (Osberg \& Biesta 2010, p. 6) that value and power are "two sides of the same coin," and while neither "opening up" nor "narrowing down" are 
intrinsically wrong, it is vital "to acknowledge that in education both 'opening up' and 'narrowing down' involve the exertion of power and in this sense can be said to be political." Social systems, such as those expressed in educational settings, are replete with complexity. They are "open, recursive, dynamic, nonlinear, and emergent" on several levels. Educational practices and processes themselves are to some degree “characterized by nonlinearity and unpredictability and by a fundamental gap between 'input' (teaching, curriculum, pedagogy) and 'output' (learning) . . . Knowledge, understanding and reality" emerge through educational processes. Moreover, "unique, individual beings" emerge "in and through educational processes in . . . unpredictable ways." The authors stated, "complexity helps us to ask [the important question:] how in a complex 'universe' it is possible to achieve a reduction of complexity. ... [W] [Wo is ... reducing complexity for whom, and whose interests are at stake or being served by doing so."

These questions were central to my inquiry about power dynamics in the setting I was studying. I wanted to understand "whose interests [were] at stake or being served" as contemplative approaches were brought into the setting.

Also, my role as a researcher was dynamically related with issues of power (Hetherington, 2013). I wanted to be explicit that I am making choices - consciously and unconsciously — that are motivated by my awareness, and my ideas about, and my previous experiences with, power differentials. The lens through which I, in particular, perceive power dynamics informs how I use the power I have as a researcher to bring awareness to (what I perceive to be) power dynamics in the setting. 
I have explicitly investigated the research process itself as a complex process, in the following interdependent ways: looking for how my particular presence and engagement as a researcher affects the complexity of the case that I research (Hetherington, 2013); looking for how engaging in this research affects how I understand my own complexity, including my perceptions and motivations; looking for how and why, and with what ramifications, I reduce complexity.

\section{The Aims of Interpretivist Research Methodology}

Qualitative research attunes the researcher and audience to nuanced and subtle experiences, and thereby contributes vitally to a study of the values, concerns, experiences, and interpretations people bring to, glean from, and enact per, the emerging Center and their roles in that emergence.

In describing an interpretivist approach to research, Erickson (1986) stated that both rigor and reflexivity are vital. He urged researchers to investigate variations in how people make meaning, and act and interact, rather than how they theoretically should act, or purport to act. He asserted the value of exploring rigorously, and in great depth, how people interact with one another in particular settings and under particular constraints, while also exploring — and explicitly articulating - conceptions of larger social dynamics that impinge on these specific settings. In his focus on investigating the lived experience of participants, including specifically studying the choices they make and actions they take in relation to the constraints of relational and institutional contexts, resulting at times in vitally important novelty, Erickson's approach to research is very useful in this case study of learning and engagement within and across individual, organizational, and 
institutional contexts. His approach also accommodates and helps ground the perspectives from complex systems theory which inform my study. Finally, his approach demands that the researcher rigorously investigate her own assumptions and interpretive processes, a requirement at the heart of many contemplative orientations.

\section{Case Study Method Scaffolds the Research Project}

For this study of the implementation of contemplative practice in a higher education setting, the research methodology was based in a case study approach. Case study research, following Yin (e.g. 1994), is best used in a current situation where one wants to understand what happened or is happening, and particularly how and why something happens the way it does, within its real-life context, in which the researcher has little or no control over outcomes. He wrote, "[T]he distinctive need for case studies arises out of the desire to understand complex social phenomena. [ . . T] he case study allows an investigation to retain the holistic and meaningful characteristics of real-life events."

Erickson (1986) suggested spending much time in the particular setting studied, focusing on both trends and nuances, and to be tentative in generalizing one's assertions to other settings. A case study approach suggests some similar parameters to Erickson's (1986) and others' ethnographically based research. There are important distinctions, however, in case study methodology. Whereas some ethnographic research avoids "prior commitment to any theoretical model," Yin's (2003) view was that case study requires the researcher to bring some degree of theory about the case, and related propositions, into the research project at the front end. Yin $(2004$, p. 6) suggested that a researcher can 
choose how much theory development to bring to the design of a study, but he also stated (1994, p. 27) that, in contrast to related research methods such as grounded theory or ethnography, some degree of front-end theory development is essential to case study research, whether the case study will be used to further develop, or to test, theory.

As Yin (2004) suggested, such theory and propositions provided a structure for me to choose data sources, and methods of collecting and analyzing that data, my goal not being to prove my initial theory and propositions correct, but to examine them in light of data that may have supported, contradicted, or complicate them. My theoretical framing and propositions provided a point of reference, and made reflective and explicit my sensitizing assumptions and priorities. The process of developing theory and propositions demanded a disciplined approach to research design, and to the ensuing engagement with the case itself. Moreover, following Yin's case study approach required me to ongoingly refine theory and related propositions as data was iteratively collected and analyzed. Research questions and propositions pertinent to underlying dynamics in the case facilitated interesting results, in ways that were both confirmatory and contradictory of my initial propositions.

Erickson's (1986) methods result in thick ethnographic description, from the analysis of which the researcher derives "themes and assertions," generalizing to other settings only very cautiously if at all. He maintained that over the course of contrasting and comparing many related studies, each with unique findings from within unique settings, some more generalizable themes and assertions may be supportably proposed. Similarly, a case study can include multiple cases, across which the researcher looks for similar or different results; these differences and similarities become data for an 
overarching analysis. But even in a single case study, Yin's case study method, in contrast to Erickson's (1986) method, will inherently yield results generalizable beyond the particular case simply because, "It begins with explicit theory development and propositions, and therefore its findings will be generalizable in relation to the theory itself, if not directly or immediately to other cases" (Yin,1994, italics added).

\section{Evaluation and Participatory Action Research Methods within This Case Study}

According to Yin (1994, p. 15), evaluation is a viable purpose of a case study. House and Howe (1999) elucidated the pivotal role of values in program evaluation; values are certainly of interest in this case study. Although my study was not a formal evaluation, my methodology incorporated elements of formative program evaluation (Chen, 2005) and developmental evaluation (Patton 2010). Both forms of evaluation focus on processes and relationships rather than outcomes, the goal being to provide useful feedback for a program to incorporate toward its healthy development. Their principles guide researchers and practitioners in elucidating stakeholders' implicit and explicit aims for a program (and variance among stakeholders' aims), and coherence or incoherence between these aims and the program's design and/or enactment.

In writing about formative evaluation, Chen recommended that evaluations inquire about "program theory, a configuration of the [explicit and implicit] prescriptive and descriptive assumptions held by stakeholders and thus underlying the programs stakeholders create" (Chen 2005, p. 16). In-depth interviews (ibid p. 64) can assist one to understand what stakeholders believe about the nature of the problem the intervention will address, and therefore what elements should comprise the intervention. Chen (p. 37) 
specified that stakeholders' assumptions about what needs to change, and how, can be "science-based or based on personal beliefs and experiences." I assert that both realms of assumptions include participants' values, theories of change, and perspective on how ends and means are related. An interesting element of this case study was to discern how stakeholders work, implicitly or explicitly, to integrate their "science-based" assumptions with those "based on personal beliefs and experiences". That is, some stakeholders were bringing practices or proclivities from their personal lives into their academic,

professional setting. This brought to the forefront shifts in the range of what they want to explore as part of their professional identities; it also brought up concerns about whether personal experience and beliefs equip higher education professionals to advocate for practices outside their areas of academic expertise. The tensions that these questions point to may amplify the need for a rigorous contemplative praxis challenging to, but well suited to, an academic setting.

Program evaluation practice can be very participatory (Chen 2005, p. 64), particularly when stakeholders' perspectives help inform the research agenda, as is often the case with a formative evaluation. In my research, I explicitly and implicitly asked for stakeholders' perspectives to inform my research agenda from the beginning. Additionally, principles of participatory action research (PAR) can usefully extend Yin's $(1994,2004)$ premises about case study methodology, particularly in the realm of a formative evaluation. Participatory action methods (e.g. Tolman \& Brydon-Miller 2001) position the researcher and participants in mutually informative relationship to each other. During the design phase of the study and onward, as I engaged in iterative processes of developing research questions, building theory, and studying the literature, I 
invited input $—$ on theory, research questions, and literature - from stakeholders I tentatively identified as key to, and/or representative of, the case.

As previously mentioned, Yin (1994, p. 28) stated adamantly that theory development must precede the researcher's entry into the field for collection of data. As he suggested, I developed a blueprint for the study, including "research questions, propositions, units of analysis, logic connecting data to propositions, and criteria for interpreting the findings," in order to construct a research design which provided "guidance in determining what data to collect and the strategies for analyzing the data." My study incorporated Yin's acknowledgment that a case study with an evaluative component may be informed in its design (including theory development and forming research questions) by stakeholder' interests, including the interests of those stakeholders pivotal to the development of the Center, as well as the development of other contemplative initiatives at this HEI and beyond. Although my research was not framed formally as an evaluation, I was interested in the motivations of key stakeholders, and in explicitly helping these stakeholders reflect on their motivations. I was somewhat engaged in the setting while developing my research plan, in that I asked some stakeholders for their input on what research questions, theoretical lenses, and sources of data (in terms of both literature and participants) they saw as valuable to bring to this study. Their responses generally confirmed my own priorities about research questions and propositions, while contributing clarity and some nuances which enriched the research strategy. My intention in the initial conversations I held with such stakeholders was to deepen my understanding of, and questions about, the dynamics involved in the case, as seen by those within it. Their input informed, but did not subsume, my research 
agenda, which developed through engagement with multiple sources of information. In sum, rather than waiting to enter the field until the research design was complete, I chose to incorporate stakeholders' perspectives to some degree during the design phase, invoking the same rigor and reflectivity into that phase as into later phases of the iterative processes of data gathering and analysis.

This element of my research strategy, informed by principles of PAR, was an approach continued throughout the data collection, analysis, and report phases of the study, and which I believe strengthens the study. As interviewees responded to questions about their perspectives on contemplation, the incorporation of contemplation into higher education, and the instantiation of that at this university via the Center and beyond, I listened for implicit and explicit suggestions of theoretical and practical approaches that led me into new resources in the literature, and informed my data gathering and analysis. This research was also participatory in that I have engaged stakeholders in reflection that may affect their understanding of, and orientation to, the Center.

Finally, I applied what I know both theoretically and experientially about contemplative practices and orientations to my research design, implementation and analysis. As I constructed my research plan, engaged in data gathering and analysis, and described the results, I endeavored to be explicit about the influences of such theory and experience on my research. When engaging with participants, I made purposeful choices about articulating my perspectives on contemplative practice and orientation, and I analyze the effects of these choices as part of my study. In this regard, I diverged somewhat from Yin's advice to feign ignorance of substantive issues while conducting interviews in order "to collect data carefully and fairly" (Yin, 2004). In keeping with 
priorities in both PAR and formative and developmental evaluation practice, I have opted to engage with participants more collaboratively, and reflect in my analysis on the effects of doing so. My advocacy for the Center's general stated mission was part of my researcher identity, as was my commitment to bring focus, critical inquiry, and reflectivity to my own, and other stakeholders', explorations of nuances and concerns.

\section{Research Design}

The research design facilitated me in refining the questions I was interested in, and in choosing how to go about answering them. I followed Yin's (1994, pp. 20-26) template to include five major components in my research design: formulating research questions, composing propositions, determining the unit of analysis, "linking data to propositions" (p.25), and "the criteria for interpreting the findings" (p. 20). Yin asserted (p. 27) that the researcher must engage in theory development while addressing these five components.

Theory development will help the researcher in framing data collection and analysis, and is also vital to decisions about reporting findings, as [t]he appropriately developed theory is also the level at which the generalization of the case study results will occur (p. 30).

As mentioned earlier, the case study method is aiming for "analytic generalization"- a comparison of the case study's results with the theory that the case study has been designed to investigate (p. 31)—rather than "statistical generalization," which would require the researcher to make "an inference about a population $(. .$.$) on the$ basis of empirical data collected about a sample.” (p. 30)

\section{Research questions}


The primary research aim in this study was to elucidate the (explicit and implicit) multi-level (individual, organizational, institutional, higher education, societal) change theories held by stakeholders in the emergence of contemplative initiatives at one HEI, including but not limited to a Center. I wanted to see whether, how, and why these change theories are enacted in making change on the ground. I looked for coherence and discrepancies: between stakeholders' implicit and explicit theories of change; between stakeholders' theories of change and their enactions of them; between the theories of change stakeholders hold on different levels (i.e. theories of how individuals change vs. how institutions do). More simply: How do stakeholders' contemplative praxis, learning praxis, organizational change praxis, institutional and higher education praxis-through the change processes each invokes and produces - inform each other in this case? I looked for themes in how participants view and engage in these change processes, and analyzed these themes from my position as researcher, with access to the perspectives of multiple stakeholders via interviews, data gathered as a participant-observer, data from document review, and sensitizing concepts from my theoretical framework and ongoing theory development.

\section{The primary research question}

How may contemplative praxis (analysis and practice of contemplation) inform and even transform higher education praxis at a particular university? How do, or do not, and with what impact, the Center's stakeholders and others invoke contemplative praxis as they theorize (implicitly and explicitly) and act, regarding vital purposes, processes and potentials of pedagogy (across disciplines; curricular and co-curricular), research, professional practice, organizational practice, institutional change, and engagement on 
and beyond the campus? And, what constraints, pressures, priorities and habits in contemplative praxis may inform its incorporation in the HE setting?

\section{The secondary research question}

How, in this case, may higher education praxis inform and even transform contemplative praxis? How do, or do not, and with what impact, stakeholders in the Center, and at a particular university more broadly, bring their assets-disciplinary expertise, multiple levels of inquiry, praxis, research capabilities, analysis and articulation of findings and new questions, generative discourse within, across, and beyond disciplines and institutions - to bear, in evolving fuller, more nuanced understandings of contemplative practices and orientations, and their potentially radical effects in education and in society? And, what constraints, pressures, priorities, and habits in HE praxis may inform or even transform what contemplative praxis means, and to what purposes it is put, in the setting?

\section{Unit of Analysis}

The primary unit of analysis was the CIC, and as such the design was a singlecase study (Yin1994, pp. 21-25, 38-45; \& 2004, p. 5). Part of the CIC's stated mission is to facilitate the differentiated needs of stakeholders across disciplines at SEU, and part of its mission is to facilitate interdisciplinary cross-fertilization (CIC website; Charles, personal communication). The fact that the CIC itself was my primary unit of analysis has enabled me to investigate the relationships of sub-cases with the organization as a whole, the underlying purpose being to test key propositions about the CIC as a whole. 
Since the CIC is also contextualized within a movement in U.S. higher education to incorporate contemplation in HEI settings, I collected and analyzed data from participants at other HEIs, and in organizations such as the Association for Contemplative Mind in Higher Education (ACMHE) and MiEN (the Mindfulness in Education Network), that focus, respectively, on the role of contemplation in higher education and education generally, to help me understand the CIC in relation to these layers of contextual conditions. The CIC is also contextualized in a particular HE setting in which are emerging a range of contemplative initiatives, many of which are tied loosely if at all to the CIC per se.

Thus, I framed my research as a single-case design, a rationale for this being that it represents to some extent what Yin $(1994$, p. 39) called "an extreme or unique case." The particular case I studied, the CIC at SEU, is not entirely unique, in that it is one exemplar among others of initiatives to incorporate contemplation into HEI contexts, and one exemplar among others of contemplative initiatives at SEU. I took this into account as I contextualized the CIC within a broader movement, both in the literature review and in data gathering which included interviews with several interested participants outside of SEU, and within SEU but not affiliated with the CIC. I studied how stakeholders inside and outside SEU—while they may perceive some characteristics of the CIC to be "extreme or unique" - extrapolate characteristics of the CIC to other actual or potential initiatives at SEU, in other HEIs, and even outside academia. This aspect of the study situated it within a larger inquiry, contextualized in the dynamics of a social movement to incorporate contemplative practices into higher education settings and beyond.

\section{Connecting Data to Propositions}


Yin (1994, pp. 25-26, 102-16) suggested that what he calls, after Campbell (1975, p. 4), a "pattern-matching" approach to data analysis, is appropriate when the case study is designed to be "explanatory." Though certainly there are overlaps among “explanatory," "descriptive," and "exploratory" approaches to case study, in an explanatory study the researcher hopes to explain the findings in more explicit relationship to propositions. Yin suggested that these propositions emerge in the theorybuilding process of research design, and though they may evolve over the course of the study, they serve as vital points of reference throughout iterations of data gathering and analysis, and in the final report of the study.

It was useful to frame this case study as an explanatory one, because I did bring some tentative theoretical propositions into my study, and an explanatory framing required me to rigorously analyze my findings in relation to these and alternative propositions. This case study was partly descriptive and partly exploratory, but the explanatory component required more analytical discipline, which I believe made my findings more useful.

In a pattern-matching approach to an explanatory case study, during the design of the study the researcher may, in addition to propositions, suggest some alternative propositions that offer "other plausible or rival explanations" (Yin 1994, p. 111). While collecting and analyzing data, I was alert to the evidence for and against this range of contrasting explanations or propositions.

\section{Propositions}


The following initial propositions provided a degree of structure for the ongoing process of data collection and analysis that this case study entailed. Propositions, as well as the research questions, assisted me in selecting participants to interview, designing interview strategies and questions, deciding what data to look for in document reviews, and focusing on the most informative settings and phenomena as a participant-observer. Propositions were hypotheses to be tested, extended, contested, contradicted, or complicated in the process of research. What I found in relation to propositions in the early stages of the study informed research strategies in later stages. The propositions developed along the way; the analysis refers back to these initial propositions, as well as later permutations of them.

\section{Primary propositions in the study}

The study explores how the stakeholders in the Center, and others, theorize and enact change at the nexus where contemplative praxis, organizational praxis, learning praxis, and higher education praxis converge. An assertion pivotal to the study is that across specific praxes, transformational praxis has common features. This assertion informs the proposition that in each arena, transformational praxis entails explicitly interrupting habits of perception, understanding, engagement/action, and identity, to support inquiry into deeper levels of meaning, feeling, relating, desiring, caring, and sense of identity, thus informing stakeholders' conceptions, interests, and action on organizational and institutional levels.

The following were my initial propositions: 
- Initially, my primary proposition (hypothesis) was that, since contemplative praxis explicitly aims to foster capacities which assist significantly in interrupting habits and in inquiring deeply, its introduction into the setting would be found to facilitate, and even catalyze, the transformative potential of learning organizational and institutional praxes.

- A correlative proposition was that even if contemplative praxis may facilitate or catalyze transformative potential in the other arenas of praxis, it may or may not be brought to bear in these arenas.

- Therefore, a pivotal proposition here is that to the degree to which stakeholders (implicitly or explicitly) incorporate contemplative praxis as they engage in each of the other arenas of praxis, transformative changes will more likely occur in these arenas.

- A correlative to this proposition is that stakeholders' understanding of purposes and methods of contemplative praxis will change as they, or others they observe, bring it to bear in these other arenas. 


\section{Propositions evolved over the course of the research}

Over the course of my study, as I incorporated a complexity lens into my conceptual framework, I developed the following propositions:

- Awareness/attention can produce disturbance in a human complex system, whether that human system is intra-personal, interpersonal, organizational, institutional or beyond.

- In a disturbed complex system (implicit and explicit), choices are made that reduce complexity or guide emergence; these choices can have real consequences involving: the entrenchment or transformation of inequitable power dynamics; marginalization of difference; dampening adaptive learning and innovation.

- In addition to power and value, a pivotal element informing choices about reducing complexity or guiding emergence is capacity to guide the system successfully through chaos to emergence.

- Capacities to disturb complex systems and to guide/scaffold them toward emergence are congruent with capacities that proponents say contemplative praxis develops: proactive use of awareness and attention.

- (Explicit or implicit) perception of, and engagement with, any and all dimensions of praxes as involving complex systems (wherein diverse, connected, interdependent agents learn adaptively together) is resonant or even consonant with a contemplative approach, and may amplify the transformative potential of each praxis. 
These propositions correlate to my original ones, but bring in more sensitivity to the power dynamics I had begun to see more clearly as my study progressed. These power dynamics showed up as institutional barriers — external and internalized —in the higher education setting. By "power dynamics" in this case, I mean influences that tend to reproduce the status quo, by reducing complexity rather than scaffolding the emergence of more inclusive, dynamic and novel initiatives.

\section{Counterpropositions}

My original counterpropositions continued to prove useful as a framework for analyzing the data:

Contemplative practice and the institutional structures of higher education are unnegotiably incompatible at SEU, and this case sheds light on that incompatibility.

- Power dynamics —implicit or explicit—within SEU and/or within the CIC dilute or coopt transformational potentials of contemplative praxis and of the CIC.

- The CIC's agenda and means of implementing them are pre-determined and limited by the funders, other powerful influences at SEU, or members of the CIC's Planning Circle, in ways that constrain transformative change on any or all of the arenas of praxis - contemplative, learning, organizational, institutional.

- Since a pivotal proposition is that to the degree to which stakeholders (implicitly or explicitly) incorporate contemplative praxis as they engage in each of the other arenas of praxis, transformative changes will more likely occur in these arenas, a counterproposition is that stakeholders will incorporate contemplative praxis as they engage in other arenas, but that transformative change will not occur. 
- Stakeholders' understanding of purposes and methods of contemplative praxis will not change as they, or others they observe, bring it to bear in these other arenas.

- Stakeholders' focus is limited — particularly in this early stage — to implementing contemplative practices for students (and perhaps academic professionals) in the learning arena; beyond adjustments to support that agenda, transforming organizational or institutional praxes, and transforming even contemplative praxes, is not prioritized.

\section{Interpreting findings}

Yin (1994) stressed that the research design should set the stage for later, when it comes time to interpret findings. This aspect of the research design deals with issues of construct, internal, and external validity, as well as generalizability. Yin said that construct validity requires that the researcher specify what aspects of change she will study, and requires also "that the selected measures of these changes do indeed reflect the specific types of change that have been selected" (p. 34). By internal validity as it applies to case study research, Yin meant the need for the researcher to use caution in extrapolating causal relationships, and also in making inferences. He suggested that a pattern-matching approach, as described in the section above, can help assure internal validity (p. 35). External validity, or generalizability to other settings, is not fully attainable in a case study, and particularly not in a single-case design (p. 35-36). As stated previously, generalizability in the context of this study refers in great part to how my findings related to my propositions. Further, because this case study does take into account input from settings and stakeholders beyond this single case, I will make some 
cautious statements about possible generalizable findings. For this case study to achieve a high degree of reliability, I document my investigation-including plans, data collected, and analytic processes — carefully, so that my methods can be clearly traced.

\section{Data Collection and Analysis}

The study included interviews, participant-observation, and review of documents, and I sought to triangulate findings from these data sources in my analysis. To do so, I engaged in continuous documenting of my research activities, recording and transcribing interviews, and note taking in settings where I was a participant-observer. My analytic process involved creating analytic memos, as described by Erickson (1986), wherein I explored my emerging understanding of the data as it relates to my theory and propositions going into the study. I discovered, created, named, and analyzed themes and tentative assertions, and showed how these developing understandings, themes, and assertions have related with my propositions, and have guided me iteratively back into the field for further data gathering.

Yin (2004, p. 3) specified that often case study research requires data collection and analysis to be done together as a mutually informative process. When information derived from interviewing one participant conflicts with that derived from interviewing another, "surfacing the conflict is considered data analysis," which should lead to "modify[ing $\ldots$.. data collection plans while still in the field ...." Following Yin's advice has required that while gathering data, I kept track of the substantive issues involved, performed ongoing analysis to allow incoming data to inform my understanding and perspective, viewed my original propositions through the lens of fuller 
knowledge, and adjusted my data gathering to respond to newly apparent gaps or conflicts.

\section{Interviews}

This case study relied heavily on one-on-one, semi-structured interviews, to gain perspectives from a range of stakeholders on contemplative practice, its place in higher education, and the CIC. Preparation and follow-up from each interview included reading my interviewees' writings, and work that they recommend by other authors, related to my research topic. Interview questions were tailored as appropriate to the relationship of the interviewee to the Center and other contemplative efforts in the setting. The target interview length was $1 \frac{1}{2}$ hours.

\section{Anonymity and confidentiality}

I have used pseudonyms for nearly all participants, and for the setting and organizations within it. In an effort to respect anonymity and confidentiality concerns in regard to participants, and to the setting in general, I chose not to cite some sources in my References, including website information for the CIC and SEU.

However, in a few cases, in which interview participants were also presenting material publicly at conferences, I have used their real names in reference to statements they have made to me in interviews, when those statements were elaborations on their public statements, and the participants did not indicated that they were confidential.

\section{Interview participants}


The field of invited participants included stakeholders at SEU, at other HEIs, and in organizations dedicated to contemplative practice in higher education. The field also included three participants (other than CIC donors) not currently affiliated with an academic setting, who had an interest in contemplative social change. Interview questions were tailored as appropriate to the relationship of the interviewee to the Center and other contemplative efforts in the setting.

Over two years and ten months, I conducted 93 interviews with 54 participants. I conducted follow-up interviews with some participants over the course of the study to clarify, update, or deepen my understanding of their perspectives. I conducted 19 second interviews, seven third interviews, and two fourth interviews, for a total of 90 interviews.

A strong limitation of my study was that my interview participants were purposefully selected because of their roles as stakeholders in relation to contemplative efforts. Although they represented a range of views, backgrounds, and roles in regard to contemplative approaches, they did not represent the range that a random sample would have. More research in this topic area, with a wide range of participants, will be needed for a fuller understanding.

\section{Participants at SEU}

The strong majority of interview participants were purposefully selected because of their roles as stakeholders in relation to contemplative efforts in this university setting. At SEU, I engaged stakeholders with a range of perspectives on the Center and contemplative praxis more generally. Divergences in perspective arose from, or correlated with, five factors, which I name in here in no particular order of importance. 
First, professors, students, and even staff at SEU are most often affiliated with a particular academic discipline and/or institutional role, lenses through which they might view the value, challenges, and applicability of contemplative orientations. Second, each stakeholder has a particular relationship (or lack thereof) to contemplative orientations, which may be informed by avocational experience or interest, or by exposure to the use of contemplation in an academic context, or both. Third, stakeholders vary widely in their degree of involvement in work related to the CIC and other contemplative initiatives. Fourth, stakeholders' degree of influence in the CIC's trajectory ranges widely. Fifth, I have not limited my participant pool to stakeholders who are affiliated with, or advocates of, the CIC. I was interested in the perspectives of stakeholders who are involved in contemplative praxis outside of the Center's purview.

Interview participants have included:

A) Eleven members of the CIC's Planning Circle, among whom there has been some turnover during the course of my research. I have purposefully chosen, and invited to participate, members of the Planning Circle who represent a range of disciplines. Also, key members of the Planning Circle, including CIC's Director "Charles," Dean of Nursing "Barbara," and School of Education professor "Roberta" have played pivotal roles in the inception of the CIC, and I have asked them additional questions to help me understand the CIC's "creation story."

B) Nearly all of the CIC's full-time staff, among whom there has been significant turnover during the course of my research. 
C) Two of CIC's Board of Advisors members who are also CIC donors and SEU alumni.

D) SEU professors, administrators, and students (none of whom are minors), who were engaged in CIC-related activities. Two Deans and one former Dean, Two Vice Presidents: for Development and for Human Resources; the Vice Provost for Academic Affairs, and the Associate Director for Equity and Diversity. I interviewed the Associate Director of the university-wide center for teaching resources, who has led efforts there to provide professional development for faculty interested in incorporating contemplative orientations into their courses. I also interviewed the Director for an SEU-based center for research on higher ed teaching and learning, The CIC states an intention to offer contemplative practice opportunities to students in the co-curricular arenas of recreation, residential life, and student life (i.e. leadership development); my interviewees include SEU staff and faculty in each of these areas who have expressed interest in this endeavor. I interviewed a current student and a recent SEU alum who were activist leaders on campus.

\section{Participants at other HEIs}

A significant pool of stakeholders consists of academics at other HEIs who express interest in the CIC. A few of these are among this study's interviewees. They were asked to identify and describe their interest and stake in how the CIC unfolds, as well as to describe correlative work they are doing on their own campuses. I interviewed the Director of a center for wellness and contemplation at another public university in the same state. I have enriched the breadth of my understanding of contemplative studies in 
U.S. higher education through communications with colleagues I met through the Association for Contemplative Mind in Higher Education (ACMHE) at its annual conferences in 2012 and 2013, at the annual meeting of the Mindfulness in Education Network (MiEN) spring 2012, and at a conference held April, 2013 at Virginia Polytechnic Institute and State University (Va. Tech), called Contemplative Practices in a Technological Society, and MOOC's, Money, and Mindfulness Conference held at Naropa University March 2016.

\section{Founders and national leaders of the movement}

I have had extended conversations with Daniel Barbezat, Executive Director of ACMHE and co-author of the recently published book Contemplative Practices in Higher Education: Powerful Methods to Transform Teaching and Learning (Barbezat \& Bush, 2014); I have twice interviewed Rhonda Magee, a national leader in this movement as well. As individuals heavily engaged in and helping to lead the movement to bring contemplation into Higher Education, and particularly to make inclusion and equity central to the movement, their input is invaluable to my research.

\section{Participants outside of higher education}

I conducted two interviews with a consultant who works nationally in the field of systems change with an equity lens, and one with a local organizational consultant whose expertise is in contemplative organizational change and leadership.

\section{Interview methods}

I conducted one-on-one, semi-structured, in-depth interviews with the purposefully selected participants described above. I approached potential participants by 
telling them that I am researching the roll-out of SEU's Center for Investigating Contemplation, and that I would like to talk with them about their perspective on, and engagement in (if applicable), the CIC, and arrange a convenient time for the interviewee. With interviewees at a distance, I conducted interviews on the phone or on Skype. I asked each participant to sign a consent form before beginning an interview. During the interview, I invited them to respond, or choose not to respond, to my questions as they preferred. They were explicitly free to express or withhold information and perspectives according to their own interests, willingness, and degree of comfort in doing so. I let them know in my consent procedure that they were free to end or change the conversation at any time. I explained that, in general, I was not able to ensure anonymity or confidentiality, and that if they did not want to be quoted or have particular viewpoints traceable to them, they were free to tell me that, and I would respect their requests. I told them that if I had any concerns that an opinion expressed, or the way it was expressed, might compromise the privacy of a participant, perhaps even entailing negative consequences, I would check with him or her before choosing to include it in my findings.

For my sample interview protocol, please see Appendix A. In interviews, I asked participants to articulate questions, visions, aspirations, and concerns that most drive them regarding the relationship of contemplative practices and orientations to higher education, and the CIC if applicable. In regard to the CIC, I asked them how they perceived its value and mission, and for their suggestions about how the CIC might achieve the goals they desired, and about whether and how they engaged in the CIC. For participants not affiliated with SEU, I adapted questions to allow them to express their 
perspectives about the $\mathrm{CIC}$, contemplative practice in higher education in general, and their experiences and interests at their own institution. I asked most participants whether they considered themselves to have their own contemplative practices and orientations. I asked many participants, as appropriate, about the history and impact of these practices or orientations in their lives, and about future goals in the arena of personal practice and experience. My purpose was to correlate their self-reports about how they valued contemplation for themselves with how they valued contemplation in the context of higher education.

\section{Participant-observation}

I attended all CIC events to which I had been invited, and a great majority of CIC events which were open to all, as a participant-observer. The data collected included notes and recordings of 12 CIC-sponsored meetings and conferences, and many other CIC-sponsored lectures, from 4/17/12-3/1/16. Nearly all of which were open to the public, but I was also included in a few invitation-only CIC events. I also attended 11 national and regional conferences, from 2013 through 4/01/16, focused on contemplative initiatives in higher education and other social institutions, and contemplative leadership. I recorded and transcribed many keynotes and other presentations as part of my data collection. Among these presenters were approximately 10 of my interviewees.

In addition, I attended approximately 12 events at SEU over the course of my study that were focused on social justice issues. I was interested in whether and how these events, or particular stakeholders involved in these events, invoked an implicit or explicit contemplative approach. These participant-observations served as counterpoints 
for my correlative inquiry when attending other events, through the CIC and otherwise, where the overt focus was on contemplative matters, as to whether social justice concerns were acknowledged or addressed by presenters or participants 


\section{Document review}

Documents analyzed included those produced by the CIC, including material on the CIC's website. I also used publicly available material from SEU to contextualize the CIC within its institutional context.

\section{Conclusion}

In this chapter, I have introduced the setting for my case study, discussed areas of interest in my project, and described my research methods. In the next chapter, I present a review of related literature. 


\section{Chapter Two}

\section{Review of Related Literature}

\section{Framework for the Study}

In this study, I sought to understand how participants relate individual, organizational, and higher education institutional change with contemplative praxis, in theory and in action. What can stakeholders' aspirations and concerns about learning and change in HEI's, in organizations within them, and for individuals in these contexts, tell us about their perceptions about whether and what transformative change is needed and possible, and moreover their perceptions and actions vis-a-vis enacting such change? How might stakeholders define a contemplative approach to learning in individual, pedagogical, research, organizational, and institutional praxes, and how might they say that such a contemplative approach facilitates or fails to facilitate transformative aspirations and outcomes?

To sensitize my research to underlying questions about what constitutes, facilitates, and fails to facilitate these transformative praxes, I have engaged in the following literature review of current tensions - and responses to those tensions - at what I suggest are some leading edges of the fields of learning praxis, organizational praxis, higher education praxis, and contemplative praxis - in itself, and as applied to all of them. I began below by exploring definitions, attributes, and sources of contemplative practices and orientations (CP\&Os). I then described some benefits and concerns about their incorporation into higher education settings of relevance to this study. 


\section{Contemplative Practices and Orientations}

What are CP\&Os, and what are they for? What kinds of contextual factors do they involve? How may CP\&Os reframe what we mean by learning?

\section{Toward defining contemplative practices, orientations, and their purposes}

There is a long and rich history of cultivating the contemplative throughout the wisdom traditions. Contemplative practices have included meditation that has endured for thousands of years in Buddhism, various forms of yoga from Hindu traditions, contemplative prayer in Christianity such as that of St. Theresa of Avila or Thomas Merton, radical questioning through dialogue such as that expressed by Plato or the self-inquiry of Ramana Maharsi, metaphysical reflection of the Sufi tradition that leads to the deeper intuitive insight of the heart (qalb), or the deep pondering suggested in the Jewish Kabbalah. Each of these practices and many, many more offer an approach to interrupt habitual thought routines and deepen awareness (Hart 2004, p. 30, italics added).

Practitioners and scholars of transformational change - whether personal, organizational, institutional, or societal — describe methods of bringing attention to current subjective and objective conditions, including unexamined assumptions and dynamics of difference and conflict, and responding to and engaging with those conditions in ways that facilitate change that is transformative to underlying processes and structures.

W. Astin, H. S. Astin, and Lindholm (2011, p. 148-149) state that meditation "refers to a family of spiritual/contemplative or psychophysical methods and practices that while considerably diverse in approach, share as a common theme or goal: the discovery of a deeper realm of experience or awareness beyond the ordinary discursive (thinking) mind." 
There is indeed a range of definitions of what constitutes and characterizes contemplative practice and orientations. This is to be expected, as many contemplative traditions are rooted in religious and spiritual traditions with different philosophies and views of reality, of the place of human experience within reality, and of means of developing capacities valued in those traditions. Certainly the differences across definitions are important, and such distinctions are a provocative part of my research focus, as I have queried stakeholders on their own definitions based in theory and experience, and how these definitions inform, and are informed by, these stakeholders' values and priorities.

Despite important and consequential differences among them, it is reasonable to assert that an underlying premise of most contemplative orientations, and the practices that derive from and/or support them, is that our taken-for-granted subjective experiences do not provide us full awareness of the nature of reality, our own human condition, and the relationship between ourselves and the rest of reality. Added to this premise is the general assertion by proponents across traditions that it is indeed possible to increase one's awareness in these arenas, and that there is value in doing so; contemplative practices have been developed to help in that aim.

\section{Buddhism-derived contemplative practices}

It is interesting, but not surprising, that many proponents of the widespread dispersion of contemplative practices in U.S. medical and educational settings promote practices derived from Buddhist traditions. Some of these proponents (e.g. Barbezat \& Bush, 2014, p. 78) assert that these practices require no religious faith and therefore do 
not impose on people to adopt or change religious belief systems in order to reap the benefit of increased well-being through better self-awareness and self-care, particularly in terms of better physical, emotional, and mental health. Many also assert (e.g. Zajonc, 2009; A. W. Astin, H. S. Astin, and Lindholm, 2011; \& Davidson, 2012) that such increased self-awareness and well-being will, in turn, increase practitioners' capacity and motivation for compassionate awareness of others, creating a ripple effect that makes ethical and altruistic action more likely.

The Buddhist-derived practices popularized by Mindfulness Based Stress Reduction (MBSR) (Kabat-Zinn, 2005), Insight Meditation (Kornfield, 1993), and related approaches, are said by proponents to help practitioners - in the meditation period itself and, increasingly in one's daily life — suspend some habits of mind such as the tendency to ruminate discursively, leap to judgment as contrasted with discernment, and react emotionally without full awareness of what gives rise to those reactive processes. Jon Kabat-Zinn (2005) wrote that "Mindfulness means paying attention in a particular way: on purpose, in the present moment, and nonjudgmentally," and that this "nurtures greater awareness, clarity, and acceptance of present-moment reality."

Shapiro, Warren, Astin \& Duerr (2008, pp. 8-9) said, “Although this practice is simple, it is not easy and calls for effort and discipline" on the part of the practitioner, and that while attention may at times have to be paid to difficult or painful thoughts and emotions, it also "opens channels to deep reservoirs of creativity, intelligence, imagination, clarity, determination, choice, and wisdom within us.” Rosch (2007) emphasized that bringing attention to previously unexamined aspects of one's subjective experience involves the experience of pain. These authors cumulatively describe a sense 
of increased awareness of both self and of interdependence, and an experience of both well-being and growthful challenge.

Given that Buddhist-derived practices inform much of the field of "secular" contemplative practices, I offer here a description of the major tenets of Buddhism. Buddhist teachings have arisen in many variations across cultures and over time, but they are traceable to some key tenets. Buddhist doctrine is based on the idea that the human condition is inherently one of delusion, in that we each falsely experience ourselves to be a discrete, abiding entity, separate from the rest of reality. This subjective condition gives rise to constant craving, as we feel persistent desire for or aversion to objects, other beings, experiences, etc. that we assume to be fully outside ourselves. Even when we temporarily have attained something we want — or have avoided something we dislikeon an underlying, often subconscious level, we are prisoners of a pervasive sense of anxiety and discontent, since some part of us is aware that yet another craving or aversion will inevitably soon arise, with its inherent discomfort. Therefore, duhkha or dis-ease is at the substrate of our experience, and is the true cause of our most primary suffering. The passing sufferings of sickness, loss, painful emotions, and hunger are all sufferings of a relative, transient quality incomparable in primacy to duhkha.

The concept of rebirth, and the related belief in karma, are also central to Buddhism. These concepts express a natural law of cause and effect, whereby one's status in any particular life is a direct outcome of one's actions and states of consciousness in previous lives. Also central to Buddhism is the concept of enlightenment as an attainable state. Generally, in this state one will experience oneself as nonseparate, and reside in deep tranquility - the antidote to the condition of duhkha. 
Barnhill (2000, p.19) said that there are two contrasting "conceptions of the ideal of consciousness (withdrawal and insight/wisdom) and two different ideal stances in relation to the world (detachment and nonattachment).

Varela, Thompson, and Rosch (1991) wrote that the characteristics of mind described and addressed by the contemplative traditions of Buddhism are the same as those discovered by Western cognitive science. Their premise held that full consciousness is possible (only) via contemplative practice that requires reflective, hereand-now attention to increasingly subtle emotional/cognitive phenomena intrinsic to embodiedness. They asserted that Buddhism's practice-based contemplative disciplines are intended to expose one's awareness to the layers of assumptions and emotional biases brought unconsciously to all experience.

\section{Centering Prayer from the Christian tradition}

Whereas some contemplative practices derived from Buddhist traditions have become secularized and widespread in the West, contemplative movements in Christianity cannot be secularized, as they are unequivocally based in faith. I look next at another contemplative practice revived, updated, and practiced in the U.S. today, Christian Centering Prayer. I invoke this practice because it derives from the Christian tradition, which is the most common religious tradition in the U.S. and among members of the SEU community. I also invoke this practice as a proxy for a range of contemplative practices and orientations from a wide range of religious traditions which cannot be described as secular, and therefore provoke concerns about separation of church and 
state, particularly at a public university. These concerns will surely become important over time in the context of the CIC's developing work at SEU.

Centering Prayer derives from a tradition of contemplative prayer in Christian traditions, but was updated and mainstreamed over the last several decades by Fr. Thomas Keating and others (e.g. Bourgeault, 2004). Centering Prayer is based in a cosmology in which divine love is ever present, always available to be experienced as a source of healing, and of inspiration to become more loving oneself. Christ is conceived by some Centering Prayer proponents (e.g. Bourgeault, 2008) to have been an exemplar of the capacity to radically release the identification with the "small" self that considers itself separate from the source of love that is, in this worldview, the fabric of the universe. Bourgeault (2008) wrote that following Christ's example allows one to experience the valued effects he espoused: the sense of being loved, and an increased capacity for being a source of love and compassion for others.

Buddhist-derived mindfulness meditation and Christian Contemplative Prayer do have some ends and means in common: suspending one's usual parameters and habits of awareness of oneself and "reality," seeking greater insight about oneself and reality, and the relationalities this involves, and compassion for oneself and others. Both practices develop kinds of meta-awareness, and reframe human capacities and identity. Both seek to integrate the conceptual and the experiential. Both assert the vital importance of increased awareness about what motivates us, including our implicit biases, rationalizations of these biases, and emotional limitations passing for rationality. Both support an increased ability to tolerate difficult emotions, conceptual tensions, and inputs that threaten our familiar sense of identity. The ensuing ability to enter into, and gain 
insight through, disequilibrium is vital for the resiliency and growth that engender transformative learning.

\section{Focus beyond the individual}

Jennings (2015) wrote:

Mindfulness promotes a sense of belonging and connecting. As we experience present-moment, nonjudgmental awareness, we can more readily recognize our common humanity and our interdependence on one another and on all of life, not as a philosophical abstraction but as direct experience of interconnection. The act of caring for one another, for living things, and for our planet becomes an ethical mandate because we recognize our oneness ... . When we widen our perspective, our mind makes connections that we didn't realize existed before. [183-185]

Before leaving the question of what may constitute or characterize contemplative practice, I cite Greenberg's (2012) admonition to expand the conception of contemplation beyond silent, still, and solitary practices. He asserted that yoga, movement, dance, other artistic endeavors, dialogue, storytelling, martial arts, athletic disciplines, teamwork of various kinds, and many other practices, can and should be considered potential contemplative practices. He suggested that it would be very worthwhile to study what factors facilitate and amplify practitioners' contemplative experience within these activities. Moreover, Greenberg (2012), Macy (2007), Senge, Scharmer, Jaworski and Flowers (2004), Kabat-Zinn (2005), Zajonc (2006 \& 2009), have all asserted that there is great value in bringing contemplative practices and orientations into group settings such as work or classroom, where the content of study and/or the purpose of the group's efforts are informed by a shared contemplative attitude. And, correlatively, the real measure of the value of contemplative practice according to these authors is in whether such practices make a difference in how people interact and work together for the 
common good. This theme was highlighted as well by the title (and content) of an April 2012 presentation, "Mindfulness Is Not Enough," given by Judith Simmer-Brown at the April 2012 Tibetan Medicine and Meditation Symposium at the University of Virginia.

\section{Contemplative practices, context, and worldview}

Most contemplative practices derive from historical, cultural, aesthetic, philosophical, and religious contexts in which practices are embedded in and supported by teachings about the nature of reality. "Reality" here may be on a cosmological scale, on the scale of the human being, or span the spectrum. The contemplative practice is often an epistemological means of experiencing an ontological reality held as truth by a particular tradition, or at least a means of exploring reality based on questions and values held as valid by a tradition. Moreover, particular practices and teachings are very often contextualized in communal experience, and thereby reinforced through shared worldview and learning. I use the term contemplative orientations to convey the fact that practices themselves are, to some degree, related to particular perspectives toward at least some dimensions of reality. We should take seriously questions and concerns that arise when we extricate specific practices from their contexts, not just cultural but ontological; and, conversely, we should use care when implementing practices—new, old, or amalgamated-in new contexts.

Contemplative practices derive from many contexts; as previously stated, it is noteworthy that practices derived from Buddhism have been particularly welcomed in the West. Kabat-Zinn (2005) and many others have drawn from Buddhist traditions to develop and teach methods of meditation and correlative understandings of how the 
human mind operates and can operate better. The Buddha taught people to investigate and work with mind-states, within their own experience, rather than take on faith his description of the mind and of reality. Therefore, it makes some significant sense that Buddhist practices have been disseminated in a range of contexts, including very secular ones, wherein faith or belief are not required as prerequisite to experience. However, even the Buddha's directing people to investigation rather than blind faith was couched in teachings about human nature, the nature of reality, and the means by which to investigate both.

Many traditions have since arisen in Buddhism, synergizing teachings and practices in varied ways, and each embedded in cultural, aesthetic contexts. Questions and concerns indeed remain as to what may be lost, found, or simply different about such practices and their effects, when extricated from the contexts (explicit and implicit) that generated and sustained them (Kahane, 2009). The dispersion of Buddhism-derived practice and teaching into Western contexts is an intriguing case for examining these concerns, because there is a very wide range of such practice and teaching now available in the West. Some approaches include a great deal of teaching of a Buddhist worldview (ontology) (e.g. Wangyal, 2011), some distill this worldview into what proponents consider its essence and impart that along with the teaching of practices (e.g. Kornfield, 1993; Salzberg, 1995).

Rosch (2007) strongly critiqued the popular use of the term "mindfulness" that conflates present-moment awareness with full meditative experience. She asserted that in Buddhist teachings about meditation, cultivating present-moment awareness is only one element of a holistic approach to meditation; moreover, she asserted that meditation itself 
is only one element of a holistic approach, involving nuanced study and practice, to transforming one's awareness. Nonetheless, some may minimize the need for, or desirability of, explicitly teaching anything but practices, either due to unconcern with worldview or due to belief that the practices will, by themselves, lead naturally to worldview changes. There is rich ongoing discussion of these questions. For example, a recent issue (Vol. 12, Issue 1, May, 2011) of the journal, Contemporary Buddhism, was a special issue on mindfulness, edited by Kabat-Zinn.

Controversy about worldview changes has arisen from the perspective of Christians and others who reject the premise that practices such as mindfulness meditation or yoga are indeed secular and should therefore be welcome in public institutions. C. G. Brown (2013), in The Healing Gods: Complementary and Alternative Medicine in Christian America, raised a red flag about what she called deception on the part of many who espouse "alternative and complementary" health practices-including body-based contemplative practices such as yoga — that have become rather mainstream. She asserted this because methods such as acupuncture and yoga are based in conceptions of what is needed for healing (i.e. unblocking energy channels) that conflict with Christian teachings about the power of faith in a divine source. She wrote that perceptions and beliefs are affected by these "alternative" experiences, even when the people taking part have been assured that they are engaging in "secular" practice. She articulated an important concept: that experience changes us, and that there are issues of honesty, integrity and choice involved as we explore how these changes may occur, and their impact. 
Questions and concerns about the interdependence of practice, belief, and effect should be important to proponents of contemplative approaches to higher education. I explore a meta-level perspective, that the dichotomy we assume in our culture, and perhaps more so in academic culture specifically, between religious faith and other kinds of belief systems (e.g. materialist) is fair game for dismantling. Our taken-for-granted sense of how reality works, and particularly the relationship between physical reality and human consciousness, is dissonant with newer understandings in science (e.g. Palmer \& Zajonc, 2010).

\section{How might contemplative practice and orientations reframe learning praxis?}

In what ways do findings and assertions about the results of contemplative practices and orientations affirm and extend current theory about learning, and about human experience more generally, and in what ways do these assertions diverge from or transform current learning theory? Current theory (e.g. Siegel 2007) asserts that cognition, affect, and bodily experience are all inextricably, synergistically implicated in learning, and moreover that our sense of individuality—our simultaneously cognitive, affective and bodily "self" - is conditioned by past and present relationships. We are intrinsically interdependent beings, and we also have capacities for self-awareness and agency. Approaches to learning that acknowledge the importance of both interdependence and agency have been validated by researchers in the field of education. Concepts and tools in the arena called Social Emotional Learning (SEL) are based on the assertion that the quality of relational interactions (e.g., between teacher and student, and among peers) strongly affect the emotional well-being and competence of students, as well as their academic learning, and moreover that these two realms are inextricably 
connected (Jennings, 2011). SEL and the correlated concept of Social Emotional Competence (SEC) affirm the value of teaching and reinforcing emotional self-awareness and self-regulation, and some advocates and researchers include prescribed methods that encourage both students and teachers to attend to bodily experiences such as the breath, to gain more awareness of one's own, and others', patterns of reactivity, and to intentionally interrupt these patterns by choosing productive means such as relating needs and feelings directly, practicing empathy, using self-soothing practices, etc.

The field of "positive psychology" has burgeoned in the last decade or two, and focuses on the value of positive emotions, in contrast to psychology's often overriding focus on pathologies. B. Fredrickson, a leading positive psychology proponent, has developed what she calls the "Broaden and Build hypothesis," which means that

[t]he expanded cognitive flexibility evident during positive emotional states results in resource building that becomes useful over time. Even though a positive emotional state is only momentary, the benefits last in the form of traits, social bonds, and abilities that endure into the future. The implication of this work is that positive emotions have inherent value to human growth and development and cultivation of these emotions will help people lead fuller lives. (Fredrickson, Cohn, Coffey, Pek \& Finkel, 2008)

Neuroscientists have achieved phenomenally expanded capacities in recent years to study the "brain"- which includes the nervous system and, by extension, bodily processes generally — and how such measurable physiological activity correlates with measurable behavioral and cognitive attributes or changes, and also with our subjective experiences. Fredrickson et al. (2008) performed studies showing changes in the brain, heart and the vagus nerve induced through Buddhist Loving Kindness Meditation. Brain imaging with participants who are long-time meditators has shown changes in the parts of the brain thought to be correlated with increased capacities for equanimity and 
compassion (Davidson, 2012). Very new research (www.contemplativeresearch.org) using brain imaging as well as self-report, has purportedly illuminated the difference between experiencing empathy, as resonating with the pain of another, and compassion, as a sustainable state in which one not only resonates with another's pain, but is also poised for helpful action, all while maintaining a sustainable internal state of well-being. These studies purport to show the difference between states of caring that may lead to burnout, and states — apparently available to experienced meditators — that may lead simultaneously to increased well-being and increased capacities for altruism. Other research (e.g. Neff, Rude \& Kirkpatrick, 2007) refined parameters of self-compassion, versus conceptions of self-esteem, and postulates that self-compassion has comparatively greater value for intra- and interpersonal well-being than does self-esteem.

Research thus far on the effects of contemplative practices at the University of Wisconsin, MIT, Yale, and Harvard Medical School, among other leading institutions, has shown that they may increase attention and cognitive control (Wallace, 2006), body/mind coherence (Shusterman, 2008), physical and emotional well-being (Goleman, 2006; Davidson, 2012), and resilience - the ability to tolerate and respond to distress (Siegel, 2007, 2010). These findings, and others like them, have taken the practitioner's well-being as the primary locus of study. However, some studies have explored explicitly what has perhaps been implicit in some of the earlier ones: how changes in the individual contemplative practitioner - whether neurobiologically evidenced, subjectively reported, and/or measured through improved health, or cognitive or affective skills-impact relationships and behavior toward others. While many (e.g. Macy, 2007; Senge et al., 2004; Simmer-Brown, 2012; \& Zajonc, 2009) have asserted that a primary value of 
contemplative practices is their positive effects in interpersonal, group, and even societal —rather than simply intrapersonal — realms, Greenberg (2012) stated that only 3-5\% of studies on the effects of mindfulness practices had thus far focused on interpersonal effects, and that far more emphasis should be placed on these dimensions.

\section{Cultivating "second person" (relational) capacities}

Barbezat and Bush (2014, p. 16) cited the work of neuroscientist Tania Singer, writing that she "argues that we are coded, that is, wired to have empathy," and that empathy is a passive response. "However, compassion is not a passive response; it includes the desire to relieve the suffering." Moreover, these authors postulated, based on Singer's findings, that a state of compassion does not lead to burnout, whereas a state of empathy can. "Empathy is limited and reactive, whereas compassion is cultivated and boundless." Compassion needs to be cultivated, they assert, and contemplative practices facilitate this cultivation.

Practitioners and scholars (e.g. Zajonc, 2010; and Barbezat \& Bush, 2014) have been exploring "second person" applications of contemplative practices in the service of developing capacities for empathy and compassion. They wrote about methods of guiding students into processes such as Buberian dialogue (Scott, 2014), eye gazing experiences (Baugher, 2104), and "presencing from the intersubjective field" (Gunnlaugson et al., 2014). Along these lines, contemplative practices have been shown to increase participants' ability to become aware of implicit biases (Dasgupta, 2009), respond productively to paradox, tension, and conflict (Kabat-Zinn, 1994) and feel compassion 
for [self and] others (Wallace, 2012). As a pivotal theme of my findings, I will develop this line of inquiry further in my exploration of contemplative pedagogy, contemplative organizational change work, and contemplative institutional change work.

\section{Contemplative Practice in Higher Ed Teaching, Learning, and Research}

In the following sections, I have explored perspectives on the incorporation of contemplative practice into higher education contexts. I have examined the interface of contemplative praxis with current conditions in higher education, described approaches to implementation and research, and brought forward some concerns.

\section{The context for contemplative pedagogy in higher education}

In a social climate where the study of external technologies (i.e. STEM) is heavily funded and prioritized, students are typically provided scant opportunity to take seriously the exploration of their internal experiences, and to bridge this exploration with academic learning.

Mark Nepo, in his foreword to Parker Palmer and Arthur Zajonc's The Heart of Higher Education: Transforming the Academy Through Collegial Conversations (2010), wrote,

... for each generation there is a developmental window from approximately the ages of eighteen to thirty-five in which these capacities for compassion and community can be awakened. These ages happen to correspond to the span of undergraduate education, graduate education, and professional schools ... . Within this context, the individual's journey through higher education, if made meaningful, holds a crucial turning point which Harvard researcher Robert Kegan describes as the movement from the individual, personal mind to the social, relational mind. He suggests, in fact, that higher education's chief responsibility is to foster this ... transformation from independence to interdependence. (p. xi, italics added). 
A. W. Astin, H. S. Astin, and Lindholm (2011) conducted a large, recent nationwide seven-year study on how students develop over their undergraduate years in terms of what the authors call their "spiritual growth," as well as their "religious" engagement. The Astins and Lindholm distinguished spirituality from students' religious life, and characterized spirituality as comprised of the following five components, each of which they investigated separately in relation to their study's participants: "Spiritual Quest, Equanimity, Ethic of Caring, Charitable Involvement, and Ecumenical Worldview" (pp. 18-19). They found that, while students' religious engagement declined during their college years, their scores on the Astins' and Lindholm's measures in these five areas increased. They found that two thirds of college students surveyed expressed strong interest in questions of spirituality, as they defined it, and that students said that most of their professors never encouraged conversations related to these spiritual arenas, religious questions, or even questions about finding meaning or purpose in one's life.

The Astins and Lindholm suggested that college students, and also many faculty, are hungry for more engagement about how to live a meaningful and "spiritually" engaged life, which by their definition involves commitment to one's own deeper wellbeing within a larger context of respect for others and active concern for their well-being. Many students enter college, the authors said, hoping that their studies will be framed by these larger themes, and although students tend to develop capacities in these areas over their college years, more can be done to directly reinforce the learning they are ripe for.

The Astins and Lindholm found that many recent trends in higher education, such as service learning, study abroad, interdisciplinarity, interracial interaction, leadership training, and volunteerism, all support students' spiritual growth accord to their measures. 
They strongly asserted, however, that their study "found that contemplative practices are among the most powerful tools at our disposal for enhancing students' spiritual development. Our data show that meditation promotes growth in all five spiritual qualities" (A. W. Astin, H. S. Astin, and Lindholm, 2011, p. 148, italics theirs). They also point to recent research finding that "the use of meditation in higher education has demonstrated its positive effects on cognitive performance, releasing stress, and aiding in the development of the whole person, including development of interpersonal skills, emotional balance, and academic skills" (p. 149).

Much of the literature about introducing contemplative practices in higher education, in the secular settings that have been my focus, present contemplative practices derived from traditions of Buddhist meditation, as if these were entirely secular and entirely different from practices and traditions tied to religions like Christianity, Judaism, and Islam. The pivotal difference is likely perceived as whether faith or belief is required in order to undertake a practice in a valid way, or whether one can embark on a practice as an empirical study, maintaining one's rationality and discernment while genuinely investigating the effects of that practice. There are indeed differences across practices in what kinds and degrees of belief are suggested or required by the traditions that uphold them, and these are differences that do make a difference, as John Dewey might say. Particularly in a public university, there are significant concerns about the separation of church and state, and injunctions against proselytizing. But, again, I assert that from a broader perspective, the more cogent insight is that we are always subject to worldviews, our own and others'. There is no neutral, objective perspective on reality; if 
we seek insight, the best we can do is hone whatever abilities we hope will serve us best in our quest.

\section{Implementation of contemplative pedagogy in higher education}

The Association for Contemplative Mind in Higher Education (ACMHE) calls itself "a multidisciplinary academic association with an international membership of educators, administrators, staff, students, researchers and other professionals committed to the transformation of higher education through the recovery and development of the contemplative dimensions of teaching, learning and knowing." (www.contemplativemind.org, retrieved 1/28/16)

On 5/15/2013, I retrieved a definition of "contemplation" from the website for The Center for Contemplative Mind in Society, ACMHE's home organization. The definition began, "A practice designed to quiet the mind in the midst of the stress and distraction of everyday life in order to cultivate a personal capacity for deep concentration and insight." On 1/28/16, the definition of contemplative practices had been revised to: "Cultivate a critical, first-person focus, sometimes with direct experience as the object, while at other times concentrating on complex ideas or situations. Incorporated into daily life, they act as a reminder to connect to what we find most meaningful."

By foregrounding, in its newer definition of contemplation, the term "critical, first-person focus" rather than "quiet[ing] the mind," and by invoking the idea of “concentrating on complex ideas or situations," ACMHE seems to be promoting active engagement, within the self and in the world. The updated version goes on to describe 
“calm centeredness," as "an aid to exploration of meaning, purpose and values." It also says that contemplative practices "are practical, radical, and transformative." It appears that ACMHE's definition may have evolved over the last few years to convey contemplative practices as both involving and inspiring action and engagement. This foreshadows a theme of effort by some proponents of contemplative approaches in higher education, and others, to define and deploy contemplative practices in HEI settings and in society generally: as we inquire into what contemplative practices are, we are also asking what they are for.

Advocates assert that incorporating contemplative practices into higher education complements the latter's traditional basis in rationality, engages students more fully, increases their attention, decreases their stress, opens their minds, deepens learning, and increases compassion. Colleges and universities across the country, i.e. Brown, Amherst, Stanford, Emory, and UCLA now have initiatives which incorporate contemplative practices into teaching, learning, and research. Shapiro et al. produced a compilation in 2008 titled Toward the Integration of Meditation into Higher Education: A Review of Research, and the rate of such research has rapidly increased since then (Bush, 2010, 2011). Lindholm, Millora, Schwartz \& Spinosa, in Promising Practices: Facilitating College Students' Spiritual Development (2011), asserted that HEIs provide fertile ground for a wide range of offerings; their book lists and describes these interventions on campuses nationwide.

Shapiro et al. (2008, p. 5) wrote, "Four decades of research provide evidence of the significant effects of meditation on education-related variables. [There have been] major findings in three areas: Cognitive and Academic Performance; Mental Health and 
Psychological Well-Being; and Development of the Whole Person.” The authors said, "Several recent studies with adults offer evidence that meditation may enhance attentional capacities and attention-related behavioral responses." They further asserted that divided attention and multi-tasking have been shown to increase the tendency to achieve only rote learning, whereas having a single focus of attention increases the ability to generalize learning to new situations. They wrote that, despite the pivotal role attentional abilities play in learning, little or no direct training of these abilities occurs in educational settings. Therefore, they concluded that it could be very useful to introduce into these settings meditative practices that have been developed to train attention.

There is much concern about the incidence of stress, anxiety, and depression among college students. Stresses of adapting to college include new social and emotional demands, and meeting academic challenges. As Daniel Goleman (2006, p. 268) noted, stress "handicaps our abilities for learning, for holding information in working memory, for reacting flexibly and creatively, for focusing attention at will, and for planning and organizing effectively." Clearly, this range of impacts can affect psychological wellbeing and academic achievement. Shapiro et al. (2008) cited Baer (2003), Brown, Ryan, \& Creswell (2007), Murphy \& Donovan (1997) as sources in claiming that "[f]our decades of research with adult student, community, and clinical populations has provided evidence that meditation reduces negative mental health symptoms, including stress and anxiety, and enhances psychological well-being."

\section{Concerns that the incorporation of contemplative practices in higher education could entrench societal power dynamics}


There is, however, concern about how CP\&Os are understood and deployed in the context of higher education. There are a range of concerns, touched on above, about separation of church and state and related issues about the place in higher education for practices that could be described as "religious" or "spiritual." In addition, there are less discussed but pertinent concerns such as those expressed by Vokey (2014) in his chapter "Contemplative Disciplines in Higher Education: Cutting Through Academic Materialism," where he invokes concerns about "academic capitalism" as related to contemplative praxis. Vokey (pp. 253-270) cautions that "two specific socio-political dynamics related to neo-liberalism . . . are operative inside and outside higher education, limiting or undermining the benefits of educational initiatives" such as introducing contemplative practices. These two dynamics are what he calls "the individualistic bias" and "commodification" (pp. 261-262). Commodification of contemplative practices can lead to marketing contemplation in its less-than-transformational forms, to enhance the prestige or competitiveness of an institution, in this case an HEI, that wants to sell itself as embracing the newest trends. The "individualistic bias" locates each individual's problems within her- or himself, thus ignoring and therefore colluding with inequitable systemic conditions. The "solutions" to these problems are also seen as the responsibility of the individual; contemplative practices may become such decontextualized solutions, helping students cope with conditions that they and others should be working instead to change.

[W]e cannot assume that introducing contemplative disciplines into higher education will necessarily promote transformative change. We must acknowledge the possibility that contemplative disciplines will be taken up in ways that serve existing priorities and leave the educational status quo intact. For example, mindfulness meditation could be introduced into . . . university communities to improve productivity via stress-management. 
Vokey (2014) stated that neoliberal economic biases may press HEI's to prioritize "forms of inquiry oriented to enhancing productivity and efficiency." He used the concept of "technical rationality" (Schon 1983, 1986, cited in Vokey, p. 261), critiqued by Schon, which assumes that professional practice consists of "the application of theoretical knowledge to practical problems: theory identifies which variables must be manipulated and in what fashion to achieve desired results." This approach is "epistemologically naïve," as it fails to account for the complexity of professional practice contexts. Moreover, in its narrow focus on "instrumental efficiency," such an approach is "amoral," as it does not question "the moral appropriateness of the ends and means of practical action, educational and otherwise.” (p. 261) It does not ask whose interests are being served, and whose are not. Vokey was concerned that contemplative practices may be co-opted in these instrumentalist ways, to develop students' capacities to be productive and efficient within the current socioeconomic system, rather than to help them question that system, its inequities, and its underlying values assumptions. Vokey wrote (p. 263) that "[W]hile contemplative disciplines might have some genuine benefits to practitioners, efforts to introduce them into public educational institutions should not function as substitutes for equity-oriented social change."

Along these lines, R. Gottlieb, in Spirituality of Resistance (1999), expressed vehement concern about the uses of contemplative practices to shield one from the very real struggles that need our active engagement. D. Forbes (ACMHE conference sessions 2012 and 2013) voiced concern about the possible co-optation of contemplative practices for instrumentalist use to promote neoliberal agendas in education and the workforce. If contemplative practices help students and others relax and pay attention, he asked, might 
they then create docility and complacent cooperation with whatever tasks are assigned to them, by a banking system of education and later by an exploitative capitalist economic system?

\section{Integrating contemplative practices with systems awareness in higher education}

Responding to such concerns, professors and researchers - in the interest of understanding where contemplative praxis and learning praxis converge as transformative education-explicitly explore ways to help students not only hone their attentional skills and sense of well-being, but also concurrently bring attention to issues of collective wellbeing. In this section, I invoke some ways that educators are framing transformative pedagogical approaches that develop in students first and second-person awareness and compassion, in concert with awareness about the dynamics of systems both small and very large. Toward developing this transformative praxis, they investigate pedagogies that synergistically lead students toward, rather than away from, reflectivity about their own motivations. These motivations include internalized oppression and unconscious privilege (first-person awareness); more awareness of, and compassion for, others (second-person awareness); more understanding of systemic patterns of exploitation and extraction, and the ways that these systemic patterns can be perpetuated and interrupted.

Transformational education-understood as educating the whole person by integrating the inner life and the outer life, by actualizing individual and global awakening, and by participating in compassionate communities - has become a quiet but sturdy movement that encourages the recovery and development of the academy as a liberating and capacity-building environment. (M. Nepo in Palmer and Zajonc, 2010, p.7). 
Some scholars and practitioners assert that explicit teaching, and learning, must take place in order for students to integrate the effects of contemplation into a transformed understanding of social and environmental injustices, and their responsibilities to act ethically in local and global contexts. Challenging (explicit and implicit) claims that contemplative practices may inherently transform students' awareness and response to social justice issues and other pressing concerns, they propose that contemplative praxis and transformational learning praxis may indeed be complementary, as strongly suggested by the following assertion in this announcement by the Mind and Life Institute's International Symposium for Contemplative Studies 2014, describing the Pre-Conference titled A Tale of Two Movements: Why Contemplative and

\section{Transformative Education Need Each Other:}

What is contemplative and transformative education, and how can their integration lead to systemic changes in education? Contemplative education integrates practices that promote self-reflection, compassion, openness to experience, and an ability to understand one's perceptions and actions. These skills are critical to personal and social transformation in this increasingly complex world. Transformative education extends the capacities developed by contemplative education so individuals can address issues of equity, social justice, and lasting change, not only when they are in school systems but also when they move beyond them. (http://www.iscs2014.org/PreConference.asp)

Transformative educators who are informed by critical theory use the term "transformative" to mean experiences that bring one's awareness and attention, as fully as possible, to transforming the deep conditioning undergone by each person and by groups of people. Such conditioning, both in the form of internalized oppression and of unconscious privilege, limits one's sense of agency, by which I mean a subjective sense of choice. Moreover, if one is in a position of privilege in some way, one's own choices constrain the choices of others. The term transformative evokes "conscientization" 
(Freire, 2002) or coming to consciousness (implying prior unconsciousness) as the espoused ends and the means of critical education for all, whether oppressed or oppressor.

In her recent book, Integrating Mindfulness into Anti-Oppression Pedagogy: Social Justice in Higher Education (2016), Beth Berila explored the ways that contemplative approaches can leverage self-awareness and other-awareness to deepen students' understanding of the impact of oppressive social systems on themselves and others. She showed how these practices can be used to help students tap their embodied experience, which is often suppressed in higher education settings, and which she shows to be a powerful source of fuller understanding of, and engagement with, feminist and critical race theory. Systemic oppression, internalized oppression, and privilege are all lived, embodied, relational experiences; Berila's work highlights the importance of bringing awareness to these experiences, and methods of doing so that are pedagogically sound, respectful, and empowering.

Law professor R. Magee, in The Way of ColorInsight: Understanding Race and Law Effectively Through Mindfulness-Based ColorInsight Practices (draft 2015), wrote about

... the idea of curated, adapted compassion - and mindfulness-based practicesexperienced at the level of the personal, interpersonal and the systemic - as central components of effective if lifelong paths of insight and understanding around issues of race, social identity and their impact in the world.

Magee stressed the necessity for a first-person contemplative practice to develop "meta-awareness capacities most important to cultural sensitivity and effectiveness in diverse learning communities." These "meta-awareness capacities," she wrote, include 
"self-awareness, ... perspective-taking, emotion-regulation, and the empathy which supports compassionate action.”

Goleman and Senge (2014) have developed an approach they call "Triple Focus," which asserts that in order to respond productively to the problems we face today, we must cultivate capacities in three domains. The first domain is the realm of selfawareness and self-regulation; the second is the social realm, in which we need capacities for feeling and acting on empathy and compassion; the third domain is "systems thinking," wherein we develop understanding of the way complex systems work, and how to engage in them productively. They have asserted that in order to understand our roles - in perpetuating and in working to transform—-large-scale social and environmental systems, we must be sensitized to the principles underlying the dynamics of complex systems. Education from the very early years, they said, should impart this understanding and support children (and adults) in applying that understanding to systems large and small. They provided an example of six-year-old boys creating a "systems map" of an ongoing dispute they are enmeshed in. The boys then apply their understanding of "feedback loops" in a way that shows them how to transform their interactions. This systems thinking synergizes with the self-awareness/self-regulation components, as well as the empathy/compassion components, of the "triple focus" education they have been receiving, such that they are able to inform their objective ("third-person") understanding with "first-person" and "second-person" capacities, and thus collaboratively "emerge" more adaptive ways to interact.

Some have said that contemplative practices may offer conceptual and experiential alternatives to assumptions about the nature of the self in relation to others 
(Varela et al., 1991; \& Macy, 2007), resulting in increased motivation to engage responsibly in a world beset by social and environmental problems (Senge et al. 2004). As I described above, Varela et al. (1991) claimed that his field, cognitive science, has corroborated the Buddhist premise of a non-abiding self. They suggested that grasping at a stable sense of self is the cause of much human suffering, and that a more healthy and realistic awareness of the non-static nature of self can refine and promote healthier states of attention, relationality, and awareness of reality as it is, dissolving habitual patterns that limit "bare" experience.

Contemplative practices and orientations can be seen to affirm and extend theories of learning such as Dewey's (1916) that prioritize kinds of learning that develop truly democratic sensibilities, as well as Freire's (2002) and hooks' (sic) (1994) that empower agents to engage in anti-oppression work. These theorist-practitioners value learning based in embodied, lived experience, consider affect and relationality as vital to learning, and assert that learning on these levels involves significant shifts in both one's habitual sense of self and the group/societal norms one may have taken for granted. Contemplative practices and orientations, if they de-center these habits of perception and interaction, may support the emergence of fuller awareness of self and one's social contexts that lead to more compassionate motivations.

Furthermore, some assert that implicit in contemplative pedagogy is the radical idea that students' inner lives can provide them with worthwhile knowledge, and even wisdom. They say that this radical idea - that one's subjective experience is valuable in itself - presses back against the very objectives of instrumentalism, even without or before introducing an explicit "systems view" to students. Oren Ergas (2015) wrote, "A 
student that is given proper instructions throughout these 'interventions' [contemplative practices], tacitly surmises that in here counts, that 'education' is about 'me' too, that exploring the first-person inner-terrain is an educationally worthwhile activity." Ergas went on to say that he is not suggesting that "here and now (the present) is such a lovely place to be at. My claim is not about romanticism. It is about reality. Mindfulness is about realising that we can't be anywhere else but here and now." This in itself, he said, is revelatory. 'When seen in this way, our public 'curriculum' is revealed as somewhat of an 'out-of-body experience': it tells us that we live here now, but we really ought to be 'there in a future, then.",

Ergas (2015) stressed, "If we start allocating curricular time to activities that ask students to note their breathing, thoughts, sensations - their inner workings and the hereness and now-ness of their existence-we are transforming the social understanding of 'education' and 'the educated person'." For those who are concerned that these contemplative interventions are couched in an valuation of "attention" deployed instrumentally to "cater to an economic educational narrative," Ergas suggested that "beyond [such instrumentalism] lurks the trajectory of a contemplative educational turn that may be outwitting over-instrumentalisation through [the valuing of looking for knowledge within, espoused by] wisdom traditions."

\section{Higher education's role in researching effects of contemplative practices in general}

Research continues, and more is needed, on how contemplative practices impact those who use them, during the initial learning stages and beyond, to investigate what factors facilitate and hinder their effects, and to study outcomes, both intended and 
unintended, desirable and problematic. Situating these practices in HEIs provides a convenient setting for formal research on their effects in the lives of students, staff, and patients, in the contexts of education, medical and nursing schools. Cross-disciplinary initiatives are needed to support exploration, through research and experiential learning, of the application of contemplative practices to a range of fields, tapping into a research arena that is rapidly expanding worldwide, as evidenced by recent presentations and attendance at the First and Second International Symposia of Contemplative Studies (www.contemplativeresearch.org), "a collaborative effort among Centers and Laboratories around the world to explore the correlates and consequences of contemplative practice.”

\section{Higher education's role in researching pedagogical effects of contemplation}

Within the educational context of a university, the impacts under investigation could include how coursework and contemplative experiences inform each other, and how contemplative practice affects college students' identity formation and capacity to learn. Such research could focus on how contemplative practice can inform current learning theory, pushing the envelope on concepts about reflective practice and transformative learning, and opening new territory for research on social-emotional learning, self-awareness, motivation and engagement, ethics, and embodied, experiential learning, and the effects of all these on cognition, affect and behavior.

This research could also acknowledge and address the potential risks posed by contemplative practice for some students (Britton 2014) who may be psychologically vulnerable to exacerbation of Generalized Anxiety Disorder, psychotic breaks, etc. In a 
more general sense, say both Dunne and Britton, research on the effects of contemplative practices with college students should be concerned about effects of challenging students' sense of identity in ways that result in unintended negative consequences for their wellbeing.

Some (e.g. Berila 2016) call for research on contemplative practice in higher education learning that focuses on purposes and outcomes of contemplative praxis vis-avis its interface with transformational education that invokes critical praxis. As some professors are bringing contemplative practices into courses with distressing and challenging content, related to students' and others' identities and their taken-for-granted roles, whether privileged or not, in oppressive systems, research that explores the uses and misuses of these practices in helping students open to a fuller understanding of the world, and of themselves in it, is a potent realm of inquiry.

\section{What is Higher Education For? Some Current Tensions in HE Praxis}

Astin \& Astin (2011) asserted that the "ivory tower" remains the norm, where in perhaps all but the hard sciences, academic pursuits often remain largely theoretical, lacking practical testing and the reflective practice (Schon, 1987) that this entails. They write that students, despite some desire for a more holistic educational experience, most often succumb to the path of least resistance, conforming to the norms and expectations of the institution; by and large, faculty may do the same. Some voices are weighing in to the national conversation about higher education by pressing for far more integration between academia and the world outside the ivory tower. 
Many advocates of contemplative praxis in higher education affirm that such praxis lays the groundwork for a more integrative approach to learning, by supporting students (and professors) in overtly exploring their motivations for learning and acting, seeing themselves and the world afresh, and encouraging compassionate and engagement. These authors articulate the need for changed priorities in higher education, but do not focus on how this may play out structurally in HEI's. In How Universities Can Help Create a Wiser World: The Urgent Need for an Academic Revolution (2014), Maxwell adamantly asserted that the focus on knowledge acquisition, per se, in higher education disconnects academia from its vital responsibility to engage cooperatively with all stakeholders to take on solving urgent global problems. He stressed the need for deep structural changes - transformation - in higher education praxis, stating (p. 18) that

... academia as conducted today ... is all but organized in such a way as to ensure that it has little impact on the rest of the world. Transforming academia ... would radically alter this situation. Academia would have, as a central task, to learn from and engage with the rest of the world; academics would no longer be primarily concerned to talk to each other.

The distinction his argument relies on is between "knowledge inquiry," the conventional mode in academia, and "wisdom inquiry," which demands that we investigate underlying causes of problems, and respond integratively to solve them. His approach strikes me as both contemplative and transformational, on levels including the organizational and institutional.

Underlying the issues that this case study addresses are concerns about the current and future mission and viability of U.S. higher education. Higher education stakeholders and decision makers confront tensions, explicit and implicit, involving questions about ideals and values, concerns about financial survival, issues of identity and culture for 
institutions and their constituents, and the dynamic interface where values and viability, continuity and change, are weighed against each other. Decision-making processes themselves can be explicit or implicit, and can be more or less inclusive, or exclusive, of divergent interests and perspectives. "Higher education, both public and private, is challenged to meet the demands of a new economy and students with very different expectations, needs, and skills than in previous generations. Moreover, it must do so in a time of profound economic inequality." (Rogers, 2013)

\section{Higher education funding and philanthropic support}

HEIs compete with one another for funding, faculty, grants, donations, and programs; collaboration among colleagues from different HEIs is rare. Additionally, funding sources - whether from parents' tuition, the state, grantors, or donors - come with strings attached, inherent agendas, however explicit or implicit. State funds, and certainly policies about their distribution, are tied in part to political perspectives if not biases, as well as economic factors. The availability of grants for particular kinds of research sways university's research agendas. The structures and processes through which Boards of Trustees are selected and provided oversight, and the structures and processes through which they communicate with stakeholders and make decisions, vary by institution and can strongly impact an HEI's direction. Administrations and boards make choices, often by default, about whether and how to prioritize diversity, inclusivity, and equity, in selection and support of faculty, staff and students, whether motivated by a commitment to accessibility, or an understanding that the learning environment will 
thereby be enriched for all. Research and teaching practices that explicitly address issues of social justice - e.g. service learning, civic engagement, and university-community partnerships - are not typically funding priorities at HEIs.

The question of how private donors' values and desires may drive decision making, in any of the arenas described above, is a pervasive question in higher education (Pusser, Kempner, \& Ordorika, 2012), and certainly factors into this case study. Barbezat and Bush (2014) asserted that higher education, particularly of the kind that goes beyond "simply convey[ing] information and train[ing] narrowly for the workforce" (p. 199) "provides profound benefits to our society." These authors stated that while higher education in itself contributes to the public good, when this education incorporates contemplative orientations, this contribution is all the greater. "To support our students in the discovery of what means most deeply to them and provide them the tools to live out that meaning in the world is the primary mission of education." (p. 201) The authors asserted that higher education is what economists (and Barbezat is an economist) call a "positive externality," which improves "society at large, outside of those who are directly consuming or producing them," and yet is likely to be undersupported by a free market economy. Therefore, intervention is needed in the form of subsidization. In the U.S., the vast majority of HEIs rely on subsidies beyond tuition, in the form of public funding, grants, or donations (p. 199). The authors imply two significant assertions: First, as public funding decreases, grants and donations must increase; second, grantors and donors who are concerned that higher education support students in discovering deep meaning, and in developing tools to live and act from that meaning, should fund initiatives in that vein. 
Rogers (2013) warned, however, that

... philanthropy is no longer, if it ever was, benign and benevolent - it is powerful. This shift of power to the economic elite via philanthropy makes it even more important to our democracy's health that we support a viable public option in higher education that is not determined by the priorities and judgments of the very wealthy, however well intentioned they may be.

Rogers (2013) invoked the term "philanthrocapitalism," which she said is "[t]he new trend in philanthropy," the purpose of which is "to transform whole institutions through strategic giving .... Perhaps most important for higher education, philanthrocapitalists seek to leverage public money [by funding particular interventions in public HEIs] and to engage in 'catalytic giving' that ripples far beyond the reach of the original donation.” Rogers asserted,

Changes in higher education are necessary; I think we can all agree on that. Philanthropy, however, can become de facto public policy making. The continued existence of an informed, educated, independent citizenry will be possible only if leaders in the philanthropic sector are accountable to the public whose tax money is being leveraged to shape America's future.

\section{Higher education and organizational change.}

Organizational theorists/practitioners, Udall (2014), Senge (1990) and Senge et al. 2004), and Scharmer $(2005,2014)$, all of whom articulated principles and practices of organizational change praxis that I call both contemplative and transformational, advocate strongly for cross-sector collaboration, among business, NGOs, and governmental organizations. What roles do, or can, academic stakeholders uniquely play in these cross-sector collaborations? How do the CIC's stakeholders conceive of its own and SEU's roles in such collaborations? 
This study tracks how this all plays out on the ground, given the contexts within which the CIC is embedded, including administrative habits and policies, the varied priorities of stakeholders across SEU's community, SEU's espoused mission and strategic plan, SEU's culture, history, and identity, the changes that SEU's new "responsibility-based management" process may bring about and the financial pressures it may exert on schools and departments, and the perspectives of the donors.

\section{Some Approaches to Transformative Organizational Praxis}

In the process of organizational change in which the CIC is involved, stakeholders will likely contend with significant conflicts of perspective, strategy, and priority, within the ranks of those aligned with the CIC's mission, with others who object to part or all of that mission, and in relation to structures, policies, and habits at SEU and higher education more broadly. A dynamic at play in a developing organization, and particularly one that purports to tap and support emergent initiatives, rather than dictate direction in a top-down manner, is the tension between inclusivity and focus, or, stated differently, between dissonance and agreement.

In this section, I introduce the work of some recent and current practitioners and researchers of organizational change who propose theories and methods coherent with practices valued by many contemplative orientations, wherein participants bring awareness to, suspend, and transform habitual and limited ways of thinking, feeling, acting, and interacting. The organizational change processes they describe could in many cases be considered, implicitly or explicitly, both transformational and contemplative. 
These theories, drawing implicitly and explicitly from interpretivist, critical, pragmatist, and contemplative perspectives, all have several things in common. First, they are theories of learning in which learning occurs in collaboration with others. Both the individual and the community or organization learn, through group interaction; to the degree that there is a teacher or leader, that person learns as well. Second, these theories are intended to be enactable - to go beyond description of how collaborative learning happens to prescription for how it should happen. Third, they intend to be transformative: to facilitate lasting change in processes and structures.

Across a range of disciplines and methodologies, practitioners and theorists describe several theoretical constructs all of which give rise to methods for leveraging conflict in the service of inclusive, adaptive learning, and in so doing, facilitate transformative changes. Cultural-historical Activity Theory (CHAT) (e.g. Engestrom, 2008) proposes a framework to describe the interface between personal and institutional change, and to prescribe useful ways that groups can work at this interface. CHAT promotes practices wherein participants create a joint depiction of "what is," and work to transform it into what could be. Participants articulate their own experiences and viewpoints and listen to those of others, which corroborate or challenge their own to varying degrees. Depicting "what is" does not mean rushing to consensus, but first entails mapping more explicitly the agreements and disagreements among participants, or resonances and dissonances among interests. Contradictions among viewpoints are an opportunity for learning, when we "externalize" (ibid) — that is, identify and explorethese contradictions. After externalizing a range of particular viewpoints, participants are 
guided to identify themes and tensions that have become "visibilized" in that process; then, they collaborate in constructing an "expansive" alternative activity system.

Freire (1998) described the transformation from "ingenuous curiosity" to "epistemological curiosity," which can occur when participants are invited to articulate their own experiences and then guided to collaboratively discover and name themes and patterns; only then can they construct interventions that respond to underlying problems. Hooks (1994), similarly, wrote that sharing personal stories is vital, but that to engender full learning in teller as well as listeners, "theory" must be applied to, or developed from, these stories. Framing the particulars in a more overarching model of meaning is a liberatory process, she said. Lederach (2005), practitioner-theorist of conflict transformation, said that people from opposing sides of a conflict can develop "paradoxical curiosity," the ability to look outside the normal parameters of dualisms. Lederach's process entailed looking together at the way things "seem to be"- their outward presentation or "face value"—and at the same time to explore their "heart value," which is the meaning that people find in, and ascribe to, these externals. Lederach's quest was not for a narrowly defined common denominator or compromise, but instead was for something more dynamic and elusive. He wrote that "truth lies in but also beyond what is initially perceived." Lederach suggested the value of suspending how we delineate the world, and of learning not just to tolerate ambiguity, but to develop our capacity for experience and engage ambiguity.

John Dewey (1916) wrote about what he called "the disavowed self," aspects of one's experience which we often suppress, especially in public settings. He talked about how important it is that people get a chance to un-suppress this disavowed self in 
environments wherein that self can educate others who have not been exposed to the differences which that self expresses; also, that self, because of its own limitations, needs educating through exposure to others' different perspectives. In other words, we are generally encouraged to suppress aspects of ourselves - both positive and negative - that may be seen as too different from societal norms. By setting conditions wherein people can productively open their minds to others' differences, a mutually educational process unfolds. Our prejudices, Dewey says, are reduced, and our wisdom increases.

Martin Davidson's work on Leveraging Difference (2011) described the ways in which an organization or business benefits from incorporating differences, in meaningful ways. He provided guidance by which to identify, see, engage and leverage difference, acknowledging and working along the way with resistances as they arise.

All of these approaches cohere with a complex systems view, as they affirm the dynamic potential for generating novel, adaptive, unpredictable-emergent — outcomes via collective learning processes made possible when diverse stakeholders acknowledge and leverage the connectedness and interdependencies among them, and accept, make explicit, and even amplify existent tensions in the service of emerging new possibilities.

Our taken-for-granted and very often unconscious fears, defenses, and resentments drive much of our action and interaction, however dysfunctional these underlying psychological dynamics may make us. Stone (1989) asserted that in public conversations about policy, stakeholders create and align with "causal stories," or explanations for how things got to be the way they are. These are similar to what Hewitt \& Hall (1973) called "quasi-theories." These stories or "theories," which are nearly 
always framed not as possible interpretations but as fact, implicitly and explicitly point blame and posit particular solutions, and may well get in the way of addressing problems in creative, collaborative ways.

Organizational theorist Chris Argyris (2003) explicated two distinct kinds of learning: "single loop" and "double loop" learning. He said people are "programmed" to think "inside the box" of our assumptions about the way the world works. In the second kind of learning, people wonder about root causes of problems, especially causes that are rooted in our own habitual ways of thinking. Argyris said that the proclivity to the limited first type of learning is "programmed into human beings early in their lives," and we go on to extend this orientation in our organizations. "Human beings . . create systems that support self-defeating action.”

Further, Argyris (2003) wrote, people have a very hard time critiquing the dysfunction in the systems they are part of, others in those systems, and certainly themselves, as we are conditioned to express an upbeat attitude and avoid questioning underlying dynamics. Additionally, people employ "defensive logic" to avoid having to confront the most threatening, embarrassing, and simultaneously most systemic problems. This unwillingness can be particularly acute for leaders, who are conditioned to present themselves as infallible. So, Argyris stated, people by-pass uncomfortable subjects, and prioritize the maintenance of a "positive," safe-feeling environment over working toward a more productive one, wherein people are challenged, and helped, to look at our own difficulties and failures. 
Argyris (2003) wrote that people's commitment to these habits, rather than simply evidence of a lack of skills in regard to human and organizational behavior, in fact reflects a great deal of skill at non-learning_- "skilled incompetence" and "skilled unawareness"- that guides people in creating and sustaining environments wherein learning will not take place. Defensive reasoning mindsets, said Argyris, drive us to defend the actor or the group, to make premises tacit, and to test the validity of claims through self-referential logic. Self-deception is protected to avoid transparency; selfdeception must be denied, and this denial must be denied.

Argyris and Schön (1974, p.6-7) proposed that people's espoused theories of what motivates their actions, what they called "theories-in-action," diverge from the theory that actually governs their actions, which they called people's "theory-in-use." Thus, there is incongruence between people's (usually unconscious) "theories-in-use," based on tacit "mental models" of how things work, and the theories they espouse themselves to be acting on. They asserted that developing congruence between espoused theories and theories-in-use is important for personal and organizational effectiveness.

Solutions and strategies to address problems "out there" arise most fruitfully from a relational substrate wherein people have been given ample space and time to explore what others, and they themselves, bring to the situation. Seeing others as viable, complex, capable human beings, not just an oversimplified "other," takes rich interaction in a setting that assures equal voice for all. Creativity and willingness to risk, the capacities Lederach (2005) describes as necessary for conflict transformation, may displace a healthy pessimism, a less healthy defensive logic, and "contrived collegiality" (ibid), only as relationality becomes a relatively safe substrate in which to explore new possibilities 
together, and to design changes and means of implementing these changes. Lederach stresses that this all requires artfulness, intuition, responsiveness, and spontaneity as well as logistical skills. Our artfulness tends to be more available to us when we feel more related and therefore less fearful, more expansive rather than entrenched in our perceptions.

In Immunity to Change (2009), Kegan and Lahey affirmed that when groups begin to work together to help each other disturb and transform behaviors based in entrenched assumptions, they scaffold each other's movement through chaos into emergence. A major thrust of the Immunity to Change work is that people's outwardly dysfunctional behaviors — such as needing to be in control-stem from a defense that we each rally in a seemingly intractable way, to protect ourselves from having an underlying anxiety triggered. The scaffolding process given by Kegan and Lahey (2009) - an often collaborative investigation of four layers of motivation for each member's problematic behavior - is conducive to this ongoing work of guiding emergence together, and is an implicitly contemplative practice.

\section{Complexity and organizational change.}

In Organizational Learning (Collinson and Cook, 2007), the authors stressed the vital importance to healthy organizations of systemic thinking, asserting that the tools and templates of the modern industrial era, based on linear thinking, are insufficient in our postmodern knowledge-based era, which requires thinking focused on interrelationships among factors. Organizational theorist Senge (1990, p. 185) proposed "systems thinking as a philosophical alternative to the pervasive 'reductionism' in Western culture - the 
pursuit of simple answers to complex issues." He stated (p. 94) that, "structures of which we are unaware hold us prisoner" and that "learning to see the structures within which we operate begins a process of freeing ourselves from previously unseen forces and ultimately mastering the ability to work with them and change them." Senge et al. (2004) asserted that if we do not acknowledge, as individuals but moreover as organizations, where we are - the reality of our situation, including the often painful unintended consequences of our actions - we will simply be unable to respond adaptively.

Capra and Luisi (2014, pp. 315-320) in discussing organizations as "living [complex] systems," stated that human organizations always have a "dual nature": the explicit purpose or mission; and the fact that organizations are "communities of people who interact with one another to build relationships, help each other, and make their daily activities meaningful at a personal level." Organizations "always contain both designed and emergent structures." The designed, or formal, structures are the "rules . . . that define relationships between people and tasks, and determine the distribution of power. " The informal structures consist of "interconnected communities of practice," in which the organization's "aliveness resides." These informal networks can be nurtured to become "developed and sophisticated." The more "social space [is provided] for informal communications to flourish," the more the organization will "be able to learn, respond creatively to unexpected new circumstances, change, and evolve. The authors recommended that understanding the "living nature" of the organization can help facilitate the interplay between its designed structures and its "informal, self-generating networks." 
Citing the Santiago theory of cognition, that "A living network responds to disturbances with structural changes, and it chooses both which disturbances to notice and how to respond," the authors asserted that in an organization, what people notice and how they respond depends on their interests as individuals, and on "the cultural characteristics of their communities of practice." Humans respond, individually and collectively, to what they find meaningful. "Meaningful disturbances will get the organization's attention and will trigger structural changes" (p. 318). A living system, they wrote, cannot be controlled; it can "only be disturbed." Disturbance takes the form of "offering impulses and guiding principles rather than strict instructions [which] evidently amounts to significant changes in power relations, changes from domination and control to cooperation and partnerships."

For emergence to occur in an organization, said Capra and Luisi (2014), it must first be sufficiently open, "[willing] to be disturbed, And there has to be an active network of communications with multiple feedback loops to amplify the triggering event." This gives rise to

... the point of instability, which may be experienced as tension, chaos, uncertainty, or crisis. At this stage, the system may either break down, or it may break through to a new state of order, which is characterized by novelty and involves an experience of creativity that often feels like magic.

The authors said that because this process is "thoroughly nonlinear, involving multiple feedback loops," we cannot bring to bear our "conventional, linear" means of analysis, and therefore "we tend to experience it with a sense of mystery." 
The task of managing an organization skillfully, said these authors, is to "understand the interdependence of design and emergence," and to ongoingly find dynamic balance "between the creativity of emergence and the stability of design.

\section{Conclusion}

My study has explored the interfaces of contemplative praxis with learning, organizational, and higher education praxes. In this chapter, I have introduced a range of literature pertinent to this exploration. In the next chapter, I describe the case which has been the focal point of my research, the development at Southeastern University of the Center for Investigating Contemplation. 


\section{Chapter Three}

\section{The Case}

SEU (Southeastern University) is a highly selective, highly ranked, major public Research 1 university, founded nearly 200 years ago by one of America's "Founding Fathers." The University's website states that its founder "Reinvented higher education," in part by convening students and faculty to live in close proximity" together, "Inspiring each other and reaching together for a higher standard." Further, the website asserts:

Two centuries later, as a major research institution, we continue to uphold the ideals that made us unique among universities: our pursuit of discovery through collaboration and cross-disciplinary exploration .... And today, our diverse student body, faculty and staff are as rich in background, ideas and perspectives as the world we live in.

In its public-facing image, as expressed on its website, SEU stresses its eagerness to hire new faculty who "are dedicated to challenging conventions, leading with ingenuity and advancing knowledge for the common good." The website also states:

“Considered one of the nation's greatest and most iconic public universities, SEU continues to break traditional boundaries, advance knowledge and further the 'illimitable freedom of the human mind."

Over the course of 16 months in 2012-2013, the University's president led a strategic panning process, involving input from “over 10,000 people including faculty, staff, students, alumni, the Board of Trustees, parents, community members, and friends of the University." The resulting strategic plan was approved by the Board of Trustees in late 2013, to begin the implementation of five "Foundations"- and multiple strategies within each Foundation. The Foundations direct SEU to: "enrich and strengthen" its "distinctive" residential culture; bring its "research, scholarship, arts, and innovation" to 
bear on "advanc[ing] knowledge" and on public service; create opportunities from "new levels of student engagement"; attract and "support" a "distinguishing" faculty; "steward resources" in the interest both "excellence" and "affordable access."

SEU comprises 11 schools, serving close to 16,000 undergraduates, and more than 6,000 graduate and professional students. SEU has a highly ranked health system, serving as a teaching hospital for students in its medical and nursing schools. SEU's website (accessed 2/15/15) states its "operating budget" as 1.39 billion dollars. Contributing to that budget are: 221.6 million in research awards (nearly $20 \%$ of the income), 155.7 million in philanthropic gifts and endowments (another 20\%), and 144.7 million ( $10 \%$ of its income) in state support. Beyond that, tuition and fees cover $38 \%$ of its budget, and "sales, services \& other revenues" another $12 \%$. Clearly the institution's reliance on both research grants and philanthropic support is quite significant, particularly in contrast to support provided by the state. Despite this minimal state support, tuition for in-state students is highly subsidized; in-state students pay about $30 \%$ of what out-ofstate students pay.

SEU's Board of Trustees is comprised of 17 voting members appointed by the governor, as well as a student member and a faculty member. The Board is "responsible for the long-term planning of the University, approv[ing] the policies and budget ... and is entrusted with the preservation of the University's many traditions..." As is typical for university boards, most of SEU's Trustees have backgrounds in business-related fields, rather than in any field related to education. 


\section{Legacy of Racism at SEU}

I choose to highlight issues of racial equity and marginalization here, both in this brief overview of SEU and in the research project itself, because it has become clear to me in the course of my research that "transforming higher education praxis" must involve transforming systemic marginalization and inequity. I mean this on multiple levels. To transform higher education praxis will require transformation in means and ends of that praxis. Roberta, recently retired SEU education professor and associate dean whose academic career spanned four decades, told me, "American higher education is all about white privilege, money, and power. We pretend it isn't, but it is." To transform current higher education praxis means to interrupt rather than reproduce systemic inequities. This will require practices and policies that not only address these inequities within the HEI, but that make foundational to its mission the transformation of inequities in the what Maxwell called "the real world" outside academia. This includes a commitment to transformative education, research, and engagement, responsive to concerns (e.g. Maxwell 2014) that higher education must direct its assets toward addressing pressing and critical problems in the "real world," prioritizing "wisdom" over "knowledge."

Race is certainly not the only concern related to systemic marginalization and inequity in SEU's legacy or current culture. The limited focus available to me here constrains me from including other historical and ongoing issues, such as gender discrimination and sexual violence, which have also been an extremely significant factor in the University's culture. I do not intend to diminish the unique and specific detrimental effects of racism by stating that I choose to bring racism through my research analysis as emblematic of the unconscious privilege and systemic oppressions woven into the fabric 
of SEU's institutional praxis. I do not intend to suggest that SEU's past or current issues are different from, or worse than, those at many HEIs. In fact, it is the prevalence of such issues in the context of HEIs that make it important to address them in a research study about transforming higher education praxis.

In recent years, there has been a movement at SEU, among other universities, to explore the historical role of slavery at HEIs. In April 2013, a working group was formed, with the support of the president and the president's cabinet, and charged to "explore and report on [SEU's] historical relationship with slavery," and to advise and provide recommendations on "the commemoration of [SEU's] historical relationship with slavery and enslaved people.” In fall 2014, SEU hosted a well-attended national conference on the topic of universities acknowledging their involvement in slavery and the ongoing repercussions of such involvement.

Not only was the physical construction of SEU dependent on enslaved laborers, as well as its upkeep and its services to students and faculty, but SEU's founder himself relied on enslaved laborers to maintain his lifestyle on his nearby plantation. Recent scholarship has exposed an increasingly stark vision of his exploitative practices vis-a-vis his slaves. This scholarship also exposes the discrepancy between his personal and political collusion in perpetuating the institution of slavery, and his assertions that it was ethically wrong. Not only was it diametrically in opposition to his professed belief in human liberty and equality, he understood as much. Promulgating the idea that he was simply a product of his times is not only a simplistic whitewashing of his culpability, but a way to avoid contending with a very uncomfortable paradox at the root of SEU's history. The founder was a visionary and a polymath, whose powerful historical legacy is 
based in great part on asserting the value of human liberty and equality, and yet he failed to find a way to match his actions to his principles. This was in part a political quandary, as slavery was so entrenched in the economics of the time, but it was also a personal unwillingness, consciously chosen, to give up the privileges of a lifestyle made possible through, among other exploitations, the coerced efforts of 10-year-old boys who worked in a nail-manufacturing enterprise under inhuman conditions, providing the income to cover their master's household expenses.

The first African American graduate student was admitted to SEU in 1950, after protracted legal wrangling. The first black undergraduate enrolled in 1955. SEU did, however, resist full integration until well into the 60 s. The fact that some local community members, among them SEU employees, call this University "The Plantation" refers not only to its founding or early years, but also to its history of exploitative practices since then, in regard to race. SEU is located in a small city that was named in 2014 by the U.S. National Bureau of Economic Research as "America's Happiest City," an ascription which SEU's website is in turn happy to feature. The city is marked by significant division along racial lines in terms of economic wellbeing and educational attainment. An independent organization dedicated to racial equity at SEU and in the local community has, over the last several years, brought members of that local community together with stakeholders at SEU (the city's largest employer) to explore the significant negative legacy and current effects exerted by the University's inequitable practices.

Over the last two years, in the context of burgeoning national awareness of 
ongoing race-based inequities, students and others on campus have held conversations and events such as teach-ins on campus to raise awareness about the experience of marginalization that some students of color say marks their experience at SEU. In spring 2015, a nationally reported event took place involving an African American student being pushed to the ground by officers near campus, spurring adamant protest by students and other supporters. Soon after, a document was circulated through social media channels at SEU. It was composed as a collective statement by students of color, and in it they described a deep and pervasive sense of being marginalized in an ongoing way on the campus, and the emotional burdens they carry from this experience. They also strongly requested a holistic educational environment in which students are mentored and cared about as whole people, and in which faculty are willing to stretch beyond their own comfort zones to learn about structural racism, and to engage with students and their concerns more fully.

A prominent organization of SEU's students of color wrote a letter to the University's president, saying that recent events had served to raise awareness of underlying systemic issues. The letter outlined changes needed-in admissions and financial aid practices, faculty hiring and support, curriculum and programming, and in other arenas - to institutionalize the more reflective and equitable practices they said were needed.

It is in the context of this long, paradoxical, and continuing legacy — wherein aspirations and efforts to nurture the "illimitable freedom of the human mind" have co-existed with exploitation and marginalization - that the Center for Investigating 
Contemplation (CIC) was conceived.

\section{The CIC's Conception and Emergence}

The complex systems framework is helpful in looking for ways in which the CIC has framed its mission, and its efforts toward fulfilling that mission, over time. The CIC's stated mission implicitly highlights the value of complexity and emergence, in saying that the Center wants to facilitate integrative, mutually informative, generative relationships across arenas of difference. A major interest of my study is to track how the Center enacts this value: whether and how it develops capacities to help guide emergence, whether and how it reduces complexity, and with what effects. Emergence and complexity reduction are not mutually exclusive, in that reducing complexity in one context may facilitate emergence in another context. I am interested in the motivations and results of choices made, implicitly or explicitly, by the CIC and by stakeholders, regarding value, power, complexity reduction, cultivating capacity to guide emergence, and emergence itself.

I begin with a retrospective description of the CIC's beginnings given by Charles, who was pivotal to the CIC's emergence in an unofficial leadership role, and not long after that became its official Director. He is a Tibetan Buddhist scholar in SEU's Religious Studies Department. He gave this description at the start of an open panel presentation by six key CIC stakeholders at the Mind \& Life conference in Boston, fall 2014. Charles highlighted the fact that SEU is a public Research 1 university, and therefore a "heavily-differentiated institution," which has given rise to "a series of distinctive qualities that relate to how we've engaged in programming over the last three years." By differentiated, he meant that teaching and research both place great—and 
competing - demands on faculty time and energy, and that although the state pays little of SEU's budget, it requires "external engagement, especially to the state, ... which has [significant] expectations [for] what we pay back to the state and the region that we're located in." This was the background, Charles said, against which "about 30 months ago we had the opportunity to think about what we might do with a relatively significant gift, if it was provided to the University, to explore what one might do with regards to contemplation in higher education." He explained:

When we were given this gift, the choice we made was not to set up a resource center that would offer instruction in yoga - that was the preliminary idea the donor came to us with, to establish some type of yoga center or a mindfulness center-but we thought we'd like to think about it, and take this as an opportunity to consider: what would it look like, at a major Research 1 university, if you thought systematically about organizational change across each of these different quarters?

Charles continued:

Rather than saying, 'Come and get it, here's the field of dreams! Contemplation, and so forth - it has all of these different benefits that are going to be useful to you,' we could consider a strategic plan for each one of those 11 schools, as well as thinking holistically across those 11 schools.

Charles spoke of how the 11 schools "could be bound together across these different types of divides," such as Sciences and the Humanities, the Liberal Arts and the Professional Schools, and among the several different Professional Schools. Charles depicted the work of the previous 30 months as a time of "not only thinking strategically about how to do that in each one of these quarters in an intensely differentiated fashion," but also "thinking about and implementing ways in which we could [put in place] programs that would connect us up together across those boundaries." Charles stated that 
over that timeframe, the CIC had been able to get "significant traction at each one of those 11 schools."

There is a lot packed into this concise history given by Charles, to a small audience that included one of the CIC's major donors and supporters, Robert, who had been on the Board of Advisors of the CIC since very early on, and had been contributing financially toward its success. Another major SEU donor was in the audience as well: Angela had, with her late husband years before the CIC's emergence, endowed two Contemplative Chair faculty positions, one each in the Schools of Nursing and of Medicine.

The description Charles gave focused on many elements of an embedded complex system: diversity in the form of differentiated schools (i.e., SEU's several professional schools) as well as diverse perspectives (i.e., Sciences and Humanities). He spoke of organizational change in an "intensely differentiated fashion" in each setting, which could refer to "each setting" as a complex system with its own interdependent diversity. He spoke of "connecting up," and "binding together," terms that could connote the connectivity intrinsic to a complex system. He said that the CIC was "thinking holistically" across all 11 schools, implying some degree of interdependence and mutual learning.

He also indicated that "in several of the schools, from the dean's office on down," the CIC had been able to begin to bring "systematic, transformational change." I do not know exactly what Charles means by this last statement, but it is significant, through a complex systems lens, that his language frames this change as a top-down one. Not only 
is the change "from the dean's office on down," but it is a change brought into each school by the CIC.

Charles's depiction above can be interpreted as identifying, connecting, fostering, supporting, and connecting extant and nascent initiatives, and this is indeed what the CIC had begun to do. But his depiction could also be taken to mean the CIC had been responsible in a major way for generating contemplative initiatives across campus for the past thirty months (that is, since spring 2012). In contrast, VP for Development Peter told me that in spring 2011—before the initial donor approached SEU—there were already "five or six schools very much seriously involved [with contemplative approaches], with the dean and their faculty, and [already] using [such approaches] in a variety of different ways."

It also may be that Charles presented here a depth and degree of activity, and of collaboration under the auspices of the CIC, beyond what had been happening on the ground. He has called this "the accordion model," indicating that programs and collaborations currently existing on a small scale, or perhaps even as concepts, have the potential to actualize and expand. He has also said that only an "audacious" mission is worth pursuing, or likely to galvanize interest and support. This points to an ongoing question of how the CIC talks about its work and the changes it is bringing about through that work. The intention of the rhetoric is what I call "performative"- meant not only to convey the facts, but to impart a vision of the potential, and to enroll others in actualizing that potential. 
I have attempted to tell an accurate story of the CIC's emergence and evolution, while also acknowledging that parts of the story I tell are unavoidably conflated with the CIC's public self-description. Though my perceptions are informed by many hours of participant-observation and many more hours of interviews with key stakeholders and others with valuable insight, I cannot claim to know that the story I tell, and the appraisals I make along the way, are fully accurate.

\section{The "Yoga Dinner" and negotiation with the donor}

The story of the CIC had indeed begun in spring 2011, with the approach of George Daniels, on behalf of himself and his wife Madelyn, to University President McArthur. Daniels was an SEU alum, who though still in his fifties had already become one of the largest donors in SEU's history, primarily by having funded a major building project.

The initial suggestion of an offer from Daniels for a new project was in the form of a very brief email to President McArthur, indicating his possible interest in funding a yoga program at SEU. President McArthur and Peter, SEU's VP for Development, made a pivotal decision to respond, in Dean of Nursing Barbara's words, "By going through a listing of people who did work in what looked like yoga, alternative therapies, and inviting us to think of [whether and how] all the schools could work together." They were invited to what was later fondly called by several of my participants who were there, the “Yoga Dinner" held at President McArthur’s home in May 2011.

Peter said that he was "very, very surprised" by "the depth and breadth of quality academics who were using some form of mindfulness, centeredness, or yoga for relaxation." He was struck that so many were finding benefit for themselves in such 
practices, as well as using them with "students, and patients, and those who are in the last stages of life." He said five or six schools were very involved, with the dean and their faculty, using these practices in a variety of different ways. Barbara said, "Half of usmore than that — had no clue who each other was." Yet some connections had apparently been forming. Peter told me, "What we started finding out was many of them already were partnering up. There were a lot of surprises, but I was taken that a number of them had found each other already and were doing joint things, 'mostly just one-off projects."' He said that they had already been working "across disciplines, and with no money coming, no permission of deans. The kind of organic things that happened, if you will." And, those who attended the dinner suggested many other colleagues who were also “doing some extraordinary work." Peter told me,

I had fully expected when we had the first dinner with a few faculty that they would be very skeptical about the efficacy of having something like that on the [campus], as well as our ability to fund it. Well, there's still a question about the ability to fund it, but there was no question at all that they were more excited about that project than any other single thing I've brought forward with the president or the provost or a dean.

Peter said not only were many academics very excited about the topic, but that, " It was as close in my time, practically 23 years, . . to being truly interdisciplinary as anything I've been involved in." Those attending the "Yoga Dinner" collectively asserted that "Yoga [was] way too limited relative to what this University could bring," according to Peter. He and the President decided immediately to suggest a larger project to the donor. Peter told me that in his work he has become adept at identifying the person in a meeting or collaborative venture that people "look to . . for the key thought on how to synthesize everything. ... [Charles] was that person at the "Yoga Dinner." He said of 
Charles that, in addition to his having "brought the Dalai Lama here one time, he was just known as this really substantial researcher in Tibetan studies, and would go on these long journeys, and he really got it, you know?"

Peter met with Charles and strategized about how to respond to the donor. Peter said Charles convened a "workgroup of half a dozen people, and we had a very short timeline. This guy [Charles] is kind of a workaholic."

According to Peter, Charles was "able to bring together the faculty and let them have their say of what they [and their schools] could contribute. They worked to write a proposal that included at least five different schools, at a level that they felt comfortable." Peter indicated these stakeholders saw potential for "academic research that [they and the University] could benefit from greatly if this thing ever took off." Daniels responded positively to the proposal Charles and the group drafted, and began having clarifying video conversations with Charles, another faulty member, and sometimes Peter. "Daniels really got turned on. He said about Charles, 'He's a '10.' An absolute '10.” Peter said they presented to him "what would be the best program, certainly in the country, maybe in the world: one hundred million dollars." Daniels respond by offering "to start" with what amounted to " 15 million in outright and kind of bequest support," which amounted to "several hundred thousand dollars a year in cash." Peter credited SEU's different schools, according to his sense of what each brought to the table in garnering the donors' support. Half of that credit went to the College of Arts and Sciences, and some went to the Education School, the Nursing School, and the Medical School, to report in their campaign totals. 
Peter stressed that, in response to University stakeholders who object to this money being used for a Center for Investigating Contemplation when they can identify other worthy uses for such funds, he says, “This isn't about, we get 15 million for unrestricted use in the University or 15 million for Investigating Contemplation. It's 15 million for [the CIC] — or zero!” His point was that this donor-like many-had an interest in funding a particular kind of initiative, not just a general desire to give money for whatever use the University wanted to put it to. The task of Development is to reach a mutually desirable agreement with donors. The implication in Peter's statement is that some SEU stakeholders' misunderstanding that the money could have (perhaps along with their belief that it should have) been allocated elsewhere may fuel their objection to the CIC's existence.

\section{"Initial Conditions"}

A complex system is highly dependent on initial conditions (and further,

sometimes very small, perturbations over time). There were three notable "conditions" at the emergence of the CIC. One was the pre-existent contemplative initiatives, and their interested and engaged stakeholders, at SEU; the second was Charles, known as visionary, charismatic, and extremely hardworking, and whose academic specialty was related to contemplation; and the third was the donors, without whom the CIC would very likely not have been conceived.

\section{Contemplative initiatives at SEU pre-dating the CIC.}

Some of the contemplative programs pre-dating the CIC's conception were in medical and nursing arenas. "The donors ... were interested in health benefits," said 
Nursing Dean Barbara. "Well, we [in Medicine and Nursing] had the health data," in work investigating the use of yoga, dance, and other alternative therapies with fibromyalgia, cancer, and other chronic diseases.

There was a Mindfulness Center at the Medical School, overseen by Dr. George Smith. The Center had been offering Mindfulness Based Stress Reduction (MBSR) to students, faculty, and patients for nearly 20 years.

Moreover, Dean Barbara had been a pivotal player in espousing contemplative institutional change at SEU from "before the beginning" of the CIC. When Barbara came to SEU as Dean of the Nursing School in 2008, she said she wanted to do three things in in the service of "creat[ing] a healthy work environment ... really do more in professional education; collaborate; and the last thing was diversity." The outgoing Dean of Nursing had a friend, Angela, to whom she introduced Barbara almost immediately. Angela and a long-time friend of Barbara's, a bioethics professor, taught together-at a Zen center in another state - an eight-day intensive course on bringing compassion into end-of-life care. Angela paid for many people from SEU to attend the course, and she and Barbara's friend suggested that Barbara go herself. Barbara's first response was to say, "No, I'm the new dean. And then finally I said, "Maybe I should go. Maybe that is the most important thing I could do." She chose to attend the course in April 2009, and

... that was the beginning, when I experienced personally mindfulness meditation and reflection, all directed towards getting better care to the dying. What I realized then was that this was a very powerful tool: meditation, mindfulness, paying attention, looking at how the brain impacts our behavior, looking at how we change ourselves, and I decided that this should be a signature of the Southeastern U. 
Soon after, Angela and her husband endowed a chair in the medical school, calling it a "contemplative chair." It was several years before Barbara filled the correlative chair in the nursing school. During those intervening years, Angela permitted Barbara to fund seven workshops co-led by Barbara's bioethics professor friend, in partnership with an internally known expert on leadership and capacity development, that were offered free to anyone at SEU and beyond. The workshops focused on how personal and structural transformation are mutually informative, and reinforced that working toward self-understanding is primary to affecting change in the world. Moreover, the premise of these workshops was that such inner work should be used toward such outer effectiveness, rather than simply for personal fulfillment. Through these workshops, other efforts, and continuing to send people to the intensive Zen center courses - funded at first by Angela, and then by Barbara's own funding — Barbara said she began "building an army." The initiative that emerged over those several years was named the Care for All Initiative.

Following the "Yoga Dinner," Barbara recalls that the proposal was written, and the donor came over the Summer 2011, and got a tour of the resilience room- "Angela had built us a resilience room where we were doing free yoga and meditation every week.” Barbara continued:

We were just kind of building ourselves slowly over here. Religious Studies, the College [of Arts and Sciences] — nobody really knew what we were doing here, because I didn't know who they were and what they were doing. I didn't know we have a world-class Center for Tibet I did not know! Yes, that's really the story! How you can have 11 great schools and not know what each other is doing!

In addition to the programs in the Nursing and Medical Schools, SEU had a top Tibetan Studies program, in which Charles was a professor. Charles had also been 
involved for years in work in Tibet, and had put much effort into the creation of an online Digital Himalayan Resources. The Dean of Education was interested in contemplative approaches, as were professors at the Graduate Business School, the School of Architecture, and even the undergraduate School of Business. Professors in the School of Arts and Sciences had designed and taught courses involving experiential methods for self-awareness and community building. SEU's Fitness and Recreation Department had incorporated mind-body practices for many years. And importantly, Diane had a strong connection to ACMHE (the Association for Contemplative Mind in Higher Education), the national umbrella professional organization in the field of contemplative pedagogy in higher ed. Through her work at SEU's University-wide teaching resource center she had coalesced study groups of professors interested in contemplative pedagogy.

This is an incomplete listing — though indicative of a wide range of interests —of initiatives and individuals who had been exploring explicitly contemplative approaches across settings at SEU—in many cases over the course of several years—before the donor approached President McArthur to explore the creation of a contemplative initiative there.

\section{Charles's role}

According to both Barbara and Peter, it was Charles who coalesced the widespread interest into a viable movement. Dean Barbara recalled that Charles immediately became a leader. In our first interview (2014) she said, "He wanted to make sure everyone had a place at the table, but he truly is our intellectual and inspirational leader." She went on to say, "We had a soft rollout that April (2012) because this Tibetan 
conference was going to be here." She said she had put people on the planning committee, and "it was a great event and we got a lot of great press."

Peter told me he doubted the initiative would have "flown" without Charles, and attributes this to "his knowledge of these things, and his great expertise ... and his reputation around it helps very much." The other thing was "his ability to bring together wide-ranging faculty with wide-ranging research, and being respectful of all of this and making them feel like there was a place for them in this Institute." Peter said,

Having been here all this time, getting people to quote 'play ball' is something that's very, very difficult, because they're generally looking at, 'What's this going to cost me?' Or, 'This is something that I could do better myself,' or 'I'd rather go it alone in the Graduate Business School or in the Architecture School," or something like that. For him to have them brimming from excitement, bringing key faculty from all over campus, from Medicine over to Education for a particular program, or someone from biomedical engineering coming to the Medical School ... All of those things, I thought, worked very, very well.

"This was one of the ones that virtually had all of the right reasons," said Peter.

\section{The initial role of funding}

Peter spoke from many years of Development experience when he asserted that "academic initiatives generally ... gain traction," when there is both an "internal advocate" who is "knowledgeable, persuasive, and respected," and also an "external champion," who makes a financial commitment "that forces the University's staff to take it seriously." An internal advocate provides "leverage, credibility, and ability to bring people together," and to "have status with the president and the provost and their own dean to move things forward." 
It appears that money, and the potential for lots of money-was pivotal to bringing people together around the project. Peter said that fact was a factor in people's enthusiastic engagement with the idea of an initiative. It meant that, "There's enough in it for us that we can join this and do it with some level of enthusiasm, and we see that there could be academic research that we could benefit from greatly if this thing ever took off." I will speak to this issue further in Chapters Four and Five.

\section{Coming Out Contemplative: The CIC's "Soft Roll-Out"}

The CIC used the occasion of a Tibetan Medicine and Meditation Conference held in spring 2012 to stage what Barbara called its "soft roll-out." It is noteworthy that in telling the story to the public of how the CIC came into existence, the initial impetus on the part of the Daniels to fund a Center at SEU focused on yoga was replaced by their enthusiasm for a far more expansive, exploratory, and integrative approach to contemplative practices writ large. The public story, while essentially accurate, therefore skipped the important nuance of their initial approach to President McArthur and Peter, the ensuing feedback from the University to the Daniels, and the swift negotiations that followed and transformed into a far more complex and ambitious vision.

Thus, the public version of the CIC's "birth story" was that when private donors George and Madelyn Daniels chose Southeastern University as the recipient of twelve million dollars to initiate what is now called SEU's Center for Investigating Contemplation, or CIC, several factors motivated them, including the fact that there were already established programs across the University that focused on contemplative practices for their clinical and pedagogical value and as research arenas. An SEU reporter quoted George Daniels as saying that SEU had long had remarkable expertise in different 
sectors. "What we need now," he said, "are threads to tie them together and weave them into a greater whole. Our goal with this gift is to enable the Center for Investigating Contemplation to function as an integrative force that pulls together disparate parts of the University." The reporter quoted Madelyn Daniels as saying,

At this juncture, our educational system needs to consider new ideas and practices for the mind and body that can complement its traditional valuation of critical thought and debate. We think contemplative and yogic traditions offer transformative possibilities in this regard, and hope that our gift will enable SEU to engage in an extraordinary experiment aimed at reassessing learning and wellbeing in relationship to these traditions.

The Daniels added that, in the next five to ten years, they would like to see SEU emerge as "the world's center of thinking about how higher education, and society at large, can be transformed by contemplative and yogic practices, ideas, and values."

The question of how the narrative was framed speaks importantly to how the CIC, the University, and the donors wished to be perceived, and particularly how these entities chose to frame their relationship to one another.

\section{Early Structure and Leadership}

In spring 2012, rumors flew among some interested in the CIC's emergence that a director had been hired and was on his way to SEU to lead the Center. This individual was Ms. Daniels' highly valued yoga teacher, with a recently earned doctorate in Tibetan Buddhism. I gathered that the Daniels had pressed for his being hired in a joint position to direct the SEU and simultaneously enter a tenure-track professorial position.

A few participants spoke with me later about this hiring, all of the opinion that this decision regarding the directorship was in the best interests of neither the Center nor 
of the individual involved. One considered it highly unfair to expect someone to run a center while also establishing himself as a tenure-track professor, as the split focus required could easily doom his success as a professor. These participants also held that, despite his other strengths, he was not equipped to lead the Center. Interestingly, another director was also hired almost simultaneously, who had earned a doctorate in Tibetan Studies several years before. He left the position within less than a year, in spring 2013. The official titles, as well as the distribution of roles and authority between these two directors has not been fully clear to me, in my communications with them (and with other stakeholders) at the time, nor in retrospective interviews with participants since. I believe this unclarity is in large part a function of the somewhat amorphous and shifting dynamics in the Center during its first years. The fact that a particular hiring took place because a donor pressed for it adds complexity to these dynamics, on top of the understood need for confidentiality about personnel issues.

The shift toward Charles' becoming the CIC's official director happened during the 2012-2013 academic year. From the first approach of the donors in spring 2011, he had played the very active and vital roles described above, leading interested academics in coalescing around the topic of contemplation, working with SEU's development office and administration in negotiating with donors, establishing direct relationships with donors, and presenting the CIC to a range of audiences and interested stakeholders at SEU and more broadly. He had also been pivotal in calling together an interdisciplinary planning group that met more or less monthly. He invited collaboration in writing internal documents to explore the Center's intended mission and foci, and in drafting material for 
donors, the website, and beyond. He took the lead in organizing this input as well as in writing the great majority of this material himself.

I heard from a knowledgeable stakeholder that when in early 2013 Charles became the CIC's official (though officially very part-time) director, it was because SEU's administration asked him to do so, concerned that without his official and ongoing engagement the venture might not succeed and the donors might be disappointed. From the perspective of many, Charles had been directing the CIC for all (or most) practical purposes since its inception, filling roles that needed his particular skills. He had simply worked far overtime to fill these roles in addition to his actual job as a scholar and professor of Tibetan Buddhism, and — not incidentally—his lengthy travels to China most summers, where he has engaged for many years in efforts on behalf of the Tibetan people.

When Charles became the CIC's director, the percentage of his time paid for by CIC funds was 10 percent. Over the three years since, that percentage has risen to approximately 40 percent. This does include, he says, time spent working on issues related to the Contemplative Academy, described below_an online project of particular interest and importance to him.

Charles has a widespread, and by all evidence well earned, reputation for working far beyond a normal work-week, however-about 80 hours by his recent account. I believe it is safe to say that Charles is devoting himself to CIC related work in a way that for some would constitute a full-time position. This is despite his strong statements in my interviews with him claiming he does not personally wish to be an administrator, and that 
he is doing it because he perceives his unique set of skills to be strongly needed at this time for the CIC to succeed. He has stated that it is extremely unusual to find an academic in the liberal arts who has also learned about professional fields such as business and education. He said he began to take on such learning out of necessity, to inform his efforts to help the Tibetan people. These efforts had been inspired by his experiences in Tibet, where he had seen the unmet needs and unfair treatment of Tibetans by the Chinese. He is accustomed to expending unusual time and effort on behalf on people who are suffering. He believes that the CIC can play significant roles in reducing suffering, and that he can and should contribute mightily to that effort.

In a later section, I will return to the topic of CIC staff. For now, I will state that Charles is the only paid staff who has been part of the CIC since its beginning.

\section{Original Stated Foci}

The CIC launched its website (accessed 4/15/13 for the following information) delineating three areas of focus. I provide an overview in the following sections.

\section{"The Contemplative Campus"}

This focus was described as "an initiative to systematically explore the transformative impact of contemplation in learning, research, and social engagement across all schools, disciplines, and organizational units, at a major public research university." The website briefly described and provided links to several "current programs." The following were among those described. The Mindfulness Center at SEU's School of Medicine's stated mission (ibid.) is "to support the integration of mindfulness-based practices into the clinical, educational, and research programs of the 
SEU Health System and the [regional] community." A statement about the Care for All Initiative, based at the School of Nursing, described its aims to develop clinicians' capacities for compassion in order to foster wellbeing in these clinicians and those they serve. The Center for the Study of Alternative and Complementary Therapies, an interdisciplinary program administratively based in the School of Nursing, was described as facilitating research on mind-body, and body-based, approaches to healthcare and well-being.

In the College of Arts and Sciences, scholar of Tibetan Buddhism Charles had long taught courses about that tradition's contemplative practices. The CIC's website stated, more broadly, that the Religious Studies Department provides "multiple course offerings on the history and practice of contemplative traditions." Diane, Associate Director of SEU's university-wide teaching resource center had, for several years, been helping professors develop more holistic approaches to pedagogy; per the CIC website, she and that center provided "mindfulness-based programming and training to Southeastern University teachers."

The School of Education had a program committed to "healthy programming for young people" listed on the CIC's website, as was the School of Architecture's new Open Space Initiative, which "incorporates ideas of contemplation-friendly space and designs." Other programs listed on the CIC's website included an undergraduate group exploring contemplation, and offerings through SEU's Fitness and Recreation Department including yoga, Mindfulness Based Stress Reduction (MBSR) geared toward undergraduates, and other "Mind \& Body" courses. 
The CIC's website descriptions of contemplative initiatives such as the preceding ones have not generally stated clear parameters of what constitutes their relationship with the CSC. For example, there are statements about what initiatives "we" are engaged in, but this usage of "we" appears often to mean the University, rather than the CIC per se.

\section{"The Contemplative Academy"}

The CIC website described this second area of focus as

... an online portal that will be simultaneously a digital library, social networking site, and online educational institution ... a profoundly dynamic site where partners from all across the world and social sectors will be empowered to contribute to form a remarkable distributed network of knowledge production about contemplation in all aspects."

The stated plans for the online library included the development of a

“Contemplative Encyclopedia," a massive and unprecedented reference resource that will provide an elaborate guide to the true diversity and depth of the world's traditional and modern contemplative practices and traditions, as well as contemporary research and applications (ibid)." The website stated that the Contemplative Academy planned to offer global social networking for people and organizations of all kinds to share interests and knowledge, and also intended to make courses related to contemplative science and practice available online, worldwide.

\section{"The Contemplative Symposium"}

According to the CIC website, the CIC's third area of focus would offer an annual private symposium at SEU to "explore the possibility of transformative impact by new contemplative approaches in a specific social sector," including a three-year follow-up to each event, during which subject area experts would collaborate with experts in 
contemplative practices, to develop innovative approaches to the issues identified at the symposium.

\section{"Core Commitments"}

The CIC identified its core commitments as: "creating new relationships across the sciences and humanities"; "building integrated relationships between tradition, research, innovation, application, and engagement"; and "fostering inclusivity ... and addressing issues of social justice in local and global communities." In line with its first two commitments, the CIC set up a planning group composed of approximately 15 members representing a range of schools and stakeholders across SEU.

\section{National Context for the CIC}

Although the CIC's initial funding was significant, and its aspirations were particularly expansive, at its inception Southeastern University was not at all alone among U.S. higher education institutions in exploring how to incorporate contemplative practices into its teaching, research, and engagement agendas. Literature was burgeoning about implementations of contemplative practices in various ways into curricular and cocurricular facets of college students' lives, and in universities' research agendas. Research on effects of contemplative practices, the great majority of which was taking part in university settings, had likewise burgeoned. The narrative presented highlighted the CIC's potential to be the first, biggest, and best in the world, not fully acknowledging the broader context of quickly expanding interest and activity nationally and even internationally. Its website did not, and has not since, referenced or provided links to ACMHE or, more generally, to initiatives elsewhere. Although this could certainly be 
attributed in part to the CIC's limited personnel and broad focus - a combination through which some of the CIC's stated priorities have not yet been accomplished - it appears to express a dynamic that was invoked in the founding moments of the Center. In complexity terms, the CIC portrayed itself in terms that reduced the complexity of its context, as part of an already dynamic movement within which rich conversations and networking had begun. This complexity reduction, intentionally or unintentionally, leverages power in relation to potential donors and other supporters.

On the other hand, the stated intentions of the CIC did extend beyond the range of what centers and initiatives at other HEIs were articulating. The Contemplative Academy, Institute, and Network were ambitious ideas unlike most of the work undertaken or perhaps eve planned at other HEIs. Initiatives at other HEIs were focused on pedagogy and research, correlative to the CIC's Contemplative Campus Initiative. This brings up an issue which has been ongoing for the CIC: How to choose foci, and follow through on the chosen foci.

\section{Early Efforts by the CIC to Gather Input}

On 9/24/12, the CIC's newly-formed Planning Group held two "Open Meetings," one in the morning and one in the late afternoon, to garner input from those interested in its direction and efforts from across the University. Both were held in large rooms in School of Nursing buildings. Several dozen attendees came out to each meeting, to voice interests and some concerns about the CIC, based on what they knew of the Center thus far. The following excerpts from these meetings convey a sense of the spectrum of concerns and interests that stakeholders brought forward at this early stage in the CIC's development. Notably, one of my interviewees left the Open Meeting that day with the 
impression that "[Some] people came to those meetings trying to get money for what [they themselves] are already doing," rather than coming together in a spirit of collective discovery." I did not perceive this as an overriding theme, but I may not have been as sensitive to that possibility as this stakeholder.

Charles helped launch the morning meeting by asking the gathering,

What are we teaching our undergrads? If you look at the courses, it often doesn't add up to a person. We're absconding from our responsibility. It's not just critical thinking, but other skills that make someone a moral person. And rather than complaining about other schools [within SEU], [we should] knit them together.

Claire, a graduate business school professor, said that the CIC can or should "connect things that have already been ongoing for many years" across the campus. She said, "We have been doing mindfulness in our classes for many years." She added, "We've discovered [that it's] useful [to call] things co-curricular rather than extracurricular. We're increasingly thinking of our program impact, rather than just course impact." She closed by affirming the value of "treat[ing] people as full people, not just from the neck up."

The Tibetan Studies professor who was at that time a CIC director asserted, "It is no accident that the money given to make this happen has been coming from the private sector. We're interested deeply in expanding that range. Breakthrough contemplative traditions are connected with entrepreneurialism."

Eric, professor of marketing research in the undergraduate business school, described the course he had been teaching in the undergraduate school of business, on "wisdom traditions." He asserted that there were common misconceptions about what is being taught at business schools. Another Tibetan Studies professor on the Planning 
Group asked whether the fact that some of the contemplative practices being talked about by those interested in the CIC are religious in origin bother Eric, or his students. Eric replied, “No; they're hungry for this. This is not just that someone's given some money and now we're going to go meditate. Why is [the CIC's mission] necessary? Because we're in an age where we need to know where are we going. People need to be invited to contemplate where we as a planet and as a society are going.” He further advised, "Get off the Eastern focus," and invoked "brain research from [Richie] Davidson's lab and elsewhere, etc." Eric then asserted, "This overlaps with an enormous [movement] in happiness research, and findings about the importance of Gross National Happiness rather than Gross National Product.”

Roberta, long-time professor and administrator in the School of Education, who had been engaged as a key CIC stakeholder since its inception, brought up a "challenge of communication," saying "language matters," and that she had experienced reactivity on the part of some Christian students to some mindfulness approaches she included in her course content. A professor of Greek Orthodox Christianity made strongly cautionary statements. He spoke rather heatedly against what he called the "instrumentalism" of using Buddhist-derived practices for their health effects. He also stated that not all contemplative practices were appropriate to introduce in a public university setting, and used the example of iconography or saying "the Jesus Prayer," practices which, he asserted, require faith to genuinely experience. He said that he taught about these practices in his courses, but should not teach the practices themselves.

The topic of organizational praxis was raised. A meeting participant cautioned, based on her background in what she called "interprofessional education," that, "The 
science of how you [within the CIC] work together is really worth examining." Charles responded that it was indeed important how the CIC would build the institutional and human capacity to work together, and work in the context of the University. The same participant pressed, "Among the individuals [involved], skills are needed."

At that point, an anthropology professor who has long studied ritual process and energetic healing mentioned a book she'd written about "communitas," the felt sense of at-one-ness that groups can evoke in members when conditions are right, particularly in liminal situations and contexts - that is, under conditions of profound transition wherein old roles and expectations are suspended in service of collective growth or healing. A medical student expressed great gratitude to the Planning Group members, asserted that they were doing vital and strenuous work, and implored them to "get support," logistically and emotionally, so as not to burn out.

A Planning Group member remarked, "Yes, the Planning Group is very diverse," and went on to say that each discipline brings a different viewpoint to the Center's inquiry into how to "optimize human capacity." A bit later, Charles made a statement that I have heard from him many times since: "People rush to agree on the value of contemplation; we [on the Planning Group] all disagree."

Someone asked about research grants. Charles responded that there were ongoing "intensive conversations about how to support programs we have now, and additional high-impact studies.”

A former SEU professor with a strong interest in both Buddhist and Native American contemplative approaches asserted the importance of diversity, and the 
importance of developing programs in ways that do not "put up barriers to people coming to the table." She said, "The contemplative movement at its core is really about dismantling systems of oppression that keep non-Western [ways of making meaning] marginalized. Contemplation is about bringing awareness to inner barriers [in the service of dismantling these outer oppressive systems]." In becoming more aware of their limited and limiting viewpoints, she said, practitioners will become more inclusive—-more likely to respect the rights and value of others with different perspectives, and also more likely to incorporate a broader range of capacities into their human repertoires. Charles responded by affirming that social justice concerns are "near and dear" to him.

Some attendees spoke further to the need to stop privileging a "rational," "cognitive," "selfish" orientation. The general tone of these meetings was enthusiasm and curiosity, and while there were a remarkable range of disciplines and interests represented, there were no heated disagreements in evidence.

At the close of these meetings, Charles spoke of the existence of 250 pages of "framing documents" that had been written by those closely involved to that point. $\mathrm{He}$ then said, adamantly, "We need people to step up to the plate - the people thus far who have stepped forward to 'kill ourselves,' to go beyond what's reasonable, have come from Buddhism." He stated the need for others to do likewise, from other traditions and approaches. He closed by saying, "We also need to know it will be excellent."

\section{Further Engagement by Stakeholders}

Each town hall meeting detailed above ended with an announcement that beyond the nascent Planning Group, "a very broad 'Contemplative Council'," consisting of SEU 
faculty and staff with core interests in contemplation that would be regularly consulted through a mailing list and town hall meetings, was "in formation." This "council" would be "very broad," and would provide a way for all those interested to "be connected." There had been no word since about this "Contemplative Council," until spring 2016, three and one-half years after these Open Meetings, when the term appeared on the CIC website, and Charles told me that this Council would be actualized in the near future.

However, the newly formed Planning Group, composed of approximately 19 invited participants from many of the 11 schools on campus, met several times over the course of the following academic year. Charles continued to negotiate with donors on behalf of the Center.

\section{Donor Documents}

Graduate business school professor Claire, who focuses on leadership development, contributed her time and expertise over summer, 2013, toward meeting a request by alum, CIC Board of Advisors member, and CIC supporter Robert. Claire told me that Robert was eager to have a three page "donor document" to show people he thought may be interested in supporting the CIC. Claire said she ended up donating 80 hours to help reduce and refine a message that would be understandable and compelling for donors. Charles, and to some degree other Planning Group members, had created "working documents of all kinds." The challenge was that there were Google docs

That had become unwieldy because so many people [on the Planning Group] had contributed, and there was so much desire to be ultra-clear and specific about things that were important for the group identity formation, but were not necessarily important for representing the group with the donor.... The group was at this stage of organizing in which they were creating a story they wanted to tell themselves about what they were doing, but then came the opportunity and 
requirement to tell other people who were not group members what it is we do and why. And you have to kind of get into to a different head to do that.

Charles's attempts to distill all this material into the brief document requested had been stymied, Claire said, by the fact that "his writing voice has been groomed by years and years of writing for academic readers," whose interests are different from those of most donors. Claire was brought onboard at the suggestion of Peter, who knew her strengths well. She worked to extract the essentials from some of these documents, keeping in mind the intended audience. In doing so, she implicitly, and most likely explicitly, brought to bear her understanding of donors as "audience," in the sense she invokes when describing her work on "leadership presence." That is, she wanted the rhetoric - the "framing of ideas" - to be informed not only by the "interior exploration" on the part of the CIC itself, but also, pivotally, by the timely need to "understand how audiences [in this case donors] are moved and how they participate in the performance itself." In this way, the overarching contribution Claire brought was the capacity to integrate first person (the CIC's self-understanding), second person (attunement to the presence and needs of the donors) and third person (analytic framing of ideas), in a way that improved the effectiveness of CIC's communication with donors.

Claire said that she "brought fresh eyes to the project and offered another way of self representation." In this process, she began to press for reframing not only the way the CIC represented itself on paper (in the donor document, which was still twenty pages long when she stepped back from the project at the end of the summer), and on the website, but also in how those guiding the CIC's development conceptualized it on a structural level. She suggested that the CIC "break outside of" framing itself primarily- 
at least on its public face-in terms of the major initiatives, i.e. the Contemplative Academy and the Contemplative Symposium, and present itself instead in terms of "Five Contexts," each of which would be an entry point for interested participants, including donors, to approach the center based on frames of reference that they already understood. These have remained prominent on the website.

The Contexts, as defined on the CIC's website as of fall 2015, are: 1) "Professions and Performance - In business, athletics, and art for professionalism, productivity, and innovation"; 2) "Culture and Wisdom—Religious studies, ethical reasoning, cultural contexts, and humanities with sciences"; 3) "Health and Well-being-Through research and learning in the health sciences, psychology, and other disciplines"; 4) "Education and Learning-Personal, cognitive and social knowledge in 11 schools and the developmental spectrum"; 5) "Design and Place-Contemplation and design thinking in place, building, engineering, courses, products." Claire's efforts, by some accounts, assisted the CIC in shifting how it framed itself, both in terms of its public presentation and its self-understanding. However, it is unclear whether and how that reframing has been borne out, since the website currently (spring 2016) features both the (now four, rather than the initial three) foci and the five contexts. Notably, the links to current activity and people through the Contexts are two years out of date, whereas the links through the Foci are more up to date.

The three initial Foci - the Contemplative Campus, the Contemplative Academy, and the Contemplative Symposium, retain somewhat similar descriptions as of spring 2016 to those from three years earlier, that I outlined above. The description of the Contemplative Symposium appears identical, not updated with information about the fact 
that the first Symposium was held nearly one year ago. The description of the Contemplative Campus has expanded significantly, as have the number of links to individuals and schools involved. It carries essentially the same message as before, about the CIC's intention to work in and across differentiated arenas at SEU, toward organizational transformation. The description of the Contemplative Academy, as of spring 2016, is similar to three years ago, with the addition of a description of long-term plans for a "Contemplative Mapping" project, which "will build a rich, interactive map of contemplative organizations, facilities, and spaces. This tool will include multiple scales, beginning with SEU's historic campus, and scaling up to global coverage ...."

\section{Events to Build Relationships with Colleagues Beyond SEU}

Following are some examples of early efforts by the CIC that demonstrated an interest on the CIC's part to engage in generative conversations with stakeholders in the national contemplative higher education movement. I am not aware of particular projects that have arisen from these conversations. However, at the time they appeared to spark enthusiasm among all parties involved.

- The CIC hosted a "closed door meeting" with a delegation from Emory University in late 2012, organized as a rather ad hoc convening to allow Planning Group members and a few others to talk with Emory faculty and researchers interested in contemplative approaches.

- A small delegation visited and lectured in spring 2013 from Brown University, where Hal Roth had been bringing contemplation into his classroom for 10 years, 
and Willoughby Britton has been researching unintended consequences of meditative practice.

- An "Architecture and Contemplation" took place later that spring, featuring speakers from SEU and beyond speaking on the featured theme.

- In late January 2014, several visitors from Naropa University came to converse over breakfast and lunch with invited members of the Planning Group, and others, on the theme of contemplative pedagogy. Several Naropa guests, Charles, and a CIC staff person gave "lightning talks" to which the public was invited.

\section{Events to Foster Relationships with Donors}

Other events that seemed targeted at raising widespread interest in the CIC were arranged in collaboration with the original donor. In April 2013, the CIC sponsored a very large Ashtanga yoga practice session led by the two master yoga teachers who are the holders of the lineage with which the major donors are involved. There followed a private reception to welcome the donors and the yoga teachers. The CIC invited to this reception representatives from a local yoga community and from a local communitybased wellness center, in addition to other interested community members, and University-based faculty and administrators. It was a significant effort on the part of the CIC to raise interest in its presence at SEU. My general sense at the event was of invited guests' enthusiasm and interest regarding the CIC, and appreciation for having been included in the gathering.

In fall of 2013 the Center — at the suggestion of its donors - organized a visit to SEU by two celebrities: one a well-known alternative medicine advocate and prolific 
author appreciated by many in the New Age movement, and the other an author and internationally known media mogul, who media outlets have called one of the world's most powerful women. This event was geared toward fundraising, and involved great efforts on the part of Charles and the CIC staff, as well as the Development Office, to invite and host many alumni and others they had reason to think might be interested in learning about, and potentially helping fund, the CIC. There was a short event open to all University and community members in the center of campus, led by the two guest speakers. The main purpose of the visit, however, was a luncheon and dinner to mix the celebrities and a few CIC key stakeholders with potential donors.

\section{Speaker Series}

The Center sponsored or co-sponsored many speakers in its first two years, hosting guests including a well-known neurobiologist who studies effects of meditaion, a trauma specialist who recommends yoga and other body-based practices, and a wellknown American Buddhist teacher. Charles said that the Speaker Series was quite an investment of time and focus for him and his staff. The number of speaker series of events seems to have tapered in the last year. It became more promising and efficient for the Center to co-sponsor or publicize ongoing related talks and events hosted by various departments and schools throughout the University than to operate as a sole sponsor and host for such events.

\section{Staff Concerns and Changes}

The staff turnover in the short time since the CIC's inception has been significant. Five full-time members have come and gone in four years. Staffing has been very lean, 
and so with the added stress of turnover, personnel issues have strongly marked the CIC's early years. I touch on these below, and revisit this topic in later sections focused on the CIC's organizational praxis.

Four Planning Group members, and Charles, told me there have been "bad hires," referring to people whose skills and interests are mismatched to the roles required of them. I gathered from what these stakeholders said that they felt this was an assessment shared by other key stakeholders. This reflects some dynamics that muddy the waters when describing the CIC's staffing history. One dynamic is that people's job descriptions were not always clear cut, and may have changed as the organization's needs and trajectories shifted. Another dynamic is that there were disagreements between the director and some of his employees about how they could best contribute in their roles. And last, because the director has had the ear of stakeholders after employees left, his interpretation has influenced these stakeholders' views of staffing issues.

I spoke in depth to every former full-time CIC staff member. They concurred that many of the challenges in working for the CIC are common in start-ups. Roles continue to need to be refined, and there can be dissonance about what that entails.

However common it may be in a start-up, though, I was struck to hear how challenging an experience working for the CIC has been for the former staff members I talked to. All of them admired the director in many ways, and saw him as genuinely desiring to facilitate positive and collaborative work. Each stated that an underlying dynamic is that Charles's focus has been spread extremely thin, and yet they felt that tasks were not delegated effectively. Staff stated that too often they did not feel supported 
in their roles, as the director was juggling many foci and, by reports of former staff, shifted priorities often and wanted them to follow suit. I heard that, rather than prioritizing tasks, Charles assigned more tasks concurrently to each staff member than he or she could reasonably take on. Most expressed that they had needed more followthrough and input from Charles than he provided, in order to fulfill their own responsibilities.

A staff member with a background in development work was hired summer 2014 to take on fundraising responsibilities along with Charles. Her job title soon changed to associate director; in addition to her role as chief development officer, she oversees fundraising and communications, and works with the CIC's director on administration and strategic planning.

\section{Organizational Issues}

Both CIC staff and many stakeholders in closest proximity to the CIC have expressed strong concerns with its organizational structure and governance. Howard, who serves on the executive arm of the Planning Group and whose academic and professional work is in organizational consulting, said that there are indeed challenges in being a startup, and traced some "real similarities" between "a young Apple, some of these tech companies" headed by a charismatic entrepreneur, and the CIC.

There is a science of how you set these things up, but people don't necessarily know the science. And I don't think we understood the science, the best practice, here. When you start something up, here's what you need to be covered, and then there's how you do it, how well are people managed, and that's a big issue of course. [But], it's not really rocket science. 
Howard went on to talk about the importance of designing into the organization "particular functions" such as fundraising, office management, and supervision of staff filling those functions. "And it seems to me like the Center [and Charles] have struggled with that, just knowing exactly what to do at first .... I'm not certain that our [Planning Group] was always clear and aligned about exactly what to do."

The Planning Group was always very large, because it was structured as involving people from different disciplinary backgrounds. Claire [interview, 11/01/13] expressed concern that Charles's early commitment to inclusivity in forming the Planning Group was strategic, in that it gave the Center "a more interdisciplinary identity and sensibility," but that as a decision-making body having a 19-person decision-making body was cumbersome and may have "stymied progress."

There was little business expertise represented on the Planning Group. Howard said, "Of all of us, I'm the only person whose work I think is actually about how you structure these things." He said he does not "advise [the CIC] in a direct way or anything." However, for reasons that Howard thinks may have to do with the managerial skills of the associate director, his opinion is that recently, "[CIC's leadership team] just got smarter."

\section{Structural changes among CIC stakeholders}

The Planning Group was purposely constructed to have members from a wide range of backgrounds and expertise, but the organizational structures needed to share that expertise in generative ways have been lacking. Some Planning Group members I interviewed expressed that Charles's leadership style may have inadvertently made this 
generative sharing more unlikely. From the beginning, Charles urged Planning Group members to provide input to him and CIC staff via Google Docs, and communicated with them in this format as well. I heard from some of these members, and from Charles, that this method of sharing information was unsatisfactory for practically everyone. Charles was trying, during the 2012-13 and 2013-14 academic years, to encourage Planning Group members and others to collaborate among themselves and with others, and to develop ideas for research or other initiatives, and seek grant funding together. Meanwhile, Planning Group members expressed to me that they felt deluged with information and, at times, requests from Charles to engage in ways that they were not willing or able. There was no clear plan as to how to form collaborations, and all were very busy in other parts of their professional lives. At Planning Group meetings, Charles spent much time—-in most stakeholders' view—"downloading" information that participants seemed unsure how to weigh in on. A major theme in how Planning Group members expressed to me their relationship to the work of the Center, and to its director, was that he was "so far out ahead that I can't keep up," and the fact that he was willing to work so hard made people unwilling to bring up disagreements they might have had with the direction the Center was taking.

\section{Planning Group retreat and after}

Some Planning Group members pressed for a retreat in spring 2014, for the duration of which the normal dynamic in which Charles directed communication and decision making was shifted to a more collaborative process. With the support of an outside facilitator, members collaborated to develop a new mission statement, bylaws, and a new organizational structure with clearer roles for Planning Group members. An 
executive arm of the Planning Group was created, which included a person to represent each of the CIC's five Contexts.

The perception about the success of the retreat was mixed. The mere fact of having a retreat was a relief to Sarah and others, who had been wanting a longer set-aside time to meet as a Planning Group ever since its inception 18 months earlier. She said, "It was the first that we all really got together. We had these meetings but the meetings were so chock-full of the business, that there was no process time, and there was no time for us to step back [and consider a bigger picture].” In addition, Sarah said she was thrilled with the new structures, which she foresaw supporting her and others who wanted to play a more active role, to contribute meaningfully to the work and decision making of the CIC going forward.

Following the retreat, for the academic year 2014-15, the executive arm of the Planning Group met only sporadically, and when they did, the meetings were short and somewhat similar in tone to the larger Planning Group meetings, according to two of its members. Charles reported news, and solicited input, but the sense I gathered from members of this group, including Charles, was that it had indeed not become a true decision making group. Charles continued to carry much of the weight of the work. During the academic years 2014-15, and particularly in 2015-16, the Planning Group met less frequently. In fall 2015 they met only for two social gatherings.

Charles told me in spring 2016 that "no one liked the [retreat] facilitator," a sentiment I had not heard from others. He also stated that while he had convened the executive arm of the Planning Group for meetings over the two years since the retreat, some of those who had made commitments at the retreat to take responsibility for other 
coordination efforts had not necessarily followed through. He said that, at the time of the retreat, it had become clear to him that the large Planning Group was unwieldy as a decision-making group, and that these stakeholders did not have capacity, in terms of their time and other professional commitments, to fill decision-making roles. Therefore, he had come to see the need to consolidate decision-making power in the paid CIC leadership, rather than attempt to further distribute that power. Retrospectively, he said, he thought he should have made that clear at the retreat, rather than standing by while the group designed a change process that he saw as unworkable.

In spring 2016 the website description changed to state, "The [CIC's] governance consists of a [Planning Group] of faculty, student, and staff representatives drawn from multiple schools at SEU, an external advisory board, and a very broad 'Contemplative Council' consisting of SEU faculty and staff with core interests in contemplation that will be regularly consulted through a mailing list and town hall meetings."

Charles has acknowledged several times, to me and to others, that his role has been unsustainable not just for him personally_-“There aren’t enough pieces of the pie [of his time and focus]"- but for the organization as well, meaning that if he suddenly disappeared, the infrastructure would not be in place to carry on without him. Yet he has also asserted that no one else has the needed combination of skills to produce the kinds of results he can. He said that his ground in the liberal arts is a major strength in understanding what direction the organization should take, and that his experience in interfacing with business and entrepreneurialism is pivotal to the CIC's development, at least given the choices about that development thus far. 
I heard from six participants—Planning Group members and staff—-that there was ongoing conversation that some said included a donor, about the need for hiring an additional director for the Center. Charles told me in spring 2016 that he very much wanted to have a "manager" position funded; he said that a person in this role could take care of lots of the management work that he himself was too busy to do well. It is unclear to me precisely how Charles and the current associate director share management responsibilities, and how roles and responsibilities would be shared with an additional manager or director. However, there appears to me, and to many stakeholders I spoke with, that there is plenty of work to be done, and additional staff could be very helpful to the CIC in its efforts to fulfill its mission.

\section{Relationships with Donors}

Donors have continued to offer support to CIC initiatives. Fundraising is clearly a major time commitment for the director and associate director. Early on, an advisory group made up of donors was created, and over time it expanded beyond the initial donors. The relationship between the CIC and donors is virtually all directly through Charles and the CIC's associate director, who is also its chief development officer.

Peter said that the Development Office has been able to help Charles "think through" his relationship with donors, as the donor base has continued to expand. Charles's relationship with donors is by many accounts exceptional in the context of academia. There can often be a "cultural divide" between the interests of donors and academics, said Claire. Donors are usually more pragmatic in their orientation, and academic jargon can seem "not very useful" to them. Moreover, "Donors can be very directive, and academics value their freedom and autonomy. "Given these challenges, 
Charles and these donors have found generative ways to work together. Claire said that Charles is able to "speak other people's language well."

By many accounts, the donors have also developed in their thinking, in major part because of Charles's diplomatic and informative relationship with them. One of the donors with whom I spoke had an extremely positive view of Charles's capacity to "unify" and "build community" among stakeholders.

\section{Current and Evolving Foci}

The website continues to list the CIC's five Contexts, and its homepage strongly features links to them. These links lead to narrative descriptions of each that have inaccuracies and outdated information; the information on each Context's page to "Events" and "Instruction" related to that specific Context is two years out of date. The website also lists and links to the mission and to four "Initiatives"- the three initial Foci: Contemplative Campus, Contemplative Symposium, and Contemplative Academy, and now a fourth, the Contemplative Alliances. The website states the CIC's commitment, via Contemplative Alliances to "forming a variety of affiliations and partnerships with other institutions," locally, regionally, nationally, and internationally.". Links describing these Initiatives are more updated than those for Contexts, but are not entirely up to date.

It appears from my interviews that as of fall 2015 the CIC has three current major foci. One, corresponding to the "Education and Learning" Context is a major initiative to bring an "integrated health and wellness curriculum for elementary students" into a 25 school system in another state. An announcement of the project states, "The research is the most comprehensive ever undertaken of a 21 st century health and wellness 
curriculum in an elementary or secondary school setting and was developed for K-5 students." Lisa, an education professor whose new position at SEU was funded in part, and her hiring facilitated, by the CIC, has been developing the curriculum, and an education school colleague is designing research protocol to measure the program's effectiveness. One CIC donor has spearheaded the fund-raising for this project, and the CIC's original donor has also provided support. This project has taken enormous energy, time, and coordination from Charles, Lisa, her research colleague, the donors, and others. The project employs a program manager on the ground at the site of the intervention. The funding hit a snag in 2014, and despite the great effort involved in pressing on, Charles told me that he chose to continue to focus on bringing that project to fruition, because he felt concern for the elementary school students, and did not want to withhold this potentially beneficial program from them.

Another current major focus is the "Student Initiative," corresponding to both the "Education and Learning" Context and also to the "Contemplative Campus" Initiative among the "Foci." This is a multipronged approach to bringing contemplative opportunities into student life at SEU. Two program directors were hired summer 2015 to run this program, one of whom has a recent doctorate from SEU's Education School. He is taking on tasks related to research and assessment. The other program director has a strong background in providing contemplative experiences to young adults and others. This Student Initiative also draws on the expertise of an SEU professor who directs a center to research effective teaching in higher education. The Student Initiative is interfacing with SEU's student advising services, hoping to cultivate skills among these advisors so that they can help students make healthy choices, which correlates with one 
of the Five Foundations in SEU's strategic plan. The two new program directors for learning are very active as well in bringing contemplative resources into classrooms upon professors' requests, and cultivating co-curricular contemplative opportunities for students, such as a recent Spring Break Mindfulness retreat.

The CIC efforts also include significant initiatives to network and share learning and knowledge production. Corresponding to the Contemplative Network Initiative, and perhaps the "Education and Learning" Context as well, the CIC sponsored a regional conference May 2015 on contemplative approaches in higher education, of which one of the stated goals was ongoing regional networking in which the CIC would play a strong role. I attended, and have not received any follow-up communication in the nine months since, however.

The Contemplative Academy, one of the original Foci, has been developing under most stakeholders' radar. Under construction by Charles and coders that work under his direction, it is an online platform to garner and distribute a massive range of information about contemplation, and seems designed to extend far beyond the walls of this university and academia in general. Charles told me in winter 2015 that he had hired coders in Guatemala and elsewhere to work on this donor-funded project. He does not want to unveil this project for public scrutiny until significant progress has been made. I gather that Charles sees the potential for it to have far-reaching impact as a source of information sharing about a wide spectrum of contemplative interests.

A Contemplative Symposium, also one of the original Foci, was held June 2015 and brought together more than sixty participants from across the country, all expenses paid, to share insights and concerns about the field of K-12 education. Moreover, the CIC 
has committed to follow through from this Symposium by helping facilitate continued collaborative inquiry. The financial outlay was very high, and both Lisa and Charles spent many hours in preparation, in hour-long conversations with each participant in preparation for the event. The original plan had been to host Symposiums annually beginning in 2014, and follow up with funding for projects conceived by Symposium participants. Some say that this may not be the case going forward; as far as I know, there are no plans in place for future Symposiums.

The Center gave six small research grants (up to $\$ 15,000$ ) for the 2013-14 academic year to SEU-based researchers. It has not had a grant program since, though Charles told me that they are working on making grants available again before long.

\section{Conclusion}

In the nearly four years since its official rollout, the CIC has evinced significant growth as well as experiencing some growing pains. Remarkable enthusiasm and lofty ambitions characterized its emergence from the beginning. Both an ungainly organizational structure intended to be inclusive but without clear, workable ways to channel that inclusivity, and the ongoing dynamics of interaction among and between the director and some members of the Planning Group have produced less collaborative results in some ways than many anticipated in the early stages. However, the director reports that he is continually engaged in generative conversations with stakeholders in various positions and schools across campus, working collaboratively to develop initiatives that will serve needs specific to a diverse range of settings, which the program directors are helping to design and enact. The director, apparently with increasing partnership from the recently promoted associate director, controls access to and 
communications with donors, and with the provost's office which officially, though lightly, oversees the CIC.

The director is also in charge of meetings and communications with Planning Group members, which have decreased in frequency, and of the executive arm of the Planning Group as well. Some Planning Group members attempted, via a retreat nearly two years ago, to change the organizational structure in ways they believed would facilitate them in contributing their efforts more effectively. This attempt seemed very briefly successful to at least one key stakeholder I heard from, but the director was reportedly not aligned with these changes, stakeholders have not pressed hard to follow through with them, and it appears that communications and decision making continue to be significantly top-down, at least vis-a-vis Charles' relationship with the Planning Group. As of spring 2016, Charles has stated that it is inappropriate to charge the Planning Group with decision making, as it is far too large to coordinate for that purpose, and its members' competing commitments elsewhere do not allow them to contribute the time and focus required for the task of leading the Center. The Center's governance is becoming more explicitly structured to be governed by the director along with the associate director, in negotiation with the donors-individually and through the advisory board - and with input from the executive arm of the Planning Circle. In addition, there will be a newly announced "Contemplative Council," which the website describes as "consisting of U.Va. faculty and staff with core interests in contemplation that will be regularly consulted through a mailing list and town hall meetings"

CIC initiatives are now underway in various arenas, and the director is involved in most or all of them. Staff turnover has been very high, with all former staff expressing 
concern about job conditions, indicating explicitly or implicitly that the CIC has been a very "uncontemplative" place to work. These staff and a few key Planning Group members also expressed strong concern about the CIC's organizational and governance structures. They said that the organization itself, and in particular its director, is spread too thin, and that the director's management style — at least under these circumstances_may significantly undermine the organization's effectiveness.

Many stakeholders expressed, early in the CIC's emergence, great hope that the CIC could facilitate significant collaborations among those interested, a major part of the CIC's mission statement. Many continue to hope for this in a general way. Some contemplatively oriented collaborations are certainly occurring on the campus and beyond. Whether the CIC is directly involved or at all responsible for any of these, and whether the CIC's existence affects these collaborations' trajectory, is an interesting question vis-a-vis conditions that support emergence and interdependence of such initiatives.

Questions about funding are pivotal in the Center's functioning, as well as in its choice of foci. It seems clear that early enthusiasm was generated by the significant initial funding and reason to expect that this funding could increase dramatically. Increases in funding appear to be quite measured. At this time - other than the Compassion in the Schools project, the Contemplative Academy, and the Contemplative Symposium, which a key stakeholder told me had been part of the intended purpose of the initial gift-much of the funding is spent on staffing for the Center and its campus programs. Charles has expressed hope that stakeholders might come up with projects that would appeal to current or future CIC donors, but he has also made it clear that the CIC is not in a 
position to simply disperse funds from its limited coffers. The CIC gave small research grants over one academic year, but has not reinstated that program. It is unclear how stakeholders (including deans) seeking funding for their own programs might benefit by allying with the CIC, or conversely feel they are better off taking care of their own fundraising autonomously from the CIC. 


\section{Chapter 4}

\section{Analysis of Findings}

In presenting and analyzing my data, I depict a range of viewpoints. My intention has been to engage some concerns, aspirations, and interpretations about contemplative praxis in higher education. In this descriptive and explanatory case study, I have focused on relating data to propositions, in order to refine understanding of both the setting and of my theoretical approach and interests. I have not focused on quantifying my results. Therefore, the meaning I elucidate is not contingent on finding agreement among a majority of participants, but rather on exploring a spectrum of perspectives and explicitly exploring what interests might motivate, and be served by, different perspectives. The fact that some concerns - such as those about equity, marginalization, and privilege, whether based in race, professional status, or socieconomic differences_-are explicitly expressed by fewer than half my participants does not minimize my sense that these concerns are central to my responsible inquiry. I am also protective of the vulnerability of some of my participants based on these very concerns. There are power dynamics in the setting, as well as other relational concerns, which make some participants understandably wary of having their views connected to them in a publicly accessible document. I make some assertions about these dynamics in the sections that follow, without divulging all of the specific data that lead to these assertions.

In general, I try to convey a sense of how much agreement or divergence I found among participants related to key themes and sub-themes found in the interview data. However, my interviews were semi-structured, and significantly adapted to particular 
stakeholders, to tap their unique perspectives based on the wide spectrum of roles and backgrounds they brought to the inquiry. Therefore, the key themes and sub-themes that I explore below are better characterized as patterns arising in a tapestry that was created through a synergy of my interests and those of my participants. It conveys relevant information about dynamics in the setting, brings attention to important concerns, offers analysis, and suggests further avenues of investigation.

In reporting my results, I focus to a considerable degree on stakeholders' aspirations and concerns (in contrast to ascertaining outcomes per se) about what contemplative praxis may bring to bear on personal, learning, institutional and organizational levels. I have also focused on the complementary question of what organizational, institutional, and learning praxes bring to bear on contemplative praxis.

\section{Data Sources}

My primary data source was in-depth, semi-structured interviews. As previously stated, I conducted 93 interviews with 54 participants. Over two years and 10 months, I interviewed participants with a wide range of roles in relation to the $\mathrm{CIC}$, SEU, and the contemplative movement in U.S. higher education. I interviewed two of CIC's Advisory Board members/donors. I conducted 20 interviews with 11 members of the Planning Group and its executive arm (excluding CIC staff), who come from a range of roles and disciplines across the campus. I conducted four interviews and had several intermittent informal conversations with the CIC director. I conducted 15 interviews with eight of the CIC's former and current full-time staff. Three of my interviewees were current or former SEU deans. 
In addition to the above, I interviewed the VP for development, the vice provost for Academic Affairs, the associate director for Equity and Diversity, the vice president for Human Resources, and the associate director of the university-wide center for teaching resources, the director for an SEU-based center for research on higher ed teaching and learning, and the director of SEU's Women's Center. In addition to the professors on the Planning Group and its executive arm, I interviewed five SEU professors, as well as visiting professors from other universities who came to visit, speak, or teach about contemplative pedagogy or mindful leadership, through the CIC or elsewhere at SEU. In addition to those in the groups above, I interviewed a recent SEU alum and one current student, who were activist leaders on campus, and the director of a university community organization that explores the SEU's ongoing legacy of racial harm. I conducted two interviews with a consultant who works in the field of systems change with an equity lens, and with a local organizational consultant whose expertise is in contemplative organizational change and leadership. In addition to these interviewees based at SEU, I interviewed the director of a center for wellness and contemplation at another public university in the same state. I also conducted five interviews with two national leaders in the field of contemplative higher education.

In addition, as noted in the Methods section of Chapter One, I engaged in many hours of participant-observation over the period of my study, at numerous CIC events and other events on SEU's campus, and at 11 national conferences. I consider talks and presentations to be a valuable part of my data. Moreover, 10 presenters - including CIC stakeholders - are also among my interview participants. 
A major interest for my study has been participants' orientation to change agency, and I have used complexity as well as contemplativeness as lenses through which to explore that interest. The next section highlights general findings from my study, in relation to my propositions that a complexity view and contemplative approaches may help stakeholders perceive and act on possibilities for transformation, whether on personal or collective levels.

\section{Analysis Through the Lens of Propositions}

My propositions state that perception of, and engagement with, any and all dimensions of praxes as complex systems (wherein diverse, connected, interdependent agents learn adaptively together) is resonant or even consonant with a contemplative approach, and amplifies the transformative potential of each praxis. Therefore, in the sections that follow, I explore how participants implicitly and explicitly relate to the self, to learning, to an organization and to an institution as complex, and to contemplative praxis as a way to help guide that complex system toward transformation. Because contemplative praxis on the level of the individual, contemplative learning praxis, contemplative institutional praxis, and contemplative organizational praxis are all mutually informative, I will show connections that participants made across praxes.

I had proposed that capacities to disturb complex systems and to guide/scaffold them toward emergence are congruent with capacities that proponents say contemplative praxis develops: proactive use of awareness or attention. I looked for language, and action, that implicitly (or even explicitly) describes contemplative, learning, institutional, and organizational praxes in terms of complex systems dynamics. I frame complex 
systems as those in which diverse, connected, interdependent agents adaptively learn together, giving rise to emergence. Emergence is characterized by changes that cannot be predicted by analyzing a system's constituent parts, because it is the relationality among unique inputs, synergizing to respond to unique conditions, that can result in novel, creative, adaptive, and often self-organizing ways.

I found, in general, support for my propositions. There is correlation in my data between participants' descriptions of contemplative praxis and their descriptions of transformative change. Participants invoked the concept that contemplative praxis helps bring awareness to habits in systems - whether those systems are intra-personal, interpersonal, organizational, or institutional — and that this awareness can facilitate the transformation of these habits into new understanding and behavior. Stakeholders' descriptions of contemplative praxis - whether on the level of contemplative praxis per se, or in bringing contemplative praxis to bear in learning, institutional, and organizational arenas - illuminated to some degree the ways in which scaffolding and guiding a system through disturbance, chaos, and emergence can help that system change adaptively.

As I looked for language, and action, that referenced emergence, as characterized by unpredictability, novelty, and self-organization, I also looked for language and action that reduces complexity by reducing diversity, connections, interdependence and/or adaptive learning. Motivations to reduce complexity can be expressed in terms of amplifying what one values, or of reducing what one does not value; either framing exerts power, as reducing complexity controls the kinds and degree of emergence a system can produce. Motivations are based on assumptions that are not always explicit or 
even conscious (Kegan and Lahey, 2009), what Argyris \& Schon (1974) call "theories in action." I have proposed that the difference between reducing complexity and guiding emergence has real consequences, which can involve the entrenchment or transformation of inequitable power dynamics, marginalization of difference, and dampening adaptive learning and innovation. My counterpropositions proved useful as a framework for analyzing the data. These counterpropositions were variations on the theme that institutional structures and power dynamics, either implicit or explicit, at SEU and/or within the CIC, would dilute or co-opt transformational potentials of contemplative praxis.

Participants' descriptions invoked the concept that complexity reduction can be used to entrench current habits, and to resist change. Their descriptions of the factors that lead to complexity reduction, and of some consequences of complexity reduction, illuminated some challenges that can arise when entrenched patterns are disturbed but there is not willingness or capacity in the system to guide it toward emergence.

I have also proposed that in a human system, capacity to guide a system from disturbance, through chaos, and into emergence is a pivotal element informing choices about reducing complexity or guiding emergence. The findings support my proposition that in the arenas of praxis to which participants brought contemplative praxis, contemplative praxis could increase capacity to guide that system in such a way that transformative changes would be more likely to occur. Participants described this in aspirational as well as actual terms: they believed that bringing contemplative approaches into settings and praxes could help increase capacity to guide emergence, and could often tell me why they believed this. Also, there is some support in my findings for the 
proposition that participants' understanding of purposes and methods of contemplative praxis will change as they bring it to bear in these other arenas.

\section{First, second, and third person praxis through lens of propositions.}

It has been my goal to organize data and analysis in a way that best explores participants' insights about how individuals' relationship to contemplative praxis inform their views on bringing contemplative approaches to learning, and institutional and organizational work. I have found that as one moves from focus on the individual to focus on the collective, the need increases for practice that includes second person and third person perspectives, as well as the first-person perspective highlighted by most advocates of contemplative practice. Varela (1991), Gunnlaugson et al (2014), Petty (2014), and Goleman and Senge (2014), among many others, affirm the necessity of cultivating capacities to engage contemplatively—with awareness-from each viewpoint, and especially the necessity of integrating these viewpoints. Goleman and Senge (2014), Capra and Luisi (2014), and Page (ND), and some participants assert that "systems thinking”- perceiving and engaging with complex systems as complex systems-is a vital capacity to cultivate in the arena of the third person (objective) perspective. Participants in my study spoke of developing these capacities, through contemplative practices that cultivate such awareness.

As part of my inquiry into the relationship between complexity and contemplation, I have become more acutely aware of the need to investigate how first, second, and third person viewpoints - self-awareness, other-awareness, and, ideally, system awareness as third person awareness-require and elicit different yet 
complementary qualities of awareness. I watched for how people (including myself) invoked or expressed, implicitly or explicitly, first, second, and third person perspectives, and described contemplative practices that purport to cultivate and even to integrate these perspectives. I looked for how these practices might scaffold emergence, or reduce complexity, thereby disturbing or reinforcing power dynamics intra-personally, interpersonally, and beyond. I looked for how contemplative practice may or may not help people understand structural oppressions, how systems work and change, and their individual change agency.

Bringing the study's propositions and counterpropositions to bear on the data helps me articulate a major assertion based in the findings. I have found that many participants' primary framing of contemplative praxis is as an individual praxis. Although some do describe such praxis in ways that resonate with a complexity view, they do not explicitly or fully extrapolate that complexity view into the organizational or institutional praxis they engage in. It is through this primary framing — contemplative praxis on an individual level — that many participants identify its value in learning, organizational, or institutional praxis. Proponents of contemplative praxis expressly valued becoming more self-aware and resilient as individuals. Many also described an enhanced sense of relationality, including increased second-person capacity described as empathy or compassion. In their professional roles in an HE setting, they saw and acted on the value of bringing contemplative practices into their teaching, and to some extent they advocated on institutional and organizational levels for the value of contemplative praxes for individuals. Thus, many participants expressed implicitly that their own and others' individual contemplative praxes might inform institutional and organizational 
transformation. Most were not explicit about how that might occur, except to indicate that as more individuals in these settings develop self-awareness and empathy or compassion, the institutional and organizational culture would improve.

For some of my participants, however, contemplative approaches explicitly informed their perceptions of their organizational and institutional praxes, in that they described how bringing awareness to bear in the systems they were part of could disturb constraining organizational or institutional habits and potentially propel some more novel, inclusive, and adaptive responses.

Confirming one of my propositions, I found that participants who (implicitly or explicitly) invoked a systems view, characterized by highlighting interdependencies among actors, including themselves, had particularly cogent and explicit insights on the challenges and possibilities of a contemplative organizational and institutional praxis. These participants spoke explicitly about exploring their agency toward effecting change in an organizational or institutional system, and expressed concerns about their collusion with habits in the setting. They conveyed an understanding that their agency was dynamically interacting with external contextual factors, including others' agency and collusion. They expressed interest in their own internal complexity, including their own diverse motivations such as internalized oppression and unconscious privilege, and in how these dynamics interacted with the complexities in the context. Participants' perceptions and concerns about how contemplative praxis informs change agency, in the service of transforming collective complex systems they were part of, deepened my understanding of what contemplative organizational and institutional praxes may entail. 
This range of insights participants provided informs my findings as to how contemplative and HE praxes (including learning, institutional, and organizational praxes) may transform each other. I found evidence to support my proposition that a systems view is resonant or consonant with a contemplative approach. Some participants described a systems view, applied primarily to individual contemplative praxis which for many included an enhanced general sense of relationality. Others extrapolated a systems view to organizational and institutional systems they were part of. Those who did the latter in addition to the former were more likely to not only value first and second person contemplative approaches, but to engage in systems thinking as a third person perspective.

It has become clear to me that if higher education is to fulfill what some hope and believe is its transformative mission, an HEI must become a rich, though intensely challenging, context for exploring how to develop and integrate first, second, and third person perspectives In fact, in the course of the following analysis I assert that focus on first-person perspective, without a concerted effort to explore how second and third person - particularly systems thinking — perspectives are mutually informative with a first-person perspective, risks collusion with econosociocultural tendencies pressing for a less than transformative higher education praxis, one that continues to overemphasize the autonomous individual, and underemphasize systemic interdependencies.

\section{Interview Findings}

Five key themes emerged from the data gleaned from interviews, as well as participant-observation and document review. In the sections below, I have described 
these themes and related sub-themes, and interpret them through my conceptual framework.

The first theme: A strong majority of participants asserted the value of a range of contemplative approaches_-for themselves and/or students, and often more generally as well — in cultivating self-awareness and compassion, as well as resilience. In this vein, 20 participants said that for contemplative practices to be truly transformative, they should be combined with learning about needs or inequities in larger systems, and how to be change agents in those systems.

The second theme: Participants said the HE setting presents both opportunities and challenges for incorporating transformative approaches. In the context of this theme, a few participants expressed concern that contemplative approaches could be watered down, commodified, or co-opted in the HE setting to reinforce status quo power dynamics.

The third theme: Many of the contemplatively oriented initiatives described by participants were independent of, or only loosely related to, the CIC. Generative connections with the $\mathrm{CIC}$ have been occurring, there is potential for much more, and there are questions and concerns about the dynamics involved in forging these connections.

The fourth theme: The organizational praxis of the CIC has begun to, but does not fully, support its stated mission, which includes building relationships across differences, disciplinary and otherwise. The director has forged connections with many stakeholders, but there is limited infrastructure or method for facilitating collective inquiry, decision- 
making, and collaboration. Also, it is unclear whether the CIC has the capacity to address issues of inclusion and social justice, which is a part of its stated mission.

The fifth theme: Participants suggested changes to address problems in the CIC's organizational praxis. These included suggestions for contemplative approaches to the organizational praxis, and suggestions for structures to facilitate collective inquiry and collaboration.

\section{The Value and Nature of Contemplation}

In this section, I present some themes gleaned from participants' perspectives on, purposes of, motivations for, and results of contemplative praxis $(\mathrm{CP})$. In later sections, I will return to these themes as I bring in more discussion about contemplative approaches to concerns in learning, institutional, and organizational praxes. As stated in Methods, my participants were purposely chosen for their interest in contemplative praxis in higher education, or their relationship to the CIC in their official capacities at SEU. As expected, I did not encounter the full range of perspectives on contemplative approaches that could be found in the setting at large. My purpose was focused on those who brought some interest and support to the general topic, as even among these participants there were important nuances to explore. This exploration of nuances related to my interest in how the rubber meets the road when incorporating CP in the HE setting, and how organizational praxis is involved in this - all within the larger context of concerns and aspirations both in the particular setting and in the national movement for contemplative approaches in higher education. 
Nearly all participants asserted the value of contemplative practices for students to cultivate self-awareness, well-being, and relational skills. A majority of participants said that they themselves had contemplative practices that were meaningful to them and significantly affected their personal and professional lives. About 20 participantsnotably including two leaders I interviewed from the national movement for contemplative higher education - asserted strongly that for contemplative practices to be useful in transforming larger systems, they should be combined with learning about needs or inequities in larger systems, and learning how to be change agents in those systems. These 20 participants said that self-awareness, empathy/compassion, and systems awareness can and should synergize to show people how they and others have internalized the dynamics of systems of which they are a part. Through a complexity lens, I interpreted participants' descriptions of contemplative praxis as building capacity for proactively disturbing intra-personal, interpersonal, and (for some participants) larger systems, and for guiding disturbed systems — on one or more levels — to emerge new, more adaptive modes of relationship and action.

\section{Contemplation can take many forms}

A strong majority of participants held that contemplative awareness can be developed through many different forms of practice. Sarah, professor of nursing and director of the Caring for All Initiative, who herself has practiced meditation in the Buddhist tradition regularly for 20 years, said, "Well, contemplation could be a set of approaches," to a greater sense of awareness of self and the world around one. "I don't see it as solely meditation. There are types of contemplative interactions-with people, with nature, being in silence. Art as contemplation. Music as contemplation. Dance as 
contemplation." She said that through manifold contemplative practices, the goal is "this sense of reconnecting with who we are. And through that knowing of who we are and how we relate to the world around us, we can be more thoughtful in how we live our lives."

SEU psychologist Joseph said, "Contemplation is not anything special. When I'm playing with my kid who only wants to look at the gravel instead of hike up to the mountain where I want to see the view, if I relax and stop cursing my fate and really meet my kid at my kid's level, I'm being contemplative.” Joseph continued, "Really, it's about doing things with deliberate volition and attention .... The key question is not what's contemplation - the key question is what's practice." Practice is what people engage in deliberately, "over and over and over again, "in order to "enhance your ability to do it, for the purpose of doing it per se, just being in that state." Joseph went on to say, "becoming a really good pianist is exactly analogous to any other kind of contemplative activity."

\section{Contemplative practices can bring awareness to habits.}

A majority of my participants described the cultivation of awareness as an important purpose of contemplation. This was often framed as the ability to "see" or "watch" or "feel" one's experience with a sense of spaciousness or detachment that allows one to welcome aspects of experience that into consciousness that previously have been out of conscious awareness and yet influence patterns of thinking, feeling, and relating. 
CIC director Charles has stated that "contemplation is fundamentally about practices, awareness, and values," and therefore "it's really asking a much broader question than do you like yoga, or mindfulness, or Buddhism and so forth." He asserted that a contemplative approach to higher education will teach students "about how to understand the practices they have learned and the outcomes that those practices are generating." By "practices" in this context, Charles meant those that were "given when they were two months old . . three years old . . six years old—social, emotional, cognitive." In the context of higher education, he said, contemplative practices bring students' awareness to those instilled practices:

All this plasticity, this malleability opens up, and we need practices to envision other possibilities, other possible practices that can generate different outcomes, and then you need practices that will allow us to take those new practices, make them hardwired into our sensibilities.

A point of reference invoked by half or more of my study's participants was drawn from an approach to contemplation that Jon Kabat-Zinn (e.g. 1990) introduced in the West, a "mindfulness" practice to cultivate "present moment, nonjudgmental awareness." As these participants point out, this practice, and the awareness it is meant to cultivate, are in part an antidote to mental and emotional structures that limit our sense of reality to what our past experience has been and what we project, based on past experience, into what future experience will be. They described that by bringing awareness to these self-perpetuating patterns, we disturb the complex system of our selfexperience (which includes how we experience relationality). Contemplative practices may provide scaffolds by which to guide emergence of new "structures" through which to experience. 
For example, Jeffrey—an anatomy professor turned full-time Mindfulness Based Stress Reduction (MBSR) teacher of undergraduates — said that in teaching MBSR to these students, he introduces them to practices for "look[ing] at your own poor, crazy mind, get[ting] familiar with it, and not being run by it." By "poor, crazy mind," he means the constant churning of thoughts and worries that "take us away from what's real." "We take this in small steps. Start where you are, do this little thing and see what you notice and we'll talk about that," and so on. "By the end of the semester they're understanding that what they do affects not only themselves but everybody around them." Despite speaking (tenderly) about our "poor, crazy minds," he said that MBSR classes should be "non-judging, non-pathologizing, and non-instrumental." He went on to say that, "When you're a Buddhist teacher, you're the expert. You have the answers. When you're an MBSR teacher, you never have the answers. You only have questions .... The student needs to look to their own experience." And, "Your practice is all day, every day. There's nothing magical, there's nothing supernatural, it's about paying attention to your entire life." In fact, Jeffrey is concerned that when people are taught mindfulness practices in a watered-down, superficial way, they will not know they are missing a more challenging and more worthwhile experience. He said he believes this is "dangerous." He said he himself practices mindfulness meditation because he wants "never to cause harm again, like [he has] done in the past."

Many participants asserted that contemplative practices such as mindfulness practice can, in and of themselves, help us become more self-aware, and simultaneously as one participants asserted, "our interdependence on one another." Sarah specified that through contemplation, one 
... cultivates self-awareness, and through that self-awareness being more aware of other people and the world around you, and doing that in a way that invites a sense of engagement. It's an inner knowing; it begins with inner knowing. . . . A lot of the mindfulness practices are about sort of noticing [your mental filters] and doing your best to let them dissolve, put them aside, and let [yourself] see things more clearly and true as they are, and they're always as true as they are to you, because it is through this veil of consciousness.

\section{Contemplative practices can reinforce or antidote overemphasis on individualism}

What might characterize some of the (non-contemplative, unconsciously imprinted) "practices" that Charles referred to in the earlier quote, or that Sarah invoked by "mental filters," or that may arise from "our poor, crazy minds"?

One significant basis for unexamined habits is our societal emphasis on the isolated individual, and concomitant personal and relational dysfunctions. The CIC has twice brought in John Makransky for its speakers series, and also for an intensive weekend workshop for caregivers. His focus was on the web of caring relationality that characterized the traditional Buddhist monastery. Far from isolating the individual in his or her spiritual journey, Makransky asserted that the monastic context offers an atmosphere of warm acceptance. He perceives that when practices derived from monastic traditions have been brought into contemporary Western social contexts, people take on practices in isolation, exacerbating what he says is a general tendency in the West to aspire to individuation at the expense of accepting and cultivating a sense of interdependence. Makransky is concerned that contemplative practices be used in ways that affirm and respond positively to these needs, rather than exacerbate practitioners' sense that they should transcend these relational dependencies. He has committed himself 
to teaching professional caregivers - whom he says too often abnegate their need for caring, unconditional affirmation — to recall memories of being held with loving care (even if by a pet, or a nature scene), and to invite the sense of wellbeing thus generated to suffuse oneself.

A strong majority of participants asserted that contemplative practice can help one develop awareness of, and interest in engagement in, relationship to others and to the "greater whole." There was much agreement about this result of practice, whether or not that practice is embedded in a set of teachings. Some alluded to Buddhist teachings that the fabric of reality is interdependence, and that therefore the purpose of contemplation is to wake up to that interdependence, Also mentioned were Christian teachings about bringing compassion and love into action to meet the needs of others, or indigenous traditions centering on our relationship with all of the natural world. Others did not frame an increased experience of relationality in terms of a philosophical or religious tradition.

A range of perspectives arose among my participants regarding the need to teach ethics in an explicit way, concurrent with the teaching of contemplative practices.

Most participants indicated that self-awareness will in fact lead naturally to concern for others. This is a nuanced arena, wherein participants' expressed views about the desirability of 'formal' ethical teachings as against 'informal' and more general framings were never clear cut. The predominant view, however, seemed to be that while it was paramount that students be invited to explore their own experience with the help of CPs, some gentle guidance could help them make meaning from what they discovered through that experience. For most participants, this guidance was based in what seemed 
to these participants a commonsense view, for which they did not cite particular religious or philosophical tenets, that students — and the world into which they will be movingneed more kindness and wisdom.

In this vein Rose, CIC's program director for Learning, said,

What I feel about teaching people meditation and its ethical implications is that I'm there to empower them to see the world from their own [laughs] agency; I am not there to impose a set of ethics on them that they need to follow, but to help them be, you know, the master of their own body and their own mind . . . . Teaching somebody to practice mindfulness will help them be more aware of when they hurt somebody - how does that make you feel inside - you know what I mean?

Yet, she later invoked the Buddhist admonition to practice 'right' mindfulness, which she said meant that mindfulness can indeed be practiced in ways that are not 'right,' as simply self-serving methods of refining attention or soothing one's own stress. She said that when she introduces mindfulness practices, she does in fact state to participants that the benefit they gain as individuals from these practices should be contextualized in concern not only for their own well-being, but for how they might contribute to the well-being of others. Rose also bemoaned the effect she saw too often among contemplative practitioners, especially of yoga, wherein they wanted to keep their sense of 'inner peace' intact, and shunned anything or anyone that might disturb that peace. Her sense of the purpose of practice is that it prepares one to engage more, rather than less, fully and compassionately with those aspects of the world that are disturbing.

About 20 participants expressed a similar concern: that when contemplative practices are introduced as self-help tools to people who have been conditioned to focus on themselves as isolated individuals, these practices may entrench a Westernized over- 
focus on the individual. These participants said that under these circumstances, wellbeing can be conflated with one's personal comfort. They concurred in saying that this approach does not help practitioners value and learning discomforts that can emerge from becoming more aware - of oneself, of others, and of systemic issues.

Only a small minority of five expressed these concerns in terms of a need to avoid extricating CPs from particular traditions. One of the five, an SEU alum with a rich background in the study of Eastern religion and yoga, and is now in seminary to become an Episcopal minister, warned that it may be vital to embed the teaching of practices in some context that can be called religious or philosophical or ethical. She said,

It becomes a commodity for some people: 'How can I use this practice or this technique to better manage my stress for my better job.' You know this isn't really changing our system that needs conversion, if we're using these practices that are meant for conversion for the sake of continuing at our own egoic pace.

Mary: Can you talk about conversion?

Lora: Yeah, well, I want to talk about it more broadly, I guess shifting your lens towards God or-I know in Buddhism there's not that language, but release of the ego would be the language there. Totally reframing your way of being, so that it is beneficial to the greater whole and not just clinging to ... desire. That's Christian and Buddhist language.

\section{Effects of contemplative practices are difficult to parse.}

John Dunne, who holds the Distinguished Chair in Contemplative Humanities at the University of Wisconsin - Madison, and was an invited speaker at a Regional Conference held by the CIC in May 2015, said that teaching students contemplative 
practices with the aim of increasing their academic focus is akin to giving them Ritalin. Others speak in more nuanced ways about the relationship between instrumentalist and transformative uses of contemplative practices. Often these nuances express conflations that may or may not be conscious.

Joseph's assertion that "becoming a really good pianist is exactly analogous to any other kind of contemplative activity" might garner objection from those concerned with the use of contemplative practices for instrumentalist reasons. Interestingly, in the example he gave of attuning to the needs of his child, Joseph described a contemplative experience which was thoroughly relational, empathetic, and compassionate, in which the awareness he brought to his immediate reaction of "cursing his fate," and the awareness that he brought to his child's interests and needs, informed a response on his part that was in support of his own, his child's, and the relationship's well being. Practicing to become a really good pianist does take "deliberate volition and attention," but does not necessarily require the qualities of self-awareness, other-awareness, and relational awareness that his story centered on, and that many participants say are intrinsic to contemplative practice. It is noteworthy that he did not make the distinction that his story contained elements that many participants viewed as important to the experience of, and the purpose of, contemplation: self- and other-awareness, and compassion. He highlighted "volition and intention" as primary, which is an amoral and not necessarily relational definition. He was likely implicitly saying that his intention was self- and other-awareness and care, but "intention" itself can be used in other ways, and thus does not replace awareness or compassion. His definition, if not his example as a loving father, is the kind of thing that concerns some of those concerned with instrumentalist uses of 
contemplative practices. A more overarching point is that this distinction is not always made, and that people may be prone to conflate varying motivations or experiences — as in this example, relational awareness with volition and intention.

\section{Contemplative practice may engender "spiritual bypassing," or support greater relational awareness by increasing resilience.}

I have heard Charles say several times that when people choose to meditate in order to be happy, they are misguided. In fact, he has said, meditation is about waking up, not about being happy; in waking up, we become aware of the suffering in the world. Others speak to this as well. Rosch (2007) emphasizes that bringing attention to previously unexamined aspects of one's subjective experience involves the experience of pain. Contemplative practice may open our awareness to our own suffering and that of others. Moreover, more awareness - of self, other, and interconnectedness, can show us the ways we have perpetuated suffering.

If the whole purpose of contemplative practice is framed as feeling better as individuals, then even practitioners who awaken to suffering - their own and others'may lack a context (scaffolding) for this, and may engage in complexity reduction through "spiritual bypassing" (Masters, 2010) — that is, engaging in a kind of denial by using "spiritual" concepts to avoid psychological distresses. This could be experienced as very liberating and empowering — even transformative - for the individual, while further entrenching resistance to acknowledging and responding to societal concerns like unconscious privilege and other biases that affect the collective good. Many say, in fact, that we need to acknowledge and contend with deeply distressing feelings that arise as we 
attend in a more nuanced way to our felt experiences, intra-personally, interpersonally, and collectively.

Many stakeholders expressed, in nuanced and contextualized ways, perceptions that there is dynamic tension between increased focus on one's own wellbeing and focus on the greater good. Resiliency, along with awareness, can help one engage things that are distressing, in oneself and beyond. According to many participants, a major aspect of this is the overall restorative effect of contemplative practice. Sarah said,

Essentially, though, for each of the tasks that the brain is doing, it really, really takes energy... we need to give it breaks. It's like gardening-you need to aerate the soil, right? We need to put some air in there, so there can be some better movement, better activity for growth and to flourish. The brain is doing it the same way. We know from the neuroscience literature that the brain needs to recharge and it really can't multitask. It's a complete misnomer.

I heard from many participants that resiliency and awareness can help us engage our inspiration, desire for growth, and - especially in concert with openness to engaging with distressing contexts - take into account a bigger picture rather than defensive reactivity, and become agents of change. I also heard from some the caution that one should be proactive in this process. Claire said, "I think a misuse of mindfulness and yoga is using it to console yourself or to escape or to not take action in the world." She acknowledged that, "While you can be calming and clarifying and all those things it needs to set you up for action.” She offered

... a critical reading of positive psychology: that it can be solipsistic or narcissistic and it's all about me and kind of fulfilling my desires. And there may be a time in the developmental process where that needs to be a focus because let's say a person just feels so divided about who they are or their place in the world, or they're overcoming depression or grief or something like that. We really just have to keep focusing on getting better, but then there's a point of diminishing returns, and we have to look outward. 


\section{Contemplative practice may cultivate self-awareness, resiliency, and change agency.}

Audrey described to me her participation in a Wisdom 2.0 conference, saying,

It's more business oriented-how mindfulness supports productivity, creativity and people's personal journeys and how it led them to find their particular innovation and calling. There isn't a social justice, social change perspective which for me I find curious. Disappointing is another [word for it], but the more that you delve into this work I think you discover the desire to [pause] make the world a better place.

"This work" Audrey referred to is the work of integrating self-awareness, resiliency, and skills for change agency, which together she calls "social transformation."

When Audrey described the work of her international organization dedicated to social transformation, she said, "Our intersection is this complex [mix of] international development, social emotional learning and personal leadership, mindfulness-based personal transformation, and working in post-conflict zones with women and girls." They bring a curriculum based on experiential learning and focus on community, combining practices for mind/body trauma healing, stress reduction, mindfulness, and social entrepreneurship. All these components, she asserted, are relevant in many contexts, not just to the very particular demographic her organization serves. "So I think all of these things can serve anyone who's trying to make a difference."

The organization's work is based on the premise that social change efforts are more effective when all stakeholders are more self aware and more resilient. Selfawareness includes proactively exploring one's motivations, including those that one would prefer to disavow, which Audrey calls “shadows.” Practices to increase selfawareness include methods that explore somatic, kinesthetic, and emotional experience, 
as well as cognitive dialogue, "so that it really lands, which has tended to work for me with undereducated and highly educated populations because once we have an experience that we can relate to, really that's what contemplative practice is about."

Just as complexity can be reduced so as to focus on the individual, so can it be reduced to focus on outer issues without cultivating awareness of one's intra-personal dynamics, which in themselves are complex and thus a site for complexity reduction or emergence. It can be uncomfortable, but necessary, to disturb these intra-personal structures, which Charles called "unconscious practices" and Audrey calls "shadows."

\section{“Contemplative practices are necessary but not sufficient;" invoking a systems view}

SEU professor Angie has asserted (ACMHE Annual Conference 8/2012; CIC Open Meeting, 9/24/12) that the contemplative movement at its core is concerned with dismantling systems of oppression, such as those that keep non-Western perspectives marginalized. The purpose of contemplative practice, she said, is to bring awareness to inner barriers. In becoming more aware of their limited and limiting viewpoints, she asserted, practitioners will become more inclusive-more likely to respect the rights and value of others with different perspectives, and also more likely to incorporate a broader range of capacities into their human repertoires.

However, 20 of my participants said contemplative practices themselves are be only part of what is needed to bring awareness to inner barriers and thereby become more inclusive and ethical. They asserted that explicitly disturbing our unexamined assumptions about the larger systems we are part of is vital to a more accurate understanding of reality and one's place in it. I attended the pre-conference to Mind \& 
Life Institute's (MLI) International Symposium of Contemplative Studies in October, 2014. The pre-conference was titled, "Transformative Education and Contemplative Education Need Each Other.” The closing keynote was given jointly by Arthur Zajonc, founder and former president of MLI, and Sheryl Petty, an African American consultant who specializes in large-scale equity-based social change projects. Petty invoked the term radical presence, offered by the morning's keynote speaker john powell [sic], asserting that radical presence was what the theme of the day challenged us to cultivate.

She asked, "How do we have practice [that cultivates] the skills and competencies around presence and awareness, and not get lost in the clouds?" She said that contemplatives, whether their practice is tradition-based or non-tradition-based, "are profoundly prepared, hypothetically (sub voce), for engaging and really dealing with frustrating, confusing, painful ... you know, conflicting emotions.... You've got a practice or a tool that you sort of fall back into." She went on to say that contemplative practice is "one domain. And it is ... necessary but not sufficient." She stressed that, resonant with the theme of the pre-conference, "the other set of tools ... that are needed, are some hard knowledge, historical knowledge, around difference, around the impact of difference, around things like structural inequity and how that actually has shown up in education systems over time." She asserted that the kind of "presence" one seeks to cultivate by means of contemplative practice "will get you to stay," in contexts that trigger extreme discomfort and disequilibrium. But this presence, she stated emphatically, won't help one

... fully understand ... what someone else may be trying to convey, share, or ... the structures and systems within which we are teaching and learning. There are 
domains of competence, and there are domains of knowledge. These are like muscle groups for us to build over time.

At a spring 2016 conference on contemplative higher education, Daniel Barbezat, director of the Association for Contemplative Mind in Higher Education (ACMHE) spoke about the need to bring contemplative practices to bear on "unexamined white privilege," which he said,

... is so embedded, not only in institutions and classrooms, but in our own communities [of contemplative educators], and "in here" [indicating within himself], and it is up to us to begin to do what we say we do - to not only be here now, but really be here, and really be present with what's here.

He continued by speaking about his personal struggle to "look at power, and to open to" giving up his white male privilege. Further, contemplative practices are

... perfectly situated to examine that which is difficult, to help us see what's here. They can also be movements of complete disassociation. ... And the difference between those two for myself is quite subtle. So we're going to need help. . . . We will have to look outside ourselves in order to do this work.

This help will come in part, he asserted, from partnering with and learning from those who understand these issues well. Barbezat was expressing a systems view in which his white privilege and others' disempowerment go hand in hand, and he asserted that he needs the tools of contemplative practice and he also needs to learn about systemic oppression. He states, as does Petty, that these are complementary and necessary tasks in becoming change agents to help transform oppressive systems.

The commonality among the range of emphases that participants expressed in this study is that awareness disturbs the system, prompting the opportunity for the systemon whatever levels or levels are involved - to produce new possibilities for understanding 
and action. However, as Petty and Barbezat expressed, we need explicit information about systems we are part of, and our often unconscious roles in those systems (Senge, 1990), because we are implicated in systems that are more complex than we may understand through paying attention only to ourselves and our immediate relationships (especially if we tend to relate with others much like ourselves). Conversely, we need contemplative practices in order to take in that information and let it affect us. Otherwise, awareness may disturb us but we may respond defensively by entrenching patterns of unconscious privilege or internalized oppression, reducing complexity as needed to do so; that is, not assimilating diverse inputs.

While Barbezat eloquently described bringing awareness to internal and relational habits that reinforce their unconscious privilege, two of my participants described bringing awareness to habits that perpetuate internalized oppressions. One, a black student leader, said, "It takes being okay with "in here" before I can be okay with anything out there." She told me that her experience with contemplative practice (especially in a collective inquiry such as PULSE, which I describe later) is that,

What mindfulness and talking about these things can ... help you realize is ... that what maybe you see on TV about you isn't what you are, and what your family is and what your friends are. Internalized oppression . . . sort of turns into the self-hate, and sort of not being able to disconnect what the world has told you from what is.

\section{Contemplative practice, a systems view, and "transforming the collective shadow."}

Another way a participant expressed a systems view was Lora's description of the systems view she brings to her efforts to do "shadow work" in her religious tradition, by 
bringing awareness to historical and current violence done in the name of Christianity. She says "belonging" to a tradition requires "transforming the collective shadow. If we don't do that, we are stripping these practices of the real heart of the matter. We really can't just do that."

Lora continues,

I know there's a lot of talk of letting go of the story, and not being attached to the story, and I agree with that, of course - I'm a contemplative - but at the same time you need to know something deeply before you can let go of it. You need to stand in, for example you need to stand in the pain of the past, before you can release the pain.

Lora objects to the tendency for many proponents of contemplative practices to,

Teach all these principles, but yet in the act of taking them out of their religious trappings, it's contradictory, there's a paradox. We're teaching that we need to be present pain to let go, but we're not being present to our traditions.

\section{First, second, and third person experience in contemplative praxis.}

First person praxis is what most people mean when they talk about contemplation.

Petty and others, explicitly and implicitly, said that these are "necessary but not sufficient." First person practices may promote self-awareness and self-compassion, and help increase resilience. Such practice may help us navigate a dynamic flow between what Senge (1990) calls chaos and rigidity, and to tap into what Audrey called "intrinsic joy."

My propositions state that the transformative potential - the potential for emergence — of and through contemplative praxis is amplified as one experiences, engages, and enacts one's "self," intra-personally and relationally, as a complex living system. Self-as-living-system is characterized by diverse, connected, and interdependent 
modes of experience — such as knowing, feeling, sensing, desiring — that adaptively learn as a complex system, among and within living systems. Self-as-living-system can also be characterized by diverse motivations, conscious and unconscious, which interact internally and in relationship with other systems to perpetuate patterns or give rise to new, more adaptive patterns. I propose that awareness/attention disturbs the existing structure/patterns of the self-as-living-system, giving rise to possible emergence of new, more adaptive structures. Between disturbance and emergence, the self-as-living-system can engage scaffolding — internal and relational— to facilitate emergence, or reduces complexity dampen emergence.

As referenced in the preceding literature review, and as I will explore below, some contemplative pedagogy and other contemplative approaches focus on cultivating capacities for second-person experience. The strong majority of my participants cared a great deal about the use of contemplative approaches to help develop empathy and compassion. They asserted that self-awareness honed by first-person contemplative experiences can help us then open through second-person practices to caring about others' experiences, to come to more fully understand that others' experiences are different from our own, and yet others and their experiences can be as real to us, and they can matter as much to us, as our own experiences. In the pedagogical, leadership, and other arenas to which they described bringing contemplative approaches, they generally described feeling that these approaches were beneficial to themselves, students, and colleagues.

Third-person experience, a honed objectivity, is the stated goal of much traditional higher education. Contemplative approaches that cultivate first and second 
person awareness and compassion can enhance capacities for objective understanding, helping one to shift away from rationalizing one's unconscious reactivity, "logically" defending oneself from the discomforts of engaging with others' challenging viewpoints. Third person, objective, awareness can be brought to bear on reality as embedded systems within which all members affect each other.

Contemplative approaches to pedagogy can promote such first-, second-, and third- person awareness, and sensitize students to systems thinking. Different pedagogical approaches focus on different parts, and sometimes all, of this spectrum. Below, I describe and bring analysis to some examples of contemplative pedagogical approaches taken by professors at SEU, as they described them to me. This section and its subsections bridge my discussion above, exploring participants' views on contemplative praxis, with later sections exploring their views on the challenges and opportunities in the HEI setting to contemplative approaches broadly conceived.

\section{Contemplative Learning Praxis with Classroom Examples}

In 2013 Diane and the university-wide teaching resource center, with some support from the CIC, brought Mark Thurston - in his capacity as director of the Program for Consciousness Studies at George Mason University — to SEU to speak to and meet with a wide-ranging group of faculty interested in contemplative approaches in higher ed. When Thurston opened the floor and asked his audience to share about ways they were incorporating contemplative practices in their pedagogy, it was striking that many professors' descriptions centered on purposefully creating a sense of safety and community in their classrooms, in ways that were not at all esoteric, but nonetheless 
seemed to be perceived as other than the norm. Thurston himself offered that the key to his approach to contemplative pedagogy is something he learned from his child's Waldorf School teacher many years ago: "It's vital to allow our compassion to intuitively inform our teaching."

Seventeen of my participants (14 at SEU, and two professors elsewhere) reported directly incorporating contemplative practices into their pedagogy or co-curricular programs they led. These participants described pedagogical practices they had developed to help students connect with their own subjectivity, with the professor and other students, to leverage an exploration of what matters to them, how to explore what matters, and how to express it. Thurston described a course he has co-taught, focused on self discovery and self care. It began with a five-day-long immersion in many approaches to self care, all of which were immediately applicable, continued as an online course and in-person check-in, and ended with each student creating a self-designed "vision quest" experience over the last two weeks. An important element of the course was inviting students to see themselves as co-researchers, tracking and describing their experiences. In the first hour of the course, they filled out a battery of questionnaires; another assessment battery was given mid-way through, and they "kept data points, especially narrative," during the last two weeks. Thurston's invocation of compassion as “intuitively inform[ing] our teaching," along with the guidance he offered to students as they engaged in self-discovery, combining first- and second- person contemplative approaches. His demonstration of compassion models for students the value of extending compassion toward themselves and toward others. 
Paul and Diane have been teaching their course, "Adventures In Young Adult Fiction," to help students read for self discovery, after they had become jaded from all their preceding academic experience. They gear the course particularly toward fourthyear English majors, who have been steeped in critical approaches to literature, and who have often lost their affective connection to it. Diane calls it "a warm invitation to imaginative thinking." They also facilitate students' "connecting to each other and themselves," engaging a "deep quality of connection—not just connection available anytime anywhere." By this last, Diane likely refers to "connecting" through social media, which several of my study's participants similarly decry as providing a superficial and perhaps illusory sense of connection. However, Diane and Paul say they have remarkable success using an online blogging platform for class participants, to facilitate community building beyond the classroom time together.

One manifestation of contemplative practice in Paul's and Diane's class is an experiential project: students are asked to write creatively, but they are asked to place their focus not on the end product, but on the experience they have while "experiencing creative writing and reflecting on it." Paul said that many students find this transformative, because they "let go of the prison of the pressures of the critical judgments that [they're] putting on [themselves], and that everybody's putting on [them]." Some students "Get in touch with this sense of joy that they had lost since... pre-puberty," and

get back in touch with why they originally wanted to write something in the first place. And so they are suddenly having this moment where they are really experiencing something, and then recognizing - and in their reflections they're saying, wow! I had no idea that I had an alternative to this mindset that I've gotten 
so narrowly focused into. What we want to do . . is allow them to make that discovery. To allow them to have experience apart from the critical faculty.

Students' conditioned "critical faculty" in this case has reduced complexity, disinviting intra-personal complexity - suppressed emotions and motivations, the “disavowed self” (Dewey, 1934). The vital factor guiding the emergence of new modes of experience is the professors' explicit permission and support as students explore their subjective experience and articulate what they discover. The professors are providing scaffolding through which students can disrupt their habitual patterns, which express a kind of internalized oppression, and move through whatever distress they may encounter on the way to discovering a wider range of choices.

Diane and Paul have been sensitizing the students throughout the course by telling them their well-developed critical faculties are valuable, and that "we're going to use all that in a new way." They explicitly leverage the students' skill in analyzing texts not to "reject . . . the way they've been trained, but to open their exploration up to a new text." They are invited to "read" the "text" of their own felt emotional experience. "So they can apply those critical faculties in their reflections, but the point is to allow the experience as opposed to what we posit" is too often the case: in the course of academic training, students experience

dramatic loss of joy, dramatic loss of engagement with the text, a dramatic sense that the path was not a fruitful path, a full path. ... The path of intellectual inquiry was a narrow stultifying path, and so what we posit is that it doesn't have to be that way, and that students have an alternative if they can just access their own feelings, emotions, ... experience and read those. ... And by doing that, almost all the students have a transformative experience of seeing something freshly, experiencing it deeply, richly experiencing the joy of that and then reflecting on it. 
Paul extends this to say explicitly that he thinks of mindfulness and meditation as similarly "reading" his felt experience. As he scans his body for tension, "one part of my reflection is reading, reading that tension." He says, "scanning that, observing it, and analyzing it—but you're analyzing it in such a much more inclusive way than if I'm simply in a traditional academic, intellectual mindset [which is] more about control and judgment than about acceptance and inclusivity."

Contemplative approaches in higher education will need to explore ways in which the rigors valued in critical thinking can be transformed by compassion without losing their usefulness. Some of my participants asserted this is the case. Explicitly or implicitly, they said that compassion can give us courage to develop a more truly critical stance, in the sense of bringing critical awareness to power dynamics, including our own place within them.

Paul says he had a breakthrough moment years ago, when a student wrote in her reflections at the end of the semester that if someone had asked her whether she has control over her mind, she would've said, "Of course!" She went on to write, "all I had to do is have one minute of silence to realize that I had no control over it whatsoever." Paul feels strongly that it's quite possible for students to "sail through their entire undergraduate careers, possibly their whole lives, and never be invited for one moment to just sit and be quiet, just see what comes up." He asserts that for some students, that that one moment of silence, the realization that they cannot control their thoughts, is transformative.

Even if it's not a straight line trajectory, that this is a conversion experience and they're going to do this forever, that they know that there was this moment in their 
undergraduate career when they had this and they'll come back to it .... It's an experience that's provocative, and really engaging to them, they'll cycle back to it.

The realization that one is not in control of one's thoughts, especially in concert with exploring somatic and emotional aspects of one's self-experience, can begin to disturb patterns that limit one's sense of self. These patterns have reduced the complexity of self-as-living-system to cognitive processes and, moreover, to assume one controls those cognitive processes.

A major part of the value of the course, the professors say, is in creating community through blogging. Students share their work and responses, and in so doing develop a sense of community. This element enhances community building in the course, in ways that involve second person contemplative practice.

\section{Getting to know our "poor, crazy minds"}

In teaching MBSR to undergraduates, Jeffrey objects to using any Buddhist language. He simply tells students that all of us have "poor crazy minds." Jeffrey purposely reduces complexity by not using esoteric terminology, in order to bring focus to what he values: that students engage in practice that brings awareness, and thereby disturbs, (them)selves-as-living-systems. The scaffolding he provides through his teaching, including the discussions he facilitates as students share the discoveries they are making and the challenges that are arising as they begin to practice mindfulness meditation, is intended to assist students in navigating the turbulence they experience as their previously adaptive intra-personal structures, habits, and patterns are disturbed by their own awareness. For Jeffrey, couching this in a "foreign" or religious-sounding language could shift some students' focus to wrestling with their discomforts about those 
things, and thereby detract from his intended focus on their own inner workings, and by extrapolation, their empathy for the inner workings of others.

\section{The role of compassion}

Sarah and Diane taught a course together called "Mindfulness and Compassion: Living Fully Personally and Professionally," during spring semesters of 2014 and 2015. Sarah said it was "really, really profound; deeply transformational." The key elements of the course were personal practices, formal and informal, intellectual readings on research and theory, and reflective writing, through blogging and weekly papers. The class time combined discussion and practice. They designed the course to focus on mindfulness for the first half, and on compassion and prosocial behaviors in the second half. Sarah said, "The mindfulness [practice] really set the foundation for the prosocial. The prosocial behaviors, or qualities, covered compassion, empathy, lovingkindness, gratitude, generosity, forgiveness and sympathetic joy." The students practiced all of them, they wrote about all of them, and they read about them on a practical level and also an intellectual level, exploring the pertinent scholarship. Sarah spoke very movingly about her experience teaching the course. She found students to be extremely receptive to, and affected by, their participation.

Students had to apply and submit an essay to be admitted to the class, which likely set a tone of intentionality from the beginning. The professors prioritized having a disciplinarily diverse class makeup, so they enrolled students from everywhere on campus. The 29 students came from the psychology and religious studies departments, as well as from the professional schools: engineering, business, education, and nursing The 
professors built an eight-hour retreat into the course design, which was a revelatory experience for many. According to Sarah, "They were pretty blown away by it." The last class day, students submitted portfolios, and were invited to share with the group anything they wanted to say. "There were three [seniors] who said this was the best class they [had taken] in their entire four years. . . Another student said, 'this is the only class that really helps us to think about the big questions about life."'

Though Sarah acknowledged that "we are not therapists; our purpose is not therapy," she said the course

is definitely therapeutic, there's no doubt about it. We spend two weeks on forgiveness. And that's huge. And how could that not be part healing - therapybut what it does is, it brings them back to their self knowing, and they can more wisely decide how they're engaging with certain people, certain memories. For some people they changed their relationship with their therapist. A lot of students are in therapy. A lot of students are on medication.

Sarah said that the course she and a different colleague had taught in the fall 2013 semester had focused simply on mindfulness. But, she told me in an intense and hushed voice, "I feel like it needs to be balanced with compassion. In particular with mindfulness, you go to a very dark side, and it's unsettling, so [we must be compassionate to what shows up]." She said that even while the first half of the course she taught with Diane was explicitly devoted to exploring mindfulness, they had implicitly brought in compassion throughout. Sarah quoted a student who wrote in a blog post, "If mindfulness is like the foundation of a house - the bricks and mortar, compassion makes it a home."

In the next to last class, the focus was on how to be of service, which some students said strongly impacted them, particularly after exploring mindfulness and compassion. Sarah's description is of an experience that provides students with tools, and 
a sense of belonging. Sarah reports that "these students have changed-they've changed what they're going to do with their life." Sarah's description was of facilitating an experience for students in which they could undergo transformation, emerging some new possibilities for understanding and action in their lives.

Sarah and Diane taught this course for the second time during the Spring 2015 semester. It was during that semester that an African American university student was pushed to the pavement by Alcohol Beverage Control officers, which inspired protest and other actions on campus. Sarah and Diane focused some of their class time on discussing these issues. Sarah was very struck by how little her students understood about marginalization their African American peers experienced on SEU's campus and beyond. She was particularly struck by their lack of understanding and knowledge because this was a cohort of students especially committed to approaching their lives mindfully and with compassion. Sarah had only recently come to work at SEU, and this incident sensitized her to issues of marginalization on campus, and galvanized her to want to collaborate with others to bring more awareness to these concerns. The pedagogical intervention, through which Sarah and Diane incorporated a look at systemic marginalization and oppression, worked synergistically with the first- and second- person contemplative approaches they had been guiding the students in using.

\section{Contemplating "wisdom" and "presence" in the business schools.}

Eric teaches a course on "Wisdom" in the undergraduate school of business, where he is a professor of marketing research. He is acutely aware of systemic issuessocial, economic, and environmental—and the need to 
... be thinking about who we are and where are going as a species, including how are we teaching and training our upcoming generations of people who are going to be in position to be leaders who will come into positions of power and influence and can we get them to ask good difficult questions and believe that it's worth together trying to answer these questions in new, invaluable, and possibly hybrid kinds of ways.

By "wisdom," Eric means "knowing what are the important questions and why we need to ask them and why it's urgent for us to try to draw on all resources of knowledge," including "contemplative" resources, very broadly defined. In order to be wise, he says, one must work on and improve attentional resources. Though he does introduce them to an experience of mindfulness meditation, Eric centers his course on Western philosophy and recent neuroscience.

Claire, a professor at the graduate business school, told me that she had been incorporating a range of what could be called contemplative practices—including reflective writing, somatic and mindfulness practices, and drama-based experiences—into her courses on leadership and communication for several years. She has brought to her academic background in rhetoric and performance studies, an evolving understanding of somatic and embodied experience. In her teaching, and in a book idea she is developing, she emphasizes the importance of cultivating what she calls "Leadership Presence."

Her message is three-pronged. One dimension, she says, it to become present with oneself, "an interior exploration: calming and inner critic, clarifying your values, clarifying your objectives - all that centering kind of work." Another dimension is to "present," frame ideas, through rhetoric, "so helpful because it gives a methodology for framing ideas, and training your mind to frame ideas." The third dimension she invokes is "expressing the ideas ... and creating presence with an audience." She values drama 
methods for helping leaders learn that "presence," rather than "being something that one can possess," happens in interaction, both with another actor, and especially in relation to an audience: "understanding how audiences are moved and how they participate in the performance itself." Claire is adamant that "presence," thus developed, is only of value if one uses it for some public good.

Howard told me that contemplative practice has been "a foundational paradigm in terms of who I am and what I do." He said that it is "infused into [his] teaching," informs his "ideas about what knowledge and expertise are." Pedagogically, in mentoring junior faculty who are anxious to do their job perfectly, Howard suggests that they suspend that self-referential anxiety and look at the bigger picture.

I always [ask myself] this question before I start, which is what will help the learning, and everything else falls away. ... It allows me to do my best, but it also releases me from the focus and anxiety on myself. It helps relax all of that, helps me focus on them. To me, that's a practice, and it's about being present.

And, when he does not do as well as he would like to in his teaching, he takes a learning orientation toward his own development. "Part of what I'm committed to is creating a context where people can learn to learn from failure."

\section{First, second, and third person orientations in contemplative pedagogy}

At the Regional Conference sponsored by the CIC in May 2015, speaker John Dunne asserted that the primary rationale for bringing contemplative practices into higher education should be that these practices are a "means of radical critical inquiry." Dunne stated that contemplative approaches can provide a crucial means of a rigorous inquiry that would otherwise be missing. Rigorous first-person inquiry extends a 
well-established paradigm [of critical inquiry] in higher education, but also provides a new integration of perspectives: the opportunity to take the first-person perspective and integrate it into the third person, scientific ways of knowing. It's integral to any university mission. It's extensible across all disciplines.

Dunne said the first-person perspective refers to "phenomenological inquiry into the nature of experience from the first person standpoint. [It is an exploration of] the nature of consciousness, perception, cognition, emotion, and so on-an inquiry into the interpretive experience." He went on to talk about the experience of studying, for example, engineering:

We end up with disciplines in which the subjectivity has been erased. Objectivity requires the erasure of the subject, or the reemergence of the subject in irrational ways. This does not lead to an integrated way of knowing. [Instead, we should] create an integrative mode of inquiry that [explores] the first person [perspective] in a way that is integrated with second person and third person [perspectives].

Explicitly and implicitly, the professors teaching the courses described above brought in second person contemplative approaches, as they supported students in developing empathy and compassion for others both within and outside the class community. They integrated first and second person contemplative methodologies in doing so.

It could be said that these professors, whether consciously or not, prepared the way for students to understand systemic oppressions, by helping students see how they themselves had internalized conditioning that limited the choices they had been perceiving for themselves, whether in the arena of creativity, relationality, or imagining the lives of service they might lead. These students observed, and came to care about, their peers' struggles to come to greater awareness and sense of choice as well. Following up on this first and second person learning, Sarah was able to turn students' attention 
toward racially marginalizing structures in their own community, giving them a chance to incorporate the self-awareness and empathy they had been developing into a third person understanding of the fact of systemic oppression.

Professors have made inroads with contemplative pedagogical practices at SEU over the last several years, separately from CIC initiatives. A major part of the CIC's mission, the Student Initiative, is now underway, staffed for the last nine months by two program directors for learning. They are working in curricular and co-curricular arenas to support professors who want to bring contemplative experiences or methods into their classrooms, as well as with student groups and others who invite their consultation to design contemplative co-curricular programming. There are many dynamics in the HE setting that contextualize contemplative pedagogy and other contemplative approaches. In the following sections I explore themes that participants identified as challenges and opportunities for contemplative approaches in HE praxis.

\section{Challenges and Opportunities for Contemplative Praxis at SEU, and CIC's Role}

Participants described ways in which the HE setting presents both challenges and provides opportunities to incorporating contemplative approaches, and to doing so in the interdisciplinary ways that the CIC wants to promote. My findings indicate that despite challenges, interdisciplinary and contemplative initiatives have emerged successfully at SEU, and some of these may provide insight for the CIC into fulfilling its own mission.

Most of the contemplative activity that participants described was independent of the CIC. In general, I found that the CIC's presence on campus tends to legitimize and otherwise indirectly support such activity in this HE setting. Participants who were not 
directly involved in the $\mathrm{CIC}$ expressed interest in partnering with the $\mathrm{CIC}$ for joint ventures. The CIC is now staffed to support co-curricular initiatives on campus, and is strongly engaged in doing so. The Center is also very focused elsewhere, particularly on a major K12 program in another state, and on an online initiative. All in all, emergence of contemplative initiatives is occurring, via the CIC and otherwise, and there is potential for much more.

\section{Tensions in the HE context may open the door for contemplative approaches.}

When I asked Charles in spring 2013 about the higher education context in which the CIC is emerging, he outlined the following major sources of disruption of "business as usual" he perceives in U.S. higher education today. First: digital technology is being harnessed for online learning via MOOCs (massive open online courses), challenging HEIs to re-assess claims about the value of on-site college experiences. Second: globalization affects economic conditions, job markets, and social and cultural patterns. The complex social, economic, and technological conditions in our present and future may require skill sets and capacities very different from those developed in a traditional college or university setting. And third: amid this turbulence, parents and other stakeholders are concerned that colleges not only prepare students for financial stability, but also foster emotional and social skills to launch them into an engaged and meaningful life.

In his speaking and writing on behalf of the CIC since its inception, Charles has said that contemplative approaches to HE praxis today will include not just the introduction of a broadly conceived range of contemplative practices per se. Rather, he 
has often asserted that in a more overarching way a contemplative approach to HE will also include, and support, a revisioning of traditionally siloed approaches to knowledge production, and cultivation of methods to prepare resilient students to engage the world's critical and quickly changing needs.

In the following sections, I will begin to explore how participants discussed contemplative approaches in relation to the "disruptions" Charles named above, as well as in relation to other tensions. To do so, I engage a range of arenas, in each of which I present stakeholders' descriptions of challenges and opportunities to contemplative approaches in the HE context. These are challenges and opportunities related to incorporating specific contemplative practices per se, and challenges and opportunities regarding the larger contemplative mission of revisioning HE's purposes and structures. As I present participants' perspectives on opportunities and assets in the HE setting that allow or even support contemplative approaches, I describe some exemplars of such approaches. In this context, I will also explore participants' views on the ways that the CIC in particular is, or is not yet, promoting contemplative approaches, and on potential or actual affiliations between the CIC and a range of contemplative initiatives.

\section{Participants report incorporating contemplative approaches successfully.}

I found evidence in my data of both challenges to, and support for, the incorporation of contemplative approaches at SEU. Participants did reference some challenges to incorporating contemplative approaches in the setting, but I heard far more enthusiasm than discouragement as they described efforts and results thus far in bringing contemplative approaches into the domains of pedagogy, leadership development, and 
community building/social justice efforts. Participants who were engaged in these efforts described their work in terms of celebrating students', colleagues', and their own deep learning.

Seventeen of my participants (14 at SEU, and two professors elsewhere) reported directly incorporating contemplative practices into their classrooms or co-curricular programs they led, and all were very positive about the results. In addition, I interviewed two deans who found contemplative approaches profoundly important in their development as leaders and who strongly endorsed contemplative pedagogy in their schools. One of these deans, as well as an Assistant VP for Human Resources and Leadership Development, said they had successfully incorporated contemplative approaches in leadership development trainings they offered across the SEU campus. Another participant, an Assistant Dean of Students, expressed her sense that her contemplative approach with students strengthens her ability to assist them holistically. Only a few of the participants just described said they had initially been cautious about how colleagues, students, or administrators would respond, but they also said they had experienced increasing openness to these approaches in recent years. The presence of the CIC may be beginning to help with such acceptance, and three of these participants had been hired by the CIC to disseminate practices. But, 15 of the 19 SEU participants had been successfully implementing contemplative approaches, with little or no external resistance, before the CIC's emergence.

Notably, all 21 of the participants described above told me that they had themselves engaged in long-term (though not necessarily consistent) contemplative practices. It is also notable that virtually all were tenured professors, or working in 
another role in which they were sufficiently supported in incorporating contemplative approaches. Moreover, they were teaching courses, or involved in co-curricular activities with students, in which content was conducive to their explicitly contemplative pedagogical approaches. Contemplative experiences - whether or not directly related to course content — are being brought into a wider range of courses and other settings. Each unique setting presents challenges and opportunities for such incorporation. Beyond that, the institutional setting presents some overarching challenges, which I describe next.

\section{Participants report challenges to incorporating contemplative approaches.}

Despite the successes of these proponents of contemplative pedagogy, there are significantly more challenges to making changes beyond an individual classroom, toward contemplative revisioning of HE's purposes and structures. All of these challenges take the form of incentive structures that are also internalized by individuals and organizational units in the setting, and that reinforce the identity of the institution itself.

Individuals, groups (i.e. schools, departments, centers), and SEU itself are incentivized to prioritize prestige and competition, to commodify knowledge and skills and create narrow specializations, to "manage" rather than learn from difference, to focus on the decontextualized individual, and to perpetuate biases toward disembodied discursiveness and away from relationality, emotion, and embodied awareness. Fifteen participants - among these two leaders in the national movement for contemplative HEexpressed concern that even contemplative approaches themselves could be watered down, commodified, or co-opted in the HE setting. Some of the influences in this dynamic, they said, were the desire to enhance institutional prestige, or relationships with 
donors. On a more underlying level, all but one of these 15 expressed concerns that in the HE setting, the use of contemplative practices might be limited to enhancing individuals' well-being or performance, rather than helping to cultivate capacities like wisdom and compassion in order to better contribute to the collective good. Twelve of these participants invoked the concept of unconscious privilege, particularly white privilege and in three cases white male privilege, as a vital issue that they said contemplative practices can be very helpful in addressing, but far too often leave unaddressed.

What tendencies in HE praxis might work counter to contemplative revisioning of its purposes and structures? The following views were expressed to me by Roberta, a senior professor and founding member of the Center's Planning Group:

I think the university system rides on prestige — on a lot of things that are really not measurable and not accountable - and operates in a way that is self-serving and egocentric. All of these things [laughs] run counter to contemplative approaches. All of the American universities are so westernized into reward structures that are totally contradictive with contemplation. I think part of the problem is that the Center is trying to fit a square peg into a round hole. I'm just extremely pessimistic about the university structure and what gets rewarded in the university setting. And it's totally contrary to what I see as the contemplative approach, as to intellect, study, learning, all of that.

None of my other participants spoke nearly as pessimistically about HE challenges to contemplative approaches, but about one quarter of them alluded to these concerns: that incentive structures that reward competitive and self-serving dispositions and behavior, and prestige as a motivating factor, often play out on the part of individuals, departments, schools, and the institution as a whole. This senior professor's view, that such reward structures are "totally contradictive with contemplation," suggests that she views a contemplative approach to be more collaborative and authentic, and to implicitly express a systems view, which she has not found to be facilitated or even 
welcome in the HE setting. Next, I describe participants' views on how incentive structures that reward individualism and competition, and a focus on prestige, can be "totally contradictive with contemplation." 


\section{Commodification, in the service of institutional prestige concerns, can challenge contemplative approaches.}

Prestige and competition concerns inform priorities on institutional, organizational, and individual levels. Prestige and competition are in the service of financial viability or profit, for an HEI and for each of the individuals and sub-units within the institution.

A recent example involving perceived institutional prestige and competition serves to illustrate a hijacking of the concept of transformation, or the invocation of transformation but in a direction that many object to, by SEU's Board of Trustees. In recent years, the board made a particular decision in the direction of commodifying learning, such that (in their thinking) learning could be delivered in a way that leveraged profit and prestige, two drivers of higher ed praxis. Many objected that the methods they invoked toward commodifying learning were antithetical to the underlying mission of the university vis-à-vis students' learning and development. This represents a transformation on one level (the means of achieving success) within a system that Board members were, consciously or unconsciously, motivated to further entrench. This HEI's Board of Trustees, like most, is composed not of educators but of political appointees, many of whom have been successful in business; and while their business acumen may be an asset to the HEI, the assumptions and expertise that have served them in business must surely sway their perspective on the means and ends of education. This is an example of complexity reduction as exertion of power that leaves out values that others deem vital. The Board stated that their actions were in the service of "transforming" SEU. This use of 
the term "transformation" is perhaps accurate: they saw what they thought was a way to invoke new strategies in the interest of increasing prestige and the bottom line. There are reasons to be concerned that this could happen with contemplative praxis in higher education as well.

Along these lines, on the level of institutional praxis, I looked in my data for stakeholder concerns about, and actual evidence of, possible effects exerted on contemplative praxis by "academic materialism." Vokey $(2014$, p. 262) used this term to caution stakeholders in the broad movement for contemplative HE that practices and their results could be "commodified." He stated that academic capitalism-which he defines (p. 259) as referring to "entrepreneurial 'market or market-like' initiatives by universities and their faculties to obtain funding from external sources"- may set conditions in which some version of a "contemplative" pedagogical approach, a "contemplative" focus of research, or even a "contemplative" offering in the realm of service inside and outside the university, may be appropriated for its cultural and social capital. Further, this may well be more likely for contemplative practices that accept as a starting point - as an initial condition, in the language of complexity - the competitive individual, to support the neoliberal ideal of production and competition and rally contemplative resources of the kind that will continue to reinforce and reify the isolated individual.

Nine of my participants did express concerns about an HEI's stake in using and framing contemplative practices in commodified and instrumental ways, co-opting their more transformational potential. It was a former staff member who recommended Vokey's work to me, specifically in reference to what s/he perceived as the orientation of one or more CIC donors. 
Relatively few participants at SEU suggested strong concerns about this issue, but those who did had some insightful comments. Fred, professor of education, voiced concern that, despite the transformative potential of contemplative practices, they might be used to amplify the tendencies within an HEI to exert control and, as he said, "manage" resistance to stressful working conditions or objections to status quo institutional practices in general. When I asked Charles in an early interview whether this concern had come up in conversation at or about the CIC, he seemed unfamiliar with the concern. He responded that he thought it was always a good thing for students to become more able to self-regulate emotionally and cognitively. I do not disagree with his statement, but I find it significant that more nuanced concerns about this subject are not on the radar screens of many stakeholders in the setting. Rather than diminish my concern about the issue, this heightens my concern, because without ongoing and nuanced discussion about the means and ends of contemplative practices, proponents may collude in producing unintended results. I think it is very important that the conversation is happening on a national level, particular to higher education and far more generally as contemplative practices are used in a wide range of settings, in business and otherwise. I hope that stakeholders here join in, or at least listen in, on that conversation.

In addition to hearing these stakeholders' concerns about commodification of contemplative practices, I directly perceived evidence for the commodification of contemplative practices. SEU's VP for Development, Peter, told me that perhaps ninety percent of the controversy about CIC in its early stages was "either Board members who don't understand it and they see some sort of religious connotations with it, and others that would say, 'With all the [other priorities here], do we really need a Center for 
Investigating Contemplation?"” He went on to say, "My view of that is 'Anything that will place us among international leaders."” And, he added,

Fortune 500 company after company is now incorporating all of this mindful leadership, leadership presence, all of these things, stress reduction. I think they've moved beyond the religious piece, and getting the whole [research] to show, instead of just feeling better about themselves, I think the position is that it's a performance-enhancer. That that sells a lot better to a busy-especially a male - corporate CEO. If this is, 'Hey, I'm just doing this,' even though they might feel stressed in their home life, and they need to get kind of centered, you know, they can get away with it for the entire company if their position is 'data is showing that we'll have a better workforce and people ...' All of this is true, happens to be true.

\section{Prestige concerns may support a competitive approach among contemplative} initiatives.

Peter stated in describing the CIC, "We could—very quickly, with the right investments - be the finest in the country, or maybe the finest in the world. That's when we decided to pitch a Center for Investigating Contemplation that was the best in the world." It is very ironic, as some participants noted, that the CIC is presenting itself as the first, biggest, and best academic center focusing on contemplative sciences. One might expect a contemplative orientation to suggest a deep questioning of the competitive assumptions that drive academia. The CIC is indeed working to develop collaborations outside SEU. The fact remains, though, that the University has a vested interest in marketing the CIC in a way that enhances institutional prestige, and as an entity loosely coupled with that institution's priorities, the CIC must make efforts to discern and express its identity vis-à-vis competition and collaboration.

There is much evidence that the Center's director, and many of its stakeholders, are very interested in collaborations outside SEU. I described in Chapter Three the 
several occasions on which delegations from other learning institutions had been invited to visit and confer with the CIC. A CIC staff member told me that the Center has been looking into how it can partner with other programs and universities, "[B]ecause I think this knowledge should be shared knowledge. I don't think it's like a competition, you know. We want to be the most contemplative, the best. It's stupid—we should work with others." What is less clear is the degree to which the CIC feels a need to position itself as the best in order to be viable, and part of that question is whether it can work together with other entities in ways that share power equally. This staff member expressed an intention on behalf on the Center to make partnerships with a few "top universities," so as to "have a high standard," and then model that kind of partnership for other universities. The staff member has been researching "universities that are considered the healthiest, the greenest, to see what are they doing." This expresses the Center's desire for collaboration, and at the same time perhaps a rather exclusive framing about where value may be found for those partnerships. Moreover, there may be "models" for the CIC to follow, rather than consistently positioning itself as the model for others to follow. Otherwise, this approach to collaboration may perpetuate an elitist and top-down propensity that does not so easily challenge status quo conceptions about value, competition and prestige.

In contrast, Barbezat expresses a strong intention for ACMHE to engage with and support all kinds of HEIs, including community colleges. This intention expresses ACMHE's underlying concern for inclusivity in fostering a contemplative movement in higher education. Rather than collude with competition — and prestige — oriented HE practices, this inclusivity problematizes them. Some participants spoke eloquently to the 
ways in which collaborations can lead to emergence. A systems change consultant among my participants stated, "We have to think in networked ways, if we want social innovation and change to happen. [Otherwise] the world will move on without you. The competition model of institutions ... won't change the social fabric." This participant spoke explicitly from a complex systems viewpoint. "If you think fabric, you see the whole, and so you function differently, and folks get afraid, because they think either/or. That's not actually how things are."

From a complex systems perspective, capacity is needed to guide a system toward the fear that may precede emergence, so that diverse, connected, interdependent agents can learn adaptively together. Without such capacity or framework, people and groups may reduce complexity by adopting a binary mindset, which can support, competitive rather than collaborative practices.

\section{Philanthropy, academic capitalism, and contemplative praxis}

Moreover, the SEU's development office has an interest in appealing to current and future donors' desire to support a project that, as Peter said, "would be a gamechanger for the University or for something they care about." The institution has an incentive to "flesh out" a program that is "audacious and . . that would capture the donor's imagination." There is a dance involved in maintaining the institution's priorities and communicating honestly with donors, while also framing possible donor-institution partnerships in the most appealing terms possible. There is bound to be an effect on a donor-funded initiative to make choices that will keep that donor interested; some of 
these choices will be in tension with priorities of those responsible for designing and implementing the initiative.

Peter stated that his role is to perceive programs that he thinks have big upsides, and implies that part of the upside is a satisfied benefactor, who will continue to fund not just the particular project in question, but also other University projects in the future. In the case of the CIC's initial donor, the amount he has given or even will give over time to the $\mathrm{CIC}$ will be, theoretically, a small percentage in terms of his overall potential for donation to SEU. Therefore, everyone involved in a project involving donors-including not only development and administration professionals and the university's president, but also direct stakeholders in the project itself - treats donors with deference, respect, attention, and consultation.

Academic capitalism may promote the tendency to capitulate to whatever funding source is available, whether or not the funder is qualified to influence the agenda - no matter, in fact, what the donors' personal agendas or motivations are, which can include, Peter told me, agendas extraneous to the mission of an HEI. Claire suggests that "reputational factors"- how the initiative they are funding is perceived by peers, etc.may influence a donor's decisions about giving, as may a donor's self interest in related business endeavors.

Daniels has expressed strong interest in paying for a building for the CIC. In addition to what former Dean James called a "brouhaha" over a possible location for a building, and what its location could signify about its prestige in the context of SEU, not all CIC stakeholders concur that a building is a priority for the CIC at this time. As I will 
discuss later, vis-a-vis CIC's organizational praxis, this issue is indicative of, and pertinent to, the ongoing question of how HEI decisions are made, by whom, based on what motivations, about a Center's priorities and trajectory.

There is a wide range of perspectives among stakeholders on whether a building is necessary. Nathan, who has extensive experience in SEU infrastructure development and has been very engaged in the planning process for a potential CIC building, asserts that it will be vital for the CIC to have its own location. Among other reasons for this, he says, the university's intramural recreation unit has been lending space for CIC activities in an arrangement that would be unsustainable in the long term. Lisa said that a building would be a very positive focal point for the CIC's presence on the campus. Others say that if a building is what a donor wants to fund, the Center should not refuse it. One stakeholder told me, however, that "There is so much wasted space at this university," and that for the cost of a building, much more interesting results could come from investing in a range and initiatives across the campus. Funding many small (i.e. million dollar) research initiatives, he said, could be a far more generative use of money at this point in the CIC's development. In terms of the important question of whether a building would create more synergy or not, some stakeholders say that cross-disciplinary work may best happen by sharing extant (i.e. technological) resources innovatively, rather than by convening the work of the Center in its own separate building.

These varying perspectives illustrate again these recurring issues about university and center governance: Who decides what the priorities are? How do donors and the CIC - meaning, at this point, the director and associate director-negotiate to determine 
CIC priorities? How, if at all, do or should other CIC stakeholders take part in this discussion, negotiation, and decision making?

Daniels is not an academic, researcher or otherwise. What might he know, or think he knows, about the needs of faculty in working and researching together? A stakeholder told me that Daniels had stated that he was personally uninterested in research. He understands the need to do research on the K12 initiative he is helping fund, but his focus is not on that research, but on his desire that his financial support can make U.S. K12 schools better. This is not to say his insights are not valuable to designing an intervention, but it is to say his expertise is not in understanding issues related to research, or other academic endeavors.

Correlatively, it is important to keep in mind that not being "an academic" can provide a donor with insight that can be invaluable to an initiative inside of academia. Donors may be unconstrained by academics' blinders about what is possible or preferable, and bring into the conversation a broader context outside the ivory tower. As I will discuss later, the issue here is how to include diverse perspectives in a dynamic and ongoing conversation, which looks for synergy and guides emergence of deeply adaptive and novel outcomes. My study has sensitized me to concerns that power dynamics in donor relationships with institutions and initiatives within them can potentially amplify some feedback loops, reinforcing a donor's sense of expertise in arenas he or she has no reason to be expert in. These power dynamics can short-circuit feedback from a wider range of an initiative's stakeholders, amplifying rather than reducing complexity toward a goal of more adaptive, inclusive, and generative outcomes. 
There may be consequences of ignoring or understating (reducing) the complexity that is actually driving decisions in philanthropy-driven projects. $\mathrm{J}$. McCrea and J. Walker (2013) illuminate some of the motivations philanthropists bring to projects, including relational resonance in addition to concern for a cause. Other motivations may not be as generative as these. Some motivations about giving or not giving could rely on influences in a larger system, and may be important to understand explicitly. A stakeholder speculated that Daniels, having made some public, negative statements about University President McArthur may_even though he has apologized for those statements - be "standing a little more on the sidelines, instead of giving 100 million, giving smaller amounts of money" following his public apology. To ignore or suppress communication about these motivations can reduce complexity in the system; it may be important to keep asking how doing so may exert power, and what interests are served in doing so. The concomitant question is: Are possibilities for transformation suppressed in the process, and what capacities may the system need to cultivate in order to contend with complex dynamics, to engage in a more emergent process?

I heard from psychologist Joseph that, as the only scientist in the Planning Group, it was challenging for him to relate with what he considered to be in many cases religious perspectives couched as scientific ideas. As I noted in Chapter Three, in fall 2013 CIC donors brought a medical doctor who has authored many spiritually oriented books to SEU to host a CIC event heavily geared toward fundraising. The participation of this author, who is very well known among people interested in alternative and contemplative approaches to health and wellbeing, could be seen in part as his endorsement, as a scientist, of the CIC's commitment to integrating sciences with humanities, as well as 
building relationships between theorists and practitioners of contemplation. However, Joseph asserted that 95 percent of scientists do not consider this person to be a legitimate scientist. Joseph's research focuses on relationality, and specifically on how what we think of as our "self" includes the resources we feel we can depend on from others. Joseph says that this guest speaker and others perceive in his research a "spiritual" dimension, and it is important to Joseph that he maintains his intellectual integrity and resist such ascriptions. This is an interesting edge for the CIC, as donors will most likely not be scientists themselves, and may in fact tend to lean in a direction that someone like Joseph and other academics would consider unscientific, and yet there may be a press among CIC donors over time for scientific research to explore and even perhaps validate their a priori theories.

In a different vein, I asked someone influential in decision making for the CIC whether donors might be willing to fund initiatives that focus on race issues or gender violence at SEU, both issues having been raised over into the national spotlight over the 2014-2015 academic year. The response indicated that because the great majority of CIC donors are not only SEU alumni, but from the fraternity and sorority system, and that if the CIC were to

start getting too much into particulars [about the barriers to "wellness" in student culture], then you start getting involved in political disputes. ... What I'm seeing is more [generic] interest from donors about student wellness, student resiliency, [among donors who] may have very different opinions about why [students and campus culture] are not well.

This view may misjudge potential interest on the part of some donors, but this participant's caution indicated to me an unwillingness to press an idea that may seem controversial to some donors. 


\section{Incentive structures can challenge contemplative approaches: structural barriers to working outside silos.}

A prominent SEU education professor, an expert in the field of research on higher education, asserted (personal communication, 3/28/13) that universities are structured in such a way as to make cross- or inter- disciplinary communication and collaboration difficult, particularly toward bringing together humanities and sciences. Reward systems for faculty, resource allocation, and long-standing practices discourage collaboration, lean heavily toward siloed departments, and limit innovations across and even within disciplines. Research and teaching that crosses disciplines is still a rare exception at colleges and universities.

Work on behalf of a Center outside one's department is frequently not supported, and may be penalized, in essence, within current incentive structures in higher education. Working toward tenure is the overwhelming priority for newer academics, which in turn trains and embeds one in a culture that takes individualism, competition, and traditional areas of study as the norm.

Lisa told me that she felt she had not been given sufficient credit on her first departmental performance review for all her contributions of time and energy to CIC projects. She said that looking back on how she had reported her service to the CIC, she realized she should have framed her service as to her school and to the University itself, rather than to a center per se.

Joseph said he thoroughly enjoyed co-teaching a course on Buddhist meditation with Charles and Chris from Tibetan Studies. The students' experience was likely 
enriched by the perspective he contributed as a psychologist, and he and his colleagues were themselves intellectually stimulated by the joint endeavor. However, Joseph said he would not consider doing this again, assuming that it would not replace any of his obligations to his own department, which was not tangibly benefitting from his engagement in that CIC-related project. Paradoxically, though, Joseph said that when he at one point resigned from the CIC Planning Group, as it was unclear to him that his minimal participation was of any value to the CIC, he was immediately and strongly chastened by his department head for resigning. Joseph inferred from this experience that the CIC was an important initiative for SEU, that his presence on the Planning Group was a value for the CIC, and thus a value to SEU. His department head, I assume, was pressed to press Joseph to step back onto the Planning Group, despite the fact that he could not offer to lessen Joseph's departmental obligations in exchange for time he committed to the CIC.

\section{HE praxis can support collaboration.}

In spite of the previously mentioned obstacles, there are signs of change within many levels of university leadership. In addition to broadening the scope of knowledge with new and alternative approaches, many universities, including this one, have sought to promote interdisciplinary work and collaboration.

Three stakeholders had expressed concerns that the new, not yet fully implemented protocol of Responsibility Centered Management (RCM), which makes schools and departments responsible for funding their own budget, may have a chilling effect on the de-siloing, interdisciplinary work to which the CIC speaks strongly in its 
mission statement. However, Megan, who oversees (in what she says is a very hands-off way) the CIC from the Provost's office, minimized this concern and offered encouraging remarks. When I asked her about institutional barriers to cross-disciplinary collaboration, she stressed that those overseeing HE praxis at SEU were open to interdisciplinary approaches, and that there were not in fact major obstacles at SEU to such exploration.

The Dean of the School of Education said that he knows some people think that the Responsibility Centered model will "ultimately lead to the demise of things like a CIC," that count on cooperation across units, since they assume that RCM reinforces a lack of cooperation. With the caveat that, not having experienced the RCM system yet, he cannot be sure, he said, "I don't really buy that." He continued to say that what RCM

will enable us to do if we get it right is to have a very clear set of rules for how money flows, and how transactions are conducted, and once those rules are in place, then it's a matter of seeing what we want to do." It gives the deans and the faculty that work with them the capacity to act more nimbly and on their own, rather than have to wait for manna from heaven or a donor or something like that. So I would hope that it would enable us to take more control over our destiny, rather than be more passive.

The Dean's statement reinforces the hopeful idea that if a grant funder or a donor is interested in a cross-disciplinary project, two or more schools or departments can benefit from working innovatively together. Such collaboration has certainly been a stated priority of the CS since its inception. He said that he perceived the CIC as “inherently, deeply interdisciplinary," and that from his perspective as Dean and faculty member, "any effort at this university that can catalyze multiple interests across schools, and activate those interests in the service of a larger intellectual frame, an agenda, is a huge win [laughs]." He went on to call the CIC "a proof point of what a catalyzing agent 
can be and do in the context of the University. There aren't a lot of examples of that in my time here. Virtually none."

\section{CIC's roles in promoting interdisciplinary collaboration}

The CIC's mission statement strongly asserts the value of interdisciplinary partnership, and the Center's intention to support such partnership. The CIC was structured since the beginning to represent and, to some degree facilitate, interdisciplinary partnership. In its first several months of formation, and perhaps longer, generative conversations occurred among the several stakeholders, representing at least four of SEU's schools, as they worked under Charles' leadership to craft an initial plan in response to the initial donor's request for a proposal. My sense is that the idea of future collaborations was genuinely inspiring and appealing for these key stakeholders, particularly in the context of the seeming likelihood of significant funding, beyond the initial gift. This initial group of five or so key stakeholders soon expanded into a Planning Group, composed of 15 to 20 representatives from many of SEU's 11 schools who have come to know more about each other, and each others' schools, over three or four years of meeting together.

However, as time went on, funding for anything beyond the CIC's very lean staffing became available only for specific projects - the online Contemplative University, the Student Initiative at SEU, which now has two full-time staff, the Compassion in the Schools initiative in another state, and a far more modest initiative in a school system local to SEU. Charles has been suggesting all along to interested stakeholders that they find ways to collaborate across disciplines, and find funding for 
these collaborations, but the Center itself is not equipped to facilitate these collaborations or their funding. The Center has only given research grants for one funding cycle. These were small grants, up to $\$ 15,000$. A key stakeholder expressed disappointment that there was not follow-through — i.e. a research fair, or website exposure — by the CIC in facilitating the funded researchers in sharing the results of their CIC-funded research with interested others.

I know of only one major interdisciplinary project that has arisen under the auspices of the CIC. This project is still in planning stages, and has presented challenges related directly to the stated mission of the CIC. The project requires a clinical psychologist and a humanist to construct a contemplative intervention together in a medical setting, designed to explore whether that intervention is shown to affect health and wellbeing in a small sample of study participants with a particular chronic illness. It has apparently been hard for these partners to agree on the contemplative intervention. Their views of the project's priorities differ, and there are power dynamics involved in who will get to make the final decisions. Without going into issues which may be confidential, I offer the insight that this case demonstrates many of the actual challenges that will confront interdisciplinary project teams in the process of fulfilling the CIC's mission. There should be study and documenting of these processes-communication, design, decision-making - in themselves, as on an overarching level, to be successful, the work of the CIC must include learning how to engage productively in these challenging dynamics. This is another arena where a complexity view is helpful, to look at how difference, connections, interdependencies, and adaptive learning can lead to emergence of novel possibilities, or how complexity is reduced (for example, by the partner with 
more institutionally or organizationally endowed power simply trumping the viewpoint of another partner).

Stakeholders described some ideas they had about what might promote collaborations across disciplines on contemplative subjects. Sarah suggested that the CIC help facilitate the coalescence of small interdisciplinary pods to discuss shared interests related to contemplative praxis, from a range of perspectives. She suggested that one or more pod could form around the question: How might contemplative praxis inform social justice action and learning at SEU? Similarly, Howard offered the possibility that the CIC could develop research incubators, the purposes of which could vary, but which could use highly reflective methods to track their collective learning on multiple dimensions, i.e. their learning about their own group process and the effects that contemplative approaches might have on that group process.

On the level of SEU's infrastructure supporting CIC's interdisciplinary aspirations, a member of the Planning Circle is the director of Arts and Media Services for SEU's Library. She is described on the CIC website as having extensive experience in developing media collections and services, and in supporting innovative uses of educational technology for teaching and learning. She described her interest in understanding and working with the CIC from its beginnings, as the University's library system crosses disciplines and could provide support for the CIC's endeavors to develop interdisciplinary and innovative resources.

In terms of teaching collaborations, CIC stakeholders have co-taught a few crossdisciplinary courses together, and my participants told me about some of the positive 
outcomes they experienced, as well as describing some deterrents they had encountered. As an example, on a small scale, of pedagogical collaboration independent of donor funding, Sarah invited Jeffrey into the Nursing School to co-teach a course with her, a version of a course he had been teaching through the Fitness and Recreation Department. Their course was open to students from all over campus, far beyond the Nursing School, and the Nursing School was financially credited for their enrollment.

\section{Internalization of HE constraints by individuals.}

As important as the institutional incentives and disincentives in HE praxis is the fact that individuals and collectives within an HE setting internalize HE constraints and assumptions. In academia, one's sense of identity may be conflated with a need to be expert, and to keep a competitive advantage, whether on an individual or institutional level. Over-focus on the competitive identity can be a "shadow" issue, which when queried with awareness may produce wisdom, but when accepted as a given may amplify the capacities of individuals (and collectives) to focus awareness-volition and intention—on reproducing and reinforcing their own privilege, experienced as survival within the HE context. Many academics will simply not find appealing the opportunity or idea of putting time and attention into pursuits that seem unrelated to the institutionally sanctioned demands on their time and focus.

Tenured professors may be freer on a logistical level to spend time exploring interests not limited to their own departments. This may be more difficult for newer professors. An interesting slant on this was suggested to me by the Center's first associate director. He said that contemplative orientations may shift professors' priorities such that 
they lose interest in the highly competitive and individualistic norms of academia. This may be a riskier shift for younger, newer professors. To extend this perception, this expresses a tension that can be quite strong between the more holistic orientation that contemplative approaches may cultivate, and the perceived need in academia to maintain not only a sharply discursive but a critical stance, often focusing on binaries. Vying for competitiveness advantage as to who can do all that best, can only exacerbate these biases toward the cognitive and individualistic. Joseph said that right as he gained tenure, he had children, and unexpectedly found himself wanting to spend as much time as he could with his family, a trend which still continues. He said in many people's eyes this makes him a "bad academic," and is certainly a point of tension for him professionally. Conversely, Charles said when one is driven (as a "good academic," one supposes) by intellectual passion, he or she will give up some otherwise valuable things, like a marriage.

In this context, even "contemplative" methods can be focused on honing particular powers of attention and resilience for the decontextualized individual, leaving unaddressed some underlying assumptions of HE praxis. This reduces complexity and keeps in place current power dynamics, at the expense of not only a more transformative personal experience, but also ignoring a collective need for more wholeness.

Paul described realizing that his practice of "simple sitting meditation," which he had first thought of as mental hygiene, was actually "just another kind of cognitive approach, a kind of locked-in syndrome," even though he began the practice in part to "get out of being in a prison of the mind." He said, "inevitably when you first start making the alternative to the prison, you make another prison, so it was a long process of 
just kind of letting go of that complete reliance on kind of cognitive knowing, or intellectual knowing, and see that there were other kinds of knowing." He said that what he became aware of over time was that his approach to meditating was one of control, of wanting to do it right. "I had some idea of that as, if I do it right, then I'm in total control." In becoming aware of that, he says, he realized "that really wasn't what it was about."

In Paul's realization over time that he was bringing to contemplative practice his habit of seeking control, by cognitive means, I heard him expressing both the dangers of entrenchment of that habit, and the possibilities of transformation inherent in contemplative praxis. His capacity to bring awareness to the limiting effects of his habit of control opened new vistas in his conception of what contemplative praxis (a term he may not use himself) can be. Yet, Paul's habit of controlling through cognition (a means of complexity reduction) did not arise because he meditated; rather, by bringing awareness to his self-as-living-system, he disturbed the structures, patterns, habits, therein. Somehow, his awareness scaffolded a process of emergence, in which the dissonances between his habitual way of being and his motivations for change were amplified, and the ensuing discomfort helped motivate him toward a new way of experiencing himself.

Even if one goes beyond using contemplative practices to reinforce a privileging of the cognitive, concerns may remain with privileging focus on the individual and concomitant unawareness of systemic issues and one's complicity in them. Students as well as others in an HE setting are conditioned to compete and over-focus on their success as individuals. The section below addresses this issue, and the value for students 
of having the opportunity to relate meaningfully with others, in the service of dismantling dysfunctional systemic patterns.

\section{Student culture has internalized problematic HE culture; some contemplative responses.}

Nine stakeholders who represented diverse roles at SEU expressed strong concerns about the effects on students of the highly competitive culture at SEU. Professors and other professionals in the setting described observed dysfunctional coping mechanisms, which they described as antithetical to healthy relationality among students.

In teaching a January-term course on conscious social change, Audrey found students deeply concerned with the stresses of a competitive campus culture, and the mental health challenges that ensued or were exacerbated by this culture. Audrey's response has been to bring the range of contemplative practices-including somatic and relational practices that complement mindfulness practices that she uses in her social change work with women and girls in Africa-into her work with SEU students. Moreover, she seeks to empower them to become change agents, honing the wisdom gained through their personal experience, empathy for peers in similar struggles, and an increased understanding of systemic issues. Audrey wants to help students form connections and discover interdependencies with each other. She asserts that this will incorporate a more diverse range of inputs into change processes, setting stronger conditions for emergence. This aligns with her long experience that systems can be transformed by facilitating those who have suffered in a system to help inform and guide the work that needs to be done to change that system. She says this counteracts tendencies on the part of "helpers" to work in a top-down manner, instead of learning 
from the expertise of those who have been living and working for change within that setting. The former superimposes a solution from outside, which inadvertently reduces complexity. In her work at SEU, she extrapolates these lessons learned in international settings to the empowerment needs of college students. Audrey's work was with students in general, and though race and other issues of marginalization were part of her conversations with them, others on campus are working particularly with these issues, in ways that some of them explicitly call contemplative.

Paul has been involved in a faculty Sustained Dialogue group for many years, and has recently joined students as a faculty advisor in bringing an intensive, retreat-based version of Sustained Dialogue, called PULSE, into SEU's student culture. The Sustained Dialogue Institute website (www.sustaineddialogue.org) states that Sustained Dialogue "helps people to transform conflictual relationships and design change processes around the world. We define dialogue as 'listening deeply enough to be changed by what you learn." Sustained Dialogue (SD) is a student-run organization through which students meet weekly for a semester in small ongoing groups, and are led by a trained peer facilitator in conversations about their lives, interests, and backgrounds. The intention is to connect students across differences and provide a structure in which they can come to know and understand students with whom they might otherwise not engage. Through my participant-observation in settings where Sustained Dialogue members were facilitating campus gatherings on race-related issues, and from hearing two of my study participants' descriptions of their experience of Sustained Dialogue and related initiatives, I came to see such initiatives as implicitly contemplative approaches, intended 
to deepen participants' ability to engage productively in dialogue about inequity and unconscious privilege.

The PULSE program is described (www.sustaineddialogue.org) as "a new model of retreat + continued conversation." The website states that at a PULSE retreat, "students will: form deep relationships across silos; cultivate better decision-making skills; practice empathy and mindfulness; develop traits of authentic leadership, and tackle the biggest challenges of a global 21st century." Paul told me that students articulated that the competitiveness in the HE culture at SEU is antithetical to connection and mutual support, and contributes to a culture of marginalization vis-a-vis race. This last is in part, he said, because students try to "stand out," rather than to "stand with" each other. Paul was very impressed, he said, by how the PULSE approach relies on firstperson (self awareness) and second-person (relational practices that evoke empathy and compassion) experiences to precipitate participants into an understanding of systemic oppressions. Rather than didactic methods of teaching about these power imbalances, the PULSE approach facilitates the emergence of "systems thinking" — and caring to become agents of change - over the course of an intensive weekend, and then regular meetings, through experiences that guide students to relate to others with different backgrounds.

Four of my participants, including the two CIC program directors for learning, and Paul, said that explicitly contemplative approaches like body-based awareness practices can help leverage the transformative orientation that Sustained Dialogue and PULSE make available. The CIC staff members have been consulted by SD and PULSE members to help them hone the dialogue experiences that they provide to fellow students. The CIC staff members and, Paul, and a PULSE participant asserted that the combination 
of skillfully designed and facilitated dialogue and these explicitly contemplative practices help cultivate awareness and compassion, expand the sense of self, of what constitutes knowledge, and of what knowledge is for. Rose described her interest in bringing, and even paying, students trained as PULSE facilitators into CIC sponsored contemplative retreats for students, such as one-day retreats or a recent five-day residential retreat held over spring break, provided free of charge to students. She said that the silence, contemplative practices, and reflection intrinsic to such retreats would be meaningfully complemented by opportunities for students to engage — guided by peer facilitators — with issues such as difference and marginalization that are alive and pressing in the HEI context.

The "real world" is not just outside the university campus, but it is also the community that inhabits that campus. Practices that proactively explore and attend to social and environmental realities on campus can be a vital part of students' education. One African American male student who was just about to graduate told me that his experience of SEU had changed dramatically after he joined Sustained Dialogue in his junior year. He asserted that if the University community pressed for Sustained Dialogue participation, and somehow enhanced the prestige of such participation such that fraternity members, for example, were interested in joining, that the "whole culture" of SEU would "be transformed."

\section{Systemic Inequity, Student Culture, and the CIC}

The day after her keynote at the Mind and Life Institute's fall 2014 preeconference, in which she had stressed the necessary-but-not-sufficient importance of 
contemplative practice per se in effecting social change, Petty was in the audience when six members of the CIC's Planning Group presented an open panel session to describe the emergence of the CIC. Charles had introduced the session by stating that panel members would discuss the CIC's priorities across "five topics." He said the conversation would address, "learning and teaching, then research, then internal cultural change, and then address[ing] questions about moving across the boundaries from the Nursing School to the Education School to the Religious Studies Department, ... and finally end up with issues of external engagement."

Charles had not mentioned issues related to equity in his discussion of "internal cultural change" at SEU, and the example he had given of "external engagement" was a potential project in a remote, rural part of the state, offering mindfulness practices to African American males with AIDS living in poverty. Petty prefaced her question by stating her discomfort in raising it, but she wondered whether there were any social issues on SEU's campus, closer to home than this remote location, that could use the attention of the CIC. She was suggesting that to explore dysfunction in one's own setting would be a healthy challenge, involving the need to examine dynamics of unconscious privilege.

The "uncomfortable" concept raised by Petty—-that unconscious privilege plays a pivotal role in perpetuating systemic oppression - is not one I have heard Charles speak to directly. A former staff member at the CIC said he had not once heard "race" mentioned, although his job description included addressing needs in SEU's student culture. When I asked Charles whether he thought the CIC might develop an initiative to bring contemplative approaches to bear in cultural change at SEU, he responded, in part, by saying, "All students are suffering." I conveyed that response to Howard, who said 
that his own personal and professional focus on "engaging difference" sensitizes him to hear such responses as insufficiently aware of the marginalizing effects of race, similar to saying, "I don't see color." Another CIC leader, who had been present when Petty raised her concern, said afterward, "She seemed upset, so maybe this is just a personal issue for her." This is a way of reducing complexity, and may speak to a lack of full capacity on the part of CIC personnel and even most CIC stakeholders to see, disturb, and guide complexity that explicitly includes race and other systemically marginalizing dynamics.

In fact, I spoke with two participants who were key stakeholders in the CIC, and were very interested in bringing contemplative approaches into discussions of race on campus. They said they were concerned not to rely on the CIC to engage these issues effectively. Sarah said she thought that such an initiative would be better if not coordinated by the CIC, as it could be more "collaborative" than work she anticipated the CIC doing. Diane said she had voiced concerns in a Planning Group meeting, saying that the language and tone the $\mathrm{CIC}$ was tending to take in discussions about bringing contemplative practices into student life were likely to perpetuate the idea that contemplation is for white, elite individuals rather than for diverse stakeholders. Moreover, she felt that the implicit valuing of "therapeutic" aspects of contemplative practice could reinforce the tendency to ignore systemic issues such as racism, looking for the cause of students' distress of the level of the individual psyche. This aligns with Vokey's (2014) concern that contemplative praxis may be used to perpetuate what he calls "the individualistic bias," decontextualizing the individual and her/his problems from "inequitable economic, political, and social relationships (e.g. racism) as if they were simply [the fault of the individual]." 
Complex systems, such as the culture in a particular HE setting, comprise diverse, connected, interdependent agents who learn adaptively together. To explore the interdependency aspect of complexity, in terms of over-individualizing, competitive, and in many ways inequitable social systems, contemplative efforts bring awareness to the ways in which privileges and oppressions are mutually reinforcing - that is, interdependent. Especially to the degree that we have practices that support us in staying present to ourselves and with others while doing so, becoming aware of the experience of others from their different positions within the web of interdependence may help students and other in an HE setting cultivate empathy and compassion. Simultaneously cultivating capacities to see "systems," and one's roles in them, can help develop agents of change.

Next, I describe and analyze some aspects of HE praxis that are conducive to or resonant with contemplative orientations.

\section{Assets of HE Praxis Which Can Support Contemplative Praxis}

There are significant strengths in an HE setting which can be conducive to contemplative approaches to learning and to engaging. In recent decades, particularly through the rise of postmodernist, feminist, and critical race theory, academia has been unsettled in its long-held assumptions about what knowledge is, who has knowledge, how it is produced, accessed, and conveyed, and - particularly cogent in exposing and resisting long-standing inequities and marginalizations - in whose interests knowledge is framed as legitimate. These lenses illuminate complexity and the ways in which social institutions, very much including higher education praxis, tend to reduce complexity as 
they reproduce social hierarchies of power. These lenses implicitly provide a complex systems view, highlighting the dynamics through which diversity, connectedness, interdependence, and adaptive learning are, and are not, engaged productively in social institutions.

James, professor and founding Dean of SEU's School for Leadership, makes an explicit connection between contemplative approaches and shifts toward postmodernist approaches:

[T] he postmodern reaction to ... reductionist positivist approaches in the social sciences and in international politics in general, and of course ... the more philosophical aspects, are ... far more holistic. It's not so reductionist. Contemplation and appreciation are basically far more intuitive and far less positivist.

He said that when Arianna Huffington had been brought in by the CIC in 2013, he was impressed by hearing her say something to the effect of, "We are on the verge of an intellectual revolution [in the West]." He continued by asserting his thoughts that the

Standard modern approaches—positivist, scientist, reductionist—are useful, but they ... have far more flaws and shortcomings than advocates often acknowledge. And this alternative approach, whatever you call it—contemplative practices, or you can say Buddhist epistemology, or Buddhist ontological thinking - all of this is the kind of a source of some of the counter-trend that you're seeing in the social sciences.

He said he doubted there is "any direct connection [or causal link] between this kind of postmodern approach to the social sciences [and] Buddhism and contemplation and meditation." Nonetheless, "The parallels are really, really, really striking." He went on to say that the commonality is that these are holistic; "[T]he term of art is "mutually constituative,"' and that is a holistic approach. Buddhist ontology and epistemology offer insights resonant with both the "postmodern approach to the social sciences" that James 
invokes above, and to a complexity lens. All assert contingency and relationality as the substrate of reality, and suggest that the ways we approach, understand, and guide relationships must be highly reflective rather than simply objectifying.

Systems thinking is vital to critical pedagogy. Contemplative practices are being invoked to deepen and support such pedagogy for producing agents of change. Contemplative approaches are being centered in anti-oppression pedagogy (Berila, 2016; Magee, 2015, and ACMHE website). The use of these practices in the service of unsettling power dynamics entrenched in and perpetuated by much higher education praxis is a direct response to concerns that contemplative practices may be used to mollify students (and others) in the setting.

A Teach-In on Race was held at SEU in Spring 2015, convened by students and faculty and featuring a panel of nine SEU professors. This effort, and the effort these professors make daily in their work with students, was a demonstration of the press possible within academia to reframe values and priorities to illuminate power structures and empower more inclusive responses. These professors used their teaching, most of them through the arts and humanities, to scaffold not only their students' understanding of problematic dynamics within systems, but help them cultivate capacities to disturb systems, and to guide those systems through chaos to emerge creative responses.

\section{Cultivating contemplative leadership and agency}

I was struck by some participants' — especially those in leadership positionsdescription of working with consultants or coaches as pivotal to their self-awareness and their capacities to engage generatively in their professional settings. Either explicitly or 
implicitly, these were descriptions of contemplative practice. One participant said that when he became Dean of SEU's School of Education he retained an executive coach who supported him in own feeling that becoming a Dean "was essentially a developmental exercise for [him]." This coach's "sense of leadership is one that is very much embodied and part of the presence that a person establishes." To help cultivate this embodied presence, the coach encouraged the use of a variety of contemplative practices.

Richard said that for him, contemplation refers to

A set of practices and a state - the practices help enable a state of presence, and awareness - of heightened presence and awareness, and a capacity to be fully present in the moment. And that's it [laughs]. Stop there.

Mary: What is being present for? What is the value in it?

Richard: Its value is to in some sense expand the consciousness that's available in the moment [laughs] in whatever transaction's in play.

Mary: And when you say 'consciousness'?

Richard: In some sense the full resources of a person - the full psychological and personal resources of the person - to engage.

Nursing Dean Barbara asserted that contemplative practices called for selfawareness and, synergistically, for applying one's growing self-awareness to "shift[ing] systems" in work and service contexts.

When I experienced personally mindfulness meditation and reflection, ... I realized ... that this was a very powerful tool: meditation, mindfulness, paying attention, looking at how the brain impacts our behavior, looking at how we change ourselves, and I decided that this should be a signature of the Southeast University. 
Barbara's described her experience with contemplative practice, through her participation in the Zen-based program on compassionate end-of-life care she attended and sent colleagues to, and through the input from the leadership development experts, whom she brought to SEU to conduct workshops on inner and outer change agency.

[This] model for how to change yourself [requires one] not just to say, 'Oh, I'll meditate.' It has to be for solving the world's problems, and the first thing is you have to understand yourself deeply and then look at how do you shift the systems that are the barriers to solve problems. So is this incredible model, and I will tell you that [as Dean] I probably am putting it into practice every single day.

Barbara said she is "very humbled" by the successes of her tenureship, including those of the Care for All Initiative, and is very aware of the value of her collaborations with donors, and colleagues at SEU and beyond. She stated emphatically, "Now, I didn't do it on my own." But she also stated,

I'm very cognizant of two of the powers that a leader can have to make things happen. Because what you pay attention to gets noticed by others. So, I made it a signature of my deanship, and where I want the school to go, to say this (mindfulness practices for personal and systemic change) could be a unique feature of our school, and I watched people resonate.

Paul described a pivotal experience he had undergone, over the course of some extended work with consultants brought in to help SEU's library system employees develop leadership skills. He said he was guided, through extensive self reflection, to understand that he held disempowering assumptions about his agency in relation to institutional practices. In order to be an agent of change, he learned that he needed to shift his perception of a monolithic institution, and himself as wholly resistant or acquiescent; neither of which expressed his full agency. He became aware in this process that he could choose to see the institution as made up of many agents with varied interests, including 
himself and his interests. In that context, he could find potential allies with whom to negotiate productively. He described this process as one of finding a deeper integrity within himself and in his relationship to power dynamics in the institution.

These examples portray what I call a contemplative approach to HE praxis, in which agents purposely cultivate awareness of their own (first-person) assumptions, which are often unconscious, about the limits of their ability to produce (sometimes even transformative) change in a HE institutional setting. These approaches invoke, implicitly and sometimes explicitly, a systems view, in which awareness disturbs habits, intrapersonally and institutionally. Moreover, the consulting and coaching interventions described above hinge on the cultivation of capacities - in individuals and teams - to bring such disturbance through chaos and into a state of emergence, wherein new ideas can be engendered and enacted.

One of the most effective actions by a school dean at SEU can be seen in the work of the Dean of the Nursing School. Over the first few years of her deanship, which began in 2008, Dean of Nursing, Barbara, had brought in two outside experts to offer a series of seven workshops, free to anyone at SEU and beyond. The workshops focused on how personal and structural transformation are mutually informative, and that working toward self-understanding is primary to affecting change in the world. Moreover, such inner work should be used toward this outer effectiveness, rather than simply for personal fulfillment.

In addition, Dean Barbara has sent over 60 people to Being With Dying, which Sarah says is "Very heavy contemplative sciences, contemplative pedagogy, and deeply 
interpersonal." The weeklong intensive residential workshop requires, according to Sarah, "Going deep into the well of one's self." With donor backing, Barbara has sent, from within the extended SEU community, social workers, psychologists, and doctors. “[Only] about half of [those she's sent] are from the Nursing School,' said Sarah,

"Because [Barbara] believes—-this is, I think, pretty brilliant how she's done it—she believes in inter-professional" development and collaboration.

She also believes that the way we're going to make a difference is by us reaching out and for them to know what we're doing. It's all about culture change. You can't achieve culture change by doing it in your own discipline. You have to do it by basically educating the entire community and getting their buy-in.

Barbara's efforts, in bringing people together for deep learning both at SEU and at the Upaya Zen Center, evince an understanding of systemic change. She is convening diverse stakeholders from all over campus to forge connections and interdependencies through which they may join forces in some way to generate innovative ideas or projects over time. Moreover, the contemplative basis for both trainings amplifies the likelihood of cultivating first, second and third person (systems thinking) capacities.

\section{Integrating differences across disciplines, for transformation and empowerment.}

An intriguing project that invoked interdisciplinarity and complexity thinking in (and beyond) academia has taken place over recent years at Southeast University. In their article, "Complex Systems, Interdisciplinary Collaboration, and Institutional Renewal,“ authors Plank, Feldon, Sherman, and Elliot (2011) described the need and potential for significant interdisciplinary and cross-sectoral collaboration within and beyond academia, to address complex problems in the real world. They asserted that such real-world 
problems - in this case issues of sustainability involving the Chesapeake Bay watershed - are complex systems, and best addressed as such. A mono-disciplinary approach might prioritize biological factors, economic pressures, socio-cultural, or political dynamics. In fact, all these lenses provide important information for analysis, but in order to gain insight toward wiser action, collaborative work is required that can meaningfully take into account multiple arenas of expertise and, also importantly, the perspectives, insights and needs of multiple stakeholders beyond the walls of academia.

Plank et al. described the process through which they developed the SEU Bay Game, through which participants learn about the Chesapeake Bay system-but at least as importantly, about more general dynamics involved in complex systems. Students and others benefit from the challenge to their assumptions that the world, and learning about the world, is graspable through linear processes. Assumptions about predictability gives way to the necessity of, and opportunity for, generative and exciting collaborations, not only across silos within the university, but with those directly affected by, managing policy for, or advocating in the Chesapeake Bay setting. The unpredictability inherent in complex systems requires a nuanced approach to engagement, and what the authors called "innovative collaboration among different combinations of social groups, rather than top-down policy enforcement or unconnected individual actions working from the bottom up."

The authors described the years-long evolution of their collaboration as "an analog to the complex system that it is intent on modeling." [Italics added.] Experts in several fields, student researchers, and interested parties outside the academy joined 
forces to "[b]uild . . . a model of a complex socio-ecological system as a shared tool."

This process required

... translation and knowledge transfer: among faculty experts, between developers and users, between researchers and practitioners. These interactions accelerate innovative thinking because they force the re-examination of assumptions and prompt provocative questions. They also build community within and beyond the university, because they involve all the stakeholders in solving important regional problems, with national and global implications.

The authors said that their experience of collaborating in the SEU Bay Game project emphasized the potential of large research universities as sites for translational research (beyond its general usage in commercialization projects) to address complex social problems. They see universities as less hindered than other "knowledge-based organizations" by "hierarchical structures and narrow or short-term production goals." [Italics added.] However, because academia is generally organized to promote intra-disciplinary knowledge sharing, it will be vital to transcend disciplinary boundaries in order to understand and address the realities of complex problems.

The article's authors spoke to the increasingly complex problems that arise in a world in which rapid social and environmental changes are occurring. They spoke also to the insufficiency of normal academic practice, in which those with highly developed expertise in different arenas rarely communicate or collaborate deeply enough to generate synergistic understanding and response, even to problems of shared concern. But they also spoke compellingly to our increasing capacity to recognize, analyze, communicate about, and even model complexity. Doing so empowers a more accurate understanding of a system which is in actuality complex, rather than attempting to understand it through a less sensitizing lens. The complex systems lens facilitates understanding of how diverse, 
connected, and interdependent agents can share knowledge and collaboratively take on issues that are themselves characterized by diversity, connection, interdependence, and adaptation.

This work, pioneering on many levels, is a powerful model for the CIC as a university-based center and the larger contexts in which the Center may operate. By larger contexts, I mean the context of communities—-local and beyond—which are impacted by a university and a university-based organization, in generative and also suboptimal or even detrimental ways. I also mean contexts of collaborative, innovative, adaptive learning which academia should foster, and the contributions which may arise from that learning.

\section{Summary: Contemplative Approaches to Transforming HE Praxis}

I began this chapter by providing five themes which emerged from my interviews, participant-observation, and study documents. Over the course of the chapter, I have discussed the perspectives of those participants on both the challenges and assets in the higher education setting vis-a-vis contemplative approaches. These pressures include the nontraditional focus of the Center; the competitive orientation of an HEI itself, expressed in a need to gain prestige, to market itself and its attributes as commodities; the need to garner support from donors; and the structural barriers and individual limitations which restrict cross-department collaboration. These needs translate to the expectations it places on its faculty, and also students, to hone expertise in narrow subject areas, and to develop skillsets highlighting capacities to be discursive and critical, autonomous and competitive. These expectations take the form of logistical incentives and disincentives, 
but they are also internalized as demands and constraints on what qualities of awareness and relationality individuals may tend to cultivate within the setting.

However, my participants also expressed assets and strengths within higher education praxis which can promote opportunities for exploration and collaboration. Particularly when those in higher education settings — students, leaders, and any and all othere - are encouraged to examine their internalized sense of limitation, individuals and collectives may advance quite generative initiatives. I presented examples of contemplative pedagogical methods; an exemplar of an interdisciplinary action research project that extended beyond the academy with real-world impact while sensitizing participants to complexity thinking; contemplative methods to develop leadership and agency, congruent with collaboration, in those who work in the setting; and community building efforts among faculty, staff, and students, highlighting efforts to attend to issues of inequity and marginalization in the HEI culture.

These are all instantiations of ways in which participants say that contemplative praxis may transform higher education praxis. In these examples, stakeholders tap and extend learning praxis and, in some cases, institutional praxis, challenging traditional praxes in both arenas. Some of these initiatives, like Sustained Dialogue / PULSE, and the Care for All Initiative, directly involve organization-level praxis. They also, as evidenced in leadership development through HR, and the Bay Area Game initiative, interface contemplative, learning, organizational and institutional praxis.

The findings I described share the following common features: They are significantly informed by their context and constituents. They all explore ways to relate 
individual perspectives to the system they want to understand and affect. More specifically, they involve differentiated agents, who are supported in become more aware of themselves while simultaneously becoming aware of others' perspectives and of the dissonances and synergies through which they relate. They work to cultivate and integrate, to varying degrees, first-person and second-person awareness with "systems thinking."

These initiatives, and the inroads they represent, may be informative to the CIC in its efforts to "transform higher education at SEU," as Charles has often suggested is its mission. Their focus on integrating different perspectives resonates with the stated mission of the CIC, and learning from the exemplars I have described could help the CIC see how to ground its mission.

\section{Organizational Praxis and the CIC}

The CIC has been a rather "extreme" (Yin 1994) and amorphous case to study, because its mission and foci have been, from the beginning, extremely ambitious and spread out. Moreover, its constituencies and its governance structures - and how these relate to each other-have been evolving, unwieldy, and not fully transparent. Howard and others have specified that the CIC did not begin with designed, formal structures. On the level of staffing, roles and functions were not clearly defined, and continued to morph over the first three years of the CIC's emergence. Participants with experience in startups have told me that this is true of many start-ups. However, the CIC was a particularly amorphous case, because its mission and foci have been, from the beginning, extremely ambitious and spread out. Analysis of my participants' perspectives has led me to the 
conclusion that the CIC's formation was characterized both by a diversity of interests, and by a single leader's vision, without clear channels through which to integrate these polarities. Moreover, the Center was jump-started by an unanticipated initial donation, and yet funding for staff was insufficient initially to support the ambitious and diverse stated foci. The genuine hope appeared to have been that collaborative ventures would emerge from gathering together a diverse group of leaders from across disciplines. But, using Capra and Luisi's terms, (2009) insufficient infrastructure- - "designed, formal structures"- has existed to support the development of "interactive communities of practice." Other than its lean staffing, the CIC depends on the participation of people who are for the most part volunteering their time and energy amidst busy professional lives. Therefore, formal structures and roles cannot be enforced upon them, and there is limited accountability or tangible reward for their contributions. Yet seemingly these volunteer stakeholders must play a large part in designing structures that they perceive will support the emergence and interconnectivity of communities of practice.

On a very practical level, the CIC has been evolving structures for governance and participation, in support of its mission to be dynamically inclusive and support generative collaboration across differences. Seen through a complexity lens, the CIC's mission highlights the value of fostering connections and interdependences across differences, but my research indicates that the infrastructure for doing so is not yet as robust as it needs to be to fulfill its mission.

It is clear that the governance and organizational structures of the CIC are, and will continue to be, unconventional in an HE setting. The range of constituencies interested in the CIC's work is very broad, and its mission is likewise very broad. In the 
following sections, I explore some general themes related to participants' concerns and suggestions for guiding the emergence of an increasingly coherent organizational praxis for the CIC.

As of spring 2016, Charles has stated that it is inappropriate to charge the Planning Group with decision making, as it is far too large to coordinate for that purpose, and its members' competing commitments elsewhere do not allow them to contribute the time and focus required for the task of leading the Center. The Center's governance is becoming more explicitly structured to be governed by the director along with the associate director, in negotiation with the donors-individually and through the advisory board - and with input from the executive arm of the Planning Group. Paid staff, particularly those in program director positions, weigh in on the design and implementation of programs in their purview. Charles told me that he hopes to have a "manager" position funded; the person filling that role could take care of lots of the management work that he himself has been too busy to do well. In addition, there will be a newly announced "Contemplative Council," which the website describes as "consisting of SEU faculty and staff with core interests in contemplation that will be regularly consulted through a mailing list and town hall meetings." I will now approach the question: How might such a Contemplative Council be facilitated in engaging productively with the CIC?

I heard suggestions from participants for strengthening the infrastructure for communication and engagement. CIC Program director Rose asserted that hiring a marketing and communications director would allow the Center to leverage "all the good things we are doing," conveying to the University community and a much wider audience 
as well the value of programs the CIC has been developing. Rose reported that she had recently conducted a session with 75 fraternity members, giving them an introduction to contemplative practice, and that it had been an extremely rewarding experience for her, because the young men involved appeared very engaged. She said that she made sure the sessions were photographed, believing that getting this good news out about the Center's work will invite more participation and support, and inspire others elsewhere in their own initiatives.

Charles has also said that the Center needs a communications manager. He acknowledges that the website is outdated. It is so outdated that the inaccuracies and outdated information may easily erode the confidence of those who "check out" the website to learn about the CIC. The website's narrative descriptions of its Initiatives, Contexts, and Activities, as well as its information about People affiliated with the Center, contain many facts two years out of date. Some people named have moved on from SEU, but are described in their former roles through which they were affiliated with the CIC. Two people are described as affiliated with CIC in their roles as deans of Schools, this information has not been updated to reflect that years have passed since they were Deans. This is not to say that interest in the CIC is waning: there may well be descriptions missing of people (Deans or otherwise) who are more recently affiliated with the CIC. Further, it is ironic - or perhaps indicative of the CIC's priorities - that coders are at work internationally under Charles' direction on behalf of actualizing an extremely ambitious vision about the [digital] Contemplative Academy, while the website which is the face of the CIC to the SEU community and far beyond is not kept updated and accurate. 
I also heard the suggestion from a participant that the CIC develop an online newsletter that was not only interactive, but separate from the current newsletter. The current newsletter's purpose is not only to inform readers about CIC activity but also to promote the CIC - understandably, to project an image of the Center's successes and expertise. However, a separate newsletter, or listserv, could engage stakeholders in asking provocative questions, making suggestions, and perhaps offering input that challenges assumptions and presses the consideration of viewpoints not currently given "airtime" in the current newsletter's framing. Two others suggested that very little effort on the part of the CIC might be required to nurture interconnected "pods" of stakeholders to converge to discuss and perhaps plan research or action around topics related to contemplation and higher education,

\section{Research incubators.}

I introduce this section with a passage from my last interview, which was particularly generative. About 90 minutes into the conversation, I shared with my interviewee the culmination of my research findings.

Mary: My findings are that first-person, second-person, and third-person contemplative practices are all vital, if we're going to do transformative work, and that a University is a great place to be exploring all this. We're looking at [organizational, institutional, social] systems that are somewhat dysfunctional, and were trying to understand those dysfunctions, at the same time that we're understanding our own personal reactivity around our positions in those dysfunctional systems. And also, we're developing an awareness that, oh, this other person who's in the system with me is actually another person. And, on these different levels of praxis: the individual level; the level of learning, whatever that means - pedagogy, research, etc.; the level of institutional change; and the level of organizational praxis. In all of those praxes, first, second, and third person practices need to be involved. 
Howard: There is no, there's nothing close to that level of broader framing of the CIC that you just articulated. Nothing even remotely close to it - but I think what you're saying is so cool, because it would create a larger vision inside of which the Center could start doing some things, and it may not do everything at onceof course not - but it creates a container and a vision about what this could be.

Howard became animated as he shared the image that emerged for him in that moment of a model in which there were efforts in organizational, institutional, and relational, and societal domains of practice, and that

...with those particular domains of practice there's all kinds of mindfulness [efforts and approaches].... But the whole idea that these are the domains in which the Center plays would be a powerful — and then [he says excitedly] we could say things like - when we look at what's happening inside the Center itself right now, when we look at our [model], we get really, really clear we've got some [not so great] stuff going on here. [laughs] And the impact. with a more robust model, the impact that's having on our ability to affect organizational and institutional [transformation].

Howard went on to say that "this could be completely research driven: how, absent the ability to do [the needed contemplative organizational change work], it undermines the ability to do these other things, these other pieces of the whole."

He continued,

I haven't talked about this, til you and I are talking about it, but why couldn't there be sort of [pause] I don't know what the right phrase is - working circles, when people come together, like a research incubator where people are developing research around this.

This is reminiscent of the Chesapeake Bay Game project, in that it could draw diverse perspectives into a common conversation, over time, with the explicit purpose of both investigating and leveraging the complexity of the subject matter and of the research process.

Howard spoke about 
... a standard research incubator [wherein] people come together to start figuring out what are the critical questions that we need to understand better about mindfulness and mindfulness practice, and so on and so forth[crossdisciplinarily]. We keep having these conversations in the Planning Group about the scope of contemplation, and tell you the truth, even research on that would be interesting. Sort of cataloging-

Mary: research on conversation-

Howard: On that conversation!

Mary: I do hear Charles saying [that that's the conversation the CIC should be having], but I think he has to also kind of get something in motion out there in the world, and I keep thinking: But we still need to - this is something in motion. But tracking it, articulating it, seeing what the unintended consequences of things might be-really looking deep at this.

Howard went on to say that donors are likely to be "pragmatists, business people who sort of say, "A research incubator? Where people sit together and figure [stuff] outthat's a waste of time." We concurred that the relationship with donors could become part of the research that gets incubated.

I include this dialogue here to demonstrate several themes. It illustrates how I included myself in the system in my researcher role, and the generative conversations to which that approach led. It also speaks to key concerns, vital to the CIC's organizational praxis, about how the CIC may help facilitate generative engagement among stakeholders, and about power dynamics vis-à-vis donor relations.

The task of learning how contemplative praxis may transform higher education, and vice versa, must be a highly reflexive one, and involve diverse perspectives engaging each other over time. This will require, and cultivate self-, other-, and systems awareness, and will also benefit from designed structures (Capra and Luisi 2009), through which to facilitate "communities of practice" (ibid) who together may emerge novel ideas and 
actions. As Howard suggested, this may be as "simple" (and challenging) as supporting pods of people from across and beyond the campus to ask together, both outwardly and inwardly, "What are the critical questions" relating to contemplative praxis, in the context of transforming an HEI?

This inquiry process could incorporate stakeholders from, and insights gained from, the range of contemplative approaches that I explored earlier in Chapter Four, wherein stakeholders used methods that cultivated awareness for various purposes and in various settings across campus. This networking and inclusion could greatly leverage the mutual learning between disparate contemplative initiatives and the CIC.

In whatever context CIC stakeholders engage with one another, they will need to develop innovative ways to do so, that take into account the external and internalized pressures of the academic context, the aspirations for contemplatively inspired transformation of that context, and a deep inquiry into what will be needed to bring about that transformation. Relational and organizational practices that facilitate this inquiry will be essential. In the next sections, I explore some possible approaches to such practices, about which I was informed in the process of engaging with my research participants.

\section{Contemplative Organizational Change Practices}

The hope to restructure organizational praxis via the intervention of a retreat was generally unsuccessful. Roberta, from long experience, told me that one cannot expect a retreat to yield transformative results. Howard asserted that a more contemplative retreat design may have helped toward achieving a more authentically collaborative understanding of challenges, solutions, and path forward. What other efforts may help the 
CIC to reflect on its organizational praxis, which in turn undergirds the CIC's ability to engage in the work of developing and enacting its mission? The CIC Planning Group and its executive arm consist of many stakeholders who care about the mission of the CIC and their own (mostly aspirational) roles in developing and supporting that mission, but are in general unsure how, or are too busy, to enact their roles. The director envisions a deeply collaborative organizational praxis, but his leadership style, according to certain stakeholders, may not best facilitate that in all contexts. As an organization explicitly committed to contemplative approaches, what resources might CIC stakeholders tap to bring a more contemplative approach into its organizational praxis in an ongoing way?

\section{Contemplative organizational praxis: pausing and silence}

As I conveyed in Chapter Three, concern prevailed among staff and others who were most engaged in the CIC that they needed more opportunity for pausing and reflecting, in the context of meetings and in a more general sense, and that they believed that communication would be enhanced in that process. Others outside the CIC reported similar concerns about their engagement in Center events. A participant in the K12 Symposium described that, although the Symposium's design was explicitly framed as fostering emergence of ideas and connections among people, “There weren’t contemplative practices embedded in deep ways," and that events were "back to back, so it didn't allow people to actually relax and think. The spaciousness in it is not a small thing —it's how do we value — for emergence you actually have to allow relaxation enough to support "presence." 
Many participants in my study, like the one above, have been sensitized by their engagement in contemplative practices as individuals to notice when such practices are missing in a collective setting, particularly one that purportedly values contemplative approaches. They describe their sense that this omission impacts the quality of engagement and the results that emerge from engagement. The participant above said,

There is a settling - you let things settle — and you let things simmer, and you let them sit, and you let them marinate, and you see what emerges out of it. Nothing like that was present. It's a value of productivity over kind of the open dimension.

As stated in Chapter Three, certain CIC stakeholders told me that meetings were jammed with information, that such "settling" and "marinating" was not facilitated, and that despite a general interest in "seeing what [could] emerge from" collective time together, they were instead dissatisfied.

I quoted Charles earlier in saying that contemplation helps bring awareness to habits, even those things we "learned," that became part of our way of relating to ourselves and the world when we were very young. Through contemplation, he said, we can more easily understand those unquestioned "practices—social, emotional, and cognitive" and "the outcomes that those practices are generating." I quote Charles again here in saying,

There's all this plasticity, this malleability opens up, and we need practices to envision other possibilities, other possible practices that can generate different outcomes, and then you need practices that will allow us to take those new practices, make them are hardwired into our sensibilities.

Stakeholders' recommendations that the CIC incorporate more pauses for selfreflection, and more "spacious" opportunity to share from that reflective state in meetings and other engagements, resonates with Charles' idea of investigating "social, emotional 
[and] cognitive" [unconscious] "practices" that we learned long ago and that impact us still, not just as individuals but collectively.

Certain members of the Planning Group, as well as former staff members, asserted that current organizational dynamics do not facilitate as much honest, generative communication and meaningful engagement as they would like, and as they had envisioned, and perhaps had even experienced earlier in the CIC's emergence. A few acknowledged that they felt they colluded in dynamics that were less than fully generative, by withholding feedback that they felt would "rock the boat" and disrupt the collegial relationships that they valued. Thus, as observed by Argyris (2016) to be the norm in organizations, people bypass uncomfortable subjects, and prioritize the maintenance of a "positive," safe-feeling environment over working toward a more productive one, wherein group members are challenged, and helped, to look at their difficulties and failures.

A former staff member recommended a book to me, suggesting that it spoke to an intervention needed in the CICs organizational praxis. In Immunity to Change (2009) Kegan and Lahey have explicitly extended Argyris' understanding, in line with their own long work in the field of adult development, to design a process through which a group of colleagues scaffold a process of discovery and transformation, vis-a-vis what drives individuals to behave in ways that are not in the best interests of a group. In their "Immunity to Change" work, Kegan and Lahey affirm that when groups begin to work together to help members disturb and transform behaviors based in entrenched assumptions (such as what underlies the "learned practices" that Charles describes above) group members can scaffold each other's movement through chaos into emergence of 
new, more adaptive ways to be. The aim is to bring awareness to the defensive pattern and the anxiety beneath. In an assertion that resonates with Charles' assertion about the need to change unconscious assumptions, Kegan and Lahey write,

If one is not to be forever captive of one's own theory, system, script, framework, or ideology, one needs to [disturb one's internal system by] develop[ing] an even more complex way of knowing that permits one to look at, rather than choicelessly through, one's own framework.

The tendency to over-control the group process is one of many examples they give of behaviors by individuals that do not best serve the collective needs. Such behaviors, they contend, stem in each case from a defense that each individual rallies in a seemingly intractable way, to protect him or herself from an even more underlying anxiety being triggered. People's anxieties vary, as do their means of defending themselves from being triggered. The authors give the example of "fear of failure" as an anxiety that may give rise to a behavior such as being too controlling.

The scaffolding process given by Kegan and Lahey (2009)—a more or less collaborative investigation of four layers of motivation for each member's problematic behavior - is conducive to this ongoing work of guiding emergence together. New perspectives - one's own updated perceptions, the needs and interests of one's colleagues, and perhaps the insights of a coach—are brought to bear in helping uncover the anxiety beneath the behavior, and then to help emerge new ways of feeling, thinking, and relating. The environment of an organizational team can be very conducive to engaging in such growthful, if uncomfortable, change processes, as the team comes to realize it has much at stake in fostering each member's growth. Individuals divulge what they have discovered about themselves, and ask for each other's assistance in calling 
attention to reemergence of patterns they have committed to changing. Because there is a shared understanding that the undesirable pattern has emerged as a defense against anxiety, this approach suggests that responses to colleagues' difficult behavior are most accurately and helpfully framed as compassion rather than blame. Kegan and Lahey found it remarkable that people are willing to engage in these vulnerable ways with colleagues, and yet a team and its members clearly have a number of incentives to do so, including increased productivity, and more enjoyable relationships, given the opportunity to convert backbiting and blame into candor and support.

Thus, Kegan and Lahey (2009) suggest that by committing to an organizational practice that I call implicitly contemplative, people work together in the service of something that is bigger than themselves, and that may set conditions for individuals to proactively look at their "shadows" in Audrey's terms - or in complexity terms, to bring in awareness to disturb the patterns one currently lives from without conscious choice. As group members join in the larger purpose of mutually beneficial growth, Kegan and Lahey say they have observed empathy replacing blame. Audrey stressed that, in her experience, undertaking a change process oneself helps one understand how hard change is, and therefore helps one to be compassionate and supportive of others when they have difficulty changing, not just outwardly, but inwardly. The idea is that this internal change process gives rise to more congruence and capacity in our change agency.

This approach aligns with conceptions and experiences expressed by participants in this study, when describing the purpose and value of a personal contemplative practice or approach, or of designing contemplative - or otherwise transformative-learning experiences. Several stakeholders specifically stated that a contemplative organizational 
praxis was a next frontier, both for the CIC and more generally. These stakeholders expressed that bringing contemplative approaches into collective work might amplify the possibilities for transformative growth for individuals and most pertinently, for the groups they are part of. Capacities for first-person, second-person and system awareness would be both challenged and cultivated in the process.

Stakeholders offered suggestions toward that end, including that the CIC commit to retreats during which key stakeholders could spend less hurried time exploring underlying dynamics in their interactions, in the context of creating a collective vision of how to move forward as a more collaborative organization. Howard suggested that the spring 2014 retreat was flawed because Charles had received insufficient support (which Howard suggested could have taken the form of coaching for Charles ahead of the retreat) to allow him to listen to stakeholders' concerns without feeling personally attacked. As noted earlier, Howard also suggested that a future retreat should incorporate contemplative practices, to allow participants to pause and employ "first-person" methods to examine their own reactivity as well as their inspiration. This would allow participants to offer more nuanced sharing to enrich the group process. As noted earlier, several stakeholders also expressed strong opinions about changing the tone of meetings, so as to allow for more first- and second-person inquiry, which they asserted would lead to more authentic and co-creative processes and outcomes vis-a-vis collective efforts to develop the work of the CIC.

Former staff member Chad said he had raised concerns many times within the Planning Group, advocating for the Center — staff and beyond- " to pursue how we could become ourselves a contemplative organization - at least in parallel to the other things we 
were doing, if not as something we needed to do first." He said he had suggested that, without putting their other work completely aside, devoting "some really focused time to implement systems, practices, to start to cultivate a culture ... that [could] inform the work we do outside and vice versa." He said some were supportive of this idea, and at one point several months earlier, "Charles [had given him] the green light to explore what kind of staff training could be available at SEU for [the organization]." Chad said he felt he had failed in that task, but that "there was no real support for this," and that taking time to access such training, and work towards creating the kind of culture he envisioned at the CIC, would be commitments of time and focus additional to his other responsibilities. One reason he left the CIC, he said, was because

It felt more difficult for me to do this at CIC than to do it elsewhere, where I could say we're going to start this business, and a key part of that job for me is starting with these practices and values right from the get-go.

Mary: When you're talking about these practices, it sounds like you're talking about staff, but you're also talking about the whole Planning Group, at least?

Chad: Yes, absolutely. Our whole community.

Chad indicated that this contemplative orientation to the organization's work could involve the donors, as well as staff and other CIC stakeholders. "How can we not be trying to embody these things," he asked, "at a minimum just as a way to have a deeper understanding of our subject?"

Interestingly, though Chad said that he thinks it is usually helpful for people to have a regular contemplative practice - -I think it's hard to do too much without some kind of personal practice" - he was interested in "a way to start" that did not require 
people to go off and meditate. "To me, that's a nonstarter." He was interested in "doing that in our work time, together, somewhat regularly."

Chad acknowledged that people have generally related to contemplative practices as personal practices, for purposes of "personal elevation and so forth, and so translating that to a group environment can be challenging." Moreover, there is challenge simply in relating and communicating.

So much of the rest of the organizational practice and development follows from healthy communication. If you're able to communicate in nonthreatening wayspowerful ways but not threatening, not violent - then suddenly nobody's making decisions reactively and nobody's feeling belittled or put aside. . . . And yet it's one of the hardest things. We all have our styles. We all have our expectations and baggage and it's difficult to-it's hard enough to get to people living together to communicate with one another, much less a whole team.

Another former staff person, Larry, was committed to bringing into his work at the CIC Nonviolent Communication (NVC) methods, deep listening, "and all that coaching stuff that I picked up over the years - it works everywhere. Listening to people and trying to provide a new perspective by reframing." He said that some CIC stakeholders appreciated this, but that "The particular gift that I have to bring to the world just isn't resonating with Charles." Larry, like Chad and every other former staff person I talked with — and many of the Planning Group members and other stakeholders I spoke with as well — asserted the need to bring contemplative approaches into the CIC's organizational praxis.

Another former staff person said, "We should talk about this as an organization and see how we could be better-we should be practicing contemplation within the workplace like we are trying to project to the rest of the University etc., because just like 
anything, if you have a waterfall effect and it's really dysfunctional at the top, you can expect the same as it trickles down."

Chad asserted that in the CIC, as in many startups, the focus is on particular outcomes, and that for at least the first year "it feels like an impossible luxury to stop and say are we healthy, how are we communicating?" Although there would be payoff for that in the long run, it is hard to do it at the time, he said, and that he did not "fault Charles or the Center for not having put huge efforts right way into that." The mentality was, understandably, toward building momentum.

What I will fault them for is if now that the wheels are in motion and things are happening and the staff are growing, I will fault them for not starting to recognize - this is in fact how it is - the need for addressing dysfunction, improving communication, and for starting to embody the values that they espouse out there in the world.

Chad felt strongly that one way the organization could show its commitment to learning was for members of the Planning Group or its executive arm to hold exit interviews when staff people left. Chad indicated he had requested an exit interview, and only heard from one person in response.

Stakeholders expressed that the CIC is, at least potentially, an unusually appropriate setting for exploring this kind of collective contemplative praxis. Howard said, "The intersection of the CIC and the contemplative practice, which is the actual contemplative practice, would really invite us to do some- do and act and explore different ways that we don't do." Such praxis cultivates first- and second- person capacities (self-awareness and empathy/compassion), as well as an implicit sensitivity to the systemic ways that individuals' behaviors affect and are affected by a group dynamic. 
However, per the concerns raised by Argyris (2016), as well as by Kegan and Lahey (2009), is the fact that the CIC is an organization with an explicit mission to promote contemplative approaches may ironically exacerbate the tendency for some stakeholders to deny its difficulties in being contemplative. The CIC's director, in particular, may find it challenging to acknowledge the incongruence between that explicit mission and what several indicated to me is, in their perception, his noncontemplative leadership style. However, some stakeholders have acknowledged to me that they collude, through their own passivity and withdrawn engagement, in reinforcing the director's tendencies toward "controlling the narrative." As these stakeholders explore their complicity in these organizational dynamics, they bring a systems view forward, which may open new possible avenues for affecting the system going forward. This process is reminiscent of the experiences some participants described to me, and that I wrote about earlier in this chapter, of engaging with coaches and consultants to develop their change agency from the inside out.

\section{Contemplative Organizational Praxis as the Basis for the CIC's Institutional}

\section{Change Work}

Part of the challenge of understanding and leveraging the CIC's potential for affecting its institutional context is that it is unclear who, or what, the CIC is. As stated above, the CIC seems currently to be centered to a great degree on the efforts of the director with assistance from the associate director, and donors with whom they negotiate about program priorities. Staff who enact the Student Initiative and coders who develop 
the Contemplative Academy are given their general mandates by the directors. The Compassion in the Schools Initiative has been given a clear mandate as well, though the education professionals who are carrying out that project have had much responsibility all along in developing the research agenda and curricular objectives for the project.

The more general mission of the CIC, as stated by its director, is to facilitate cross fertilization that is interdisciplinary and beyond the academy, to study contemplation, its derivations and its effects, in many contexts. As to how to do all—or any-of this, I am not aware of structures in place that would facilitate such collaboration. Above, I explored some perspectives on how members of the organization-whether staff or key stakeholder - may support each other in probing and evolving the dynamics of their group interactions. With this basis for more authentic communication, they may be able to work together more fruitfully, through sharing perspectives about what priorities and values could inform the CIC's identity and priorities going forward.

Stakeholders say that contemplative processes in the CIC's own organizational work may facilitate the CIC in its larger mission, to bring transformative change to bear in its institutional setting. It appears that priority setting in a more collective manner than is currently practiced in the CIC will require practices that bring awareness to the diversity of perspectives that stakeholders bring with them. As stakeholders develop organizational praxis that helps them integrate the diversity among themselves, this may help them learn to guide a wider range of stakeholders in integrating diversity, toward the hope of helping new, more deeply inclusive, ideas and action to emerge in the HEI setting and beyond. 
Contemplative organizational praxis depends on first- person and second-person contemplative practice, and a systems view. Howard emphasized that in the process of bringing attention to how one is triggered, and how one reacts, it is extremely valuable to foreground the larger purpose of the organization or group (system), and to ask, "what is the larger goal, and how can I support that when our differences come to the table and we begin to fight and so forth, which invariably happens within a group." He views diversity as adding value to an organization, especially when the organization cultivates the ability of a range of participants to actively seek that value added. "To ask, 'What is our larger purpose here?' helps us keep perspective on wider purpose and helps [group participants] manage themselves." Howard is describing the mutuality between first-person awareness practice and practice in which one identifies as part of a group whose efforts toward a common goal are enriched by the diverse viewpoints of its members. Both one's personal well-being (i.e. avoiding burnout), and the success of the team-which he says requires incorporating difference to enhance wisdom and creativity - are incentives to track reactivity, inquire into it, and manage it productively. And, said Howard, "all of this is deeply connected to contemplative practices." It is, moreover, where the "two streams" of the Vipassana practice, especially as informed by a social justice lens through which he was introduced to it, and his leadership development training and its daily applications, converge where Howard's work "is clearly that mindfulness meditative path, and even though I don't sit regularly, I am practicing mindfulness a lot throughout the day."

Early in his professional life, Howard experienced faculty meetings in which members were emotionally reactive to the point of group dysfunction. Since then, "the contemplative practices have helped me in similar situations, to step back from the drama 
when it's happening and thereby to... see the places where I can be more helpful and insert myself [to do so]."

Howard has identified the counterpoint, or complement, to some of my study's participants' eloquent assertions that, in order to evolve, individuals and collectives need to address the "shadow, "“'metabolize" anger and other motivations however unconscious that affect one's relational effects, or venture to the source of one's anxiety and disturb one's defenses against that anxiety. Martin and other participants assert that tapping awareness of the larger purpose — one's own, but more importantly a collective purpose - provides both motivation and support for facing internal disturbance and using it for growth. Many proponents of contemplative orientations assert the need for methods and practice on an individual level, and some promote dyadic or interpersonal contemplative practices as well. The contemplative pedagogical methods described earlier, as well as dialogue-based models such as Sustained Dialogue and PULSE, support contemplative community building. I have also explored here methods and practices that help guide individuals and the groups they are part of in organizations and businesses to do contemplative work that draws from the need for personal and collective growth, and from the support of collective wisdom and care.

\section{Valuing contradiction: transformative discourse as collective inquiry}

As the CIC's mission depends on the capacity to integrate diverse perspectives; contemplative organizational praxis as described above may support such integration among key CIC stakeholders. Such organizational praxis may help the CIC as it enacts its mission to help integrate the interests of a wide range of potential participants, across 
disciplinary and other divides, in and beyond its institutional setting. It can be helpful to explore structures and processes designed to facilitate authentic dialogue across difference. The following section illustrates that "integration" across differences - a stated purpose and value for the $\mathrm{CIC}$ - will often require going through a transformative process involving chaos, tension, and confusion, on the way to emergence.

I discussed my proposed research on the CIC, while the organization was in its beginning stages, with education professor Ron, whose expertise is in educational equity. Ron told me, "I could sound pessimistic and cynical, but I've been around change efforts, what people call change, and ... I know what needs to happen for change to take place institutionally. If it's money driven as opposed to goal driven, with specific outcomes in mind that are transformational, it's not going to be integrated [into institutional praxis], and at the end of day, it [won't make] a whole lot of difference."

From his expertise and strong interest in transformational change in the interest of shifting systems toward inclusivity and equity, Ron offered a hopeful yet challenging prescription for what such change requires. "If people can be brought together, in sustained dialogue, identifying internalizations, and valuing the contradictions, then [those contradictions] can result in growth into a paradigm that's more [inclusively transformative]. That takes a lot of work." In the language of Cultural Historical Activity Theory, "internalizations" are assumptions that drive us (individually and collectively), whether or not we are aware of them, about how a system works and our roles in it. This is reminiscent of the assumptions addressed by Kegan and Lahey (2009). CHAT suggests a process in which stakeholders in a setting "identify" internalizations to ourselves and to each other, to become aware of others' internalizations, and to "value the contradictions" 
as exposing us to a larger framework than we came into the conversation with. In fact, the CHAT process suggests "amplifying" those contradictions, hoping to press the system to respond in a generative, adaptive, novel way.

Ron uses this process in his teaching, and referred to having done so in a recent doctoral seminar, in which he and his students focused on educational policy. Ron guided them to bring out their own internalizations related to the policy issues they were discussing, in the interest of coming to a fuller understanding of those issues together, and also stimulating their desire to engage in the system and to take action to press for the changes they value. "It's so powerful when everybody gets to a point when they can share their secrets, hidden from view." The CHAT model suggests a focus on the system as a system - the "collective I" - as a context for generatively exploring the individual "I." The focus is on relationality and process: "transformative discourse," in Ron's words.

CHAT, as theory, model, and process, is a potent distillation of what it takes to guide a system through disturbance and emergence. CHAT is a scaffold that not only normalizes, but holds to be necessary, the discomfort - on individual and collective levels_-of a deep change process.

Interestingly, Ron said that CHAT does not theorize deeply about emotion. As Kegan and Lahey (2009) describe, however, reactivity happens within individuals, when parts of one's "self-as-living-system" are triggered into fear of failure (a kind of survival fear), anger, or other distress. These reactive "parts" may become dominant in one's responses. So, Kegan and Lahey's insights help each individual develop something like a 
CHAT model of one's own inner dynamics, and methods to visibilize internalizations not just about the system "out there," but about our own internal systems.

As a means of action research into the dynamics of the CIC's emergence, Ron suggested trying to engage with "life-affirming parts" of possible stakeholders, as well as visibilizing internalizations, by asking them the question: "Do you have any feelings (including fears) about actively supporting this movement in this community?" This question may help bring awareness to assumptions, and even underlying anxiety. This approach asks participants to investigate their first-person experience as they think about bringing a more contemplative approach into the systems ("this community") they are part of.

The CHAT model brings stakeholders' awareness to their own and others' "internalizations" about themselves, each other, and the system they are part of. In so doing, it supports first-person, second-person, and systems level reflectivity. In the next section, I will explore an aspect of power dynamics systemic to HE praxis, in which the CIC is embedded: relationships with donors.

\section{Power Dynamics in the Donor-CIC Relationship}

The sections above explored the CIC's challenges to develop group processes that may lead the organization toward integrating stakeholders' perspectives and contributions. The organization needs to develop its capacities to guide emergence. Its explicit mission, seen through a complex systems lens, is to set conditions under which diverse agents (individuals or groups) can forge or discover connections and 
interdependencies among themselves, and dynamically learn together, producing unpredictable and adaptive ideas and actions.

There are agents pivotal to the CIC's existence, other than those stakeholders I have so far talked about. These are donors, actual or potential. The CIC's relationships with donors is a pivotal factor in its organizational praxis, and in its embeddedness in institutional praxis. This is a particularly challenging arena to approach contemplatively - that is, to bring awareness to, in a way that disturbs assumptions. There are power dynamics involved that many stakeholders take for granted. However, exploring what is taken for granted is the purpose of contemplation. Also, a systems view suggests that power dynamics are vital to understanding the settings we are part of, and our own roles in those settings.

Speaking of the emergence of the CIC, Howard said, "I'll tell you what's emerging. What is emerging is the corporate entity of the CIC." He asserted that this emergence takes the form of "a set of activities and tasks that clearly demonstrate that something of value is happening, and as a reward for it you get a building." Moreover, he said,

I think part of the role that Charles has been playing is, if it's CIC, Inc., his job is CEO of CIC, Inc. And if he doesn't produce results, the shareholders slam him. So, it's almost, in many ways, the antithesis of what CIC should be. But it's the way it's playing out. And I think that's connected to the donors' model of what's going on.

I do not know whether or to what extent this is indeed "the donors" (who are, among themselves, not of one mindset) "model of what's going on." However, it is 
significant that a stakeholder important to the CIC's governance sees it that way, and that he is stating a belief that Charles sees this as "the donors' model of what's going on."

Howard went on to assert that the fact that the CIC "is connected to the University, the institution that is the University, the business [that is] the University" means that the need to produce results is certainly real. The donors, though I was told many times by various sources that they were "thrilled," "very confident," etc. with the progress the $\mathrm{CIC}$ has been making, do need to see results that they can relate to, and feel good about investing in. Charles, as director and spearhead for the CIC since it began, is particularly under pressure to negotiate, prioritize, produce, and articulate results.

\section{Contemplating subordinance and dominance}

Howard continued, "And when I think about us as . . the governing board, to use the metaphor, I think we are subject to all—so many of the same kinds of biases . . . that groups like this have to deal with all the time." He said he "sees [these biases] all the time" in the "contemplative and mindfulness space." Nevertheless, to do the work of this organization "without ... self interrogation [about those biases], lacks integrity ... in terms of the [contemplative] practice."

Howard's suggestion was that as a start-up, Apple and its shareholders “didn't care about such a thing." They cared about the material product Apple put out. For the CIC, however, "part of our product is contemplation.” He knows of an organization whose raison d'etre is mindfulness practice, and which underwent a crisis, in the midst of which people reverted into "threat rigidity." He said he could imagine a similar thing happening at the CIC, if a crisis such as a funding cut were to occur. "I always believe 
it's part of contemplative practices to help us work through [survival reactivity]." Howard voiced concern as to whether the CIC "would actually, as a community, sort of come together to work through that."

We wondered together whether the CIC is projecting its survival—and in a deeper sense its existence - outside of itself, into the source of sustenance on which it currently depends. If this is the case, it can easily lead to a subordinant relationship to donors, leading to posturing, and limiting possibilities for full, authentic communication. Howard's recent book is about the value of seeing, understanding, engaging, and leveraging difference in organizations. He is quite sensitive to power dynamics, and has been exploring an articulation of his long experience, as a black man in America and from his professional expertise, how dynamics of subordinance and dominance are played out. We wondered together about more contemplative ways that communication and collaboration could occur. His critique was not that donors were purposely seeking a dominant position, but that feedback loops to donors may be limited to those that do not run the risk of offending or disappointing them; that being the case, some information flow will be stemmed.

This locks the system, to some degree, into what Argyris (2016) called "firstorder thinking," thinking inside a box without probing the motivations that keep one thinking inside the box. One of the boxes within which higher education praxis thinks, to which I have been sensitized in my research, is that dependence on donor funds means that recipients of funds must strategize to reinforce funders' dominance, colluding in reinforcing their (perhaps unconscious) privilege. 
I had been particularly alerted to this dynamic when, after making an offhand, unflattering comment about a donor, one of my participants said that if I quoted her as saying that, she would lose her tenured position. This is an alarming thing to hear, vis-avis power dynamics that trump free speech in HE setting. A CIC donor has said negative things about the president of the University, but no one threatens that he will be "fired"he is free to express his views however he wishes.

There may be some deeply generative conversations possible, including productive disagreements, if the premise of communication included the possibility of interrogating uneven power dynamics, if they are sensed, rather than taking them for granted. This may apply in another direction as well. The CIC's director is an academic much admired for his expertise, intellectual capacity, and visionary mind. This may intimidate some potential donors from pressing their own questions or perspectives, which could enrich the conversation rather than reducing its complexity.

If in any way CIC leadership or stakeholders assume they cannot provide straightforward feedback to a donor when they need to, or they deflect rather than respond directly, a contemplative approach would inquire into that assumption. "[There's a] deflecting quality that I see subordinant people do all the time, which is - it's never about truth to power, it's always about how do you find indirect ways to avoid or appease," said Howard. Some real potential for generative communication may be lost in doing things this way, not only because the subordinate agent's perspective may be important for the other person to hear, but perhaps more importantly, bringing awareness to the awkwardness and risk involved could open awareness for all parties about the existence and effects of a power differential. Disturbing the system in such a way could 
help stimulate each person and the system as a whole to move toward emerging new, more adaptive structures for relationship. However, opening all these feedback channels beyond their current openness would require capacities to guide the system from disturbance (sharing previously withheld responses) through the discomfort of chaos, to emergence of new relational patterns, and possibly new ideas for action. It also runs the risk of bringing to light any dissonance that exists between the mission of the CIC and the motivations of donors.

Mary: We have to hope that there's something valuable that makes it worth doing differently.

Howard: That's exactly right.

Mary: But you have experience in your own life that tells you that it is worth it.

Howard: Yeah! It is worth it, it absolutely can be.

The "difference" that Howard brings, in part, to the CIC, related to but also in addition to his background and expertise in organizational work, is that through his racial background he would be sensitive to any tendency he saw in people to assume a position of subordinance. This sensitivity would be amplified by his background both in mindfulness practice, and in having seen power dynamics played out in settings devoted to mindfulness, that those in dominant positions were not necessarily aware of.

\section{Contemplating the source of survival.}

A highly significant element of assuming a subordinant role is that it projects the source of survival outside the organization, and in doing so, subverts a more potentially empowering task for the organization. This task is to engage in intensive, sustained, 
inclusive, collective inquiry—and the relationship building that will support such inquiry - about the mission and values of the CIC. A few key stakeholders sensitized me to the danger of such projection, and their sense that the CIC's identity formation would be served by the organization asking itself what its priorities are, and then looking for ways to draw resources that support those priorities. This is a figure-ground reversal, whereby the organization assumes responsibility for its own existence, choosing-in the words of one stakeholder - "to be who are we no matter what anybody [in particular] thinks of us." These resources, and this inquiry, will and should include donors, but—in accordance with an explicitly contemplative mandate - continue to interrogate power dynamics that involve dominance and subordinance. This reframing could allow for an initiative to emerge from a more collective impetus and vision, which from its own coherence could seek sources of support that are in alignment with that vision.

As a caveat to all that I have just discussed, I must say the ongoing negotiations that the CIC's director and associate director have held with donors have certainly involved significant feedback flowing in all directions, and I believe all involved value the CIC's general mission. However, these negotiations may have superseded a more intensive, collective visioning process, which may assist the organization to strengthen its sense of collective identity and efficacy as it refines and chooses how to enact its mission.

In complexity terms, the initial conditions of the CIC's inception, in which the gelling factor was a large donor, "preconditions the entire thing to unfold in some ways in the way it's unfolding," said Howard. Dominance and subordinance are systemically reinforcing. Those in a dominant position may not be conscious of how others' sense of surbordinance conditions the interactions, and if it were brought to their attention, some 
would very likely be interested in developing a more fully authentic relationship. For subordinants, the risk may be too great for them to rock the boat and find out how fully straightforward they could be without alienating a source of support.

Authors J. Walker \& J. McCrea [2013, p. 142-143], by way of "illustrating how the worldview of a philanthropist can change over time," quote philanthropist John Megrue: "True partnership demands so much of you as an individual. It means constantly giving of your time, your energy, and relationships. It means lowering your ego, learning to really listen, ignoring hierarchy [italics added] and holding yourself and others responsible for the outcomes of the work." This points to how involved some donors are willing and able to be, "from a transformational standpoint_-giving time, energy, creativity, and ideas - as opposed to a transactional standpoint, which is just about writing a check." In complexity terms, not engaging in explicit inquiry about power dynamics with or about donors can reduce complexity. The opportunity in engaging in such inquiry is to challenge all participants in the system to wonder-out loud to themselves and to each other-what a contemplative approach to transforming power dynamics might look and feel like, and how that may inform the larger mission of the $\mathrm{CIC}$, and of the larger movement to transform higher education praxis through contemplative means.

\section{Contemplating Inequity}

Along these lines, I reintroduce a conversation in which I asked someone influential in CIC decision making whether the CIC might find funding to help support an initiative to bring contemplative approaches to bear on addressing issues related to gender 
violence, and to race, that had been stirring on campus. This stakeholder responded that, as many CIC donors were SEU alumni, and most were connected to fraternities or sororities,, they may not wish to engage these issues explicitly. I believe this stakeholder may be wrong, but the implication seemed to be that CIC leadership would be careful not to bring up something controversial about donors' alma mater. Some stakeholders I have talked with take the opposite view, and see great value in bringing awareness to issues of inequity. In this section, I will tread lightly into this arena, giving short shrift to a topic I feel is pivotal to transforming an HEI through contemplative means. I broach the topic because it needs to be broached, but I am aware of my own limited capacity to understand the depth and breadth of what is involved in transforming systemic inequity.

One of my study participants works in the field of large-scale social change, with an equity lens. She stressed to me that issues of equity and inclusion, though often addressed as an "add-on" to organizational and institutional praxis, should in fact be a "through-line," informing all choices about priorities.

It's not a diversity initiative, it's not just diversifying your staff, it's actual understanding and [capacity] building what difference actually means for how we see, for how we plan, how we vision, how we analyze, how we strategize, and what we even think is good or right or proper-how all of those things are shaped, and then what we think is valuable.

She said that racial inequity is intrinsic to U.S. society. Our “... entire political, legal, economic system was built upon slavery and our engagement with indigenous people. It was erected [on that]. Its structure has the shape of those encounters to this day. I mean look at incarceration rates, look at every social system." Yet, she is hopeful about changes underway, particularly through approaches that involve cultivating and integrating "three sets of competencies" that are usually separate. The first is the 
knowledge of social inequities. The second is understanding the process of change in systems. The third is the contemplative skills - the energetic, mind-body, emotional literacy to be able to actually hold all of these complex things. She said that it is "exceedingly rare for all those things to be present in one change process. I've seen attempts. I've never seen the full flourishing. And I think that if we do those three things together we will save the world."

This participant and about 20 others have informed my understanding that a commitment to inclusion of racially and otherwise marginalized voices is vital in developing a holistic vision for transformation in an HEI (or any other institution). And, the textured approach this participant described, which integrates learning the facts about historical and current inequity, cultivating "systems thinking” to understand change processes, and "contemplative skills" is a powerful prescription for developing change agents. This three competencies approach to learning together, combined with a commitment to inclusion, helps guide emergence of new relational structures.

The third prong of the CIC's stated mission is "taking care to address issues of inclusivity across the dividing lines of inequity and addressing issues of social justice." It is unclear how the CIC will enact that mission. "The contemplative movement at its core is really about dismantling systems of oppression that keep non-Western [ways of making meaning] marginalized. Contemplation is about bringing awareness to inner barriers, [in the service dismantling these outer oppressive systems]."

The 20 stakeholders who spoke to these issues in my study see contemplative praxis as profoundly useful in developing capacities for change agency in support of 
social justice work. Some also articulated concerns that contemplative practices are often framed in ways that reinforce "the individualistic bias," decontextualizing the individual and her/his problems from "inequitable economic, political, and social relationships (e.g. racism)" (Vokey, 2014) rather than supporting a larger and more radical purpose. A few stakeholders voiced concerns that the CIC may lack capacity to explore the nuances of this concern. Some contemplative initiatives at SEU that I described earlier in this chapter — such as PULSE — are integrating first- and second-person capacities for awareness, along with a systems view. These may be models or partners for the CIC, as it develops programs to fulfill the third prong of its mission. Rose, one of the CIC's new program directors for learning, expressed a strong interest in the creation of a three-credit course that would teach contemplative practices in an experiential way, as well as bring in neuroscience and social science understandings of the effects of these practices. However, it would also include a "critical" component, in which students would be introduced to concerns about uses to which con CP's are being put, and controversies about who is included and excluded in contemporary contemplative movements.

Input from stakeholders concerned with these issues alerts me to the need for the CIC to consider the racial homogeneity of its staff, funders, and Planning Group. The mission of the organization stresses relationships across differences. Including more stakeholders who bring racial differences, and other significant identity differences such as sexual orientation, in guiding the CIC's direction might help bring to light blind spots in current assumptions about the best purposes of contemplative approaches in fulfilling its mission. 
Alternatively, or in addition, another stakeholder suggested that organizations have many options by which to access input about diversity and equity issues. For example, a national organization dedicated to contemplative education has a group of advisors who work behind the scenes, at that organization's request, to advise about how best to bring diversity and equity priorities into the organizations practices and programming.

\section{Conclusion}

In the course of my research, I have been extraordinarily inspired by both the commitment and the graciousness evinced by all the participants with whom I engaged. I believe there is great strength of purpose, care, and creativity to tap from all sides in the forward progress of the CIC and other contemplative work on SEU campus. Honest and challenging conversations that explicitly name power dynamics and issues of inclusivity and justice are foundational to the fully transformative possibilities ahead. 


\section{Chapter Five}

\section{Conclusions}

This was a case study of the recent emergence of contemplative approaches in a major southeastern Research One University. Central to the case was a donor-funded Center for Investigating Contemplation (CIC). The larger context was a burgeoning movement to bring practice and study of contemplative methods into HE (and other) settings. There is a need to research instances of this movement in a range of settings, with a range of research approaches, to understand and respond to its implications.

The original question was, how may contemplative praxis inform or even transform higher education praxis at this university? The second question arose, how may higher education praxis inform or even transform contemplative praxis? This second question evolved to include assets, as well as constraints and pressures, that HE praxis may bring to bear on contemplative praxis.

Based on my growing understanding of the setting and honing of my research interests, I included in my study instances of contemplative approaches in the setting beyond those initiated or sanctioned by the Center. I specifically asserted that contemplative praxis can take many forms. Since the Center was in very early stages of its development, I focused on participants' perspectives, concerns and aspirations, and on organizational and institutional structures and practices important to the case, rather than on analyzing outcomes of programs that are still in formation. And, I incorporated 
perspectives of participants not working at this university, who are stakeholders in bringing contemplative praxis to HE settings. These adjustments broadened and enriched my research, to bear greater fruit in my findings and conclusions.

I used a complex systems lens as a conceptual framework. Complexity is a useful way to understand "transformation". It offers insights about relationality within complex systems, and these systems' sensitivity to "initial conditions" and to small changes. A complex system is one in which diverse, connected, interdependent agents can learn adaptively, when the system is disturbed, to produce emergent results - new structures that are unpredictable from analyzing their component parts. On the way to emergence, the system moves toward chaos, where individuals and groups might retrench-reduce complexity_rather than guiding emergence. "Complexity reduction" exerts power, and has real consequences for what does and does not emerge in systems, and for diversity, connections, interdependencies and learning in the system.

My study was to some degree a participatory action research project. As I interviewed and engaged in participant-observation over nearly three years, I was part of the complex system(s) I was studying. I made choices that affected not only my research results, but that affected the setting itself, especially in that any interviews became opportunities to collaboratively generate new ideas and questions. In my writing, I sought to "disturb" the system, and even to suggest how the system can be guided from that point of disturbance, through chaos and attendant resistance, into emergence. 


\section{Summary of Key Findings}

\section{Participants value contemplative praxis, and some invoke systems awareness.}

Every one of my 56 interviewees described the value of contemplative practices, for themselves and/or for students, for cultivating self-awareness and positive relationships with others. Most participants defined contemplative practices quite broadly, although more than half said that they themselves practiced in particular ways. Participants generally concurred that contemplative practices help one be more "present," less reactive, and feel and act with more compassion. About 20 also strongly asserted that contemplative practices should be combined with learning about systemic inequities and how to be self-aware change agents in those systems. These 20 participants articulated that self-awareness, empathy/compassion, and systems awareness can and should synergize to show people how they and others have internalized the dynamics of systems they are part of. They asserted that focus only on first-person capacities may, in the long run, reduce complexity by reinforcing focus on the decontextualized individual, and thereby perpetuate status quo systemic inequities. The cultivation of these capacities requires a spectrum of methods. Through a complexity lens, I interpreted participants' descriptions of contemplative praxis as: Building capacity for proactively disturbing intra-personal, interpersonal, and (for some participants) larger systems, and for guiding disturbed systems to emerge new, more adaptive patterns. 


\section{There are opportunities and challenges to contemplative approaches in HE.}

Participants said that the HE setting presents both opportunities and challenges for incorporating contemplative and transformative approaches. Assets of HE include access to a wide spectrum of disciplinary lenses, opportunities to collaborate, freedom of thought and expression, and opportunities to affect and learn from students. Participants who described bringing contemplative approaches into the HE setting — in the form of contemplative pedagogy, leadership development, community building, or an interdisciplinary initiative — said that this approach has enriched their own and others' capacities to be self-aware change agents in the HE context.

Challenges take the form of incentive structures that are also internalized by individuals. Participants said that these incentive structures include prioritizing prestige and competition, focus on the decontextualized individual, commodification and narrow specialization of knowledge and skills, "managing" rather than learning from difference; bias toward disembodied discursiveness and away from relationality, emotion, and embodied awareness. Most of the 20 participants who strongly asserted that contemplative practices should be combined with learning about systemic inequities, also expressed concern that contemplative approaches may be watered down or co-opted in the HE setting, to enhance institutional prestige or relationship with the donors; or to enhance individuals' performance or wellbeing, rather than the collective good. All of the above reduce complexity, dampening possibilities for emergence. 


\section{Interfaces between CIC and other contemplative initiatives at SEU}

Most of the contemplative activity participants described was independent of the CIC. Most participants who were not directly involved in the CIC expressed interest in partnering with the CIC for joint ventures on campus, and many participants express aspirations in support of the CIC's potential role in HE transformation. In general, the CIC's presence on campus tends to legitimize, and therefore indirectly support, such activity in this HEI setting. The CIC is now staffed to support co-curricular initiatives on campus. The Center is also very involved in a major K12 program elsewhere, and in an as-yet-unveiled worldwide digital initiative.

The organizational praxis of the CIC begins to, but does not fully, support its stated mission.

Many participants expressed enthusiasm for the potential of the CIC's role in $\mathrm{HE}$ transformation. It is actualizing four high-impact projects requiring significant funding and staff time commitments: the Compassion in the Schools project, its digital Contemplative University, its recent K12 Institute, and its emerging Student Initiative. The $\mathrm{CIC}$ is developing relationships across campus with a range of individuals and programs, its goal being to create partnerships that will serve the unique needs of diverse settings and constituencies.

However, the CIC's stated mission and foci have from the beginning been extremely broad and extremely ambitious. Many of its stated aspirations and intentions have not been enacted. Many of my participants closest to the work of the Center - staff and primary stakeholders - described an organizational culture that is not fully conducive 
to personal well-being or collective generativity. Despite everyone's intentions, there has primarily been top-down leadership with suboptimal infrastructure or method for facilitating collective inquiry, decision-making, or collaboration. Direction setting is done primarily by donors and the CIC Director(s). Donors have been amenable to significant adjustments in their proposed projects, and yet some controversy exists not only about particular decisions, but also about the power dynamic by which funders exert strong influence, which some participants said can result in poor decisions and moreover reduces stakeholders' sense of "ownership" of the Center's trajectory.

\section{Some participants suggested contemplative approaches and structures.}

Some of these closely engaged participants called for changes to address perceived problems in the CIC's organizational praxis. They suggested contemplative approaches to the CIC's organizational praxis, as well as some structures to facilitate collective inquiry and collaboration.

It is unclear to what degree the CIC has the capacity or full intention to address issues of inclusion and social justice, which is a stated part of its mission. Of the 20 participants who said these issues should be explicit addressed by contemplative initiatives, most described ways to begin to do that. Their overarching concern was that contemplative approaches be used to help dismantle, rather to reinforce, unconscious privilege. This overarching transformational project is not an expressed value for the CIC.

Together, these findings suggest that both contemplative praxis and higher ed praxis can reduce complexity, and collude in doing so, by focusing on decontextualized 
individuals and not on the systems they are part of. On the other hand, if contemplative praxis and higher ed praxis focus awareness on systems, both can guide emergence of unpredictable, adaptive learning, and synergize in doing so. At their best, HE praxis and contemplative praxis can challenge and support each other productively. HE praxis can engage real-world problems, and the development of change agents, through a spectrum of disciplinary lenses and vital knowledge and skills. Contemplative praxis that includes methods to cultivate $1^{\text {st }}$-person and $2^{\text {nd }}$-person awareness, as well as a systems view, may strengthen capacity to become agents of systemic change. The Center's organizational praxis appears to be pivotal in its ability to fulfill its mission. Its stated mission is to foster relationships and partnerships across disciplinary and other differences. To do this, it must develop capacities to guide emergence productively.

\section{Revisiting My Research Questions}

My first and second research questions are synergistic with each other. There are multiple feedback loops between them. The first question asks how contemplative praxis can impact our understanding and enactment of learning, organizational, and institutional praxes in higher education, in ways that may transform - produce novel, adaptive structural changes in - these praxes. The second question asks how higher education praxis impacts our understanding and enactment of contemplative praxis, in ways that may transform - produce novel, adaptive structural changes in — contemplative praxis itself.

Higher education institutional praxis exerts power (reduces complexity, by way of controlling the kinds of differences, connections, interdependencies, and adaptive 
learning to which it brings awareness) in order to reproduce its own parameters about what is of value, and what is possible, for an individual and for the collective. Contemplative praxis - insofar as it prioritizes and cultivates awareness - may disturb power dynamics and help guide higher education praxis toward emergent understanding and action that can no longer reproduce parameters that marginalize and devalue difference, connections, interdependencies, and adaptive learning. However, contemplative praxis - to the extent that its incorporation into the institutional setting is dependent on conforming to, rather than disturbing (through bringing awareness to), current parameters within higher education praxis - may collude to reproduce those parameters. What may be required if contemplative praxis is to disturb, rather than collude with, institutional praxis as usual? This question challenges proponents of contemplative praxis to develop a more robust response, across all praxes. The conditions that make this difficult are the very conditions that show what the need is, if we bring deep and collective awareness to them. Dunne (2015) and Ergas (2015) both assert that contemplative approaches may transform higher education praxis before the system knows that is being subverted. I assert that this will require engaging in a proactive range of responses to current constraints in higher education praxis, including that stakeholders seek to transform not just external barriers, but internalized barriers as well. This will include speaking truth to power on all levels (even intra-personally!) with a contemplative, compassionate approach that acknowledges our part in collusion, whether from overtly dominant or subordinate positions.

The hope for the CIC to bring transformational change to its setting, and to model such change for higher education more generally, relies not simply on the fact that 
"contemplative sciences" have real potential to respond productively to current pressures in academia. The CIC invokes its focus on interdisciplinarity, holism, meaning, and wellbeing, to counter aspects of higher education such as disciplinary silos and hyperindividualism, and to attempt to subvert the habits, logistics, and policies that reinforce them. In this process, the CIC can tap the generative capacities of higher education praxis, and amplify them. The range of knowledge and inquiry available in a higher education setting is a remarkably rich context in which to foster synergies that matter.

But the CIC may well need to subvert and transform deeper habits than these, in order to fulfill its mission. For the CIC to be an agent of transformation in higher education praxis, my findings suggest that the Center and stakeholders need to name and directly address structural, relational, and internalized habits that constrain or challenge its transformational potential. Stakeholders may need to transform, before they can help others in the system transform, internalized assumptions about power and privilege, the self, relationality, and collectivity. Throughout all the embedded complex systems involved, from personal to interpersonal, to organizational, to institutional, an organization devoted to understanding contemplative praxis must learn to foreground and nurture healthy relationality across the board. This healthy relationality includes bringing awareness to power dynamics, in order to disturb them. This in turn includes bringing awareness to, and disturbing, our internalized assumptions about our roles in these dynamics.

Even in an academic setting, it should not be taboo to prioritize and explore contemplative praxis in the service of healthy relational dynamics on interpersonal, group, organizational, and institutional levels, any more than it should be taboo to 
prioritize and explore contemplative praxis in the service of increasing health, wellbeing and productivity on the level of the individual. To the degree that it may indeed be more taboo to explore on these collective dimensions than on the individual level, we should be asking why. To the degree that we conflate "contemplative", in concept or practice, with (cognitive or spiritual) detachment that seeks to transcend rather than transform inequities, we should be asking why.

\section{Revisiting Contemplative Organizational Praxis}

Pressing questions have arisen in the course of my research. What needs are being met through the work of the CIC? Whose needs, and what particular kinds of needs? What needs in the contexts named above - the larger social field, higher education, SEU, the CIC — are addressed, unaddressed, and even subverted by the CIC's efforts? Further, for what purposes, and how, does the Center attract and deploy resources? Who decides on these purposes and methods? What motivates these decision makers? How do they communicate among themselves, and what perspectives do they invite, include, or preclude? How does the Center set its priorities and assess its progress? Underlying these questions are the pivotal question: What dynamics within and related to the CIC facilitate or diminish the center's awareness of the motivations and effects of its choices and actions? How does the CIC hone its capacities for self-awareness?

Going into this study, I asked whether the CIC itself could be characterized as a contemplative organization. I also asked what difference that would make, in the CIC's work toward its mission. These questions are implicit in asking, "How might contemplative praxis transform higher education at SEU? How might higher education at 
SEU transform contemplative praxis?” There are significant nuances in my assessment of how, and how not, the CIC is itself contemplative. However, I gather that the CIC does not prioritize a contemplatively informed organizational praxis, in the ways that I have been framing the term "contemplative" and "organizational" here. This implies that contemplative praxis on an organizational level is not part of the CIC's mission. I suggest that, whatever its mission statement means by "fashioning reciprocal partnerships [across disciplines and with practitioners]" and "building tight relationships between tradition, research, innovation, application, and engagement" (CIC website), it does not indicate in what ways the CIC will facilitate such integration. Such integration will require deeply reflective practices on intra- and interpersonal levels, simultaneous with novel practices on organizational and institutional levels. This is entirely understandable, given that the context — an elite HEI — has not conditioned and informed its members to bring contemplative approaches to bear on making organizational or institutional changes. It is remarkable, in fact, that contemplative practices on an individual level—and their extrapolation to use in pedagogy, research, and engagement- have made such inroads in the academy recently. To progress this initiative into collective change processes will require, first of all, that stakeholders see the need to access and develop methods that build on the necessary but not sufficient premises and methods of individual practices.

Many proponents of first-person contemplative practice articulate the importance of guiding emergence, through consciously chosen methods for bringing awareness to habits, disturbing those habits, and pressing through disequilibrium until a new coherence arises. In collective processes, guiding emergence also requires conditions under which diverse, connected, interdependent agents can learn adaptively together. The conditions 
required for collective emergence may often include methods and practices, correlative to, but not identical to first-person practices. My research has pressed me to fully acknowledge that exploring the terrain of collective contemplative change processes-in complex human systems - is a necessary and vital frontier.

What is the relationship between the organizational praxis of the $\mathrm{CIC}$ and the overall transformative potential of contemplative approaches at SEU? Clearly, my suggestions that the CIC develop an explicit focus on contemplative organizational praxis is not only because I think it will enable the CIC to work more productively, though I do think it will, after some initial regrouping and resetting of priorities. But I think it might also set the stage for less defended, and therefore more inclusive conversation on campus, inviting those who challenge the institutional status quo in a diversity of ways to feel invited to help inform the CIC's focus. A CIC committed to assimilating difficult knowledge even about itself will be more sensitized to the value of bringing to light, and facilitating, connections and interdependencies among more diverse interests, thus helping guide the emergence of new and mutually desired outcomes.

\section{My contemplative researcher role.}

As a doctoral student "waking up" to issues at the dynamic nexus where academic protocols (of dissertation research, in my case) interface with my attempts to be contemplative, I have been challenged to strengthen and synergize my capacities to be analytical, self-aware, compassionate, and courageous. An integrated exploration of my chosen topic area has required me to probe in a deeply experiential, embodied, and relational way, and to simultaneously bring a critical lens to bear. This challenge is 
coherent with my conclusions: that a fully contemplative approach to transforming higher education will need to include rigorous exploration of radically subjective experience, and rigorous exploration of dynamics of privilege and power, and rigorous exploration of the connections between subjective experience and power dynamics.

I am now more awake to the vital importance of interrupting, informing, and contextualizing "contemplative" approaches, to critically investigate their implicit and explicit purposes in particular settings and implementations. I am also more awake to the assets that higher education settings can and should bring to bear on leveraging that critical inquiry into the motivations behind, and effects of, implementations of contemplative practices — not just for individuals but for systems. I am more awake to the possible synergies between capacities honed in academia — criticality, diverse disciplinary lenses, freedom of thought and of expression — and those honed by contemplative methods — self-awareness, reflectivity on one's motivation, compassion, felt sense of interconnectedness. I am more awake to the possible ways that academia and contemplative praxis may collude in dampening more transformational potential in each. It appears to me that it is in acceptance of self-serving agendas that both contemplative praxis and higher education praxis sabotage their greater transformational potential. These self-serving agendas manifest on the level of the individual, the organization, and the institution.

\section{Limitations of the Study}

The breadth of the topic area I have taken on in my research has presented significant limitations as well as opportunities. In my survey of multiple dimensions of 
perspectives and activity within this setting, I have certainly blurred some distinctions and failed to note aspects of the case. While complexity as an analytical framework has helped me perceive and articulate dynamics in and across multiple dimensions in the setting, this lens may also have imposed biases on my analysis.

My interests informed my research and conclusions. In particular, I brought a sensitizing interest in both social justice and organizational change issues. Also, as participants identified issues related to these interests, I adjusted my research agenda somewhat, seeking out participants, and asking questions, for perspectives that might help illuminate these aspects of the case more fully.

A significant limitation is my own bias about the value of contemplative approaches, including collective ones. My study strengthened my understanding of these values, but had I gone into the research with a different bias, I would have perceived the case differently.

I have exerted power by focusing attention on some areas of interest rather than others. There are alternative interpretations that could be made of my findings. In highlighting the challenges that the CIC faces in regard to developing its organizational praxis, I did not explore in detail the emergence and development of the initiatives into which it is investing resources of time and focus. I also did not explore in detail the very real work that the CIC's Director, its staff, and its key stakeholders have put into developing relationships across campus that bring contemplation forward as a topic of legitimate and mutual interest. Despite the fact that my interest, vis a vis the CIC, came to center on its organizational praxis, I did not investigate existent alternative organizational 
structures and related processes, to contrast with, or as possible models for, CIC organizational changes.

My participant sample was purposively chosen. In addition to participants who were engaged with the CIC primarily through their institutional roles, I chose to almost exclusively engage stakeholders with experience or interest related to contemplative praxis. Had I engaged a random sample, I would have had a wider range of perspectives to analyze.

A limitation of my study was that my findings do not reflect a thorough analysis of sub-groups, which would make my findings and analysis more precise. My interviews protocol for initial interviews was semi-structured, and subsequent interviews with the same participants diverged significantly from this protocol. Over the lengthy research project, developments in the setting and the case, as well as my own developing interests, led me to ask new questions and follow new trains of thought offered by participants. The archived interview data can be plumbed further in the service of subgroup analyses beyond what I have done here, and this could be useful going forward, putting this data to use in the service of some of the potential future research that I describe later in this chapter.

Another limitation of the study is that I have not researched and presented a "before and after" analysis, which would be of interest in understanding effects of introducing contemplative praxis in an HE setting. As I have described, there were many contemplative initiatives in place at SEU before the CIC emerged. My study has not tracked the effect of the CIC, per se. 


\section{Analysis of Leadership}

Leadership is a vital concern in this case study, as in the study of any organization. My study has not brought a substantive analysis to this area of the case. I have not read and applied theory in the realm of leadership development, and in this, leadership in the context of academia. These theoretical lenses would have sensitized me to perceive, analyze, and report richer findings about the particular challenges involved in leadership in a higher education setting. Further research informed by both current scholarship in higher education leadership and "systems leadership" could offer particularly rich research results.

\section{Systems Thinking}

I have invoked "systems thinking" throughout the dissertation, both as a conceptual framework for my research and also as a valuable capacity which I think should be developed far more explicitly and energetically in higher education. However, though I have used a complex systems framework to scaffold my research, I have not developed a refined application of complex systems to the current study, and I have merely pointed to the need for systems thinking in HE praxis. Further research will require a robust analysis of how systems thinking may inform HE pedagogy and research, and what role contemplative practices and orientations might play in leveraging capacities for systems thinking.

Third person, objective, awareness can be brought to bear on reality as embedded systems within which all members affect each other. Goleman and Senge (2014) write that in our complex world, our actions (and inaction) affect others within systems we are 
part of but that are often invisible to us. They say that it is vital to cultivate methods for self-awareness, empathy, and for "systems thinking"- - how the relational dynamics of complexity underpin all structures, and how to guide change within systems.

Simultaneously exploring the realities of systemic inequity (and one can extrapolate any kind of systemic exploitation or oppression, social inequity, environmental degradation, etc.) while making connections between personal and relational change processes support the transformative potential of contemplative practices. Such integrated practice may help us relate intrapersonally, interpersonally, and systemically to unexamined privilege, and internalized oppressions.

When invoking "systems level thinking", I do not want to conflate that with thinking only about "systems" on a large scale. Systemic structures "out there" are perpetuated by internalizations (i.e. of privilege and of oppression) "in here". These internalizations in turn affect interpersonal and group interactions in complex ways. A mutually informative first, second, and third person (and especially systems thinking) integration in contemplative praxis may forward a quest for meaning, transformative learning, and integration for the self and for the collective. This approach to contemplative praxis responds to concerns about the use of methods to instrumentally perpetuate and amplify the sense of a disconnected, independent unitary self (which can be a person or a clearly bounded collective self, like a company or an institution). This use may exacerbate an unquestioning bias toward competition, denial of being implicated in, and impacting, systems which in any way oppress or exploit. Contemplative approaches to pedagogy can promote such first-, second-, and third- person awareness, 
and sensitize students to systems thinking. Different pedagogical approaches focus on different parts, and sometimes all, of this spectrum. 


\section{Future Directions for Research}

There are many intriguing avenues for future research in the evolving topic area of contemplative approaches to higher education transformation. I explore some of these below.

\section{Systems thinking in organizational praxis}

Contemplative approaches to organizational praxis can also benefit from a systems view. In the case of the CIC, reflecting on the diversity, connections, interdependencies and adaptive learning in its organizational praxis thus far, I assert that from the beginning, those pivotal to the CIC and particularly Charles created an organizational structure that included many (but not all) kinds of diversity and many new connections, but did not have clear ways - structures or processes - to foster interdependencies and adaptive learning. Further research could more directly probe stakeholders' conceptions about, aspirations for contemplative organizational praxis and, as part of that, contemplative leadership. The research could ask what concerns stakeholders identify in the HEI setting, that tend to produce uncontemplative organizational and leadership praxis. The most interesting query, however, could be an action research approach that helps stakeholders construct a collective vision of not only what characterizes contemplative organizational and leadership praxis vis-à-vis structures and processes - in the HEI setting, and what effects these characteristics may have, butpivotally - how current praxis can be transformed into a more contemplative one. This study could be framed in part as an Appreciative Inquiry process, inviting participants to recall and describe experiences_-even moments - in which they have experienced or 
observed contemplative organizational or leadership praxis, and its effects. The researcher, perhaps with the study participants, could look for themes in this data, and perhaps begin to enact them and experience their effects.

\section{Theories of change in contemplative pedagogy for social justice.}

I was affected by the hope and commitment that virtually all my participants expressed, that despite pressures to the contrary, higher education settings can nurture more self-awareness, resilience and compassion in its members, and that this will in turn support more collective wellbeing in HE settings and beyond. Even among those participants who did not directly speak to the need for learning about systemic oppressions, most expressed hope that helping students increase their self-awareness, compassion, and well-being would result in their becoming more ethical and compassionate toward others, thus improving the HE community and their future communities.

Future research could investigate participants" "theories of change" regarding the effects on increased ethical and compassionate action, when students are simply taught contemplative practices, and when they are taught such practices in conjunction with sensitizing concepts and information about systemic inequities and the dynamics of unconscious privilege and internalized oppression. Research could be done on actual outcomes of these divergent approaches, as well. It is important to note, though, that these approaches are not fully divergent, because practices can be taught in ways that contextualize individual wellbeing as preparation for contributing to collective wellbeing. 


\section{Institutional transformation.}

On an underlying level, this study has attempted to investigate how power works across several dimensions. I am interested in how hegemonic forces work through HE praxis and through contemplative praxis, and how each of these praxes - separately and synergistically_may help counter hegemony. A complexity lens has been helpful in this, but more focused investigation into any one dimension of the setting, vis a vis power dynamics, would be a useful refinement. I believe, for example, that bringing a critical lens informed by Critical Race Theory, feminist theory, and/or Whiteness Theory would be extremely revealing. I think that a complex systems lens could synergize well with these frameworks.

Further research could more directly probe stakeholders' aspirations vis a vis institutional transformation: whether they perceive a need for it, and if so, in what arenas. My sense is that institutional transformation will only happen to the degree that stakeholders are willing to reflect deeply—and act differently as they see the need—on the assumptions that drive their collusion with power dynamics on all levels of the system within which the CIC is embedded.

\section{Studying versus enacting contemplative practices.}

This study has provoked an underlying question: Why should we enact or cultivate contemplative practices versus just studying them? Some stakeholders might ask the converse: why should we study contemplative practices versus just enacting them? A 
third question in this vein is: How can we study contemplative practices - particularly their effects in a setting such as a HEI—without enacting them?

The CIC's stated mission is very broad, and asserts the value of investigating contemplative practices through objective study and through subjective experience. The mission particularly asserts the intention to integrate these complementary kinds of study. My research has sensitized me to some of the challenges inherent in such integration.

Future research should focus more directly on challenges involved as stakeholders engage in and articulate processes and skill-sets involved in varied efforts to integrate objective and subjective investigations. In one variation of this inquiry, practitioners and those who study them may be different cohorts; in another variation, the same participants may investigate practices subjectively and objectively. Unpacking the ways that higher education assets and constraints might habituate us to approach this general topic - the valuation of practice versus objective study — is another nuance worthy of future research. The spectrum of what "study" might mean—using methodologies ranging form from neuroscience to social science to the arts, and perhaps even triangulating among them—opens even wider doors to further research.

\section{Students' views on professors' benefit from practicing contemplation}

Future research can be conducted on the views of participants in an HE setting as to their priorities for students and for those who work in the setting vis-a-vis contemplative practices. Do students believe or experience that professors and other adults in the setting (would) benefit from contemplative practices, personally or professionally? Do students state that professors and other adults are more equipped to 
teach and interact productively and/or compassionately with students and colleagues if they explicitly practice contemplation? Are students' and professors'/other adults' assessment and description of the value of contemplative practices similar or different, for their own or the other group?

\section{Investigating a wider range of participant views}

The views of a wider range of participants in the setting should be investigated, including those with little knowledge of, and those with unfavorable opinions of, contemplative practices in higher education. Concerns about the inappropriateness of particular contemplative practices or orientations should be elicited and analyzed. In addition, action research could directly probe the perspectives of those engaged in social justice efforts on campus_ — professors and students — about the actual or potential usefulness (or lack thereof) of incorporating explicitly contemplative practices in their activist work. This research could involve and track collaborations, and could be conducted as collaborative research.

\section{Unconscious privilege}

In this study, I was able to point to, but not explore in depth, the vital importance of bringing a critical lens to the study of contemplative interventions in HE settings. There is much vital work to do, going forward, in this arena. Rhonda Magee, a national leader in bringing contemplative approaches into efforts to transform unconscious privilege in academia and beyond, told me recently that something like a "critical contemplative" movement is forming, involving academics and others who are looking at ways in which contemplative initiatives may either entrench status quo power dynamics 
or help in dismantling them. This critical inquiry is occurring to some degree in relation to the larger social movement to bring contemplative practices into a range of settings, including settings such as community centers for Buddhist meditation or yoga.

Academics, activists, and others - from outside and within contemplative movementsare bringing a critical lens to bear on practices and rhetoric within such settings that not only tend to marginalize some identities — i.e. race and sexual orientation — but tend to delegitimize the concern about such marginalization. Rhetoric that invokes the "oneness" of all beings, and/or the claim that "we are not our bodies," can shore up white and heterosexual privilege by suggesting that those who claim that their experiences of marginalization are illusory, and less advanced, from a spiritual perspective.

My findings in regard to unconscious privilege, and how contemplative approaches may help address them, or may instead exacerbate them, are mainly in the form of insights and cautions expressed by those participants most concerned about systemic oppressions. I became increasingly "awake" to these issues setting over the course of my study, due in large part to the input of participants. Therefore, I was not watching for dynamics of race and gender from the beginning of my study as carefully as I would have needed to to document from participant-observations, and to query all of my interview participants for data. Twenty participants spoke explicitly about this topic; the great majority of these 20 were sensitized to the reality and impact of unconscious privilege by their prior study, reflection, and professional and/or personal experience. All had been exploring the connections between contemplative practices and systemic oppressions. They were concerned about the nuances by which a focus on individual wellbeing, in the context of a society in which white privilege colludes with systemic 
inequities, may perpetuate rather than problematize these inequities. Three of these participants were themselves African American, and spoke from long personal experience, as well as from years of careful observation and analysis, about the dangers of contemplative orientations that diminish concerns about marginalization and inequity in the name of a purported spiritual "transcendence" of difference. These three, and Daniel Barbezat who is white, spoke movingly about the significant challenge of turning toward, rather than away from, the discomfort of confronting one's unconscious privilege and internalized oppression, and the invaluable assistance that contemplative practices can offer in this process.

These participants offered astute perceptions about the need for caution going forward as a movement for contemplative higher education. They were concerned that contemplative practices in the service of supporting students' wellbeing not be offered as a substitute for acknowledging and working to change structurally inequitable and culturally marginalizing dynamics in the HE setting.

They were also concerned that a definition of contemplative practices not be prematurely drawn, especially because doing so may continue to privilege the culturally rather narrow (and relatively privileged) spectrum of people who equate contemplative practice with mindfulness meditation or yoga. One participant expressed the concern that contemplative practitioners may try to "reinvent the wheel" of creating contemplative approaches to social justice efforts. This participant said that there are many outside the ivory tower and outside the "mindfulness" community, who have been bringing contemplative approaches into social justice work. The contemplative approaches they tap may not be secular, as familiar, or comfortable to some of us, but they and their 
practitioners have much wisdom to offer vis a vis contemplative means for dismantling unconscious privilege and working for social justice.

\section{Exploring the role of contemplative approaches in the struggle of the soul of}

\section{higher education.}

As described in the section immediately above, and cumulatively throughout this section suggesting directions for future research, I have come to see the movement for contemplative higher education as pivotal to the very current and pressing national conversation about priorities in higher education. Some of my participants have attuned me to the dramatic need for those interested in contemplative approaches to ask how the most profound responsibilities of higher education can be leveraged, rather than dampened, by contemplative approaches. This requires investigating the dynamics by which both contemplative approaches and current higher education approaches can entrench power dynamics — both on the intra-personal level and on the level of socioeconomic structures. It requires asking whose purposes, visions, and perspectives are empowered to help drive conversation and action toward the emergence or a far more equitable society. Some of my participants said that contemplative approaches can be invaluable tools, if deployed in the service of that emergence. The dynamic tensions involved in these concerns are both and galvanizing. 


\section{References}

Argyris, C. (2016). A life full of learning. Organization Studies, 24(7) 1178+

Argyris, C. \& Schön, D. A. (1974). Theory in practice: Increasing professional effectiveness. Oxford, England: Jossey-Bass Publishers.

Association for Contemplative Mind in Higher Education (ACMHE). Retrieved 5/11/2015 from http://www.contemplativemind.org/programs/acmhe.

Astin, A. W., Astin, H. S., \& Lindholm, J. A. (2011). Cultivating the spirit: How college can enhance students' inner lives. San Francisco: Jossey-Bass.

Baer, R. A. (2003). Mindfulness training as a clinical intervention: A conceptual and empirical review. Clinical Psychology: Science and Practice, 10(2), 125-143. DOI:10.1093/clipsy.bpg015

Barbezat, D. P. \& Bush, M. (2014). Contemplative practices in higher education: Powerful methods to transform teaching and learning. San Francisco, CA: Jossey-Bass.

Barnhill, D. L. (2000). An interwoven world: Buddhism, ecology, and society. Guilford College coursebook.

Bauer-Wu, S. (2011). Leaves falling gently: Living fully with serious and life-limiting illness through mindfulness, compassion, \& connectedness. Oakland, CA: New Harbinger Publications.

Baugher, J. Contemplating uncomfortable emotions: Creating transformative spaces in higher education. In Gunnlaugson, O., Sarath, E. W., Scott, C., \& Bai, H. (2014). 
Contemplative learning and inquiry across disciplines (pp. 233-251). Albany, NY: State University of New York Press.

Berila, B. (2016). Integrating mindfulness into anti-oppression pedagogy: Social justice in higher education. New York: Routledge.

Bolman, L. \& Deal, T. (2003). Reframing organizations: Artistry, choice, and leadership ( ${ }^{\text {rd }}$ ed.). San Francisco, CA: Jossey-Bass.

Bourgeault, C. (2004). Centering prayer and inner awakening. Plymouth, UK: Cowley Publications.

Bourgeault, C. (2008). The wisdom Jesus: Transforming heart and mind—a new perspective on Christ and his message. Boston, MA: Shambhala Publications.

Britton, W. (2014). The Dark Side of Meditation: an Empirical Research Study. [Presentation]. Preliminary Research presented at Mind Matters IV: The Darkness Within. University of Toronto.

Brown, C. G. (2013). The healing gods: Complementary and alternative medicine in Christian America. New York, NY: Oxford University Press.

Brown, K. W., Ryan, R. M. \& Creswell, D. (2007). Mindfulness: Theoretical foundations and evidence for its salutary effects. Psychological Inquiry: An International Journal for the Advancement of Psychological Theory, 18(4) 211-237.

DOI:10.1080/10478400701598298

Bush, M. (2011). Mindfulness in higher education. Contemporary Buddhism: An Interdisciplinary Journal, 12(1), 183-197. DOI:10.1080/14639947.2011.564838

Bush, M. (2014). Caring, listening, and resilience: Building professional skills for social work students. In Barbezat, D. P. \& Bush, M. (2014). Contemplative practices in 
higher education: Powerful methods to transform teaching and learning, pp. 3950. San Francisco, CA: Jossey-Bass.

Cannon, B. (4/10/2012). U.Va. To Launch Contemplative Sciences Center. U.Va. Today. https://news.virginia.edu/content/uva-launch-contemplative-sciences-center

Capra, F. \& Luisi, P. L. (2014). The systems view of life: A unifying vision. Cambridge: Cambridge University Press.

Chickering, A. W., Dalton, J. C., \& Stamm, L. (2006). Encouraging authenticity and spirituality in higher education. San Francisco: Jossey-Bass.

Chödrön, P. (1997). When things fall apart: Heart advice for difficult times. Boston, MA: Shambhala Publications.

Collinson, V., \& Cook, T. F. (2007). Organizational learning: Improving learning, teaching, and leading in school systems. Thousand Oaks, CA: SAGE Publications.

Contemporary Buddhism, Kabat-Zinn, J. (Ed.). 12(1), May 2011.

Dasgupta, N. (2009). Mechanisms underlying the malleability of implicit prejudice and stereotypes: The role of automaticity and cognitive control. In T. D. Nelson (Ed.), Handbook of Prejudice, Stereotyping, and Discrimination (pp. 267-284). New York, NY: Psychology Press.

Davidson, R. J. with Begley, S. (2012). The emotional life of your brain: How its unique patterns affect the way you think, feel, and live - and how to change them. New York, NY: Hudson Street Press. 
Davidson, M. N. (2011). The end of diversity as we know it: Why diversity efforts fail and how leveraging difference can succeed. San Francisco: Berrett-Koehler Publishers.

Davies, L. (2004). Education and conflict: Complexity and chaos. London: RoutledgeFalmer

Dewey, J. (1916). Democracy and education: An introduction to the philosophy of education. New York: Macmillan Company.

Dewey, J. (1934). Art as experience. New York: Penguin Putnam Inc.

Dunne, J. (2012). Presentation for Tibetan Medicine and Meditation Conference. University of Virginia, April 2012.

Dunne, J. (2015). Keynote address. Regional Conference on Contemplative Practices in Higher Education; Contemplative Sciences Center, University of Virginia.

Engeström, Y. (2008). From teams to knots: Activity-theoretical studies of collaboration and learning at work. New York, NY: Cambridge University Press.

Ergas, O. The deeper teachings of mindfulness-based 'interventions' as a reconstruction of 'education,' Journal of Philosophy of Education, Special issue: Philosophy East/West: Exploring Intersections between Educational and Contemplative Practices, 49(2), 203-220, May 2015.

Erickson, F. (1986). Qualitative methods in research on teaching. From Wittrock (Ed.) Handbook of research on teaching (pp. 119-161). New York: Macmillan.

First International Symposia of Contemplative Studies (2012, April). Denver, CO, Online archives retrieved 5/11/12 from $\underline{w w w . c o n t e m p l a t i v e r e s e a r c h . o r g . ~}$ 
Fredrickson, B. L., Cohn, M. A., Coffey, K. A., Pek, J., \& Finkel, S. M. (2008). Open hearts build lives: Positive emotions, induced through loving-kindness meditation, build consequential personal resources. Journal of Personality and Social Psychology, 1045-1062.

Fredrickson, B. L. (2012). Archived lecture from the First International Symposia of Contemplative Studies, April 2012, Denver, CO. Retrieved 5/11/12 from www.contemplativeresearch.org.

Fredrickson, B. L. (2013). Positive emotions broaden and build. In Plant, E.A. \& Devine, P.G. (Eds.) Advances in experimental social psychology, Vol. 47. Amsterdam: Elsevier.

Freire, P. (2002). Pedagogy of the oppressed. New York, NY: The Continuum International Publishing Group.

Goleman, D. (1998). Working with emotional intelligence. New York, NY: Bantam Books.

Goleman, D. (2006). Social intelligence: The new science of human relationships. New York, NY: Bantam Books.

Goleman, D. \& Senge, P. (2014) The triple focus: A new approach to education. Kindle edition.

Goodall, H.L. (2008). Writing qualitative inquiry: Self, stories, and academic life. Walnut Creek, CA: Left Coast Press.

Greenberg, M. (2012, April). Archived lecture from the First International Symposia of Contemplative Studies, Denver, CO. Retrieved 5/11/12 from www.contemplativeresearch.org. 
Gunnlaugson, O., Sarath, E. W., Scott, C., \& Bai, H. (2014). Contemplative Learning and Inquiry Across Disciplines. Albany, NY: State University of New York Press.

Hart, T. (2004). Opening the contemplative mind in the classroom. Journal of Transformative Education January 2004 2: 28-4

Hetherington, L. (2013). Complexity thinking and methodology: The potential of 'complex case study' for educational research. Complicity: An International Journal of Complexity and Education, 10(1/2) 71-85.

Hewitt, J. P. \& Hall, P. M. (1973). Social problems, problematic situations, and quasitheories. American Sociological Review, 38(3) 367-374. Stable URL: http://www.jstor.org/stable/2094359

hooks, b. (sic.) (1994). Teaching to transgress: Education as the practice of freedom. New York, NY: Routledge.

House, E., \& Howe, K. (1999). Values in evaluation and social research. Thousand Oaks, CA: SAGE Publications.

Jennings, P. A. (2015). Mindfulness for teachers: Simple skills for peace and productivity in the classroom. New York, NY: W. W. Norton \& Co.

Jennings, P. A. (2011). Promoting teachers' social and emotional competencies to support performance and reduce burnout. In Cohan, A. \& and Honigsfeld, A. (Eds.) Breaking the mold of preservice and inservice teacher education: Innovative and successful practices for the twenty-first century. Rowman and Littlefield Education.

Kabat-Zinn, J. (2005). Wherever you go, there you are: Mindfulness meditation in everyday life. New York, NY: Hyperion. 
Kahane, D. (2009). Learning about obligation, compassion, and global justice: The place of contemplative pedagogy. In Gunnlaugson, O., Sarath, E. W., Scott, C., \& Bai, H. (2014). Contemplative Learning and Inquiry Across Disciplines, pp. 119-132. Albany, NY: State University of New York Press.

Kegan, R. \& Lahey, L. L. (2009). Immunity to change: How to overcome it and unlock the potential in yourself and your organization. Boston, MA: Harvard Business Press.

Kornfield, J. (1993). A path with heart: A guide through the perils and promises of spiritual life. New York, NY: Bantam Books.

Kramer, G. (2007). Insight dialogue: the interpersonal path to freedom. Boston, MA: Shambhala Publications.

Lederach, J. P. (2005). The moral imagination: The art and science of peacebuiding. New York, NY: Oxford University Press.

Lindholm, J. A., Millora, M. L., Schwartz, L. M., \& Spinosa, H. S. (2011). A guidebook of promising practices: Facilitating college students' spiritual development. Los Angeles, CA: University of California.

Macy, J. (2007). World as lover, world as self: Courage for global justice and ecological renewal. Berkeley, CA: Parallax Press.

Magee, Rhonda. (September 21, 2012). "Contemplating Race, Law and Justice: Some Notes on Pedagogy for Changing the World." Video of the 2012 ACMHE Conference keynote address. Retrieved from https://www.youtube.com/watch?v=e_D9Dq22x7I

Magee, R. (April, 2015) Breathing Together Through "I Can't Breathe": 
The Ethics and Efficacy of Mindfulness in Working Toward Justice for All Race/Law. Video of Keynote from Center for Mindfulness Spring Conference. Retreived 3/10/16 from: http://www.fleetwoodonsite.com/ppSD2/catalog.php?id=18

Magee, R. (forthcoming, 2016). The way of ColorInsight: Understanding race and law effectively through mindfulness-based colorInsight practices. The Georgetown Law Journal of Modern Critical Race Perspectives.

Masters, R. (2010). Spiritual bypassing: When spirituality disconnects us from what really matters. Berkeley, CA: North Atlantic Books.

Maxwell, N. (2014). How universities can help create a wiser world: The urgent need for an academic revolution. Exeter, UK: Imprint Academic.

McCrea, J., \& Walker, J. C. (Eds.). (2013). The generosity network: New transformational tools for successful fund-raising. New York, NY: Deepak Chopra Books.

Murphy, M., Donovan, S., \& Taylor, E. (1997). The physical and psychological effects of meditation: A review of contemporary research. Petaluma, CA: The Institute of Noetic Sciences.

Neff, K. D., Rude, S. S., \& Kirkpatrick, K. L. (2007). An examination of self-compassion in relation to positive psychological functioning and personality traits. Journal of Research in Personality. 41, 908-916.

Nepo, M. (2010). Foreword. In Palmer, P. J., Zajonc, A., with Scribner, M. (2010). The heart of higher education: A call to renewal; Transforming the academy through collegial conversations (pp. xii). San Francisco, CA: Jossey-Bass. Orr, D. (2012). Thinking outside the academic box: An introduction to 
mindfulness meditation for education. Other Education: The Journal of Educational Alternatives. 1(1), 79-91.

Osberg, D. \& Biesta, G. (Eds.) (2010). Complexity theory and the politics of education. Rotterdam: Sense Publishers.

Page, S. E. (2009). Understanding Complexity. DVD's and Course Guidbook. Chantilly, VA: The Teaching Company.

Palmer, P. J., Zajonc, A., with Scribner, M. (2010). The heart of higher education: A call to renewal; Transforming the academy through collegial conversations. San Francisco, CA: Jossey-Bass.

Patton, M. Q. (2010). Developmental Evaluation. Guilford Press. Kindle Edition.

Petty, S. (11/30/2014). Shared keynote. Pre-conference, Transformative Education and Contemplative Education Need Each Other. Mind \& Life Institute (MLI) International Symposium of Contemplative Studies October, 2014. https://www.youtube.com/watch?v=k5tUkaOJyFQ

Plank, J., Feldon, D., Sherman, W., \& Elliot, J. (2011). Complex systems, interdisciplinary collaboration, and institutional renewal. Change, May/June, 3544.

Pusser, B., Kempner, K. \& Ordorika, I. (Eds.) (2012). Universities and the public sphere: Knowledge creation and state building in the era of globalization. New York, NY: Routledge.

Rogers, R. (2013, July 19). The price of philanthropy. The Chronicle of Higher Education, 59(42). 
Rosch, E. (2007). More than mindfulness: When you have a tiger by the tail, let it eat you. Psychological Inquiry: An International Journal for the Advancement of Psychological Theory, 18(4), 258-264. doi:10.1080/10478400701598371

Salzberg, S. (1995). Loving-kindness: The revolutionary art of happiness. Boston, MA: Shambhala Publications.

Sarath, E. W. What next?: Contemplating the future of contemplative education. In Gunnlaugson, O., Sarath, E. W., Scott, C., \& Bai, H. (2014). Contemplative learning and inquiry across disciplines (pp. 361-377). Albany, NY: State University of New York Press.

Schön, D. A. (1987). Educating the reflective practitioner: Toward a new design for teaching and learning in the professions. San Francisco, CA: Jossey-Bass Publishers.

Scott, C. Buberian dialog as an intersubjective contemplative praxis. In Gunnlaugson, O., Sarath, E. W., Scott, C., \& Bai, H. (2014). Contemplative learning and inquiry across disciplines (pp. 325-340). Albany, NY: State University of New York Press.

Seitz, D. (2009). Integrating contemplative and student-centered education: A synergistic approach to deep learning. Unpublished dissertation, retrieved from Association for Contemplative Mind in Higher Education (ACMHE) website on 11/21/2012. http://www.acmhe.org/index.php?option=com_content\&view=article\&id=19\&Ite $\operatorname{mid}=81$

Senge, P. (1990). The fifth discipline: The art and practice of the learning organization. New York: Doubleday. 
Senge, P., Scharmer, C. O., Jaworski, J., \& Flowers, B. S. (2004). Presence: Human purpose and the field of the future. Cambridge, MA: The Society for Organizational Learning.

Shapiro, S., Warren, K., and Astin, J., with Duerr, M. ed. (2008). Toward the integration of meditation into higher education: A review of research prepared for the Center for Contemplative Mind in Society. Retrieved from bibliography on ACMHE website on $11 / 21 / 2012$. http://www.acmhe.org/index.php?option=com_content\&view=article\&id=19\&Ite $\operatorname{mid}=81$

Shusterman, R. (2008). Body consciousness: A philosophy of mindfulness and somaesthetics. New York, NY: Cambridge University Press.

Siegel, D. (2007). The mindful brain. New York, NY: W. W. Norton \& Co.

Siegel, D. (2010). Mindsight: The new science of personal transformation. New York, NY: Bantam Books.

Simmer-Brown, J. (2012, April). Mindfulness is not enough. Paper presented at Tibetan Medicine and Meditation Symposium, University of Virginia, Charlottesville, VA.

Stewart-Silver, M. (2000). The active and the passive/receptive in the life and thought of Wlliam James. Unpublished paper.

Stewart-Silver, M. (2004). Pedagogy for the oppressors, too: Culturally responsive pedagogy for marginalized and privileged students. Unpublished paper.

Stone, D. A. (1989). Causal stories and the formulation of policy agendas. Political Science Quarterly, 104(2) 281-300. DOI:10.2307/2151585 
Sustained Dialogue. www.sustaineddialogue.org (accessed 4/10/2016)

Tolman, D.L., \& Brydon-Miller, M., (Eds.) (2001). From subjects to subjectivities: a handbook of interpretive and participatory methods. New York, NY: New York University Press.

Udall, N. (2014). Riding the creative rollercoaster: how leaders evoke creativity, productivity and innovation. London: Kogan Page Limited.

Varela, F. J. \& Shear, J. (Eds.). (1999). The view from within: First-person approaches to the study of consciousness. Thorverton, UK: Imprint Academic.

Varela, F. J., Thompson, E. \& Rosch, E. (1991). The embodied mind: Cognitive science and human experience. Cambridge, MA: MIT Press.

Vokey, D. Contemplative disciplines in higher education: Cutting through academic materialism. In Gunnlaugson, O., Sarath, E. W., Scott, C., \& Bai, H. (2014). Contemplative learning and inquiry across disciplines (pp. 253-269). Albany, NY: State University of New York Press.

Wallace, B. A. (2000). The taboo of subjectivity: Toward a new science of consciousness. New York, NY: Oxford University Press.

Wallace, B. A. (2006). Teachers College Record, 108(9).

Wallace, B. A. \& Hodel, B. (2012). Dreaming yourself awake: Lucid dreaming and Tibetan dream yoga for insight and transformation. Boston, MA: Shambala Publications.

Wangyal, T. (2011). Awakening the Sacred Body: Tibetan yogas of breath and movement. Carlsbad, CA: Hay House. 
Weick, K. (1995). Sensemaking in organizations. Thousand Oaks, CA: SAGE Publications.

Yin, R. K. (1994). Case study research: Design and methods (Applied Social Research Methods Series, Vol. 5, $2^{\text {nd }}$ ed.). Thousand Oaks, CA: SAGE Publications.

Yin, R. K. (2003). Case study research: Design and methods (Applied Social Research Methods Series, Vol. 5, $3^{\text {rd }}$ ed.). Thousand Oaks, CA: SAGE Publications.

Yin, R. K. (2004). The case study anthology. Thousand Oaks, CA: SAGE Publications.

Zajonc, A. (n.d.). Retrieved from ACMHE website 6/01/2014.

Zajonc, A. (2006). Teachers College Record, 108(9), 1742-1759.

Zajonc, A. (2009). Meditation as contemplative inquiry: When knowing becomes love. Great Barrington, MA: Lindisfarne Book 